\title{
Perfluorocarbon liquid ventilation
}

Citation for published version (APA):

Degraeuwe, P. L. J. (2001). Perfluorocarbon liquid ventilation. [Doctoral Thesis, Maastricht University]. Universiteit Maastricht. https://doi.org/10.26481/dis.20011128pd

Document status and date:

Published: 01/01/2001

DOI:

10.26481/dis.20011128pd

Document Version:

Publisher's PDF, also known as Version of record

\section{Please check the document version of this publication:}

- A submitted manuscript is the version of the article upon submission and before peer-review. There can be important differences between the submitted version and the official published version of record.

People interested in the research are advised to contact the author for the final version of the publication, or visit the DOI to the publisher's website.

- The final author version and the galley proof are versions of the publication after peer review.

- The final published version features the final layout of the paper including the volume, issue and page numbers.

Link to publication

\footnotetext{
General rights rights.

- You may freely distribute the URL identifying the publication in the public portal. please follow below link for the End User Agreement:

www.umlib.nl/taverne-license

Take down policy

If you believe that this document breaches copyright please contact us at:

repository@maastrichtuniversity.nl

providing details and we will investigate your claim.
}

Copyright and moral rights for the publications made accessible in the public portal are retained by the authors and/or other copyright owners and it is a condition of accessing publications that users recognise and abide by the legal requirements associated with these

- Users may download and print one copy of any publication from the public portal for the purpose of private study or research.

- You may not further distribute the material or use it for any profit-making activity or commercial gain

If the publication is distributed under the terms of Article $25 \mathrm{fa}$ of the Dutch Copyright Act, indicated by the "Taverne" license above, 


\section{PERFLUOROCARBON LIQUID VENTILATION}


Printed by: Unigraphics Maastricht ISBN: 90-5681-114-2

Copyright O2001 P.L.J. Degraeuwe. All rights reserved All chapters previously published are reprinted with the permission of the original copyright holders. 


\title{
PERFLUOROCARBON LIQUID VENTILATION
}

\author{
PROEFSCHRIFT
}

ter verkrijging van de graad van doctor aan de Universiteit Maastricht, op gezag van de Rector Magnificus, Prof.dr. A.C. Nieuwenhuijzen Kruseman, volgens het besluit van het College van Decanen,

in het openbaar te verdedigen

op woensdag 28 november 2001 om 16.00 uur

door

Pieter Luc Judith Degraeuwe 
Promotores:

Prof. dr. C.E. Blanco

Prof. dr. R.A.M.G. Donckerwolcke

Co-promotor:

Dr. F.B.J.M. Thunnissen

Beoordelingscommissie:

Prof. dr. J. de Haan (voorzitter)

Prof. dr. M.E. Durieux

Prof. dr. A. Valls-i-Soler (Basque Country University, Bizkaia, Spain)

Prof. dr. E.F.M. Wouters

Dr. L.J.I. Zimmermann (Erasmus Universiteit, Rotterdam)

The studies described in this thesis were carried out at the Research Institute Growth and Development (GROW), Maastricht University, The Netherlands

Support of the research by Boehringer-Ingelheim Pharma KG, Biberach, Germany (Alveofact), 3M Company, Zwijndrecht, Belgium (FC-75 perfluorocarbon liquid), Nellcor Puritan Bennett Europe BV, 's Hertogenbosch, The Netherlands (NPB-290 pulse oximeter), and SensorMedics Critical Care, Bilthoven, The Netherlands (SensorMedics $3100 \mathrm{~A}$ oscillator) is gratefully acknowledged. 
To my parents with gratitude 


\section{Contents}

Origin and outline of this thesis

Chapter 1

Effect of perfluorochemical liquid ventilation on cardiac output and blood pressure variability in neonatal piglets with respiratory insufficiency.

Chapter 2

High-frequency oscillatory ventilation, partial liquid ventilation, or conventional mechanical ventilation in newborn piglets with saline lavage-induced acute lung injury. A comparison of gas-exchange efficacy and lung histomorphology.

Chapter 3

A feedback controller for the maintenance of FRC during tidal liquid ventilation: theory, implementation, and testing.

Chapter 4

Conventional gas ventilation, liquid-assisted high-frequency oscillatory ventilation, and tidal liquid ventilation in surfactant-treated preterm lambs.

Chapter 5

A critical review of the literature on perfluorocarbon liquid ventilation. Hype or hope?

Epilogue

General discussion, criticism on animal comparative studies, and future prospective

Dutch summary

Acknowledgments

Curriculum vitae 
In 1992, a visit to the Department of Physiology (Professor Thomas H. Shaffer) at Temple University School of Medicine, Philadelphia, stimulated the enthusiasm of my thesis advisor for the concept of liquid ventilation. A research line focussing on this subject was set up and liquid ventilation became my thesis topic subsequently.

Tidal liquid ventilation is firmly founded on basal physiological principles, but its application is technically demanding and therefore less attractive. The paucity of hints or detailed descriptions in the literature concerning the construction of liquid ventilation systems made the development of a home-made liquid ventilator a tough job. We are grateful because the Committee on the Use and Care of Animals had still confidence in our project after so many experiments with rats and rabbits failed due to fluorothoraces. Since then, others have reported the same problems with gravity assisted liquid ventilators. Although our first prototype liquid ventilator left much to be desired, early experiments enabled us to draw the attention to increased, respiration synchronous, phasic cardiac output and blood pressure oscillations during tidal liquid ventilation (Chapter 1).

Liquid ventilation research was accelerated considerably by the introduction of a hybrid technique called perfluorocarbon associated gas exchange (PAGE) or partial liquid ventilation (PLV): in this ventilation mode a liquid filled lung is ventilated using a well-known gas ventilator. Various investigations have been devoted to the comparison of PLV with conventional (gas) mechanical ventilation (CMV). The results favoured the use of PLV in different animal lung disease models. The similarities between PLV and former HFOV research prompted us to a comparison of these techniques in a saline lavage lung injury model. Professor Bancalari (University of Miami School of Medicine) suggested to add a CMV group applying some initial lung recruitment manoeuvre. Neither in gas exchange, nor in lung histology could we find any relevant differences between the three ventilatory strategies (Chapter 2).

In our second generation liquid ventilation device, a roller pump assisted the inspiratory and expiratory liquid flow. A feedback controller to maintain functional residual capacity was designed and found to be satisfactory during in vitro and in vivo experiments. The use of the end-expiratory occlusion pressure as input signal for the controller is innovative (Chapter 3 ).

Although the introduction of exogenous surfactant administration in neonatal respiratory distress syndrome significantly improved survival and reduced acute complications of the disease, chronic lung disease remains an important health problem in NICU graduates. Since ventilation induced lung injury is dependent on the ventilatory strategy used, the search for protective mechanical support strategies is meaningful. The comparative study in preterm surfactant treated lambs fits in with this search for gentle ventilation modes (Chapter 4).

As one of the few liquid ventilation research groups in Europe, we were invited several times to give a state of the art lecture on liquid ventilation at international congresses. Liquid ventilation has been intensively studied since more than 30 years, but over the last 5 to 10 years the acquisition of experimental data is overwhelming. The history, physiology, and efficacy of this peculiar respiratory support technique are described and critically analysed in an updated review on perfluorocarbon liquid ventilation (Chapter 5). 


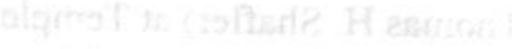


Chapter 1

Effect of perfluorochemical liquid ventilation on cardiac output and blood pressure variability in neonatal piglets with respiratory insufficiency 


\title{
Effect of Perfluorochemical Liquid Ventilation on Cardiac Output and Blood Pressure Variability in Neonatal Piglets With Respiratory Insufficiency
}

\author{
Pieter L.J. Degraeuwe, MD, ${ }^{1 *}$ Gijs D. Vos, MD, ${ }^{1}$ Gijs G. Geskens, MD, ${ }^{2}$ Jan M. Geilen, ${ }^{3}$ and \\ Carlos E. Blanco, MD, Pho' ${ }^{1}$
}

\begin{abstract}
Summary. Respiration and mechanical ventilation induce cyclic variation in cardiac output and blood pressure. We examined these phasic hemodynamic influences of mechanical ventilation during gas ventilation and partial and tidal liquid ventilation in 7 anesthetized and paralyzed young piglets (body weight, $3.0-4.9 \mathrm{~kg}$ ) made respiratory-insufficient by repeated saline lung lavage. Nonlinear regression analysis of cardiovascular parameters vs. time was done to quantify respiratory-induced fluctuations in hemodynamic variables. The amplitude of oscillations was expressed as a percentage of the mean hemodynamic variable during the study period, and was called the relative oscillation amplitude.

The relative oscillation amplitude of left ventricular stroke volume, left ventricular output, systemic arterial pressure, and systemic perfusion pressure was significantly larger (at least twofold) during tidal liquid ventilation compared to partial liquid ventilation. No such differences were observed between gas and partial liquid ventilation at comparable gas ventilator settings.

We conclude that in this animal model, within-breath modulation of left ventricular output, systemic blood pressure, and perfusion pressure was significantly increased during tidal liquid ventilation as compared to partial liquid ventilation. Pediatr Pulmonol. 2000;30:114-124.

- 2000 wiey-liss, inc.
\end{abstract}

Key words: liquid ventilation; perfluorocarbon; hemodynamics; cardiac output; cardiopulmonary interaction; nonlinear regression analysis.

\section{INTRODUCTION}

Tidal liquid ventilation (TLV) is a technique of respiratory support during which gaseous functional residual capacity and tidal volume are substituted by a perfluorocarbon liquid.' Combining gas mechanical ventilation with tracheal instillation of perfluorocarbon liquid (up to functional residual capacity) is called perfluorocarbonassociated gas exchange or partial liquid ventilation $(\mathrm{PLV}){ }^{2}$ Detailed information on the state of perfluorocarbon liquid ventilation can be found in several recent reviews. ${ }^{3-7}$ Both liquid-assisted ventilation strategies improve gas exchange and lung mechanics in animal models of hyaline membrane disease, ${ }^{8.9}$ acute respiratory distress syndrome, ${ }^{10-12}$ and meconium aspiration. ${ }^{13}$ In addition, it has been reported that there is less histologic evidence of barotrauma after tidal ${ }^{8,13,14}$ and partial $^{12,15-18}$ liquid ventilation compared to gas ventilation. Lung mechanics and histological outcome seem to be more favorable for tidal liquid ventilation when compared to partial liquid ventilation. ${ }^{13,19.20}$

Investigation of the hemodynamic consequences of liquid ventilation has focused principally on steady-state hemodynamics. Tidal liquid ventilation can be applied without substantial adverse effects on steady-state hemo두 2000 Wiley-Liss, Inc. dynamics provided an adequate intravascular volume is maintained. ${ }^{21}$ During PLV, cardiac output is only diminished at high perfluorocarbon doses $(50 \mathrm{~mL} / \mathrm{kg})$ or high gas tidal volumes $(>20 \mathrm{~mL} / \mathrm{kg}))^{22}$ Several authors reported phasic increases and decreases of systemic and pulmonary arterial blood pressures during TLV. ${ }^{23-29}$ No previous study systematically explored these observa-

'Department of Pediatrics, University Hospital Maastricht, and Re. search Institute for Growth and Development, Maastricht University. Maastricht, The Netherlands.

${ }^{2}$ Department of Cardiothoracic Surgery, University Hospital Maastricht, Maastricht, The Netherlands.

'Department of Biomedical Instrumentation, Maastricht University, Maastricht, The Netherlands.

•Correspondence to: Pieter L.J. Degraeuwe, M.D., Department of Paediatrics, University Hospital Maastricht, P. Debyelaan 25, P.O. Box 5800, NL-6202 AZ Maastricht, The Netherlands. E-mail: pde@skin. azm.nl

Received 4 November 1998; Accepted 16 February 2000. 
tions. The aim of this study was to quantify and compare phasic respiratory-induced hemodynamic alterations during gas, and partial and tidal liquid ventilation, in a pig model of respiratory insufficiency.

\section{METHODS}

Animal care was supervised and experimental protocols were approved by the University Committee on the Use and Care of Animals, University of Limburg, Maastricht, The Netherlands.

\section{Animal Preparation}

Ten farm-bred piglets (age 9-15 days and body weight $3.0-4.9 \mathrm{~kg}$ ) were anesthetized, using $4 \%$ halothane for induction and by intravenous infusion of $8 \mathrm{mg}$. $\mathrm{kg}^{-1} \cdot \mathrm{hr}^{-1}$ of pentobarbital sodium for maintenance throughout the complete experiment; muscle paralysis was achieved by pancuronium bromide $\left(0.1 \mathrm{mg} \cdot \mathrm{kg}^{-1}\right.$. $\mathrm{hr}^{-1}$ ). A cervical tracheostomy was performed, and an endotracheal tube (Portex $4.0 \mathrm{~mm}$ ID) was inserted and tied into position with the tip proximal to the carina. Volume-controlled continuous positive pressure ventilation was initiated, using a Servo Ventilator 900 (Siemens-Elema, Sweden) and an $\mathrm{FiO}_{2}$ of 1.0 , tidal volume $\left(V_{T}\right)$ of $8 \mathrm{~mL} / \mathrm{kg}$, respiratory rate of $30 / \mathrm{min}$, inspiratory to expiratory ratio of $1: 2$, and positive end-expiratory pressure (PEEP) of $2 \mathrm{~cm}$ of $\mathrm{H}_{2} \mathrm{O}$. In order to create a plateau pressure (zero flow), the inspiratory hold was adjusted to $33 \%$ of the inspiratory time. A pressure trans-

\begin{tabular}{|ll|}
\hline Abbreviations & \\
CVP & Central venous pressure \\
EELV & End expiratory lung volume \\
FRC & Functional residual capacity \\
GV & Gas ventilation \\
IQR & Interquartile range \\
LAP & Left atrial pressure \\
LVEDFP & Left ventricular transmural end diastolic filling \\
& pressure \\
PaCO $_{2}$ & Arterial CO, tension \\
PaO & Arterial O $_{2}$ tension \\
PAPD & Diastolic pulmonary arterial pressure \\
PAPM & Mean pulmonary arterial pressure \\
PAPS & Systolic pulmonary arterial pressure \\
Paw & Airway pressure \\
PEEP & Positive end-expiratory pressure \\
PLV & Partial liquid ventilation \\
PVR & Pulmonary vascular resistance \\
Qao & Left cardiac output \\
Qpa & Right cardiac output \\
SAPD & Diastolic systemic arterial pressure \\
SAPM & Mean systemic arterial pressure \\
SAPS & Systolic systemic arterial pressure \\
SVLV & Left ventricular stroke volume \\
SVRV & Right ventricular stroke volume \\
TLV & Tidal liquid ventilation \\
V & Tidal volume \\
\hline
\end{tabular}

ducer (Baxter) was connected to the side port of the endotracheal tube for monitoring of airway pressure (Paw). A carotid artery catheter was placed for continuous systemic blood pressure monitoring and blood sampling. A central venous pressure (CVP) catheter was placed into the right jugular vein.

A thoracotomy was performed through the fourth intercostal space, and the pericardium was opened. The ductus arteriosus was isolated and ligated. A close-fitting perivascular 4SB flow-probe $(6 \mathrm{~mm}$, Transonic Systems, Inc., Ithaca, NY) was placed around the ascending aorta just above the coronary arteries. The flow-probe was placed perpendicular to the curvature of the aortic arch. A second flow-probe was placed around the main pulmonary artery. Lubricating jelly was placed around the vessels inside the acoustic window of the flowprobes. A T206X animal research flow meter (Transonic Systems, Inc.) operated the perivascular flow-probes and provided a digital display of the measured volume flow and an analog output. ${ }^{30}$ Finally, vascular catheters were inserted into the main pulmonary artery and the left atrium via its appendage; the chest was then closed. All catheters are connected to pressure transducers and zero-referenced to the level of the midchest. The transducers were calibrated with a mercury manometer and zeroed to atmospheric pressure. Damping of the pressure signals was avoided by carefully flushing the catheters with heparinized $(0.5$ $\mathrm{U} / \mathrm{L}$ ) saline before periods of data acquisition. A standard limb lead electrocardiogram (ECG) was used. Maintenance fluids (dextrose 5\%) were infused at a rate of 4 $\mathrm{mL} \cdot \mathrm{kg}^{-1} \cdot \mathrm{hr}^{-1}$. Rectal temperature was monitored, and body temperature was maintained at $38.5-39.5^{\circ} \mathrm{C}$, using a heating pad. When necessary, polygeline (Haemacel ${ }^{\$}$ ) was administered to achieve a left atrial pressure between $5-8 \mathrm{~mm} \mathrm{Hg}$. Metabolic acidosis $(\mathrm{pH}<7.25$ and $\mathrm{BE}<8$ $\mathrm{mmol} / \mathrm{L}$ ) was corrected with sodium bicarbonate or THAM infusion (in case of hypercapnia). Arterial blood gases and $\mathrm{pH}$ were measured with a blood gas analyzer (Radiometer ABL 3, Copenhagen, Denmark), correcting for body temperature.

At the end of the experiment, the animals were sacrificed with an overdose of pentobarbital.

\section{Liquid Ventilator}

A home-made, intermittent-flow, pressure-limited, time-cycled, closed-circuit liquid ventilation device was used (Fig. 1). Liquid perfluorocarbon (FC-75, 3M Co., Belgium) is continuously pumped by a roller pump from the main reservoir through a membrane oxygenator (Model 0800-2A) and an ECMOtherm ${ }^{\mathrm{TM}}$ heat exchanger (SciMed, Life Systems, Inc., Minneapolis, MN). The hot water flowing through the heat exchanger is provided by a water heater/pump system (Seabrook Micro-Temp SMS-2000) running at a temperature of $41^{\circ} \mathrm{C}$. At the endotracheal tube connector, the temperature is measured 


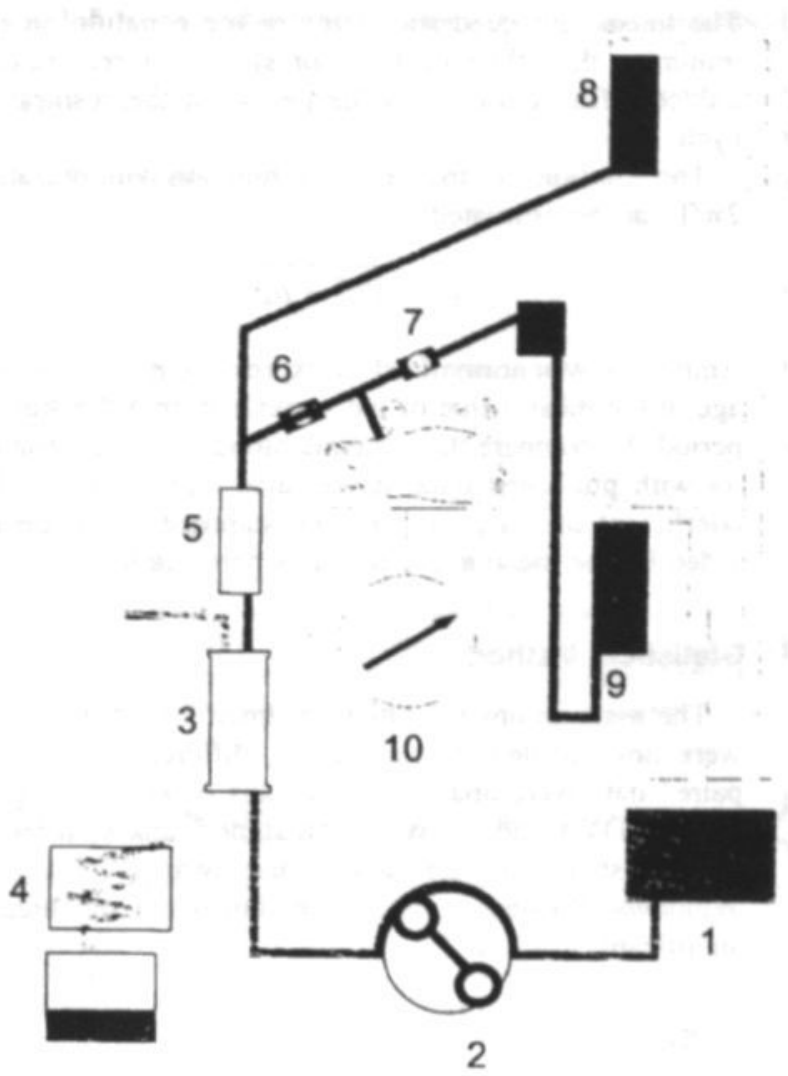

Fig. 1. Schema of the device used for tidal liquid ventilation. Perfluorocarbon liquid is pumped by a roller pump (2) from the main reservoir (1) through a membrane oxygenator (3) and a heat exchanger (5). An ice water-cooled coil (4) condenses the perfluorocarbon vapors exhaled by the membrane lung. Computer-controlled solenoid valves on the inspiratory (6) and expiratory (7) limb determine inspiratory and expiratory time. The liquid level of the inspiratory reservoir $(8)$, held constant by a connecting overflow line to the main reservoir, acts as a pressure-limiting valve. During expiration, perfluorocarbon drains by siphon pressure from the lung to the expiratory reservoir (9), which is also held constant by a connecting overflow line to the main reservoir. A bubble trap is incorporated in the expiratory line.

and maintained at $\pm 38^{\circ} \mathrm{C}$. The $\mathrm{FiO}_{2}$ of the sweepgas ( 1 $\mathrm{L} / \mathrm{min}$ ) through the membrane oxygenerator is 1.0. A condenser mechanism (ice water-cooled coil) cooled the expired perfluorocarbon vapors on their return to a reservoir. $\mathrm{CO}_{2}$ in the expired perfluorocarbon liquid is removed by the membrane lung. Time-activated solenoid valves (Controlasco B.V., Scherpenzeel, Holland) on the inspiratory and expiratory limbs determined inspiratory and expiratory times. During inspiration, the inspiratory valve is open and the expiratory valve is closed. The liquid level of the inspiratory reservoir ("pop-off") is held constant by a connecting overflow line to the main reservoir. This "pop-off" works as a pressure-limiting safety device. The inspiratory pressure is defined by the "static pressure" of the liquid column extending from the endotracheal tube connector to the level of the inspiratory reservoir plus the "kinetic pressure" produced by the roller pump. During expiration, the expiratory valve is open and the inspiratory valve is closed. Perfluorocarbon drains by a siphon pressure from the lung to the expiratory reservoir, which is held constant by a connecting overflow line to the main reservoir. The (negative) expiratory pressure, and hence the functional residual capacity (FRC), can be adjusted by changing the level of the expiratory reservoir relative to the endotracheal tube. $\mathrm{Be}$ cause of degassing in the valves, a bubble trap (AutoVent-SVrm, Pall Biomedical Products Corp., New York, NY) is incorporated in the expiratory line. Periodically, the expiration line must be purged of gas which collects during cycling. The solenoid valves are controlled by a computer, using software developed by the Department of Biomedical Instrumentation (University of Limburg, Maastricht, The Netherlands) that allows manipulation of inspiratory and expiratory time, and programmed airway occlusions. Tracheal pressure is measured through a perfluorocarbon-filled polyethylene line connected to the side tip of the endotracheal tube. This proximal "airway" catheter is connected to a pressure transducer, and the pressure is zero-referenced to the level of the midchest. During tidal liquid ventilation, the animal is situated on a balance. Tidal volume $\left(\mathrm{V}_{\mathrm{T}}\right)$ and FRC are measured by scales (Sartorius MCI, SartoriusInstrumenten B.V., Nieuwegein, The Netherlands) with a digital output channel connected to the computer.

\section{Experimental Protocol}

Before connecting the animal to the gas respirator, the internal compliance of the ventilator and tubing was measured. During instrumentation and in order to obtain baseline data, the piglets were gas-ventilated for approximately $1 \mathrm{hr}$. Effective tidal volume $\left(\mathrm{V}_{\mathrm{T} \text { eff }}\right)$ was estimated by correcting the volume set on the ventilator for respiratory circuit compliance. ${ }^{31} \mathrm{PaCO}_{2}$ was stabilized between $4.6-6 \mathrm{kPa}$. Repeated lung lavages with $30 \mathrm{~mL} / \mathrm{kg}$ of warm saline were performed until the $\mathrm{PaO}_{2}$ was below $13.3 \mathrm{kPa}^{32,33}$ Ventilator settings were adjusted to achieve a $V_{T}$ of about $12 \mathrm{~mL} / \mathrm{kg}$, positive expiratory pressure of $6 \mathrm{~cm} \mathrm{H}_{2} \mathrm{O}$, inspiratory to expiratory ratio of $1: 1$, and a respiratory rate of $30 \mathrm{breaths} / \mathrm{min}$. To avoid baro/volutrauma, moderate hypercapnia $\left(\mathrm{PaCO}_{2}\right.$ between 6-8 $\mathrm{kPa}$ ) was permitted. After $30 \mathrm{~min}$ of gas ventilation (GV), a volume of $30 \mathrm{~mL} / \mathrm{kg}$ of FC-75, preoxygenated at an $\mathrm{FiO}_{2}$ of 1.0 and warmed to $39^{\circ} \mathrm{C}$, was instilled into the lungs via a side port of the endotracheal tube over a 1-min period. During and after this procedure, gas ventilation was maintained at identical settings. Partial liquid ventilation was continued for approximately half an hour. Thereafter, additional liquid was instilled, and the endo- 
tracheal tube was attached to the liquid ventilator. Based on published work, ${ }^{34}$ tidal perfluorocarbon liquid ventilation was started at a tidal volume $\left(\mathrm{V}_{\mathrm{T}}\right)$ of $15 \mathrm{~mL} / \mathrm{kg}$ and frequency ( $f$ ) of 5 breaths/min, with an expiratory time of $8 \mathrm{sec}$. Pseudostatic end-inspiratory and end-expiratory alveolar pressures were measured at the end of a 1-sec occlusion of both the inspiratory and expiratory valve. The term pseudostatic refers to the fact that pressure equilibration between alveoli and proximal airway takes more than $1 \mathrm{sec}$. Tidal liquid ventilation was continued for another $30 \mathrm{~min}$. Blood gases were taken and hemodynamic data recorded at the end of each period of a specific ventilation strategy.

\section{Signal Acquisition and Processing}

Data acquisition and signal analysis were performed using software developed by the Department of Biomedical Instrumentation (HDAS, Hemodynamic Data Acquisition System). Pressure signals (systemic arterial pressure (SAP), pulmonary arterial pressure (PAP), left atrial pressure (LAP), central venous pressure (CVP), airway pressure (Paw), and tracheal pressure $\left(\mathrm{P}_{\mathrm{ET}}\right)$ ) were sampled, digitized at a frequency of $500 \mathrm{~Hz}$, and processed by the computer. The digital signals of left and right ventricular stroke volume (SVLV and SVRV), and liquid tidal volume $\left(\mathrm{V}_{\mathrm{T}}\right)$, were also passed to the computer. From the pulsatile (pressure) signals, the following beat-to-beat values were extracted: systolic, mean and diastolic SAP and PAP (SAPS, SAPM, SAPD, PAPS, PAPM, and PAPD) and mean values for LAP, CVP, SVLV, and SVRV. The interbeat interval was derived from the period between two successive systolic upstrokes of the SAP signal. Left and right ventricular output (Qao and Qpa) were calculated as SV $\times$ heart rate (HR). Perfusion pressure (PERF) was calculated as SAPM - CVP.

Raw data as well as beat-to-beat trend data were stored on hard disk for later analysis.

\section{Data Analysis and Calculations}

Artifact-free segments of trend-data were visually selected. Trend data during PLV were analyzed for a median of 70 (range, 41-92) heart beats and $10(8-10)$ ventilatory cycles. During TLV we investigated a median of 220 (range, 70-401) heart beats and $10(2-20)$ ventilatory cycles.

The magnitude of variability was estimated by nonlinear regression analysis of the hemodynamic variables vs. time. The following regression equation was used:

$$
y(t)=b_{0}+b_{1} t+b_{2} t^{2}+b_{3} \sin \left(2 \frac{\pi}{T} t\right)+b_{4} \cos \left(2 \frac{\pi}{T} t\right) .
$$

The linear and quadratic terms in the equation should minimize the effect of trend or slow (not respiratoryinduced) fluctuation. $\mathrm{T}$ is the period of the respiratory cycle.

The amplitude of the harmonic function with pulsation $2 \pi / \mathrm{T}$ can be estimated as:

$$
A=\sqrt{b_{3}^{2}+b_{4}^{2}} \text {. }
$$

Amplitude was normalized by expressing it as a percentage of the mean value of the variable during the studied period. To compare the systemic blood pressure variability with published data, it was also represented as the coefficient of variation, i.e., the standard deviation divided by the mean expressed as a percentage.

\section{Statistical Methods}

The assumptions on which parametric tests are based were not fulfilled. Consequently, differences between paired data were analyzed by means of Friedman twoway ANOVA and the Wilcoxon signed rank sum test. ${ }^{35}$ The statistical software package used was SPSS 6.0 for Windows. $P$-values $<0.05$ were considered statistically significant.

\section{RESULTS}

Data are presented as medians and interquartile ranges (IQR). Three piglets suddenly deteriorated hemodynamically and died shortly after initiation of TLV. A fluorothorax was noticed at necropsy. Thus, data on only the 7 remaining animals were analyzed. These piglets received a median of 20 (IQR 17.6-27.2) $\mathrm{mL} / \mathrm{kg}$ polygeline, and 2.9 (IQR 2.2-3.2) mmol/kg THAM during the experiment. Mean values of SAP, PAP, LAP, CVP, Qao, and Qpa were not different between the studied periods of gas ventilation (GV), PLV, and TLV (Table 1), confirming findings published by other groups. ${ }^{21,36}$ Blood gas parameters improved significantly with initiation of PLV, but the differences between PLV and TLV did not reach statistical significance. Tidal volume $(\mathrm{mL} / \mathrm{kg})$ was higher during TLV $(15.5 \mathrm{IQR}=14.7-17.8)$ than during PLV $(13.6 \mathrm{IQR}=11.7-13.9)(P=0.018)($ Table 2$)$. Pseudostatic end-inspiratory and end-expiratory pressures (zero-referenced to midchest level) of 16.2 (IQR 14.9 $17.4)$ and 5.3 (IQR $0.6-7.2) \mathrm{mm} \mathrm{Hg}$, respectively, were measured exactly at the same time as the hemodynamic measurements.

\section{Signal Variability}

As expected, the hemodynamic variables (SAP, PAP, CVP, LAP, SVLV, SVRV, Qao, and Qpa) oscillated at the exact controlled ventilator setting of $30 \mathrm{cycles} / \mathrm{min}$ 
TABLE 1-Hemodynamic Variables During Gas Ventilation, Partial Liquid Ventilation, and Tidal Liquid Ventilation'

\begin{tabular}{lccc}
\hline & GV & PLV & TLV \\
\hline SAPS $(\mathrm{mm} \mathrm{Hg})$ & $85.2(66.4-92.7)$ & $98.4(89.8-104.7)$ & $88.4(84.2-105.0)$ \\
SAPM $(\mathrm{mm} \mathrm{Hg})$ & $72.2(57.6-77.4)$ & $84.0(75.2-95.7)$ & $79.0(71.9-88.2)$ \\
SAPD (mm Hg) & $57.8(47.4-62.3)$ & $66.8(61.6-85.4)$ & $60.7(55.8-70.4)$ \\
PAPS $(\mathrm{mm} \mathrm{Hg})$ & $34.6(31.1-43.0)$ & $32.0(26.9-34.0)$ & $33.2(33.2-40.0)$ \\
PAPM $(\mathrm{mm} \mathrm{Hg})$ & $24.9(23.6-34.7)$ & $23.7(20.0-28.2)$ & $26.8(25.5-32.0)$ \\
PAPD $(\mathrm{mm} \mathrm{Hg})$ & $18.5(15.3-26.9)$ & $17.4(13.2-23.3)$ & $21.9(17.2-25.2)$ \\
LAP $(\mathrm{mm} \mathrm{Hg})$ & $10.8(8.3-17.9)$ & $12.2(3.3-16.8)$ & $5.4(3.2-7.8)$ \\
CVP $(\mathrm{mm} \mathrm{Hg})$ & $7.7(4.2-7.9)$ & $5.6(4.7-9.7)$ & $6.1(5.4-7.6)$ \\
Qao $(\mathrm{ml} / \mathrm{min})$ & $404.5(347.9-548.9)$ & $453.8(443.8-472.0)$ & $425.4(277.0-547.7)$ \\
Qpa $(\mathrm{ml} / \mathrm{min})$ & $734.7(502.5-735.5)$ & $610.8(360.8-681.2)$ & $541.3(383.9-560.9)$ \\
SVLV $(\mathrm{ml})$ & $3.6(2.2-3.9)$ & $2.5(2.1-3.2)$ & $3.1(1.8-3.7)$ \\
SVRV $(\mathrm{ml})$ & $2.6(2.1-3.2)$ & $3.3(1.9-4.4)$ & $3.7(2.1-4.6)$ \\
HR $(\mathrm{min}-1)$ & $147.6(103.6-254.2)$ & $192.8(141.2-240.6)$ & $154.7(115.1-178.7)$ \\
PULSE $(\mathrm{mm} \mathrm{Hg})$ & $26.6(18.9-28.7)$ & $30.5(20.4-31.6)$ & $34.6(21.0-38.3)$ \\
PERF $(\mathrm{mm} \mathrm{Hg})$ & $64.4(49.7-74.2)$ & $77.1(69.4-86.0)$ & $71.4(65.4-82.8)$ \\
\hline
\end{tabular}

'Values are median (interquartile range). None of the hemodynamic parameters differed significantly between the three ventilation strategies (Friedman two-way ANOVA, P-value > 0.05). GV, gas ventilation; PLV, partial liquid ventilation; TLV, tidal liquid ventilation; SAPS, SAPM, SAPD, systolic, mean, diastolic systemic arterial pressure; PAPS, PAPM, PAPD, systolic, mean, diastolic pulmonary arterial pressure; Qao, Qpa, left and right ventricular output; SVLV, SVRV, left and right ventricular stroke volume; HR, heart rate; PULSE, pulse pressure; PERF, perfusion pressure.

TABLE 2-Arterial Blood Gas Data and Tidal Volumes During Gas, Partial Liquid, and Tidal Liquid Ventilation'

\begin{tabular}{lccc}
\hline & \multicolumn{1}{c}{$\mathrm{GV}$} & $\mathrm{PLV}$ & $\mathrm{TLV}$ \\
\hline $\mathrm{pHa}$ & $7.22(7.07-7.27)$ & $7.35(7.30-7.37)^{* * *}$ & $7.28(7.26-7.34)$ \\
$\mathrm{PaCO}_{2}(\mathrm{kPa})$ & $7.7(7.1-8.6)$ & $5.7(5.5-7.3)$ & $7.2(7.0-7.9)$ \\
$\mathrm{PaO}_{2}(\mathrm{kPa})$ & $8.0(4.9-9.1)$ & $23.6(14.2-29.6)^{* \cdots *}$ & $7.1(6.7-19.5)$ \\
$\mathrm{BE}^{(\mathrm{mmol})}$ & $-5.6(-10.5-3.0)$ & $-2.1(-4.3-2.3)^{* \cdots *}$ & $-0.8(-2.4-1.1)^{*}$ \\
$\mathrm{~V}_{\mathrm{T}}(\mathrm{mL} / \mathrm{kg})$ & $12.8(11.9-13.7)$ & $13.6(11.7-13.9)$ & $15.5(14.7-17.8)^{* \cdots *}$ \\
\hline
\end{tabular}

'Values are median values (interquartile range). PLV improved oxygenation, but gas exchange was not different between PLV and TLV. Tidal volume was higher during TLV than during both GV and PLV. GV, gas ventilation; PLV, partial liquid ventilation; TLV, total liquid ventilation; $B E$, base excess; $V_{T}$, tidal volume.

$\bullet P<0.05$, TLV vs. PLV.

$\because P<0.05$, TLV vs. GV.

$\cdots P<0.05$, PLV vs. GV, using Wilcoxon matched-pairs signed-rank test (two-tailed $P$-value).

during PLV and 5 cycles/min during TLV. Figure 2 shows beat-to-beat trend data of hemodynamic parameters during PLV and TLV. Respiratory-associated fluctuations are very clear. The oscillation amplitudes (in units) as estimated by nonlinear regression analysis are given in Table 3. The relative amplitude of these respiratory oscillations (expressed as \% of the mean hemodynamic variable during the study period) was not significantly different for any hemodynamic variable between the GV and PLV period. When TLV was compared to PLV, the relative amplitude was significantly higher for SVLV (and accordingly for SAPS, SAPM, SAPD, and Qao) during TLV than PLV (Table 4). During TLV, SAPS, SAPM, and SAPD oscillated $2.9,4$, and 5.6 times more than during PLV. The corresponding coefficients of variation for SAPS, SAPM, and SAPD during TLV were $6.6(4.6-10.6) \%, 8.1(3.8-10.2) \%$, and $9.5(3.2-10.8) \%$, respectively, whereas during PLV they were 2.3 (1.9 $2.6) \%, 2.0(1.7-2.2) \%$, and $1.7(1.6-2.1) \%$. The systemic perfusion pressure oscillated 6 times more during TLV compared to PLV.

\section{DISCUSSION}

Respiratory-related fluctuations in cardiac output and arterial blood pressure (Traube-Hering waves) have been recognized for many years. ${ }^{37.38}$ Mechanical ventilation induces cyclic changes in lung volume and hence intrathoracic or intrapericardial pressure. The hemodynamic consequences of ventilation are complex and are considered to reflect the combined actions of increased and changing lung volume and intrathoracic pressure on both ventricular filling (preload) and ejection (afterload). During the inspiratory phase of a positive pressure breath, intrathoracic pressure rises, thereby impairing venous return and lowering transmural right atrial pressure. Consequently, right ventricular preload and right ventricular stroke volume decrease. Initially, the left ventricular preload increases because blood contained in the pulmonary circulation is squeezed out of the lungs as they inflate. Owing to this, left ventricular stroke volume initially increases. Later in the respiratory cycle, the reduced right ventricular stroke volume reaches the left ventricle, low- 

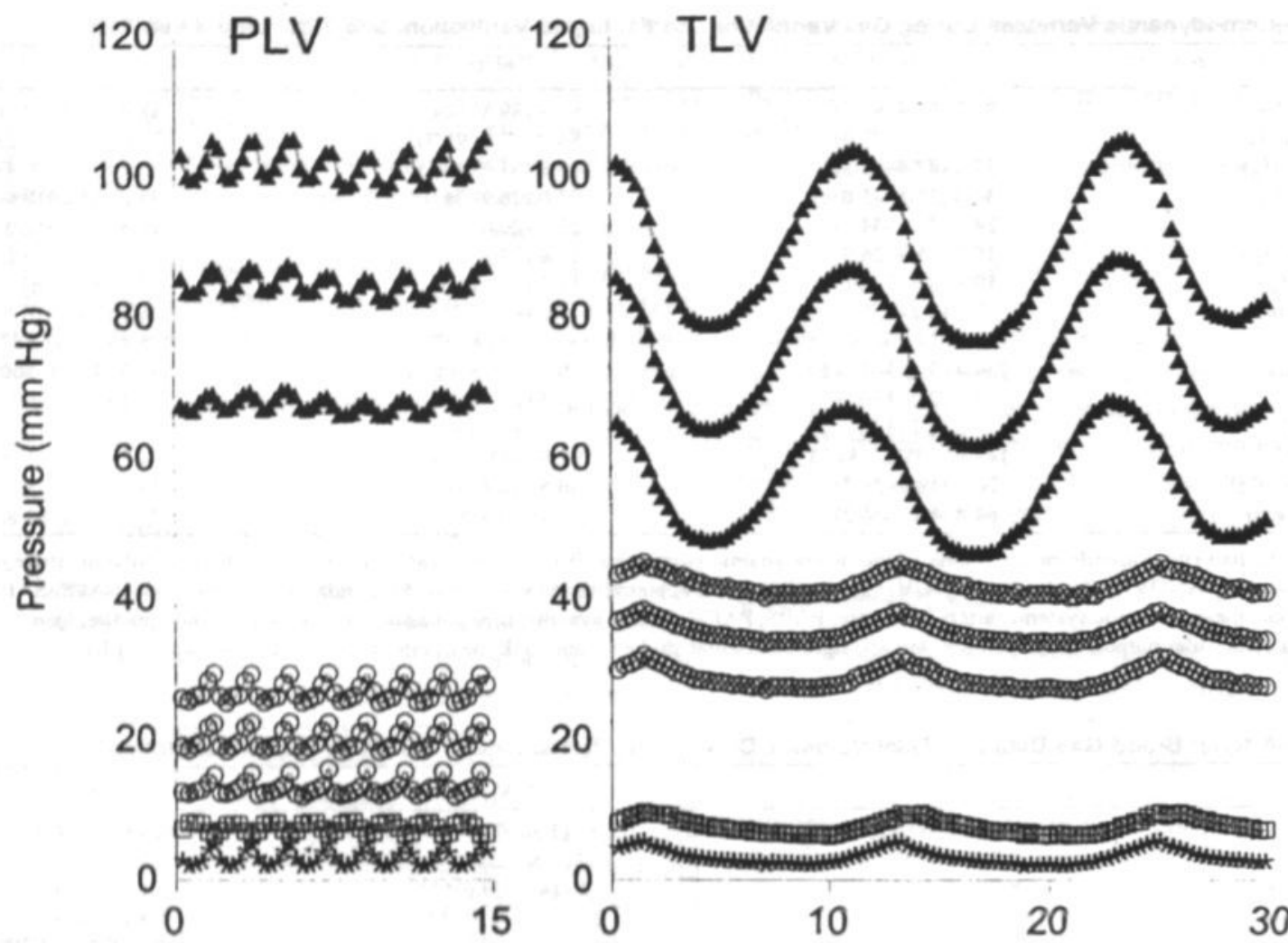

- SAPS

$\star$ SAPM

- SAPD

- PAPS

$\ominus$ PAPM

$\ominus$ PAPD

* LAP

$\square$ CVP

0

0

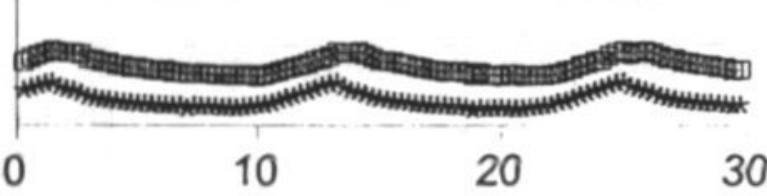

Time (s)

Fig. 2. Typical tracing of beat-to-beat trend data of hemodynamic variables: systolic, mean, and diastolic systemic arterial pressure (SAPS, SAPM, and SAPD), pulmonary arterial pressure (PAPS, PAPM, and PAPD), and mean values for central venous pressure (CVP) and left atrial pressure (LAP). The time scale is constant for both PLV (left) and TLV (right).

ering left ventricular filling and output, even below those of the right ventricle. Some authors have stressed the appearance of a decrease in LV afterload during a mechanical inspiration. ${ }^{39-42}$ Others have emphasized an increase in RV afterload. ${ }^{43}$ The work of Versprille et al. ${ }^{37}$ and Versprille ${ }^{44}$ does not support a major contribution of changes in afterload to cardiac output variability during mechanical ventilation. In addition to pre- and afterload changes, varying ventricular interdependence during the respiratory cycle has been shown to be an important factor in determining the cardiovascular response to mechanical ventilation. ${ }^{45,46}$

Results of the present study clearly demonstrate that phasic respiration-induced hemodynamic modulation was more pronounced during TLV than during PLV or GV. It should also be underscored that with adequate vascular filling, the increased within-breath variability of left ventricular output and of systemic blood pressure occurred around the same mean value. ${ }^{21}$

Before discussing the possible pathogenesis and potential implications of our findings, limitations of the present study must be considered. GV, PLV, and TLV were not randomly applied, which might have biased the results. However, a change over time or a carryover effect is unlikely, since none of the mean hemodynamic variables differed between study periods. This also implies an adequate circulating volume at all times during hemodynamic measurements. Functional residual capacity, not measured during GV and PLV, may have been a confounding factor. During TLV, the exact relation between end-expiratory weight and FRC may have been obscured by traction or pressure on ventilator tubing, blood sampling, and fluid administration. Moreover, at the start of TLV, the weighed liquid FRC may underrate the ultimate liquid FRC due to entrapped gas in the liquid-filled lung. Therefore, reliable liquid FRC data cannot be reported. End-expiratory alveolar pressures are more accurate. Pseudostatic end-inspiratory and endexpiratory pressures (zero-referenced to midchest level) were 16.2 (IQR 14.9-17.4) and 5.3 (IQR 0.6-7.2) mm $\mathrm{Hg}$, respectively. These data are in agreement with the data of Curtis et al., who reported peak alveolar and trough alveolar pressures of $18.6 \pm 10.4$ and $6.6 \pm 4.8$ $\mathrm{mm} \mathrm{Hg}$, respectively. ${ }^{47}$ The data are not entirely compa- 
TABLE 3-Absolute Respiratory Oscillation Amplitude of Hemodynamic Parameters During Gas Ventilation, Partial Liquid Ventilation, and Tidal Liquid Ventilation'

\begin{tabular}{|c|c|c|c|}
\hline Amplitude & GV & PLV & $\mathrm{TLV}$ \\
\hline ASAPS (mm Hg) & $1.56(0.77-2.04)$ & $2.39(1.72-2.61)$ & $5.59(4.84-10.14)^{\bullet \cdots}$ \\
\hline ASAPM (mm Hg) & $0.96(0.52-1.68)$ & $1.76(1.28-1.80)$ & $5.26(3.35-8.05)^{\bullet . \bullet \bullet}$ \\
\hline ASAPD (mm Hg) & $0.69(0.26-1.16)$ & $1.17(0.98-1.44)$ & $4.99(2.25-6.48)^{\bullet . \bullet \bullet}$ \\
\hline APAPS $(\mathrm{mm} \mathrm{Hg})$ & $1.59(1.17-2.15)$ & $1.76(1.62-2.00)$ & $1.69(1.34-2.06)$ \\
\hline APAPM $(\mathrm{mm} \mathrm{Hg})$ & $1.52(1.13-1.85)$ & $1.93(1.61-2.15)$ & $1.78(1.63-2.22)$ \\
\hline APAPD $(\mathrm{mm} \mathrm{Hg})$ & $1.01(0.96-1.42)$ & $1.53(0.55-1.62)$ & $1.90(1.77-2.53)^{\bullet}$ \\
\hline ALAP (mm Hg) & $0.98(0.20-1.12)$ & $1.46(0.24-1.54)$ & $1.31(0.58-1.36)$ \\
\hline ACVP (mm Hg) & $0.30(0.11-0.72)$ & $0.37(0.13-1.41)$ & $1.31(1.01-1.85)$ \\
\hline AQAO (ml/min) & $16.06(6.19-20.36)$ & $14.83(10.10-20.10)$ & $37.20(26.87-39.35)^{\bullet}$ \\
\hline AQPA (ml/min) & $41.62(23.45-58.12)$ & $42.96(40.35-60.71)$ & $61.90(39.40-78.06)$ \\
\hline $\operatorname{ASVLV}(\mathrm{ml})$ & $0.14(0.04-0.21)$ & $0.11(0.08-0.12)$ & $0.23(0.20-0.31)$ \\
\hline ASVRV $(\mathrm{ml})$ & $0.21(0.16-0.36)$ & $0.26(0.21-0.31)$ & $0.44(0.14-0.50)$ \\
\hline AHR $\left(\min ^{-1}\right)$ & $0.69(0.45-1.51)$ & $1.93(1.22-3.37)$ & $0.72(0.42-2.12)$ \\
\hline APULSE (mm Hg) & $0.86(0.79-1.20)$ & $1.37(1.23-1.73)$ & $2.39(1.00-3.25)$ \\
\hline APERF $(\mathrm{mm} \mathrm{Hg})$ & $0.79(0.49-1.42)$ & $1.43(1.27-2.68)$ & $5.54(3.78-8.40)^{\bullet . \bullet \bullet}$ \\
\hline
\end{tabular}

'Values are median values (interquartile range). Significantly more respiratory-induced oscillation was seen in SAPS, SAPM, SAPD, SVLV, and PERF during TLV when compared to PLV or GV. Abbreviations as in Table 1. Prefix A, amplitude of.

$\bullet P<0.05$, TLV vs. PLV.

$\bullet P<0.05$, TLV vs. GV, using Wilcoxon matched-pairs signed-rank test (2-tailed $P$-value).

TABLE 4-Relative Respiratory Oscillation Amplitude (\% of Mean) of Hemodynamic Parameters During Gas Ventilation, Partial Liquid Ventilation, and Tidal Liquid Ventilation'

\begin{tabular}{|c|c|c|c|}
\hline Amplitude ( $\%$ of mean) & GV & PLV & TLV \\
\hline ASAPS & $1.87(1.60-2.09)$ & $2.29(1.92-2.62)$ & $6.64(4.60-10.58)^{\bullet \bullet \bullet}$ \\
\hline ASAPM & $1.62(1.35-1.83)$ & $2.02(1.69-2.22)$ & $8.08(3.80-10.19)^{\bullet \bullet \bullet}$ \\
\hline ASAPD & $1.16(0.70-1.53)$ & $1.70(1.60-2.06)$ & $9.58(3.19-10.83)^{\bullet \cdots}$ \\
\hline APAPS & $4.50(2.72-6.94)$ & $5.50(5.30-6.61)$ & $4.31(3.98-6.21)$ \\
\hline APAPM & $5.22(3.26-7.85)$ & $7.30(6.85-9.23)$ & $6.87(5.11-8.89)$ \\
\hline APAPD & $6.04(3.59-7.26)$ & $8.48(3.29-9.27)$ & $8.70(6.50-14.03)$ \\
\hline ALAP & $9.11(1.12-14.89)$ & $12.57(15.23-46.51)$ & $25.04(6.34-40.02)$ \\
\hline ACVP & $4.20(2.37-9.42)$ & $9.83(2.46-13.90)$ & $20.62(16.59-34.14)^{\bullet \bullet}$ \\
\hline AQAO & $3.86(1.65-4.54)$ & $3.43(2.16-4.43)$ & $8.06(7.18-13.62)^{\bullet . \bullet}$ \\
\hline AQPA & $7.59(4.41-9.95)$ & $9.51(6.61-12.26)$ & $10.58(7.94-13.92)$ \\
\hline ASVLV & $4.02(1.68-5.42)$ & $4.52(2.50-5.18)$ & $8.36(6.24-9.72)^{\bullet . \bullet}$ \\
\hline ASVRV & $7.34(4.08-8.88)$ & $8.58(5.78-11.31)$ & $10.13(7.35-13.51)$ \\
\hline AHR & $0.28(0.27-1.46)$ & $1.15(0.80-1.75)$ & $0.46(0.37-1.06)$ \\
\hline APULSE & $4.18(3.04-4.96)$ & $5.22(4.35-6.63)$ & $6.24(4.21-10.03)$ \\
\hline APERE & $1.42(1.24-1.91)$ & $1.75(1.66-3.47)$ & $10.47(4.56-12.37)^{\bullet \cdot \bullet}$ \\
\hline
\end{tabular}

'Values are median values (interquartile range). Significantly more respiratory induced oscillation was seen in SAPS, SAPM, SAPD, SVLV, and PERF during TLV when compared to PLV or GV. Abbreviations as in Table 1. Prefix A, amplitude of.

$\bullet P<0.05$, TLV vs. PLV.

$\cdots P<0.05$, TLV vs. GV, using Wilcoxon matched-pairs signed-rank test (two-tailed $P$-value)

rable, since these investigators used slightly heavier animals and longer occlusion times $(2.5-3 \mathrm{sec})$ compared to ours $(1 \mathrm{sec})$. The effect of PEEP on cardiac output and blood pressure variability has been studied previously. Pizov et al. reported their findings in dogs with acute ventricular failure. Neither cardiac output, nor systolic pressure variation, was affected by incremental levels of PEEP up to $20 \mathrm{~cm}$ of $\mathrm{H}_{2} \mathrm{O}^{48}$ In mechanically ventilated man, the addition of $4.6 \pm 1 \mathrm{~cm} \mathrm{H}_{2} \mathrm{O}$ of PEEP did not increase the within-breath left ventricular stroke volume variability, but was associated with a significant drop in LVSV. ${ }^{49}$ Robotham et al. studied the effect of PEEP and plasma volume expansion in dogs with intact circulatory systems. With $10 \mathrm{~cm} \mathrm{H} \mathrm{H}_{2} \mathrm{O}$ of PEEP, the respiratory variation in LVSV was markedly accentuated in those dogs with a low left ventricular transmural diastolic filling pressure (LVEDFP $\left.{ }_{\mathrm{TM}}\right)$, but not in those dogs with an elevated LVEDFP ${ }_{\mathrm{TM}}$. After plasma volume expansion, similar variation in LVSV was noted with both low or elevated LVEDFP ${ }_{\text {TM }} .{ }^{50}$ The authors concluded that cyclic hemodynamic events are influenced by both the endexpiratory lung volume (EELV) and LVEDFP $P_{T M}$. We assume that the increased hemodynamic variability possibly caused by an augmented EELV during TLV was likely compensated for by an adequate circulating blood volume. Indeed, mean cardiac output and pulse pressure 
variability during TLV were not different from PLV or GV. Recently, Michard et al. suggested that the respiratory changes in arterial pulse pressure can be used to assess the combined hemodynamic effects of PEEP and fluid loading. ${ }^{51}$ Pulse pressure variability was not increased during TLV in our study.

The absolute blood pressure fluctuations reported in mechanically ventilated premature neonates ${ }^{52}$ were similar to those measured in our gas-ventilated piglets and definitely smaller than those measured in our TLV animals. These values were measured during paralysis, in well-hydrated animals, with relatively low tidal volumes. Recent studies used $V_{T}$ of $25-27 \mathrm{~mL} / \mathrm{kg}^{53}$ and a range of $15-25 \mathrm{~mL} / \mathrm{kg}$ is generally accepted as needed for normal gas exchange. ${ }^{54}$ This may, in part, explain the relatively modest blood gas values during TLV in our study.

The phasic modulations of cardiac output and blood pressures are known to increase with increasing tidal volumes. ${ }^{37,55,56}$ Systolic blood pressure variation was also found to be a sensitive indicator of intravascular volume status, ${ }^{56.57}$ but hypovolemic piglets demonstrated no increase of absolute variation in left ventricular output ${ }^{58}$ In our study, tidal volume was significantly larger in the TLV group, but the increase in amplitude of blood pressure oscillation by far exceeded the expected effect of $V_{T}$. Neither previous literature, nor the described study design (not measuring end-diastolic volumes or transmural pressures), provides a definite explanation for this finding. Presumably, hydrostatic forces exercised by the oscillating liquid column are superimposed on the intrathoracic pressure variations generated by changing lung volume. The specific gravity of FC-75 is $1.75 \mathrm{~g} / \mathrm{mL}$. This mechanism may amplify both the effects on ventricular pre- and afterload.

We speculate that the larger variability in left cardiac output during TLV may be explained by the combination of several mechanisms. Firstly, liquid lung insufflation $\left(V_{T}\right)$ may decrease systemic venous return more than gas $\mathrm{V}_{\mathrm{T}}$ due to hydrostatic forces. Likewise, ventricular interdependence may be enhanced during a liquid breath. Secondly, (liquid) FRC is probably higher during TLV than during GV and PLV; consequently, pulmonary vascular resistance (PVR) moves on a steeper part of the PVRlung volume or lung volume-alveolar pressure curve. ${ }^{59}$ Therefore, liquid lung insufflation causes a larger increase in right ventricular afterload during TLV than during PLV or GV. Thirdly, $\mathrm{V}_{\mathrm{T}}$ are typically higher during TLV than during GV or PLV. Finally, it has been demonstrated that longer inspiratory times increase the phasic effect of mechanical ventilation on left-sided hemodynamics. Using equal tidal volumes and I:E ratios, Scharf et al. ${ }^{60}$ showed that, at slow respiratory rates $(8-9 \mathrm{bpm})$, peak aortic flow fell less than at fast rates (23-25 bpm). The changes in aortic pressure were also more pro- nounced at short inspiratory times, but changes in respiratory rate had little effect on right-sided hemodynamics. ${ }^{60}$ The latter is in agreement with our findings showing that, in contrast to left-sided hemodynamics, within-breath variability of right ventricular stroke volume and pulmonary arterial pressure is not increased during TLV.

Whether the increased hemodynamic variability during TLV has clinical significance is not known. The relation between high beat-to-beat variability in systemic blood pressure and cerebral blood flow velocity (in the absence of autoregulation) as a risk factor antedating cerebral abnormalities in preterm infants has been advocated by some research groups ${ }^{61-65}$ and refuted by others. ${ }^{66-68}$ The increased swings in central venous pressure and perfusion pressure during TLV are also of concern, since fluctuations in central venous and perfusion pressures have been implicated in the pathogenesis of periintraventricular hemorrhage. ${ }^{69-71}$ Blood pressure fluctuations are known to be more pronounced in hypovolemic states, typically a problem in the sickest babies. The relationship between TLV and the risk of intracranial bleeding is at the moment purely speculative.

The observations made in this study have two practical implications. Firstly, the effect of mechanical ventilation on averaged CVP should be recognized. Indeed, in order to estimate right ventricular preload accurately, transmural right atrial pressure should be measured. When central venous pressure (CVP) is referenced to ambient atmospheric pressure, the confounding influence of cyclic increase in pericardial pressure is ignored. Since transduced CVP tended to be more influenced by TLV than PLV, right ventricular preload may be overestimated even more. End-expiratory CVP more closely approximates transmural pressure values and could, therefore, be used as a more accurate estimate of right ventricular preload. ${ }^{72}$ Secondly, due to the increased respiratory modulation, single injection thermodilution cardiac output measurements are more prone to error during TLV, necessitating flow correction ${ }^{73}$ or averaging 3-4 estimates spread equally over the ventilatory cycle. ${ }^{74}$

Fluorothorax, encountered in 3 animals, did not get much attention in the liquid ventilation literature. It is, however, a serious complication, supposedly caused by progressive overexpansion of the lung. Indeed, FRC remains constant if inspiratory and expiratory tidal volume are perfectly matched. If expiratory tidal volume is systematically lower than inspiratory tidal volume, FRC will increase with each mechanical breath. This mechanism is equivalent to inadvertent increases in PEEP and gastrapping. Although the (negative) expiratory pressure of our liquid ventilator could be adjusted, manual control of FRC failed in 3 animals. We agree with Baba et al. that "expiratory control" is crucial. ${ }^{75}$ Moreover, FRC assess- 
ment by weighing the animal becomes unreliable with changing fluid balance.

In conclusion, under the conditions of this study, TLV was associated with an increased within-breath variability of left ventricular output, systemic blood pressure, and systemic perfusion pressure. The elucidation of the exact physiological mechanisms requires further study. The clinical implications of the observed phenomenon are a possible link to neonatal cerebral injury, and the effect on the interpretation of central venous pressure and thermodilution cardiac output measurements.

\section{ACKNOWLEDGMENTS}

The perfluorocarbon liquid (FC-75) used in our research was kindly provided by the $3 \mathrm{M} \mathrm{Co}$. (Zwijndrecht, Belgium). The authors appreciate the technical support of Nick Braeken in building the experimental hardware, and the technical assistance of Theo van der Nagel in performing the experiments. Peter Bungenstock is acknowledged for developing the software.

\section{REFERENCES}

1. Shaffer TH. A brief review: liquid ventilation. Undersea Biomed Res 1987; 14:169-179.

2. Fuhrman BP, Paczan PR, DeFraneisis M. Perfluorocarbonassociated gas exchange. Crit Care Med 1991;19:712-722.

3. Leonard RC. Liquid ventilation. Anaesth Intensive Care 1998;26: $11-21$.

4. Greenspan JS, Cleary GM, Wolfson MR. Is liquid ventilation a reasonable altemative? Clin Perinatol 1998;25:137-157.

5. Qunitel M, Meinhardt J, Waschke KF. Partial liquid ventilation. Anaesthesist 1998:47:479-489.

6. Wolfson MR, Greenspan JS, Shaffer TH. Liquid-assisted ventilation: an alternative respiratory modality. Pediatr Pulmonol 1998; 26:42-63.

7. Day SE, Gedeit RG. Liquid ventilation. Clin Perinatol 1998;25: $711-722$.

8. Wolfson MR, Greenspan JS, Deoras KS, Rubenstein SD, Shaffer TH. Comparison of gas and liquid ventilation: clinical, physiological, and histological correlates. J Appl Physiol 1992;72: 1024-1031.

9. Leach CL, Holm B, Morin FC, Fuhrman BP, Papo MC, Steinhorn D, Hernan LJ. Partial liquid ventilation in premature lambs with respiratory distress syndrome: efficacy and compatibility with exogenous surfactant. J Pediatr 1995;126;412-420.

10. Hirschl RB, Parent A, Tooley R, Shaffer T, Wolfson M, Bartlett $\mathrm{RH}$. Lung management with perfluorocarbon liquid ventilation improves pulmonary function and gas exchange during extracorporeal membrane oxygenation (ECMO). Artif Cells Blood Substit Immobil Biotechnol 1994:22:1389-1396.

11. Curtis SE, Peek JT, Kelly DR. Partial liquid breathing with perflubron improves arterial oxygenation in acute canine lung injury. J Appl Physiol 1993;75:2696-2702.

12. Nesti FD, Fuhrman BP, Steinhorn DM, Papo MC, Hernan L. Duffy LC, Fisher JE, Leach CL, Paczan PR, Burak BA. Perfluorocarbon-associated gas exchange in gastric aspiration. Crit Care Med 1994:22:1445-1452.

13. Foust R, Tran NN, Cox C, Miller TF Jr, Greenspan JS, Wolfson MR, Shaffer TH. Liquid assisted ventilation: an alternative ven- tilatory strategy for acute meconium aspiration injury. Pediatr Pulmonol 1996;21:316-322.

14. Hirschl RB, Overbeck MC, Parent A, Hernandez R, Schwartz S, Dosanjh A, Johnson $\mathrm{K}$. Bartiett RH. Liquid ventilation provides uniform distribution of perfluorocarbon in the setting of respiratory failure. Surgery 1994;116:159-167.

15. Tutuncu AS, Faithfull NS, Lachmann B. Comparison of ventilatory support with intratracheal perfluorocarbon administration and conventional mechanical ventilation in animals with acute respiratory failure. Am Rev Respir Dis 1993;148:785-792.

16. Papo MC, Paczan PR, Fuhrman BP, Steinhom DM, Hernan LJ, Leach CL, Holm BA, Fisher JE, Kahn BA. Perfluorocarbonassociated gas exchange improves oxygenation, lung mechanics, and survival in a model of adult respiratory distress syndrome. Crit Care Med 1996;24:466-474.

17. Quintel M, Heine M, Hirschl RB, Tillmanns R, Wessendorf V. Effects of partial liquid ventilation on lung injury in a model of acute respiratory failure: a histologic and morphometric analysis. Crit Care Med 1998;26:833-843.

18. Smith KM, Mrozek JF, Simonton SC, Bing DR, Meyers PA, Connett JE, Mammel MC. Prolonged partial liquid ventilation using conventional and high-frequency ventilatory techniques: gas exchange and lung pathology in an animal model of respiratory distress syndrome. Crit Care Med 1997,25:1888-1897.

19. Wolfson MR, Friss HE, Kechner NE, Rubenstein SD, Dechadarevian J-P. Shaffer TH. Physiological basis of improved lung stability after perfluorochemical (PFC) liquid rescue of surfactant treated lambs. Pediatr Res 1994;35:357.

20. Tarezy Hornoch P, Hildebrandt J, Standaent TA, Jackson JC. Surfactant replacement increases compliance in premature lamb lungs during partial liquid ventilation in situ. J Appl Physiol 1998,84: 1316-1322

21. Curtis SE, Fuhrman BP, Howland DF, DeFrancisis M, Motoyama EK. Cardiac output during liquid (perfluorocarbon) breathing in newbom piglets. Crit Care Med 1991;19:225-230.

22. Parent AC, Overbeck MC. Hirschl RB. Oxygen dynamics during partial liquid ventilation in a sheep model of severe respiratory failure. Surgery 1997;121:320-327.

23. Modell JH, Gollan F, Giammona ST, Parker D. Effect of fluorocarbon liquid on surface tension properties of pulmonary surfactant. Chest 1970;57:263-265.

24. Modell JH, Hood CI, Kuck EJ, Ruiz BC. Oxygenation by ventilation with fluorocarbon liquid (FX-80). Anesthesiology 1971;34. 312-320

25. Tuazon JG, Modell JH, Hood Cl, Swenson EW. Pulmonary function after ventilation with fluorocarbon liquid (Caroxin-D). Anesthesiology 1973;38:134-140.

26. Walker A, Petrovic M, Ponitch J, Ritchie BC. Redistribution of cardiac output during liquid breathing in the newborn rabbit. Aust J Exp Biol Med Sei 1972;50:467-476.

27. Lowe CA, Shaffer TH. Increased pulmonary vascular resistance during liquid ventilation. Undersea Biomed Res 1981;8:229-238.

28. Calderwood HW, Modell JH, Ruiz BC, Brogdon JE, Hood CI. Pulmonary lavage with liquid fluorocarbon in a model of pulmonary edema. Anesthesiology 1973;38:141-144

29. Sass DJ, Ritman EL, Caskey PE, Banchero N, Wood EH. Liquid breathing: prevention of pulmonary arterial-venous shunting during acceleration. J Appl Physiol 1972;32:451-455.

30. Lundell A, Bergqvist D, Mattsson E, Nilsson B. Volume blood flow measurements with a transit time flowmeter: an in vivo and in vitro variability and validation study. Clin Physiol 1993;13: 547-557.

31. Devlieger H, Van Aerde J, Van Haesebroeck P. Jaeken J, Eggermont $E$. Diagram for easy volume setting of an infant ventilator. Crit Care Med 1983;11:657-659 
32. Lachmann B, Robertson B, Vogel J. In vivo lung lavage as an experimental model of the respiratory distress syndrome. Acta Anaesthesiol Scand 1980;24:231-236.

33. Nielsen JB, Sjostrand UH, Edgren EL, Lichtwarck Aschoff $M$, Svensson BA. An experimental study of different ventilatory modes in piglets in severe respiratory distress induced by surfactant depletion. Intensive Care Med 1991;17:225-233.

34. Koen PA, Wolfson MR, Shaffer TH. Fluorocarbon ventilation: maximal expiratory flows and $\mathrm{CO}_{2}$ elimination. Pediatr Res 1988; 24:291-296.

35. Siegel S, Castellan NJJ. Nonparametric statistics for the behavioral sciences. New York: McGraw-Hill; 1988.

36. Houmes RJ, Verbrugge SJ, Hendrik ER, Lachmann B. Hemodynamic effects of partial liquid ventilation with perfluorocarbon in acute lung injury. Intensive Care Med 1995;21:966-972.

37. Versprille A, Jansen JR, Frietman RC, Hulsmann AR, van den Klauw MM. Negative effect of insufflation on cardiac output and pulmonary blood volume. Acta Anaesthesiol Scand 1990;34:607615.

38. Nishikawa T, Dohi S. Errors in the measurement of cardiac output by thermodilution. Can J Anaesth 1993;40:142-153.

39. Abel JG, Salerno TA, Panos A, Greyson ND, Rice TW, Teoh K, Lichtenstein SV. Cardiovascular effects of positive pressure ventilation in humans. Ann Thorac Surg 1987;43:198-206.

40. Fessler HE, Brower RG, Wise RA, Permutt S. Mechanism of reduced LV afterload by systolic and diastolic positive pleural pressure. J Appl Physiol 1988;65:1244-1250.

41. Pinsky MR, Summer WR. Cardiac augmentation by phasic high intrathoracic pressure support in man. Chest 1983;84:370-375.

42. Guyatt GH. Positive pressure ventilation as a mechanism of reduction of left ventricular afterload. Can Med Assoc J 1982;126: 1310-1312.

43. Jardin F, Delorme G, Hardy A, Auvert B, Beauchet A, Bourdarias JP. Reevaluation of hemodynamic consequences of positive pressure ventilation: emphasis on cyclic right ventricular afterloading by mechanical lung inflation. Anesthesiology 1990;72:966-970.

44. Versprille $\mathrm{A}$. The pulmonary circulation during mechanical ventilation. Acta Anaesthesiol Scand [Suppl] 1990;94:51-62.

45. Santamore WP, Heckman JL, Bove AA. Cardiovascular changes from expiration to inspiration during IPPV. Am J Physiol 1983; 245:307-312.

46. Santamore WP, Heckman JL, Bove AA. Right and left ventricular pressure-volume response to respiratory maneuvers. J Appl Physiol 1984;57:1520-1527.

47. Curtis SE, Fuhrman BP, Howland DF. Airway and alveolar pressures during perfluorocarbon breathing in infant lambs. J Appl Physiol 1990;68:2322-2328.

48. Pizov R, Cohen M, Weiss Y, Segal E, Cotev S, Perel A. Positive end-expiratory pressure-induced hemodynamic changes are reflected in the arterial pressure waveform. Crit Care Med 1996;24: 1381-1387.

49. Innes JA, De Cort SC, Kox W, Guz A. Within-breath modulation of left ventricular function during normal breathing and positivepressure ventilation in man. J Physiol (Lond) 1993,460:487-502.

50. Robotham JL, Cherry D, Mitener W, Rabson J, Lixfeld W, Bromberger Barnea B. A re-evaluation of the hemodynamic consequences of intermittent positive pressure ventilation. Crit Care Med 1983:11:783-793.

51. Michard F, Chemla D, Richard C, Wysocki M, Pinsky MR, Lecarpentier Y, Teboul JL. Clinical use of respiratory changes in arterial pulse pressure to monitor the hemodynamic effects of PEEP. Am J Respir Crit Care Med 1999;159:935-939.

52. Hummler H, Gerhardt T, Gonzalez A, Claure N, Everett R, Bancalari E. Influence of different methods of synchronized mechani- cal ventilation on ventilation, gas exchange, patient effort, and blood pressure fluctuations in premature neonates. Pediatr Pulmonol 1996;22:305-313.

53. Stavis RL, Wolfson MR, Cox C, Kechner N, Shaffer TH. Physiologic, biochemical, and histologic correlates associated with tidal liquid ventilation. Pediatr Res 1998;43:132-138.

54. Wolfson MR, Cox CA, Shaffer TH. Tidal liquid ventilation: is lung size or age a physiological limitation? Am J Respir Crit Care Med 1998;157:460.

55. Laude D, Goldman M, Escourrou P, Elghozi JL. Effect of breathing pattern on blood pressure and heart rate oscillations in humans. Clin Exp Pharmacol Physiol 1993;20:619-626.

56. Szold A, Pizov R, Segal E, Perel A. The effect of tidal volume and intravascular volume state on systolic pressure variation in ventilated dogs. Intensive Care Med 1989;15:368-371.

57. Perel A, Pizov R, Cotev S. Systolic blood pressure variation is a sensitive indicator of hypovolemia in ventilated dogs subjected to graded hemorrhage. Anesthesiology 1987;67:498-502.

58. Versprille A, Jansen JR. Tidal variation of pulmonary blood flow and blood volume in piglets during mechanical ventilation during hyper-, normo- and hypovolaemia. Pflugers Arch 1993;424:255265.

59. Lowe CA, Shaffer TH. Pulmonary vascular resistance in the fluorocarbon-filled lung. J Appl Physiol 1986;60:154-159.

60. Scharf SM, Brown R, Saunders N, Green LH. Hemodynamic effects of positive-pressure inflation. J Appl Physiol 1980;49:124 131.

61. Bada HS, Korones SB, Perry EH, Arheart KL, Ray JD, Pourcyrous M, Magill HL, Runyan W, Somes GW, Clark FC, Tullis KV. Mean arterial blood pressure changes in premature infants and those at risk for intraventricular hemorrhage. J Pediatr 1990;117: 607-614.

62. D'Souza SW, Janakova H, Minors D, Suri R, Waterhouse J, Appleton G, Ramesh C, Sims DG, Chiswick ML. Blood pressure, heart rate, and skin temperature in preterm infants: associations with periventricular haemorrhage. Arch Dis Child 1995;72:162167.

63. Perlman JM, Goodman S, Kreusser KL, Volpe J. Reduction in intraventricular hemorrhage by elimination of fluctuating cerebral blood-flow velocity in preterm infants with respiratory distress syndrome. N Engl J Med 1985:312:1353-1357.

64. Perlman JM, Volpe JJ. Fluctuating blood pressure and intraventricular hemorrhage. Pediatrics 1990;85:620-622.

65. Van Bel F, Van de Bor M, Stijnen T, Baan J, Ruys JH. Aetiological role of cerebral blood-flow alterations in development and extension of peri-intraventricular haemorrhage. Dev Med Child Neurol 1987;29:601-614.

66. Miall Allen VM, de Vries LS, Dubowitz LM, Whitelaw AG. Blood pressure fluctuation and intraventricular hemorthage in the preterm infant of less than 31 weeks' gestation. Pediatrics 1989; 83:657-661.

67. Coughtrey H, Rennie JM, Evans DH, Cole TJ. Factors associated with respiration induced variability in cerebral blood flow velocity. Arch Dis Child 1993;68:312-316.

68. Coughtrey H, Rennie JM, Evans DH. Variability in cerebral blood flow velocity: observations over one minute in preterm babies. Early Hum Dev 1997;47:63-70.

69. Periman JM, Volpe JJ. Are venous circulatory abnormalities important in the pathogenesis of hemorrhagic and/or ischemic cerebral injury? Pediatrics 1987;80:705-711.

70. Ghazi Birry HS, Brown WR, Moody DM, Challa VR, Block SM, Reboussin DM. Human germinal matrix: venous origin of hemorthage and vascular characteristics. ANRR 1997;18:219-229. 
71. Taylor GA. New concepts in the pathogenesis of germinal matrix intraparenchymal hemorthage in premature infants. AJNR 1997; 18:231-232.

72. Teplick RS. Measuring central vascular pressures: a surprisingly complex problem. Anesthesiology 1987;67:289-291.

73. Jansen JR, Schreuder JJ, Settels JJ, Kornet L, Penn OC, Mulder PG, Versprille A, Wesseling KH. Single injection thermodilution. A flow-corrected method. Anesthesiology 1996;85:481-490.
74. Jansen JR, Schreuder JJ, Settels JJ, Kloek JJ, Versprille A. An adequate strategy for the thermodilution technique in patients during mechanical ventilation. Intensive Care Med 1990;16:422425 .

75. Baba $Y$, Taenaka $Y$, Akagi H, Nakatani T, Masuzawa T, Tatsumı E, Wakisaka Y, Toda K, Eya K. Tsukahara K, Takano H. A volume-controlled liquid ventilator with pressure-limit mode: imperative expiratory control. Artif Organs 1996;20:1052-1056. 
High-frequency oscillatory ventilation, partial liquid ventilation, or conventional mechanical ventilation in newborn piglets with saline lavage-induced acute lung injury. A comparison of gasexchange efficacy and lung histomorphology 


\title{
High-Frequency Oscillatory Ventilation, Partial Liquid Ventilation, or Conventional Mechanical Ventilation in Newborn Piglets with Saline Lavage-Induced Acute Lung Injury
}

A Comparison of Gas-Exchange Efficacy and Lung Histomorphology

\author{
Pieter L.J. Degraeuwe ${ }^{a}$ Frederik B.J.M. Thunnissen ${ }^{b}$ Gijs D. Vos ${ }^{a}$ \\ Carlos E. Blanco ${ }^{a}$ \\ Departments of $\cdot$ Paediatrics, and 'Pathology. University Hospital Maastricht, \\ The Netherlands
}

\section{Key Words \\ Bronchoalveolar lavage $\cdot$ Respiratory insufficiency therapy - High-frequency ventilation . Fluorocarbon therapeutic use . Pulmonary gas exchange - Pressure-volume curve $\cdot$ Histologic injury score}

\begin{abstract}
It has been reported that, in diseased lungs, either partial liquid ventilation (PLV) or highfrequency oscillatory ventilation (HFOV) can improve oxygenation better and with less lung injury than conventional mechanical ventilation (CMV). This study was intended as a preclinical comparison between the effects of HFOV, PLV and CMV on gas exchange, lung mechanics and histology. Fifteen anesthetized newborn piglets, with respiratory insufficiency due to repeated saline
\end{abstract}

\begin{tabular}{|c|c|}
\hline KARGER & $\begin{array}{l}\text { O 1999 S. Karger AG. Basel } \\
\text { 0006-3126/99/0752-0118517.500 }\end{array}$ \\
\hline $\begin{array}{l}\text { Fax + } 41613061234 \\
\text { E.Mail kargerekarger.ch } \\
\text { www. karger.com }\end{array}$ & $\begin{array}{l}\text { Aceessible online at: } \\
\text { http } / / \text { BioMedNet com/karger }\end{array}$ \\
\hline
\end{tabular}

lung lavage, were allocated to either a PLV, HFOV or CMV ( $n=5$ each) strategy, and treated for $\mathbf{4 h}$. Within 30 min of commencing therapy, PLV, HFOV, and CMV improved arterial $\mathrm{Po}_{2}\left(\mathrm{~Pa}, \mathrm{O}_{2}\right)$, alveoloarterial oxygen gradient $\left(\mathrm{P}(\mathrm{A}-\mathrm{a}), \mathrm{O}_{2}\right)$, oxygenation index $(\mathrm{OI})$, venous admixture (va), and arterial $\mathrm{PcO}_{2}$ $\left(\mathrm{Pa}, \mathrm{CO}_{2}\right)$. After $4 \mathrm{~h}$, oxygenation parameters $\left(\mathrm{Pa}, \mathrm{O}_{2}, \mathrm{P}(\mathrm{A}-\mathrm{a}), \mathrm{O}_{2}, \mathrm{Ol}\right.$ and venous admixture) were significantly better in the HFOV group than in the PLV group; the CMV group showed a higher $\mathrm{Pa}, \mathrm{O}_{2}$ and lower $\mathrm{Ol}$ than the PLV group. Gas exchange at the end of the experiment was not different from baseline in the HFOV and CMV groups. Lung histology and morphometry were performed after perfusion-fixation at endotracheal deflation pressure corresponding to mean airway pressure at the end of the experiment. Lung injury score and mean linear intercept were

\footnotetext{
P.L. Degracuwe, MD

Department of Pacdiatrics, University Hospital Maastrich

P. Debyelaan 25, PO Box 5800

NL-6202 AZ Maastricht (The Netherlands)

Tel. +31 433877246 , Fax + 31433875246 , E-Mail pdeoskin.arm.nl
} 
not different between the three treatment groups. We conclude that in this model, gas exchange improved significantly in all three ventilation strategies. Indices of oxygenation improved less during PLV. The saline lavageinduced acute lung injury model used as in this study, is less stable than previously thought. The final lung injury is not influenced by the ventilation strategy. We speculate that the impaired gas exchange during PLV is an expression of diffusion limitation and ventilation-perfusion mismatch in a recovering lung.

\section{Introduction}

Combining gas mechanical ventilation with tracheal instillation of perfluorocarbon (PFC) liquid (up to the functional residual capacity, FRC) is called partial liquid ventilation (PLV) or perfluorocarbon-associated gas exchange (PAGE) [1]. Comparative (mostly prospective randomized) animal studies have demonstrated the superiority (improved oxygenation and respiratory mechanics) of PLV over conventional gas ventilation in neonatal respiratory distress syndrome [2], lung lavage pulmonary injury [3], oleic acid infusion [4] and gastric acid instillation [5] models or acute respiratory distress syndrome (ARDS), and meconium insufflation [6]. Several authors have reported lung morphology as being more favorable after PLV than after conventional gas mechanical ventilation (CMV) [3, 5-9]. The first human experience with PLV was encouraging $[10,11]$.

High-frequency oscillatory ventilation (HFOV) is another technique during which gas exchange is improved with less lung injury than conventional gas ventilation [12, 13]. Nowadays, HFOV is an accepted and safe therapy in neonatal respiratory failure [14,
15]. But a recent meta-analysis of high-frequency ventilation clinical trials underscored that the use of a 'high-volume strategy' seems to be necessary in order to improve pulmonary outcome without an increase in neurological sequelae [16]. Before the introduction of PLV into the clinical setting, superiority in comparison with HFOV should be demonstrated. Therefore, we tested the hypothesis that PLV would result in better gas exchange and decreased pulmonary barotrauma by comparing a PLV strategy [2] to either a high volume HFOV strategy $[17,18]$ or high-PEEP $\mathrm{CMV}$ in whole lung lavaged newborn piglets. Indeed, repeated saline lung lavage yields a widely accepted animal model of respiratory insufficiency suitable for the evaluation of respiratory therapeutics [19]. The study design looks much like previously published studies evaluating the short term effects of HFOV [17, 20, 21] and PLV [3]. Our proto$\mathrm{col}$, however, prescribed adjustment of ventilator settings as clinically indicated in all study groups.

\section{Methods}

Animal care was supervised and experimental protocols approved by the University Committee on the Use and Care of Animals, University of Maastricht. The Netherlands.

\section{Animal Procedures}

Seventeen neonatal piglets of either sex (8-16 days old; $2.8-4.0 \mathrm{~kg}$ ) were anesthetized with halothane in oxygen given by face mask. An intravenous catheter was inserted in an auricular vein, and intravenous anesthesia provided with $4 \mathrm{mg} / \mathrm{kg}$ pentobarbital. A cervical tracheostomy was performed and an endotracheal tube (Portex $4.0 \mathrm{~mm}$ ID) was inserted and tied into the trachea, with the tip positioned proximal to the carina.

The endotracheal tube was connected to a continuous flow, time-cycled, pressure-limited Bourns BP. 200 ventilator. Humidification and heating of the respiratory gases was provided by way of a standard humidifier. Initially the animals were ventilated with a 
continuous flow of 8 liters $/ \mathrm{min}, \mathrm{F}_{1,0_{2}}=1.0$, a PIP of $1.2 \mathrm{kPa}\left(12 \mathrm{~cm} \mathrm{H} \mathrm{H}_{2} \mathrm{O}\right)$ and a PEEP of $0.2 \mathrm{kPa}(2 \mathrm{~cm}$ $\mathrm{H}_{2} \mathrm{O}$ ); the respirator rate was $40 \mathrm{~min}^{-1}$ and I:E ratio $=$ 1:1. Proximal airway pressure (Paw) was continuously monitored by a pressure transducer at the endotracheal tube connector. A carotid artery catheter was placed for continuous blood pressure monitoring and blood sampling. A French 5 sheath catheter was introduced into the right jugular vein and a flow directed $4 \mathrm{~F}$ pulmonary artery catheter was inserted through this indwelling sheath. The location of the catheter in the right ventricle was validated by pressure wave-form analysis. Anesthesia was maintained by infusion of $8.5 \mathrm{mg} \cdot \mathrm{kg}^{-1} \cdot \mathrm{h}^{-1}$ of pentobarbital sodium; muscle paralysis was obtained using pancuronium bromide $\left(0.2 \mathrm{mg} \cdot \mathrm{kg}^{-1} \cdot \mathrm{h}^{-1}\right)$. Maintenance fluids (dextrose $5 \%$ ) were infused at a rate of $100 \mathrm{ml} \cdot \mathrm{kg}^{-1} \cdot$ day $^{-1}$. Rectal temperature was kept within a range of $38.5-39.5^{\circ} \mathrm{C}$ using a heating pad. Catheters were connected to pressure transducers, zero-referenced to midchest level, and a standard limb lead electrocardiogram (ECG) was used.

\section{Experimental Protocol}

During instrumentation and in order to obtain baseline data the piglets were gas ventilated for approximately $1 \mathrm{~h} . \mathrm{Pa}, \mathrm{CO}_{2}$ was stabilized between 4.6 and $6 \mathrm{kPa}$. During the whole experiment polygeline (Haemacel $\left.{ }^{(}\right)$was administered to maintain a right atrial pressure between 5 and $8 \mathrm{~mm} \mathrm{Hg}$. Metabolic acidosis (BE $<-8 \mathrm{mmol} / 1$ or $\mathrm{pH}<7.25$ ) was corrected with THAM infusion.

Respiratory failure was induced by repeated lung lavage with saline $\left(30 \mathrm{ml} / \mathrm{kg}\right.$; heated to $\left.39^{\circ} \mathrm{C}\right)$ [19]. Lung lavage was repeated at 3 -min intervals until $\mathrm{Pa}, \mathrm{O}_{2}$ was below $10 \mathrm{kPa}$ at the following ventilator settings: frequency $40 \mathrm{~min}^{-1}$; PIP/PEEP $2.5 / 0.6 \mathrm{kPa}(26 / 6 \mathrm{~cm}$ $\mathrm{H}_{2} \mathrm{O}$ ), $\mathrm{I}: \mathrm{E}=\mathrm{I}: \mathrm{I} ; \mathrm{F}_{1}, \mathrm{O}_{2}=1.0$. To achieve this target 5-20 lavages were performed. Two piglets died during the lavage procedure of severe hypoxia and acidosis.

After a period of $15 \mathrm{~min}$, and after another blood gas analysis confirmed severe respiratory failure, the animals were allocated to one of three treatment groups: PLV, HFOV or CMV ( $\mathrm{n}=5$ each).

In the PLV group, $30 \mathrm{ml} / \mathrm{kg}$ (a volume corresponding to the normal functional residual capacity) of FC. 75 PFC liquid (3M Company, Belgium), warmed to $39^{\circ} \mathrm{C}$, was instilled into the lungs via a side port of the endotracheal tube connector, while maintaining gas ventilation. At $25^{\circ} \mathrm{C}$, this industrial PFC liquid has a density of $1.78 \mathrm{~g} \cdot \mathrm{ml}^{-1}$, a surface tension of $15 \mathrm{mN} / \mathrm{m}$ (15 dyn/cm), and an $\mathrm{O}_{2}$ solubility of $52 \mathrm{ml} / \mathrm{dl}$. The $\mathrm{CO}_{2}$ solubility is $160 \mathrm{ml} / \mathrm{dl}$ at $37^{\circ} \mathrm{C}$. The infusion rate was
$1 \mathrm{ml} \cdot \mathrm{kg}^{-1} \cdot \mathrm{min}^{-1}$ and the infusion was continued until a meniscus of perfluorochemical liquid was consistently visible in the endotracheal tube at end-expiration without PEEP [2]. In order to compensate for PFC liquid evaporation, a continuous endotracheal infusion of FC-75 was given at a rate of about $12 \mathrm{ml} \cdot \mathrm{kg}^{-1} \cdot \mathrm{h}^{-1}$. The evaporative loss of perfluoro-octylbromide during PLV has been estimated to be $1.5-2.5 \mathrm{ml} \cdot \mathrm{kg}^{-1} \cdot \mathrm{h}^{-1}$ [4] However, the vapor pressure of FC-75 is six times higher than that of perflubron. A positive end-expiratory pressure (PEEP) of $0.4 \mathrm{kPa}\left(4 \mathrm{~cm} \mathrm{H}_{2} \mathrm{O}\right)$ was applied in order to eliminate early inspiratory airway pressure spike, and to achieve a nearly monophasic pressure curve $[2,22]$. This decided level of PEEP was maintained throughout the study. The liquid meniscus was rechecked every hour during a short ( $5 \mathrm{~s}$ ) disconnection of the endotracheal tube. As oxygenation was found to be profoundly influenced by tidal volume [22, 23], PIP could be increased every 10-15 minutes to maximize $\mathrm{Pa}, \mathrm{O}_{2}$, as long as $\mathrm{Pa}, \mathrm{CO}_{2}$ remained between 4.7 and $6 \mathrm{kPa}$.

The HFOV group received high frequency oscillation delivered by a home-made piston pump with an adjustable stroke driven by a variable-speed electric motor [24]. Oscillations, with a 1:1 I:E ratio, as produced by a single flywheel, were transmitted to the endotracheal tube connector by Super-Tygon tubing of around $60 \mathrm{~cm}$ length. Mean airway pressure (MAP) was adjusted by altering the bias flow, generated by the Bourns BP-200 ventilator. Mean airway pressure and peak to peak pressure were monitored by the pressure transducer at the endotracheal tube connector. To achieve optimal lung inflation the 'high volume' strategy $[13,17,18]$ was used. Mean airway pressure was set initially $0.3 \mathrm{kPa}\left(3 \mathrm{~cm} \mathrm{H} \mathrm{H}_{2} \mathrm{O}\right)$ higher than during conventional ventilation. Airway pressure was increased every 10-15 min in increments of 0.1 to $0.2 \mathrm{kPa}$ (1$\left.2 \mathrm{~cm} \mathrm{H} \mathrm{H}_{2} \mathrm{O}\right)$ until a $\mathrm{Pa}_{2} \mathrm{O}_{2}$ of $>53 \mathrm{kPa}(400 \mathrm{~mm} \mathrm{Hg})$, an 'optimized' value taken from the literature [17, 20, 21, 25]. Oscillatory frequency was maintained at $10 \mathrm{~Hz}$. The amplitude was altered as necessary to keep $\mathrm{Pa}, \mathrm{CO}_{2}$ between 4.7 and $6 \mathrm{kPa}$.

In the CMV group pressures were initially increased from $2.5 / 0.6 \mathrm{kPa}\left(26 / 6 \mathrm{~cm} \mathrm{H}_{2} \mathrm{O}\right)$ to around $2.9 /$ $0.8 \mathrm{kPa}\left(30 / 8 \mathrm{~cm} \mathrm{H} \mathrm{H}_{2} \mathrm{O}\right)$, augmenting the MAP with $0.3 \mathrm{kPa}\left(3 \mathrm{~cm} \mathrm{H} \mathrm{H}_{2} \mathrm{O}\right)$, comparable to the HFOV group. Subsequently, PIP was adjusted to maintain normocapnia.

Using a $\mathrm{F}_{1}, \mathrm{O}_{2}$ of 1.0 , ventilation by either PLV, HFOV, or CMV was continued for $4 \mathrm{~h}$. To avoid unnecessary baro- or volu-trauma, weaning was attempted by decreasing ventilator pressures while maintaining optimized blood gases. 
Arterial and mixed venous blood gases were recorded at base line on conventional ventilation, after the induction of respiratory insufficency and $15 \mathrm{~min}$ later, and 10,20,30 min, 1, 2, 3 and $4 \mathrm{~h}$ after the initiation of either PLV, HFOV or CMV.

All piglets were sacrificed at the end of the experiment by an overdose of pentobarbital.

\section{Measurements and Calculations}

Blood gases and $\mathrm{pH}$ were measured within $5 \mathrm{~min}$ of collection using the $\mathrm{ABL}^{\mathrm{TM}} 3$ blood gas analyzer ( $\mathrm{Ra}$ diometer, Copenhagen) correcting for body temperature. Hemoglobin concentration and oxygen saturation were obtained using the OSM3 oxymeter (Radiometer). Arterial and mixed venous blood gases were used to calculate:

(1) Oxygenation index: $\mathrm{OI}=\left[\mathrm{MAP}\left(\mathrm{cm} \mathrm{H} \mathrm{H}_{2} \mathrm{O}\right) \times\right.$ $\left.\mathrm{F}_{1, \mathrm{O}_{2}} \mathrm{M} / 7.5 \times{\mathrm{Pa}, \mathrm{O}_{2}}(\mathrm{kPa})\right]$;

(2) alveolar-arterial $\mathrm{O}_{2}$ gradient: $\mathrm{P}(\mathrm{A}-\mathrm{a}), \mathrm{O}_{2}=\mathrm{F}_{1, \mathrm{O}_{2}}$ $\times\left(\mathrm{PB}-\mathrm{PH}_{2} \mathrm{O}-\mathrm{PFC}-75\right)-\mathrm{Pa}, \mathrm{CO}_{2}-\mathrm{Pa}, \mathrm{O}_{2}$ (assuming a respiratory exchange ratio of 1 , and $\mathrm{PA}, \mathrm{CO}_{2}=\mathrm{Pa}_{2}, \mathrm{CO}_{2}$ ).

During PLV the inspired partial pressure of oxy-

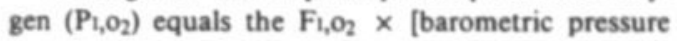
( $\pm 101.3 \mathrm{kPa}$ or $760 \mathrm{~mm} \mathrm{Hg}$ ) minus water vapor pressure $\left(6.3 \mathrm{kPa}\right.$ or $47 \mathrm{~mm} \mathrm{Hg}$ at $\left.37^{\circ} \mathrm{C}\right)$, minus FC-75 vapor pressure $\left(8.7 \mathrm{kPa}\right.$ or $65 \mathrm{~mm} \mathrm{Hg}$ at $\left.38^{\circ} \mathrm{C}\right)$ ].

(3) Shunt or venous admixture: va $=Q^{\prime}$ sh/Q'tot $=$ $100 \times\left(\mathrm{Cc}^{\prime}, \mathrm{O}_{2}-\mathrm{Ca}, \mathrm{O}_{2}\right) /\left(\mathrm{Cc}^{\prime}, \mathrm{O}_{2}-\mathrm{Cv}, \mathrm{O}_{2}\right)$ (the end capillary $\mathrm{Pc}^{\prime}, \mathrm{O}_{2}$ was estimated from the calculated alveolar oxygen tension $\mathrm{PA}_{\mathrm{A}, \mathrm{O}_{2}}=\mathrm{P}_{1}, \mathrm{O}_{2}-\mathrm{Pa}_{2}, \mathrm{CO}_{2}$, assuming equilibrium between alveolar and capillary blood gasses) [26].

\section{Lung Mechanics}

After sacrifice, static respiratory system compliance was measured in all animals. At atmospheric pressure, after completion of two standard inflations and deflations from 0 to $2.5 \mathrm{kPa}\left(25 \mathrm{~cm} \mathrm{H}_{2} \mathrm{O}\right)$, the lungs were inflated and deflated in stepwise volume increments up to a volume of $20 \mathrm{ml} / \mathrm{kg}$, with a $2-\mathrm{min}$ wait at each volume for pressure equilibration. Volumes were expressed per $\mathrm{kg}$ of body weight.

The volume-pressure ratio was then computed from the pressure measured at $10 \mathrm{~mL} / \mathrm{kg}$ volume on the inflation and deflation limb of the P.V curve and arbitrarily called the inspiratory and expiratory total static respiratory system compliance (Crs, I,st and $\mathrm{Crs}, \mathrm{E}, \mathrm{st}$ ). The area enclosed within the hysteresis-loop was calculated.

\section{Lung Histology-Morphometry}

After completing the pressure-volume loops, the right ventricle was opened and a catheter secured in

HFOV, PLV, or CMV in Acute Lung Injury the main pulmonary artery. The left auricle was opened to allow the perfusate to escape. The lungs were first expanded for $1 \mathrm{~min}$ with a transpulmonary pressure of $2.0 \mathrm{kPa}\left(20 \mathrm{~cm} \mathrm{H} \mathrm{H}_{2} \mathrm{O}\right)$. The lungs were then flushed with buffered $10 \%$ formalin at a pressure of $2.9 \mathrm{kPa}\left(30 \mathrm{~cm} \mathrm{H} \mathrm{H}_{2} \mathrm{O}\right)$ for $30 \mathrm{~min}$ as they were held at a deflation pressure corresponding to the MAP recorded at $4 \mathrm{~h}$. Immediately thereafter, the inflated lung was tied off, removed, and further perfused overnight at the department of pathology [27] using a perfusion pressure of $\pm 2.9 \mathrm{kPa}\left(30 \mathrm{~cm} \mathrm{H} \mathrm{H}_{2} \mathrm{O}\right)$. On the following day, lung specimens were taken from the right lung. Each lung lobe was cut into 3 transverse slices. Blocks of tissue (approximately $2 \times 1 \times 0.3 \mathrm{~cm}$ ) were prepared from the ventral and dorsal aspect of each slice and embedded in paraffin, sectioned at 5-8 $\mu \mathrm{m}$ width, and stained with hematoxylin and eosin. The lung sections were coded and examined by conventional light microscopy without any knowledge of the treatment group. Histologic analysis was performed on slides of the ventral and dorsal aspect of the right middle lobe. A three-point, severity-based scoring system was used. The characteristics included desquamation of (1) bronchial, and (2) bronchiolar epithelium; (3) septal edema; (4) lymphangiectasis; (5) intra-alveolar exudate; (6) alveolar hemorrhage; (7) hyaline membrane formation; (8) alveolar neutrophil infiltration; (9) interstitial edema; (10) interstitial hemorrhage; (11) interstitial neutrophil infiltration; (12) interstitial lymphocyte infiltration; (13) congestion-hyperemia; (14) granulocyte sticking: (15) thrombocytic aggregation, and (16) fibrin deposition. The pathologic changes were graded as negative or slight $=0$, moderate $=1$, and severe $=2$.

Morphometry was performed using the Quantimet Q 570 Imaging processing and analysis system (Leica, Cambridge, UK). Air space size was estimated as mean linear intercept $(\mathrm{Lm})$ in randomly sampled fields. Mean linear intercept is an estimate of the average distance between alveolar walls and hence a measure of air space dimensions of lung inflation [28]. In a pilot study, measuring 20 random fields in all 18 sections of one lung, the progressive mean of the $\mathrm{Lm}$ did not change any more after counting more than 13 fields. In 5 lungs no differences were noted in $\mathrm{Lm}$ between the three slices of each lung lobe. Therefore, 13 consecutive fields of the dorsal and ventral aspect of the middle slice of each right lung lobe were used for the final morphometric analysis.

Statistical Analysis

Except for morphometric data, the assumptions on which parametric tests are based were not fulfilled.

Biol Neonate 1999,75:118-129 
Table 1. Summary of baseline, postinjury and preterminal gas exchange data, and MAP values

\begin{tabular}{|c|c|c|c|c|c|c|c|c|c|}
\hline & \multicolumn{3}{|l|}{ Baseline } & \multicolumn{3}{|l|}{ After injury } & \multicolumn{3}{|c|}{ After 4 hours of therapy } \\
\hline & $\mathrm{CMV}$ & PLV & HFOV & CMV & PLV & HFOV & $\mathrm{CMV}$ & PLV & HFOV \\
\hline $\mathrm{a}, 02$ & $\begin{array}{l}42.6 \\
(41.6-50.5)\end{array}$ & $\begin{array}{l}55.0 \\
(51.7-61.6)\end{array}$ & $\begin{array}{l}61.1 \\
(58.4-61.8)\end{array}$ & $\begin{array}{l}8.1 \\
(7.0-8.3)\end{array}$ & $\begin{array}{l}5.9 \\
(5.5-6.8)\end{array}$ & $\begin{array}{l}6.2 \\
(5.9-6.4)\end{array}$ & $\begin{array}{l}53.1^{-*} \\
(47.9-53.7)\end{array}$ & $\begin{array}{l}32.6 * \\
(29.9-36.9)\end{array}$ & $\begin{array}{l}60.3 * \\
(57.2-65.5)\end{array}$ \\
\hline $\begin{array}{l}\mathrm{a}, \mathrm{CO}_{2} \\
\mathrm{~Pa}\end{array}$ & $\begin{array}{l}4.0 \\
(3.1-4.2) \\
\end{array}$ & $\begin{array}{c}5.0 \\
(4.5-5.7) \\
\end{array}$ & $\begin{array}{l}4.6 \\
(4.5-4.7) \\
\end{array}$ & $\begin{array}{l}6.7 \\
(6.6-8.2) \\
\end{array}$ & $\begin{array}{l}9.3 \\
(8.3-9.8) \\
\end{array}$ & $\begin{array}{l}9.3 \\
(6.8-13.6) \\
\end{array}$ & $\begin{array}{l}5.4^{-*} \\
(5.1-5.8)\end{array}$ & $\begin{array}{c}4.7 * * \\
(4.2-5.1)\end{array}$ & $\begin{array}{c}4.6^{*-} \\
(4.5-5.0)\end{array}$ \\
\hline $\begin{array}{l}(\mathrm{A}-\mathrm{a}), \mathrm{O}_{2} \\
\mathrm{~Pa}\end{array}$ & $\begin{array}{l}48.5 \\
(40.5-50.3)\end{array}$ & $\begin{array}{l}35.5 \\
(30.0-38.5)\end{array}$ & $\begin{array}{l}29.3 \\
(28.7-32.2)\end{array}$ & $\begin{array}{l}80.6 \\
(80.3-81.4) \\
\end{array}$ & $\begin{array}{l}79.5 \\
(79.4-81.5)\end{array}$ & $\begin{array}{l}79.9 \\
(76.1-81.9)\end{array}$ & $\begin{array}{l}36.9+* \\
(36.0-43.3)\end{array}$ & $\begin{array}{l}49.1 \% . . \\
(44.4-51.1)\end{array}$ & $\begin{array}{l}30.5 * * \\
(25.0-31.5)\end{array}$ \\
\hline MAP, kPa & $\begin{array}{l}8.2 \\
(8.2-8.7) \\
\end{array}$ & $\begin{array}{c}8.9 \\
(8.3-9.1) \\
\end{array}$ & $\begin{array}{l}8.6 \\
(7.9-9.0) \\
\end{array}$ & $\begin{array}{l}14.8 \\
(14.6-14.9)\end{array}$ & $\begin{array}{c}14.9 \\
(14.3-15.0)\end{array}$ & $\begin{array}{l}15.2 \\
(15.0-15.2)\end{array}$ & $\begin{array}{l}10.0^{-*} \\
(9.0-10.0)\end{array}$ & $\begin{array}{l}11.7 * * \\
(11.0-13.1)\end{array}$ & $\begin{array}{c}15.3 *, \ldots * * \\
(15.2-15.6)\end{array}$ \\
\hline OI, \% & $\begin{array}{l}2.6 \\
(2.0-3.1)\end{array}$ & $\begin{array}{l}1.9 \\
(1.9-2.2)\end{array}$ & $\begin{array}{l}1.8 \\
(1.7-2.1)\end{array}$ & $\begin{array}{l}24.6 \\
(23.5-29.4)\end{array}$ & $\begin{array}{l}32.4 \\
(29.3-36.4) \\
\end{array}$ & $\begin{array}{c}31.9 \\
(31.6-35.9) \\
\end{array}$ & $\begin{array}{l}2.5^{*} \\
(2.5-3.1) \\
\end{array}$ & $\begin{array}{c}4.4^{*}, \cdots, \cdot . * \\
(4.0-5.2)\end{array}$ & $\begin{array}{l}3.2^{* *} \\
(3.1-3.6)\end{array}$ \\
\hline $\begin{array}{l}\text { Venous } \\
\text { admixture }\end{array}$ & $\begin{array}{l}23.6 \\
(12.9-24.2)\end{array}$ & $\begin{array}{l}24.0 \\
(11.1-29.3)\end{array}$ & $\begin{array}{l}22.3 \\
(11.2-24.8)\end{array}$ & $\begin{array}{l}59.7 \\
(38.2-63.2)\end{array}$ & $\begin{array}{l}62.9 \\
(61.4-70.9)\end{array}$ & $\begin{array}{l}64.1 \\
(63.2-71.1)\end{array}$ & $\begin{array}{l}13.5 * \\
(10.8-14.8)\end{array}$ & $\begin{array}{l}26.4^{*} \cdots \\
(24.9-34.8)\end{array}$ & $\begin{array}{l}10.2 * \\
(9.6-13.7)\end{array}$ \\
\hline
\end{tabular}

The values are expressed as median (IQR).

Intergroup differences: $* \mathrm{p}<0.05$ PLV vs. HFOV; $* \mathrm{p}<0.05$ PLV vs. CMV; ${ }^{* *} \mathrm{p}<0.05$ HFOV vs. CMV.

Intragroup differences: ${ }^{*} p<0.054$ h vs. baseline; ${ }^{*} p<0.054$ h vs. injury.

Accordingly, the data were assessed by Kruskal-Wallis one-way ANOVA and Mann-Whitney U test for intergroup comparison, taking the Bonferroni principle into account. Intragroup differences were evaluated by Friedman two-way ANOVA and the Wilcoxon signed rank test [29]. Statistical significance was assigned for p values (two-tailed) less than 0.05 .

\section{Results}

The data are expressed as median (interquartile range or IQR) unless stated otherwise. The treatment groups were not different with respect to age, weight, and number of lung lavage used to induce respiratory insufficiency.

\section{Gas Exchange}

Baseline and postinjury blood gases were not different between the three treatment groups indicating comparable degree of respiratory insufficiency. During the treatment period, $\mathrm{Pa}, \mathrm{CO}_{2}, \mathrm{pHa}$, and mixed venous $\mathrm{Po}_{2}$ or saturation were not different between CMV, PLV and HFOV groups at any time. Most of the time a higher MAP was used in the HFOV when compared to the CMV or PLV group (fig. 1; table 1).

The course of median $\mathrm{Pa}, \mathrm{O}_{2}, \mathrm{P}(\mathrm{A}-\mathrm{a}), \mathrm{O}_{2}, \mathrm{OI}$, and venous admixture (shunt fraction) are shown in figure $2 a-d$. There was a significant

Fig. 1. Time course of median MAP in the three treatment groups: $\mathrm{B}=$ Baseline values; $\mathrm{L}=$ lung lavage procedure, represented by the grey speckled area. Inter-group differences: ${ }^{*} \mathrm{p}<0.05$ PLV vs. HFOV; ${ }^{*} \mathrm{p}<$ 0.05 PLV vs. CMV, ${ }^{*} p<0.05$ HFOV vs. CMV.

Fig. 2a-d. Time course of median $\mathrm{Pa}, \mathrm{O}_{2}$ (a), $\mathrm{P}(\mathrm{A}-\mathrm{a}), \mathrm{O}_{2}$ (b), oxygenation index (c), and venous admixture (d) in the three treatment groups: $\mathrm{B}=$ Baseline values; $\mathrm{L}=$ lung lavage procedure, represented by the grey speckled area. Note there are no inter-group differences before the study period. Oxygenation improved over time in each therapeutic group. Inter-group differences: ${ }^{\bullet} \mathrm{p}<0.05$ PLV vs. HFOV; ${ }^{*} \mathrm{p}<0.05$ PLV vs. CMV. Note the lack of significant inter-group differences at any time between $\mathrm{CMV}$ and HFOV. 

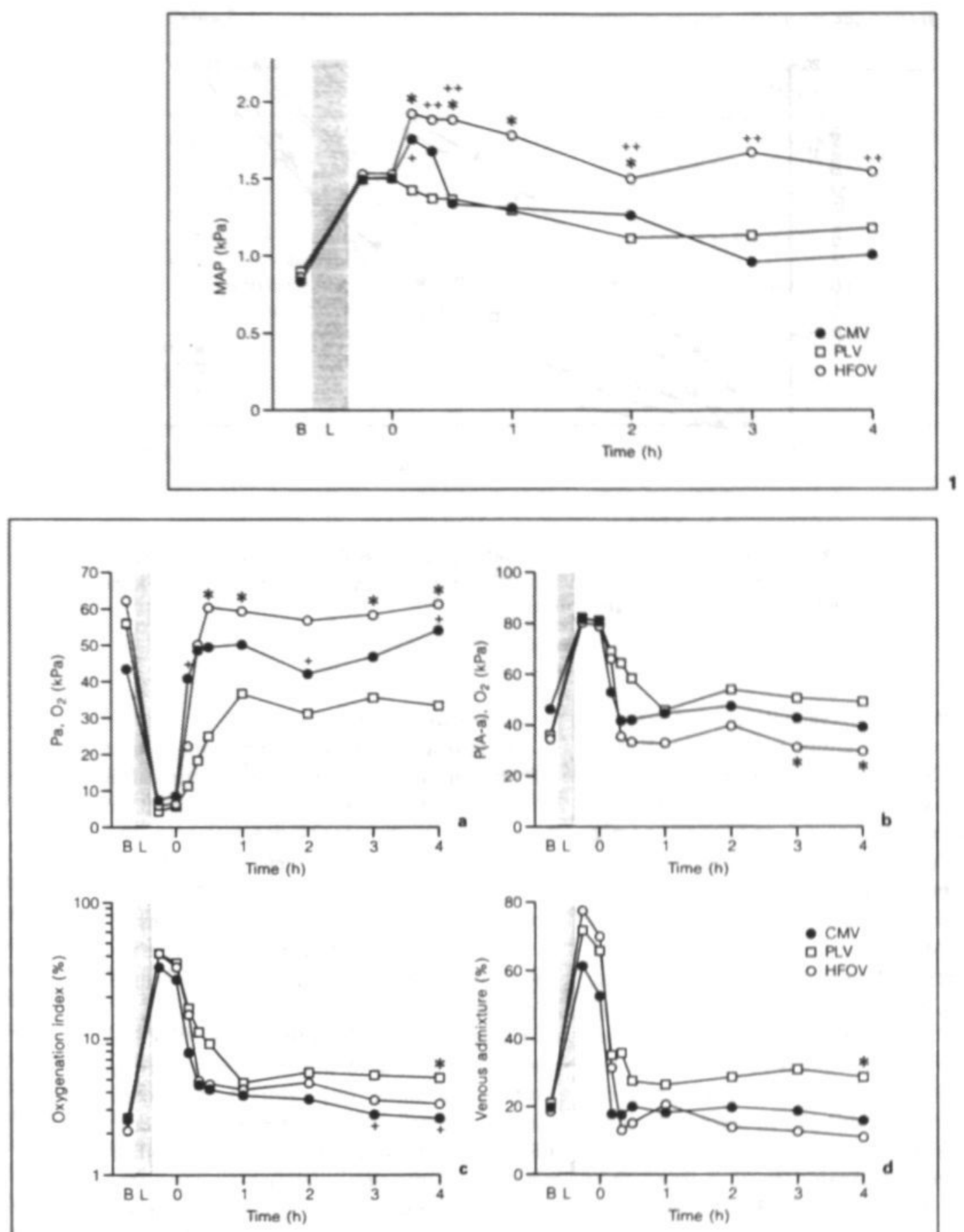

HFOV. PLV, or CMV in Acute Lung

Biol Neonate 1999,75: 1 18-129 


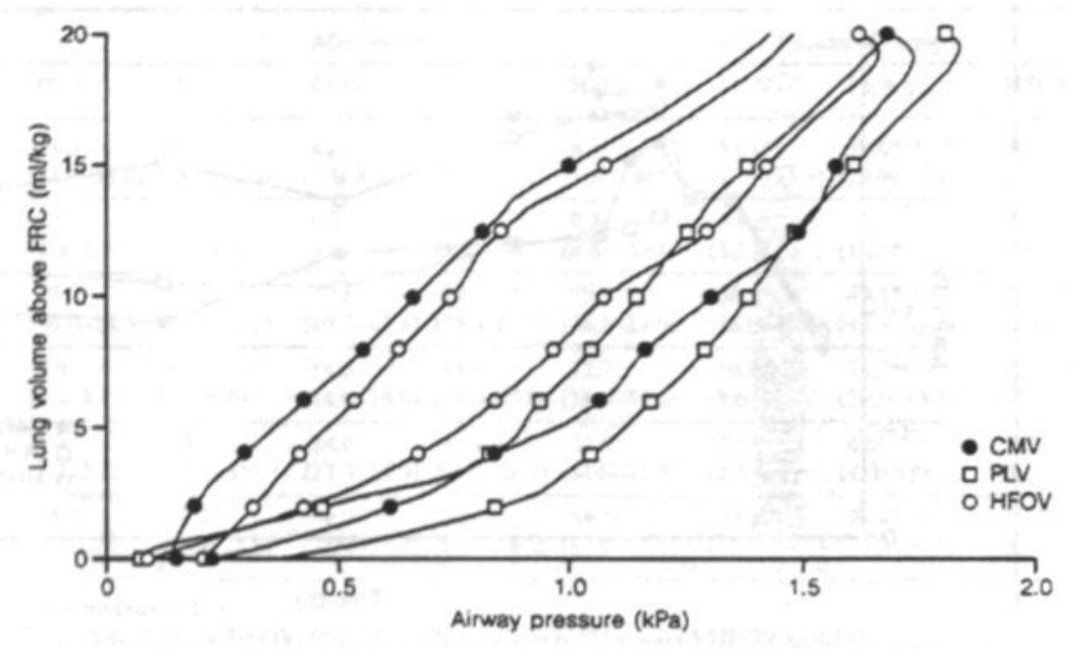

Fig. 3. Static respiratory system pressure-volume curves obtained after $4 \mathrm{~h}$ of ventilatory treatment. For clearness' sake only median values are shown. Abbreviations as in figure 1. See text for discussion of between-group differences.

improvement of oxygenation over time in each therapeutic group ( $<<0.05$ ). Within $30 \mathrm{~min}$ after initiation of therapy, all groups showed a significant increase in $\mathrm{Pa}, \mathrm{O}_{2}$ and a decrease in $\mathrm{P}(\mathrm{A}-\mathrm{a}), \mathrm{O}_{2}, \mathrm{OI}$, and venous admixture, compared to the postlavage values. Indices of pulmonary gas exchange were, at no time, different between the CMV and HFOV groups. At several time points, however, $\mathrm{PLV}$ animals showed lower $\mathrm{Pa}, \mathrm{O}_{2}$ or higher $\mathrm{P}(\mathrm{A}-\mathrm{a}), \mathrm{O}_{2}, \mathrm{OI}$, and venous admixture than either CMV or HFOV animals. At the end of the experiment all four parameters were less favourable in the PLV group compared to the HFOV group (table 1). In each treatment group, gas exchange parameters after $4 \mathrm{~h}$ were not different compared to base line values except for a lower $\mathrm{Pa}, \mathrm{O}_{2}$ in the $\mathrm{PLV}$ group.

\section{Pulmonary Mechanics}

Static respiratory system pressure-volume curves from the three treatment groups after $4 \mathrm{~h}$ of ventilation are shown in figure 3 . In comparison to the HFOV group, recoil pressures were significantly higher in the PLV group at 2, 4, 6 and $8 \mathrm{ml} / \mathrm{kg}$ lung (inflation) volume above FRC. At deflation volumes 15, $12.5,10,8,6$ and $4 \mathrm{ml} / \mathrm{kg}$, pressures were significantly higher in the PLV group than in both other groups.

Compared to CMV and HFOV, PLV was associated with a 45 and $33 \%$, respectively, decrease in static respiratory system compliance at a deflation volume $10 \mathrm{ml} / \mathrm{kg}$ above FRC. Inspiratory compliance was not different between the three treatment groups. The area enclosed within the hysteresis-loop was smaller in the PLV lungs than in the CMV lungs (table 2). 
Table 2. Inspiratory and expiratory total static respiratory system compliance and areas in hysteresis loops after CMV, PLV, and HFOV

\begin{tabular}{lccc}
\hline Variable & CMV & PLV & HFOV \\
\hline Crs, l,st, ml-kPa-1 $\cdot \mathrm{kg}^{-1}$ & $7.76(7.13-8.61)$ & $7.30(6.66-8.17)$ & $9.36(8.29-10.63)$ \\
Crs, E,st, $\mathrm{ml} \cdot \mathrm{kPa}^{-1} \cdot \mathrm{kg}^{-1}$ & $15.28(14.58-16.06)^{*}$ & $8.79(8.11-9.69)$ & $12.59(11.75-17.14)^{*}$ \\
Area for $20 \mathrm{ml} / \mathrm{kg}^{*} \mathrm{~g} \cdot \mathrm{cm}$ & $99.2(77.2-121.2)^{*}$ & $33.9(31.0-45.4)$ & $39.0(25.6-83.0)$ \\
\hline
\end{tabular}

$\mathrm{Crs}, \mathrm{l}, \mathrm{st}=\mathrm{V} / \mathrm{P}$ ratio at $10 \mathrm{~mL} / \mathrm{kg}$ inflation volume above $\mathrm{FRC} ; \mathrm{Crs}, \mathrm{E}, \mathrm{st}=\mathrm{V} / \mathrm{P}$ ratio at $10 \mathrm{~mL}$ kg deflation volume above FRC.

Conversion factor: 1 liter $\cdot \mathrm{kPa}^{-1}=0.098$ liters $\cdot \mathrm{cm} \mathrm{H}_{2} \mathrm{O}^{-1}$. Values are median (IQR).

Intergroup differences: ${ }^{\bullet} \mathrm{p}<0.05$ PLV vs. HFOV; ${ }^{*} \mathrm{p}<0.05$ PLV vs. CMV.

Table 3. Lung injury scores after CMV, PLV and HFOV in lung biopsies of the right middle lung lobe

\begin{tabular}{llll}
\hline & CMV & PLV & HFOV \\
\hline V & $26.0(22.5-28.5)$ & $24.0(21.0-28.0)$ & $21.0(20.5-26.5)$ \\
D & $29.0(27.5-32.0)$ & $26.0(23.5-28.5)$ & $27.0(21.5-31.0)$ \\
ALL & $28.0(25.5-30.5)$ & $26.0(21.0-27.75)$ & $25.0(20.75-28.0)$ \\
\hline
\end{tabular}

$\mathrm{V}=$ Ventral and $\mathrm{D}=$ dorsal aspect biopsies; $\mathrm{ALL}=\mathrm{V}$ and $\mathrm{D}$ clustered. Values are median (IQR); no significant differences between the groups, nor between $\mathrm{V}$ and $\mathrm{D}$ in either group.

\section{Histology-Morphometry}

There was a striking inhomogeneity of histomorphologic lung injury in the three groups. Irrespective of the treatment strategy, epithelial desquamation in the larger and smaller airways was present to a variable extent. Frequently, intra-alveolar edema was noticed. Alveolar hemorrhage, hyaline membranes and intra-alveolar neutrophils were scarce or absent in all cases. Interstitial edema with occasional lymphocytes and neutrophilic granulocytes was frequently present. Intravascular margination of neutrophil granulocytes, platelet aggregation or fibrin deposition were found in a single case in each treatment group. Moderate septal edema and lymphangiectasis were present in most cases. No significant intergroup differences were present in the to-

HFOV, PLV, or CMV in Acute Lung Injury
Table 4. Mean linear intercept ( $\mu \mathrm{m}$, mean (SD)) measured after CMV, PLV and HFOV in the right lung

\begin{tabular}{llll}
\hline & CMV & PLV & HFOV \\
\hline V & $68.0(29.4)$ & $72.9(29.8)$ & $76.5(32.0)$ \\
D & $60.4(24.5)$ & $74.3(31.0)$ & $67.9(29.3)$ \\
ALL & $64.1(27.2)$ & $72.4(29.9)$ & $72.8(31.3)$ \\
\hline
\end{tabular}

$\mathrm{V}=$ Ventral and $\mathrm{D}=$ dorsal aspect biopsies; $\mathrm{ALL}=$ $\mathrm{V}$ and $\mathrm{D}$ clustered; no significant differences between the groups, nor between $\mathrm{V}$ and $\mathrm{D}$ in either group.

tal lung injury score (table 3). Mean linear intercept was not different between the three groups, nor between ventral and dorsal aspects in either group (table 4). 


\section{Discussion}

The results of this study confirm that both PLV [3] or HFOV [17, 20, 30] improve oxygenation and ventilation shortly after their application in lung-lavage-induced respiratory insufficiency. However, in apparent contrast to most previous reports, conventional ventilation was equally effective. This discrepancy is to be explained by the different ventilation strategy used. Most, if not all, comparative studies maintained the ventilatory strategy applied during control gas ventilation unaltered, whereas we actively adjusted CMV settings to the increased ventilatory need induced by the lung injury.

At first glance, our results suggest that PLV is less effective in improving oxygenation than HFOV and to a lesser extent less effective than CMV. The data should however be interpreted with caution. The conventional approach to evaluate gas exchange may not be reliably comparable during PLV. This thesis is evident, based on theoretical and experimental grounds. Indeed, gas ventilation of the PFC liquid-filled normal lung is associated with a decrease in $\mathrm{Pa}, \mathrm{O}_{2}$ and increase in $\mathrm{P}\left(\mathrm{A}-\mathrm{a}, \mathrm{O}_{2}\right.$, and an increase in intrapulmonary oxygen shunt $[1,31,32,33]$. This (apparent) gas exchange limitation in healthy lungs can be explained by different factors. During $\mathrm{PLV}$, the inspired oxygen tension $\left(\mathrm{P}_{1}, \mathrm{O}_{2}\right)$ is lowered due to the dilution effect of PFC vapour pressure. At $39^{\circ} \mathrm{C}$, the FC-75 vapor pressure is about $8.7 \mathrm{kPa}(65 \mathrm{~mm} \mathrm{Hg})$. The alveolar-arterial $\mathrm{Po}_{2}$ difference results from a venous admixture component (caused by anatomical shunt and scatter of ventilation-perfusion ratios) and a diffusion component. During PLV, oxygen-exchange impairment has been attributed to a combination of heterogeneous diffusion limitation in the fluid-containing alveoli, creation of true shunt regions consisting of flooded unventilated alveoli, and ventilation-perfusion mismatch [31-33]. The contribution of each mechanism has not been quantified so far. Concerning the $\mathrm{OI}$, its calculation not only includes $\mathrm{F}_{1}, \mathrm{O}_{2}$ and $\mathrm{Pa}, \mathrm{O}_{2}$ but also MAP. In a commentary, Null states that 'One must be careful in using these indices for high-frequency ventilation, as the numbers for concern may not correlate with those for conventional ventilation' [34]. In addition, during PLV 'liquid PEEP' is not considered. Even the golden standard of oxygenation, venous admixture, is theoretically not applicable to PLV. Indeed, the oxygen content of pulmonary end-capillary blood $\left(\mathrm{Cc}^{\prime}, \mathrm{O}_{2}\right)$ is calculated on the basis of the endcapillary oxygen tension $\left(\mathrm{Pc}^{\prime}, \mathrm{O}_{2}\right)$ being equal to the ideal alveolar $\mathrm{Po}_{2}$. The assumption that diffusion impairment can be ignored is obviously not fulfilled during liquid ventilation $[35,36]$. Thus, none of the oxygenation parameters used describes the same (patho)physiological entity during PLV when compared to gas ventilation.

Oxygenation is highly correlated with lung volume. Since oxygenation and ventilation are regulated by different mechanisms, one could argue that the HFOV strategy may have overinflated the lungs. This hypothesis is however refuted by the morphometric data, the mean linear intercept being identical in all treatment groups.

At the end of the 4-hour experiment, oxygenation was not different from baseline values (except for $\mathrm{Pa}, \mathrm{O}_{2}$ during $\mathrm{PLV}$ ). This finding suggests a (nearly) complete recovery of lung function. We did not measure surfactant secretion but the PV loops add evidence to the speculation of surfactant sufficiency. Lung expansion is known to be a potent stimulus for surfactant secretion. Lung lavage probably depletes only the alveolar surfactant pool. We assume that alveolar reexpansion and ventilation which occurred in all three ventilation strategies, increased surfactant release of tis- 
sue pools. In comparison to the gas filled lungs, the liquid filled lungs had a lower (inspiratory and expiratory) compliance and less hysteresis. Our PV loops are very similar to previously reported data of normal lungs with or without FC-75 liquid filling $[37,38]$. The presumed explanation here is that surfactant not only lowers but also matches surface tension to the size of the alveolus. FC-75 like other PFC liquids has a low but fixed surface tension $(15 \mathrm{mN} / \mathrm{m}$ or dynes $/ \mathrm{cm})$ which is definitely higher than the lowest surfactant surface tension.

Our histologic findings do not substantiate any advantage of PLV or HFOV over CMV. As with the effects on gas exchange, we suppose that ongoing atelectasis was also prevented in the CMV group. This may, in part, explain the lack of difference between the three groups. On the other hand, the scale of airway, septum, interstitium, alveolar and vascular lesions was impressive. In fact, these lesions were also described by Lachmann et al. [19], when first proposing this lung lavage model of RDS. Therefore, we suppose that neither ventilation strategy influenced these preexisting lesions, or the lesions were influenced similarly. Our findings corroborate those of Hamilton et al. [20] who reported similar pathologic findings in saline lavage control animals, as in HFOV or CMV treated rabbits. Likewise, Curtis et al. [4] could not demonstrate differences in the histologic analysis after CMV, preventive or rescue PLV in oleic-acid injured dogs. Although appearing less severe compared with the CMV group, significant morphologic abnormalities in PLV treated lung lavaged adult rabbits were described by Kaisers et al. [39] as well. The same author could not document significant differences in total lung injury score between lung lavaged pigs treated with small amounts of FC 3280 and control animals [40]. More recently, Singh et al. [41] reported equal severity of

HFOV, PLV, or CMV in Acute Lung Injury lung injury induced by meconium instillation after $4 \mathrm{~h}$ of either PLV or CMV. It should be stressed that all these apparently disappointing reports refer to acute respiratory distress syndrome, or meconium injury. Preventive strategies of high frequency oscillatory ventilation [42], HFOV combined with exogenous surfactant [43] in premature baboons, and tidal liquid ventilation in preterm lambs [44] clearly reduce histologic lung injury. Recently, Kinsella et al. [45] compared HFOV, PLV, and CMV after surfactant therapy in extremely premature lambs. HFOV and PLV caused a similar improvement in gas exchange and equivalent attenuation of lung inflammation [45]. It was concluded that HFOV and PLV are equally efficacious lung recruitment strategies in preterm lungs. Which of both has the greatest potential in preventing bronchopulmonary dysplasia is not clear yet.

\section{Conclusions}

In this saline lung lavage model of respiratory insufficiency PLV, HFOV as well as CMV led to an immediate improvement of gas exchange. After $4 \mathrm{~h}$ of either treatment there is evidence of surfactant sufficiency. Less favorable lung mechanics and oxygenation in the PLV group are attributed to the presence of the PFC liquid in the lung. In order to compare gas exchange efficacy of gas and liquid ventilation, techniques should be used which differentiate the effect of venous admixture, ventilation-perfusion scatter and diffusion-perfusion limitation. No intergroup differences in lung injury score were demonstrated, and the histologic findings after $4 \mathrm{~h}$ of each therapy were consistent with the primary insult. The pulmonary lavage model, as used in this study, has two main drawbacks: the respiratory insufficien- 
cy is short-lived and the detection of respirator-induced lung damage is obscured by the model-induced histomorphologic disturbances.

\section{Acknowledgment}

The perfluorocarbon liquid (FC-75) used in our research was kindly provided by the $3 \mathrm{M}$ Company, Zwijndrecht, Belgium.

\section{References}

1 Fuhrman BP, Paczan PR, DeFrancisis ML: Perfluorocarbon-associated gas exchange. Crit Care Med 1991;19:712-722.

2 Leach CL, Holm B, Morin FC, Fuhrman BP, Papo MC, Steinhorn D, Hernan LJ: Partial liquid ventilation in premature lambs with respiratory distress syndrome: Efficacy and compatibility with exogenous surfactant. J Pediatr 1995;126:412420.

3 Tütüncü AS, Faithfull NS, Lachmann B: Comparison of ventilatory support with intratracheal perfluorocarbon administration and conventional mechanical ventilation in animals with acute respiratory dis. tress syndrome. Am Rev Respir Dis 1993; 148:785-792.

4 Curtis SE, Peek JT, Kelly DR: Partial liquid breathing with perfluorocarbon improves arterial oxygenation in acute canine lung injury. J Appl Physiol 1993;75:2696-2702.

5 Nesti FD, Fuhrman BP, Steinhorn DM, Papo MC, Hernan U., Duffy LC, Fisher JE, Leach CL. Paczan P, Burak B: Perfluorocarbon-associat. ed gas exchange (PAGE) in gastric aspiration. Crit Care Med 1994:22: 1445-1452.

6 Foust R, Tran NN, Cox C, Miller TF, Greenspan JS, Wolfson MR, Shaffer TH: Liquid assisted ventilation: An alternative ventilation strategy for acute meconium aspiration. Pediatr Pulmonol 1996;21: 316-322.

7 Papo MC, Paczan P, Fuhrman BP, Steinhorn DM, Hernan L, Leach CL. Holms B, Fisher JE, Kahn BA: Perfluorocarbon-associated gas exchange improves oxygenation, lung mechanics, and survival in a model of adult respiratory distress syndrome. Crit Care Med 1996;24: 466-474.
8 Quintel M, Heine M, Hirschl RB, Tillmans R, Wessendorf V: Effects of partial liquid ventilation on lung injury in a model of acute respiratory failure: A histologic and morphometric analysis. Crit Care Med 1998;26:833-843.

9 Smith KM, Mrozek JD, Simonton SC, Bing DR, Meyers PA, Connett JE, Mammel MC: Prolonged partial liquid ventilation using conventional and high-frequency ventilatory techniques: Gas exchange and lung pathology in an animal model of respiratory distress syndrome. Crit Care Med 1997;25:1888-1897.

10 Hirschl RB, Pranikoff T, Gauger P, Schreiner RJ. Dechert R, Bartlett RH: Liquid ventilation in adults, children, and full-term neonates. Lancet 1995;346:1201-1202.

11 Leach $\mathrm{CL}$, Greenspan JS, Rubenstein SD, Shaffer TH, Wolfson MR, Jackson JC, deLemos R, Fuhrman BP for the LiquiVent Study Group: Partial liquid ventilation with perflubron in premature infants with severe respiratory distress syndrome. N Engl J Med 1996;335: 761-767.

12 Clark RH: High-frequency ventilation. J Pediatr 1994:124:661-670.

13 Gerstmann DR, Clark RH, deLemos RA: High frequency ventilation: Issues of strategies. Clin Perinatol 1991; 18:563-580.

14 Patel CA, Klein JM: Outcome of infants with birth weights less than $1,000 \mathrm{~g}$ with respiratory distress syndrome treated with high-frequency ventilation and surfactant replacement therapy. Arch Pediatr Adolesc Med 1995:149:317-321.
15 Gerstmann DR, Minton SD, Stoddard RA, Meredith KS, Monaco F, Bertrand JM, Battisti $\mathrm{O}$, Langhendries JP, Francois A, Clark RH: The Provo multicenter early high-fre. quency oscillatory ventilation trial: Improved pulmonary and clinical outcome in respiratory distress syndrome. Pediatrics 1996;98:10441057.

16 Bhuta T, Henderson-Smart DJ: Elective high-frequency oscillatory ventilation versus conventional ventilation in preterm infants with pulmonary dysfunction: Systematic review and meta-analyses. Pediatrics 1997;100:887-888.

17 McCulloch PR, Forkert PG, Froese AB: Lung volume maintenance prevents lung injury during high frequency oscillatory ventilation in surfactant-deficient rabbits. Am Rev Respir Dis 1988;137:11851192.

18 deLemos RA, Coalson JJ, Meredith KS, Gerstmann DR, Null DM Jr: A comparison of ventilation strategies for the use of high-frequency oscillatory ventilation in the treatment of hyaline membrane disease. Acta Anaesthesiol Scand Suppl 1989:90; 102-107.

19 Lachmann B, Robertson B, Vogel J: In-vivo lung lavage as an experimental model of the respiratory distress syndrome. Acta Anaesthesiol Scand 1980:24:231-236.

20 Hamilton PP, Onayemi A, Smith JA, Gillan JE, Cutz E, Froese AB, Bryan AC: Comparison of conventional and high-frequency ventilation: Oxygenation and lung pathology. J Appl Physiol 1983:55:131138.

21 Matsuoko T, Kawano T, Miyasaka $K$ : Role of high-frequency ventilation in surfactant-depleted lung injury as measured by granulocytes. J Appl Physiol 1994; 76:539-544. 
22 Fuhrman BP, Hernan L., Leach Cl. Papo MC, Steinhorn DM: Determinants of oxygenation and airway pressure during volume regulated perfluorocarbon (P) associated gas exchange (PAGE). Pediatr Res 1994:35:51A.

23 Hernan L., Fuhrman BP, Kaiser R. Penfil S, Foley C, Papo MC, Leach $\mathrm{CL}$ : Perfluorocarbon-associated gas exchange in normal and acid-injured large sheep. Crit Care Med 1996:24:475-481.

24 Blanco CE, Maertzdorf WJ, Walther FJ: Use of continued high-frequency oscillation and intermittent mandatory ventilation in rabbits with saline-lavaged lungs. J Intens Care Med 1987:2:214-217.

25 Froese AB, McCulloch PR, Sugiura M, Vaclavick Sue, Possmayer F. Moller F: Optimizing alveolar expansion prolongs the effectiveness of exogenous surfactant in the adult rabbit. Am Rev Respir Dis 1993; 148:569-577.

26 Kelman GR: Digital computer subroutine for the conversion of oxygen tension into saturation. J Appl Phys. iol 1996;21:1375-1376.

27 Boers JE, den Brok JLM, Koudstaal J, Arends JW, Thunnissen FBJM: Number and proliferation of neuroendocrine cells in normal human airway epithelium. Am J Respir Crit Care Med 1996;154:758-763.

28 Dolhnikoff M, Dallaire M, Ludwig MS: Lung tissue distortion in response to metacholine in rats: Effect of lung volume. J Appl Physiol 1995;79:533-538.

29 Siegel S, Castellan NJ Jr: Nonparametric Statistics for the Behavioral Sciences. New York, McGraw-Hill, 1988.

30 Kolton M, Cattran CB, Kent G, Volgyesi G, Froese AB, Bryan AC: Oxy. genation during high-frequency ventilation compared with conventional mechanical ventilation in two models of lung injury. Anesth Analg 1982;61:323-332.
31 Mates EA, Jackson JC, Hildebrandt J, Truog WE, Standaert TA, Has. tala MP. Respiratory gas exchange and inert gas retention during partial liquid ventilation. Adv Exp Med Biol 1994:361:427-435.

32 Mates EA, Tarezy-Hornoch P, Hildebrandt J, Jackson JC, Hlastala MP: Negative slope of exhaled $\mathrm{CO}_{2}$ profile: Implications for ventilation heterogeneity during partial liquid ventilation. Adv Exp Med Biol 1996:388:585-597.

33 Mates EA, Hildebrandt J, Jackson JC, Tarezy-Hornoch P, Hlastala MP: Shunt and ventilation-perfusion distribution during partial liquid ventilation in healthy piglets. J Appl Physiol 1997;82:933-942.

34 Cunningham MD: Physiologic monitoring: in Boynton BR, Carlo WA, Jobe AH (eds): New Therapies for Neonatal Respiratory Failure: A Physiological Approach. London, Cambridge University Press, 1994, pp 171-191.

35 Gollan F, McDermott J, Johnson AC, Namon R: Compliance and diffusion during respiration with fluorocarbon liquid. Fed Proc 1970,29: 1725-1730.

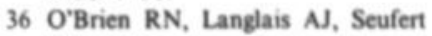
WD: Diffusion coefficient of respiratory gases in perfluorocarbon liq. uid. Science 1982;217:153-155.

37 Patel MM, Patel MK, Szanto P, Alrenga DP, Long DM: Ventilation with synthetic fluids. Surg Clin North Am 1971:51:25-36.

38 Rüfer R: Surfactant and alveolar surface forces after breathing of a fluorinated liquid. Fed Proc 1970, 29:1813-1815.
39 Kaisers U, Max M, Schnabel R, Bohm S, Hendrick ER, Rossaint R. Lachmann R: Partial liquid ventilation with FC 3280 in experimental lung injury: Dose dependent improvement of gas exchange and lung mechanics. ACP Appl Cardiopul Pathophysiol 1996;6:163-170.

40 Kaisers U, Max M, Walter J, Kuhlen R, Pappen D, Falke K, Rossaint R: Partial liquid ventilation with small volumes of FC $\mathbf{3 2 8 0}$ increases survival time in experimental ARDS. Eur Respir J 1997;10:19551961.

4) Singh AJ, Machin GA, Barrington KJ: Partial liquid ventilation (PLV) and conventional gas ventilation (GV): Histophatologic differences in newborn piglet lungs in a meconium aspiration syndrome (MAS) model. Pediatr Res 1997;41:268A.

42 Meredith KS, DeLemos RA, Coalson JJ, King RJ, Gerstmann DR. Kumar R, Kuchl TJ, Winter DC. Taylor A, Clark RH, Null DM: Role of lung injury in pathogenesis of hyaline membrane disease in premature baboons. J Appl Physiol 1989;66:2150-2158.

43 Jackson JC, Truog WE, Standaer TA, Murphy JH, Juul SE, Chi EY. Hildebrandt J, Hodson WA: Reduction in lung injury after combined surfactant and high-frequency ventilation. Am J Respir Crit Care Med 1994:150:534-539.

44 Wolfson MR, Greenspan JS, Deoras KS, Rubinstein SD, Shaffer TH Comparison of gas and liquid ventilation: Clinical, physiological, and histological correlates. J Appl Phys. iol 1992;72:1024-1031.

45 Kinsella JP, Parker TA, Sheridan BC, Abman SH: Effect of lung re. cruitment strategies on gas exchange and lung inflammation in severe $e x$. perimental hyaline membrane dis. ease. Pediatr Res 1997:41:257A 
Chapter 3

A feedback controller for the maintenance of FRC during tidal liquid ventilation: theory, implementation, and testing 
[ 7stageti]

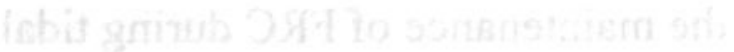

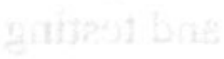




\title{
A feedback controller for the maintenance of FRC during tidal liquid ventilation: theory, implementation, and testing
}

\author{
P.L.J. DEGRAEUWE', L.R.B. DOHMEN², J.M. GEILEN², C.E. BLANCO' \\ ' Department of Paediatrics \\ ${ }^{2}$ Biomedical Instrumentation, University Hospital Maastricht, Maastricht - The Netherlands
}

\begin{abstract}
The necessity of controlling functional residual capacity (FRC) during tidal liquid ventilation has been recognized since the first description of this respiratory support technique by Kylstra et al in 1962. We developed a microcomputer feedback system that adjusts the inspired tidal volume $(V T, 1)$ of a liquid ventilator based on the end-expiratory quasi-static alveolar pressure (PA,EE), in order to maintain a stable FRC. The system consists of three subunits: (1) a tracheal pressure catheter to estimate breath by breath FRC changes, derived from PA,EE changes, and (2) a roller pump interfaced with (3) a personal computer in which a closed-loop control is implemented. The regulator sets the actual $P_{A, E E}$ against the corresponding desired value. Any discrepancy is offset by changes in $V T, 1$ and the required change in pump velocity is communicated to the roller pump. The size of any change in pump velocity is determined to both the observed and target or desired $P_{A, E E}$ (i.e., the error) and the (calibration) pressure-volume curve.

To evaluate the efficacy of the controller, a set of laboratory bench tests were conducted under steady state and transient conditions. Closed-loop control was effective in keeping FRC and $P_{A, E E}$ near the desired level, with an acceptable oscillatory behaviour. The feedback controller successfully compensated for transient disturbances of PFC liquid balance. The steady state stability was confirmed during a five hour period of liquid ventilation in five preterm lambs. (Int J Artif Organs 2000; 23: $680-8$ )
\end{abstract}

KEY WORDS: Perfluorocarbon liquid, Feedback, Microcomputers, Algorithms, Equipment design, Evaluation studies

\section{INTRODUCTION}

Tidal liquid ventilation (TLV) is a technique of artificial ventilation, during which gaseous functional residual capacity and tidal volume are substituted by a liquid (1). The feasibility of liquid ventilation was demonstrated more than three decades ago $(2,3)$ and the use of perfluorocarbon (PFC) liquids as respiratory medium (4) opened the way to the normobaric application of this technique. Since, a few researchers have convincingly

This study was conducted in the Research Institute Growth and Development, Maastricht University, The Netherlands. demonstrated that TLV is able to support gas exchange in normal and lung diseased animals. By reducing the interfacial surface tension (5-7), TLV seems especially suitable to support diseased lungs characterized by high alveolar surface tension. TLV is also a promising tool for the prevention of lung injury in newborns (8-11).

Several mechanical liquid ventilation systems have been described in the literature. Already in 1966, Kylstra used the continuous recording of the animal's weight to maintain and manually adjust liquid functional residual capacity and tidal volume, in order to prevent collapse or overdistention of the lungs (3). During the following decade, the methods' sections of subsequent papers on 


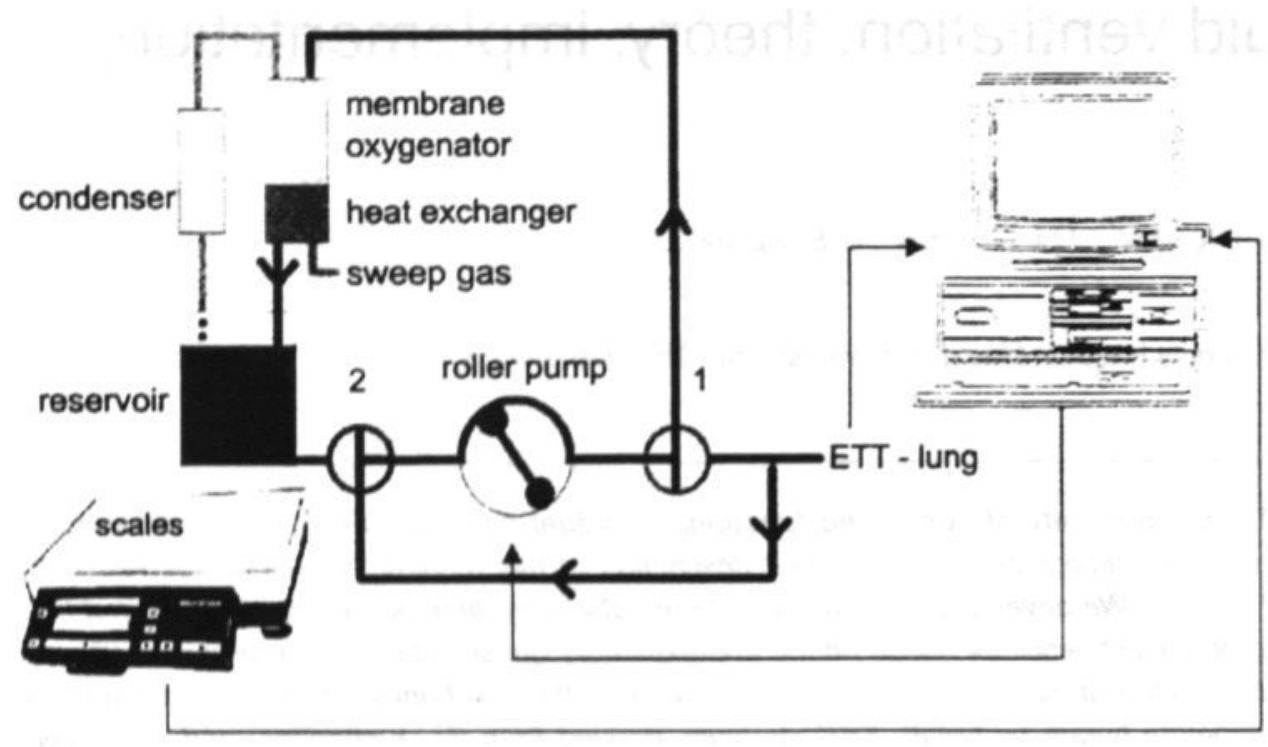

Fig. 1 - Schematic of the tidal liquid ventilator. The arrows indicate the liquid flow during the expiratory phase.

PFC liquid ventilation do not mention any feedback system designed at preserving FRC. In 1976, Shaffer et al from Philadelphia, reintroduced a strain gauge platform to measure changes in the animals weight, allowing monitoring of both tidal volume and FRC (12). One unique sentence in the description testifies to the use of a control system: "Inspiratory and expiratory flow were adjusted to compensate for changes in functional residual capacity". In 1983, Harris made reference to this system in a paper describing in detail a liquid-breathing apparatus in which a digital control system automatically actuated inspired- and expired-line solenoid valves, depending on the signal from a force platform supporting the ventilated animal (13). In 1991, a simple recirculating liquid ventilation system, apparently not servo-controlled, was described by Curtis (14), to whom the credit must be given for the introduction of a stop-flow technique for intermittent measurement of alveolar pressures during TLV. Jackson held out a prospect of automatizing alveolar pressure measurements in a clinical liquid ventilator (9). The simplified liquid ventilator designed by Hirschl (15) introduced the simple idea of monitoring tidal volume by continuously measuring the weight of the liquid reservoir in-stead of the animal. For their most recent studies (16), the Philadelphia group also monitored tidal volume by either the animal's weight changes and/or the changes in the weight of the reservoir and gas exchanger during the respiratory cycle. Target inspiratory and expiratory pressures were set, but the reader was not informed as to the zero reference. Pump flow and valve timing were microprocessor controlled in a prototype liquid ventilator build in collaboration with Alliance Pharmaceutical. Lately, a report was published on the dedicated software (17). At the moment, this sophisticated ventilator is not yet available for researchers interested in TLV animal studies (Tütüncü, AS, personal communication, november 1999).

In this paper, we describe the design and experimental testing of an adaptive control strategy for closed-loop computer control of FRC during TLV making use of endexpiratory (alveolar) occlusion pressure measurements.

\section{METHODS}

\section{DESCRIPTION OF THE SYSTEM}

\section{The mechanical liquid respirator: the liquid ventilation circuit}

A volume-limited, time-cycled liquid ventilator as described by Wolfson was used $(18,19)$. This closed circuit system (Fig. 1), primed with PFC liquid, is composed of a hardshell liquid reservoir, a membrane oxygenator with integrated heat-exchanger (Jostra Diffusion Membrane Oxygenator M16, or SciMed II Model SM35 Adult Integral Membrane Oxygenator), a condenser, two two-way pneumatically driven Hans-Rudolph valves, and Tygon tubing. A sampling port is integrated in the inspiratory limb 
and a bubble trap with gas vent (Auto-Vent-SV ${ }^{\mathrm{m}}$, Pall Biomedical Products Corp. Dreieich, Germany) on the expiratory limb. Liquid flows are achieved with a roller pump (Stöcker Instruments, München, Germany). A disadvantage of this occlusive pump is the generation of pressure fluctuations in the circuit tubing: these pressure swings were damped for the greater part at the tip of the endotracheal tube. However, multiple pumpheaders, a centrifugal pump, or piston pumps could avoid these pressure swings. The valves are computer driven. During inspiration, pneumatic valve 1 is open and valve 2 is closed towards the animal. The inspiratory $V_{T}$ (oxygenated and heated perfluorocarbon liquid) is delivered by the roller pump to the lung. At endinspiration solenoid valve 1 closes towards the animal to measure peak alveolar pressure. During expiration, valve 1 is closed and valve 2 is open towards the animal. The expiratory $V_{T}$ is withdrawn from the lungs by the roller pump and pumped to the fluid regeneration circuit. During the expiratory pause expiratory alveolar pressure is measured, and the tubing between the valves is flushed with fresh perfluorocarbon liquid. The hot water flowing through the heat exchanger is provided by a water heater/pump system (Micro-Temp SMS-2000. Seabrook), running at a temperature appropriate to maintain the inspired liquid at body temperature. The exhaled sweepgas is led to a condenser mechanism (ice water cooled coil made of stainless steel) to return perfluorocarbon vapors to a PFC reservoir. Tidal volume, and differences in end-expiratory weight are monitored by continuously weighting the liquid reservoir on electronic scales (Sartorius MC1. SartoriusInstrumenten BV, Nieuwegein, The Netherlands).

\section{Justification and description of the feedback system}

A control strategy should be based on regular comparison of the actual FRC and the target level. FRC measurements during TLV are traditionally made by scales. Although the body weight indeed reflects FRC. factors other than the PFC liquid in the lungs may interfere with body weight, such as blood drawing, fluid loss or gain. nursing activities and equipment weight. Monitoring the weight of the liquid reservoir can avoid these influences but liquid loss or leakage through evaporation or sampling make this measurement unreliable in the long run. We argued that liquid lung volume and quasi-static alveolar pressure have a fixed relation which is expressed by the pressure-volume or compliance curve. Changes in endexpiratory alveolar pressure are therefore proposed as a

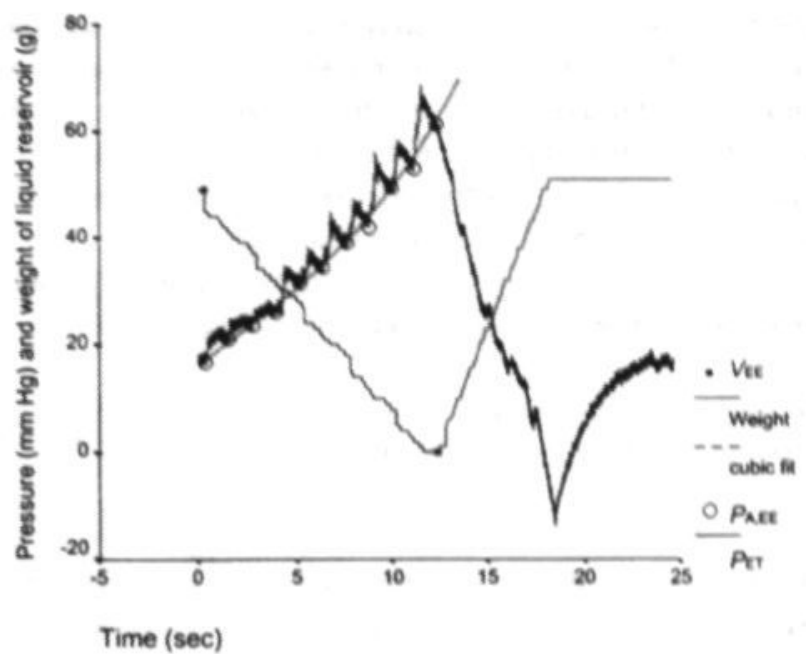

Fig. 2 - Recording of a pressure-volume plot of a calibration breath. During inspiration 10 one-second lasting stop-flow manoeuvres yielded 10 quasi-static P.V pairs (o). The compliance curve was obtained by fitting Equation 1 to this data set. $R^{2}$ was 0.995 in this case.

reflection of changes in FRC.

It is necessary to adapt, on-line, the control system to the exact relation between lung volume and static airway or alveolar pressure. For that purpose, a pseudo-static compliance curve, the so-called calibration curve, is constructed over one tidal volume $(\mathrm{VT})$ range. In practice one $V_{T}$, divided in 10 equal portions, is pumped into the lung with a one second airway occlusion following each aliquot (Fig. 2). The quasi-static P-V pairs are then fitted on a third order equation (20), describing the relationship between lung volume and alveolar pressure:

$V=f[P]=a_{1} \times P^{3}+a_{2} \times P^{2}+a_{3} \times P+a_{4}$

At the end of each respiratory cycle, end-expiratory alveolar pressure $\left(\mathrm{PA}_{\mathrm{A}} \mathrm{EE}\right)$ is read while control action is taken at every subsequent inspiration. The basis for using a breath-to-breath control action is that the effect can be assessed immediately and dysbalance between inspiratory and expiratory tidal volume can very quickly result in collapse or overdistention of the lungs.

To keep the FRC as constant as possible, two simple closed-loop control strategies are available. The algorithm using the measurement of end-expiratory weight of the liquid reservoir is expressed as follows:

$V_{T, 1, \text { new }}=V_{T}, 1$, set $-($ WEE,S, set- WEE,S,meas $) \times 1 / 1.78$ 
where $V_{T, I, n e w}$ is the new inspiratory tidal volume, $V_{T}$, I, set the desired $V_{T}$, WEE,S, set the desired and WEE,S, meas the measured end-expiratory liquid reservoir weight. 1.78 $\mathrm{g} / \mathrm{ml}$ is the density of the fluorocarbon FC75. The advantage of this control strategy is that pressure measurements and P-V curve are unnecessary.

The control algorithm using end-expiratory alveolar pressures can be described mathematically as:

$V_{T, I, \text { new }}=V_{T, I, \text { set }}-\left(V_{\text {meas }}-V_{\text {set }}\right)=$

$=V_{T}, \mathrm{I}$, set $-(f[P A, E E$, meas $]-f[P A, E E$, set $])$

where $V_{\text {meas, }}$ and $V_{\text {set }}$ are measured and desired endexpiratory lung volume; PA,EE,meas and PA,EE, set are measured and desired end-expiratory alveolar pressure, respectively. The function relating lung volume to alveolar pressure $(E q 1)$ is represented by $f$.

An alarm schedule is provided to alert the operator to abnormal changes in the animal's condition or malfunction of the (control) equipment. In case the calculated $V_{T, I, n e w}$ exceeds the desired $V_{T}$ by more than $20 \%$, indicating a Iow PA,EE, either due to leakage or to malfunction of the pressure monitoring, an alarm signal is generated. The liquid ventilator being a life-support device, a fail-save measure was incorporated here. The controller restricts the $V_{T, I, n e w}$ to $120 \%$ of the normal $V_{T}$. This should prevent lung overexpansion due to a false low PA,EE signal (e.g. disconnection of pressure transducer). When the

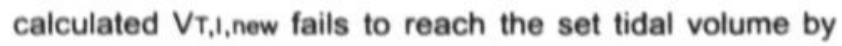
more than $10 \%$ (this value is adjustable), a visual and acoustic alarm is activated. Elevated PA,EE (and FRC) due to expiratory flow obstruction is the most likely reason that should be looked for.

The system provides interactive and display facilities for the supervising researcher. The laboratory personnel can interact with the program using keyboard and mouse. Endexpiratory weight (FRC), PA,EE, $V_{T}$, inspiratory and expiratory (pause)time can be adjusted numerically. In addition this facility allows for temporary suspension of control, switching from weight- to pressure-based control. or choosing manual mode (operation of valves and pump).

\section{System implementation}

As indicated in Figure 1, the control system comprises the following parts: 1) the roller pump of a liquid ventilator; 2) a Pentium II microprocessor equipped with a data-acquisition board (National Instruments type PClM1016) to perform digital and analog in- and output; 3 ) an endotracheal pressure catheter, and 4) electronic scales.

The endotracheal pressure is continuously obtained from an amplifier connected to a pressure transducer (Baxter) mounted on the pressure canal of the endotracheal tube (Vygon, France). The pressure signal is sampled at a rate of $100 \mathrm{~s}^{-1}$ by the 12-bit analogue to digital converter which feeds the signal to the microprocessor. The scales weighing the liquid reservoir are connected to the RS232 communication port of the computer. The pump is controlled by an analog signal generated by the 12-bits digital to analog converter; the valves are driven by digital outputs on the data acquisition board.

Dedicated software was developed using Lab-Windows version 4.0.1p2 (National Instruments Corporation) CVI language. The different functions are:

1) the timer divides the respiratory cycle in adjustable inspiratory time, inspiratory pause, expiratory time, and expiratory pause:

2) acquisition of the analogic signal of endotracheal pressure and reservoir weight at the end of the endexpiratory occlusion;

3) identification of the relationship between PA and lung volume (the calibration compliance curve)

4) the controller detects the error signal and determines the control signal $V_{T, 1, n e w}$. The equations for the controller are given in the previous section (JUSTIFICATION AND DESCRIPTION OF THE FEEDBACK SYSTEM). The pump velocity $\mathrm{V}^{\prime}$ is calculated so that $\mathrm{V}_{T}, 1$, new $=\int \mathrm{V}^{\prime}$. The output of the controller is supplied to the roller pump. This procedure is repeated on a breath to breath basis.

\section{Testing of the system}

\section{In vitro testing of the system}

The initial testing of the control algorithm was done by in vitro simulation of liquid ventilation, using a toyballoon as test lung. To evaluate the efficacy of the controller, a set of laboratory bench tests were conducted under steady state and transient conditions.

In the first place, control runs $(n=5)$ were performed without closed-loop control. Then, test runs applying 
feedback control via end-expiratory weight $(n=5)$ and pressure $(n=5)$ succeeded each other. Each pressurebased run was preceded by the generation of a calibration curve. An increasing pressure set-point was chosen (15, $17.5,20,22.5$, and $25 \mathrm{mmHg}$ ) for each run. End-expiratory weight and $P_{A}, E E$ were rccorded for 50 breaths (10 minutes) in order to study their variability and to compare the operating level of FRC and PA,EE with the set point. At the end of each pressure-based run, transient disturbances of liquid balance were simulated by intentional withdrawal or addition of liquid perfluorocarbon at the endotracheal tube connector during expiration. Thus, the response time of the control system was determined for a unique change of $\mathrm{VT}, E$ with $20 \%$ in either direction.

\section{Ventilation of RDS animals}

The feedback controller was also evaluated in five liquid ventilated preterm lambs. (Degraeuwe PLJ et al. Conventional gas ventilation, liquid-assisted high-frequency oscillatory ventilation, and tidal liqud ventilation in surfactant-treated preterm lambs. Int J Artif Organs (accepted for publication)). Briefly, in a comparative study. approved by the Institutional Animal Care and Use Committee at the University Maastricht, preterm lambs were delivered by Caesarean section at 124-126 days, and allocated to either conventional mechanical ventilation, high-frequency oscillatory ventilation, or TLV. Gas exchange and histomorphology after five hours of TLV proved to be superior compared to either gas ventilation strategy. In liquid ventilated animals, the end-expiratory liquid reservoir weight was monitored continuously while end-expiratory alveolar pressure was controlled by the microprocessor. The set point was chosen at $0 \mathrm{mmHg}$ at the most ventral (non-dependent part) of the lung. The target and observed $\mathrm{PA}, \mathrm{EE}$ were recorded to assess the controller accuracy.

The performance of the closed-loop system was judged by means of three items: system accuracy (bias or difference $\Delta$ between set-point and operating point), oscillatory behaviour expressed as (the width of) the $95 \%$ prediction interval $(95 \% \mathrm{PI})$ of the operating point, and response time (defined as the number of breaths needed to restore the operating point to within the steady-state operating range after a transient disturbance). Data were analysed using the SPSS statistical software (SPSS for Windows, Release 8.0; SPSS Inc., Chicago, IL).

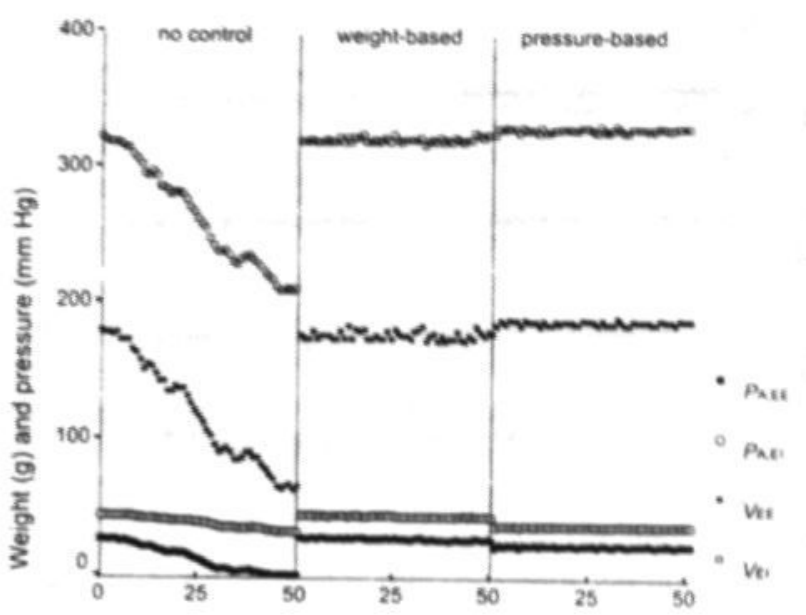

Breath number

Fig. 3 - Examples of bench test runs without feedback control, and with weight-based or pressure-based control. End-expiratory and end-inspiratory body weight (WEE, Wei), and alveolar pressure (PA,EE and $P, E_{A}$ ) were measured over time. Both feedback control strategies prevent a systematic "pumping dry" of the test lung: endinspiratory and end-expiratory pressure and weights remain stable.

\section{RESULTS}

Figure 3 shows an example of end-expiratory and endinspiratory lung volume (VEE, VEI), and alveolar pressure ( $P A, E E$ and $P A, E I)$ recorded over time during three in vitro simulations of TLV: without feedback control, and during weight-based and pressure-based feedback. Without feedback control, the cumulative effect of a systematic dysbalance between a larger $V_{T, I}$ than $V_{T, E}$ is evident, leading to collapse of the test lung. During weight-based and pressure-based feedback control, stability of in- and expiratory volumes and pressures is achieved.

Table I summarizes the distribution of the difference between operating points and set-points for endinspiratory and end-expiratory alveolar pressures and lung volumes. The liquid reservoir weight changes were converted to lung volume changes in opposite direction, using the specific gravidity of FC-75. It should be noted that there is no real inspiratory set point; instead the first measured value after starting a run was used to calculate bias and variability indices.

The set-point of PA,EE and VEE was always situated outside the $95 \% \mathrm{Cl}$ of the difference between operatingpoint and set-point, indicating a systematic bias, which was not corrected for by the controller. The width of the 


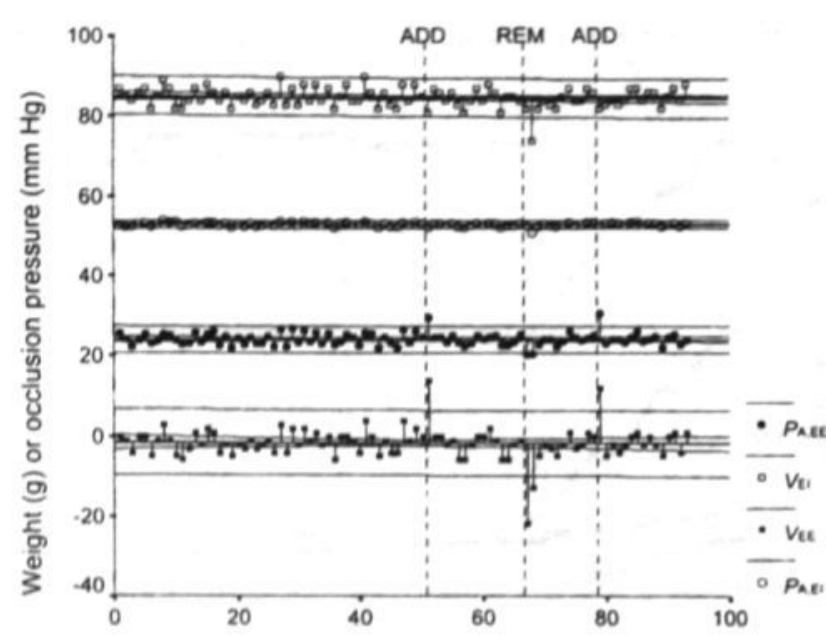

breath number

Fig. 4 - Example of two intentional disturbances of the liquid balance after a steady state observation of 50 breaths during an in vitro experiment. Individual values of end-inspiratory and end-expiratory occlusion pressures and volumes are plotted over time, as well as lines representing means, $95 \% \mathrm{Cl}$ of the mean, and $95 \% \mathrm{PI}, A D D=$ addition of $20 \%$ extra liquid during expiration; REM = removal of $20 \%$ of the VT during expiration. Temporary increse or decrease in PA,EE and VEE were corrected to within the $95 \% \mathrm{PI}$ after 2 and 3 breaths respectively.

$95 \% \mathrm{PI}$ of $\triangle \mathrm{PA}, \mathrm{EE}$ and $\triangle \mathrm{VEE}$ was at most $4 \mathrm{mmHg}$ and 5 $\mathrm{ml}$ respectively. Thus, the fluctuations of end-expiratory lung volume in the preterm lambs, were less than $10 \%$ of the FRC which was around $50 \mathrm{ml}$.

An example of transient disturbances provoked by adding or removing liquid to the system at the endotracheal tube connector during expiration is shown in Figure 4. Intentional addition of $20 \%$ of the $\mathrm{V}_{T}$ during expiration, caused a rise in $\mathrm{PA}, \mathrm{EE}$ and VEE outside the $95 \% \mathrm{PI}$ for one single breath; the $P A, E I$ and $V E I$ remained within the $95 \%$ PI. Withdrawal of the same amount of liquid during expiration caused a decrease in PA,EE and VEE below the $95 \% \mathrm{PI}$ which was corrected within 2 or 3 breaths. $\mathrm{PA}, \mathrm{EI}$ and $\mathrm{VEI}$ also fell to a lower than predicted value for 1 or 2 breaths. This delayed correction is due to the restriction of $V_{T, I}$, new to $120 \%$ of the set $V_{T}$.

\section{DISCUSSION}

During TLV, the balance between in- and outflow liquid volumes should be precisely maintained in equilibrium in order to avoid overdistention or collapse of the lungs. This article describes a tidal liquid ventilator build for research purposes in an animal laboratory, and concentrates on the development and testing of a feedback controller to preserve FRC.

We introduced the idea of using end-expiratory occlusion pressures as a representative input signal for a closed-loop system. Bench tests and animal experiments testing the automated control revealed a small bias, and clinically acceptable oscillations of the end-expiratory lung volume, being the main output variable.

For many years it has been recognized that, in mechanically-ventilated patients, insufficient expiratory time due to airflow obstruction, high frequency, or inversed ratio

TABLE I - DIFFERENCES BETWEEN OPERATING POINTS AND SET-POINTS FOR PA,EE, PA,EI, VEE, AND VEI DURING BENCH TESTS APPLYING WEIGHT-BASED OR PRESSURE BASED CONTROL, AND DURING ANIMAL EXPERIMENTS APPLYING PRESSURE-BASED CONTROL

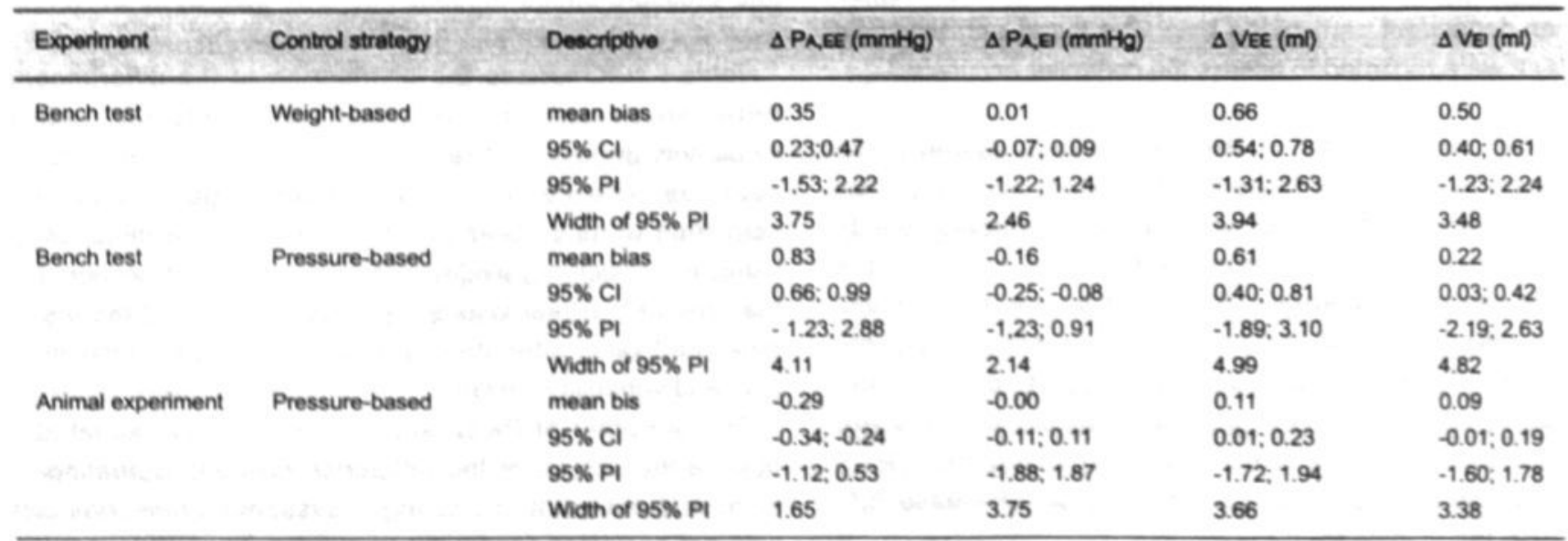


ventilation may result in auto-PEEP or inadvertent PEEP, as a manifestation of increased end-expiratory thoracic gas volume (21-23). If this phenomenon remains unrecognized and uncorrected, decreased lung compliance, impeded cardiac output and air leaks may ensue. Tidal liquid ventilation is not devoid of this problem. We and others (24, 25) have noticed that poor control of expiratory volume during TLV, as is the case with gravity assisted expiration, increases the risk of fluorothorax. Meinhardt et al showed that static peak inspiratory and expiratory pressures remained constant using pump-driven expiration but increased significantly with gravity-assisted expiration. The incidence of fluorothorax was 10 and $85 \%$, respectively. Both Meinhardt and Larrabe recently described a tidal liquid ventilator including a microprocessor-controlled, motordriven double-piston pump with apparently a very high volume precision $(26,27)$. This could not be achieved by the roller pump system incorporated in our hardware, as shown by the bench test evaluation. Therefore, we developed a microprocessor-based control system for maintaining a FRC level, as suggested by Baba et al (24). Moreover, even if the liquid ventilator per se is very accurate in cycling liquid volumes, a liquid leak or an increase in (expiratory) resistance may cause an imbalance between inspired and expired liquid tidal breaths.

In our bench tests both methods of feedback control were characterized by a similar performance (bias and variability). Nevertheless, we prefer a feedback control based on end-expiratory occlusion pressure to a feedback control based on end-expiratory weight. Although liquid ventilation offers an opportunity of measuring FRC in a very simple way, many confounders are present at the bedside. The correction for non-PFC-related changes in weight, as proposed by Heckman et al (17), is a real challenge and prone to errors in the busy and hectic environment of an intensive care unit. After some days of liquid ventilation, the exact relationship between FRC and body weight will certainly be lost. Furthermore, the definition of normal or ideal FRC during TLV has not been clearly defined. During partial liquid ventilation, full liquid FRC is assumed when a PFC meniscus is present in the endotracheal tube at zero end-expiratory pressure. However, some gas may still be present in the nondependent lung. In our animal experiments we aimed at an end-expiratory occlusion pressure around zero or slightly positive at the level of the highest situated alveoli to avoid any expiratory collapse. Considering puimonary mechanics could further optimize the level of end- expiratory lung volume. Moreover, it should be noted that the latter method is insensible to drift errors of pressure transducers which normally need regular recalibration.

Several aspects of the described feedback controller are capable of improvement. The bias can now be nullified manually, but the controller algorithm could be also adapted so that it reacts not only to the magnitude of the error but also to the accumulated error over time. More accurate hardware would obviously reduce the systematic bias too. A falsely low reading of the end-expiratory occlusion pressure due to failure of the pressure measuring device is still a life-threatening situation, since cumulative inspiration of excessive liquid volumes will lead to fluorothorax precipitously. Therefore we suggest to record the airway pressure with two pressure catheters at the same time. A pressure difference between these, exceeding a specified value, would generate an alarmsignal and eventually stop the ventilator.

In this paper we proposed a microprocessor-based controller for maintenance of liquid balance during TLV using end-expiratory occlusion pressure as representative input signal. The laboratory bench tests indicated that transient disturbances in the inspiratory or expiratory tidal volume were immediately and correctly compensated for in the subsequent breaths, restoring the FRC. Under steady state conditions the degree of oscillation of PA,EE and FRC was within clinically acceptable limits. Some suggestions for further improvements of the system were made. The availability of a reliable ventilator system could give a new impetus to tidal liquid ventilation animal research until now hindered by technical problems

\section{ACKNOWLEDGEMENTS}

The perfluorocarbon liquid (FC-75) used in this study was kindly provided by the $3 \mathrm{M}$ Company, Zwijndrecht, Belgium. The authors are indebted to Titiaan Dormaar and Theo van der Nagel for their considerable technical assistance.

Reprint requests to

Pieter L.J. Degraeuwe, MD

University Hospital Maastricht

Department of Paediatrics

P. Debyelaan 25; P.O. Box 5800

NL - 6202 AZ Maastricht

The Netherlands

e-mail: pde@skin.azm.nI 


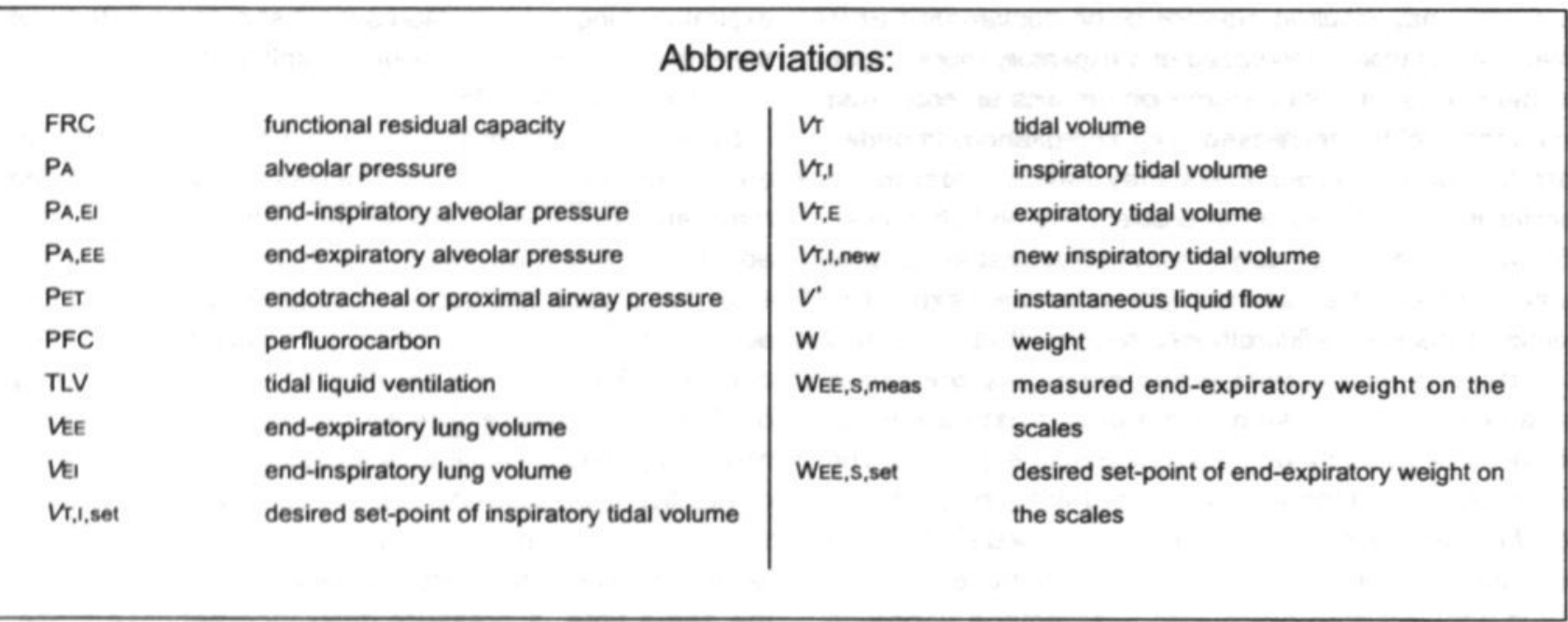

\section{REFERENCES}

1. Wolfson MR, Greenspan JS, Shaffer TH. Liquid-assisted ventilation: an alternative respiratory modality. Pediatr Pulmonol 1998; 26: 42-63.

2. Kylstra JA, Lanphier EH. Gas exchange in fluid ventilated dogs. Fed Proc 1964; 23: 469.

3. Kylstra JA, Paganelli CV, Lanphier EH. Pulmonary gas exchange in dogs ventilated with hyperbarically oxygenated liquid. J Appl Physiol 1966; 21:177-84.

4. Clark LC Jr, Gollan F. Survival of mammals breathing organic liquids equilibrated with oxygen at atmospheric pressure. Science 1966; 152:1755-6.

5. Gollan F, McDermott J, Johnson AE, Namon R. Compliance and diffusion during respiration with fluorocarbon fluid. Fed Proc 1970; 29:1725-30.

6. Kylstra JA, Schoenfisch WH. Alveolar surface tension in fluorocarbon-filled lungs. J Appl Physiol 1972; 33: 32-5.

7. Tarczy Hornoch P, Hildebrandt J, Mates EA, et al. Effects of exogenous surfactant on lung pressure-volume characteristics during liquid ventilation. J Appl Physiol 1996; 80:1764-71.

8. Wolfson MR, Greenspan JS, Deoras KS, Rubenstein SD, Shaffer TH. Comparison of gas and liquid ventilation: clinical, physiological, and histological correlates. J Appl Physiol 1992; 72: 1024-31.

9. Jackson JC, Standaert TA, Truog WE, Hodson WA. Full-tidal liquid ventilation with perfluorocarbon for prevention of lung injury in newborn non-human primates. Artif Cells Blood Substit Immobil Biotechnol 1994; 22:1121-32.

10. Ruefer R. Spitzer HL. Liquid ventilation in the respiratory distress syndrome. Chest 1974; 66 (suppl) S29-30.

11. Schwieler GH, Robertson B. Liquid ventilation in immature newborn rabbits. Biol Neonate 1976; 29: 343-53.

12. Shaffer TH, Rubenstein D, Moskowitz D, Delivoria Papadopoulos M. Gaseous exchange and acid-base balance in premature lambs during liquid ventilation since birth. Pediatr Res 1976; 10: 227-31.

13. Harris DJ, Coggin RR, Roby J, Feezor M, Turner G, Bennett PB. Liquid ventilation in dogs: an apparatus for normobaric and hyperbaric studies. J Appl Physiol 1983; 54:1141-8.

14. Curtis S. Perfluorocarbon-associated gas exchange: a hybrid approach to mechanical ventilation. Crit Care Med 1991; 19: 600-1.

15. Hirschl RB, Merz SI, Montoya JP, et al. Development and application of a simplified liquid ventilator. Crit Care Med 1995; 23:157-63.

16. Stavis RL, Wolfson MR, Cox C, Kechner N, Shaffer TH. Physiologic, biochemical, and histologic correlates associated with tidal liquid ventilation. Pediatr Res 1998; 43:132-8.

17. Heckman JL, Hoffman J, Shaffer TH, Wolfson MR. Software for real-time control of a tidal liquid ventilator. Biomed Instrum Technol 1999; 33: 268-76.

18. Wolfson MR, Heckman J, Cox C, Shaffer TH. Liquid ventilation equipment and methodology: $A$ historical perspective. In: 11th Annual CNMC ECMO Symposium; 1995 Feb 26-March 2; Keystone, CO 1995; p. 105.

19. Wolfson MR, Heckman JL, Cox CA, et al. Liquid ventilation 
technology update. In: 13th Annual CNMC ECMO Symposium; 1997 March 2-6; Keystone, CO 1997; 68.

20. Patel MM, Patel MK, Szanto P. Alrenga DP, Long DM. Ventilation with synthetic fluids. Surg Clin North Am 1971; 51 : 25-36.

21. Andersen JB. Ventilatory strategy in catastrophic lung disease. Inversed ratio ventilation (IRV) and combined high frequency ventilation (CHFV). Acta Anaesthesiol Scand 1989; 90: (suppl): S145-8.

22. Pepe PE, Marini JJ. Occult positive end-expiratory pressure in mechanically ventilated patients with airflow obstruction: the auto-PEEP effect. Am Rev Respir Dis 1982; 126:166-70.

23. Simbruner G. Inadvertent positive end-expiratory pressure in mechanically ventilated newborn infants: detection and effect on lung mechanics and gas exchange. J Pediatr 1986; 108: 589-95.
24. Baba $Y$, Taenaka $Y$, Akagi $H$, et al. A volume-controlled liquid ventilator with pressure-limit mode: imperative expiratory control. Artif Organs 1996; 20: 1052-6.

25. Meinhardt JP, Sawada S, Quintel M, Hirschl RH. Comparison of static airway pressures during total liquid ventilation while applying different expiratory modes and time patterns. Am J Respir Crit Care Med 1999; 159: 79.

26. Larrabe JL, Gómez MA. Alvarez FJ, et al. Development of total liquid ventilation technology. A practical approach. In: 1st European Symposium on Liquid Ventilation; 1999 November 26-27, 1999; Berlin 1999; p.31.

27. Meinhardt JP, Quintel M, HirschI RB. Development and application of a double-piston configured, total-liquid ventilatory support device. Crit Care Med 2000; 28:1483-8. 
Chapter 4

Conventional gas ventilation, liquid-assisted high-frequency oscillatory ventilation, and tidal liquid ventilation in surfactant-treated preterm lambs 


\title{
Conventional gas ventilation, liquid-assisted high-frequency oscillatory ventilation, and tidal liquid ventilation in surfactant-treated preterm lambs
}

\author{
P.L.J. DEGRAEUWE', F.B.J.M. THUNNISSEN ${ }^{2}$, N.J.G. JANSEN', J.T. DORMAAR', L.R.B. DOHMEN ${ }^{3}$, \\ C.E. BLANCO \\ ${ }^{1}$ Department of Paediatrics \\ 2 Department of Pathology \\ ${ }^{3}$ Biomedical Instrumentation, University Hospital Maastricht, Maastricht - The Netherlands
}

\begin{abstract}
This study was designed to compare the efficacy and potential protective or injurious effects of tidal liquid ventilation (TLV), liquid-assisted high-frequency oscillatory ventilation (LA-HFOV), and high PEEP conventional mechanical ventilation (CMV) in neonatal respiratory distress syndrome. Preterm lambs (124-126 days gestation), prophylactically treated with natural surfactant, were allocated to one of the treatment modalities or to an untreated fetal control group ( $F$ ), euthanised after tracheal ligation. LA-HFOV animals received an intratracheal loading dose of $5 \mathrm{~mL} . \mathrm{kg}^{\prime}$ followed by a continuous intrapulmonary instillation of $12 \mathrm{~mL} . \mathrm{kg}^{\prime} ; h^{\prime} \mathrm{FC}-75$ perfluorocarbon liquid. The ventilation strategies aimed at keeping clinically appropriate arterial blood gases for a study period of 5 hours. A histological lung injury score was calculated and semiquantitative morphometry was performed on lung tissue fixed by vascular perfusion.

The alveolar-arterial pressure difference for $\mathrm{O}_{2}$ was significantly lower throughout the study in TLV compared to CMV lambs; at 1, 2, and 5 hours, oxygenation was better in TLV when compared to LA-HFOV. Total lung injury scores in TLV lambs were significantly lower than in either CMV or LA-HFOV animals, but higher when compared to F. CMV and LA-HFOV induced an excess of collapsed and overdistended alveoli, whereas in TLV alveolar expansion was normally distributed around predominantly normal alveoli. CMV and LA-HFOV, but not TLV, were associated with an excess of dilated ainways.
\end{abstract}

Thus, in the ovine neonatal RDS model, TLV compared favourably to either gas ventilation strategy by its more uniform ventilation, reduced lung injury, and improved gas exchange. (Int J Artif Organs 2000; 23: 754-64)

KEY WORDS: Respiratory distress syndrome, Fluorocarbons, Respiration, Artificial, High-frequency ventilation, Positive-pressure respiration

\section{INTRODUCTION}

The ventilatory strategy used early in the management of neonatal respiratory distress syndrome may modify the course of the disease itself and its long-term respiratory outcome. New techniques have been developed in order

This study was conducted in the Research Institute Growth and Development, Maastricht University, The Netherlands. to minimize ventilation-induced lung injury, but studies comparing their respective gas exchange efficacy and lung protective properties are scarce. Moreover, conventional ventilation strategies have evolved too, based on new physiological insights (1).

High frequency oscillatory ventilation (HFOV), especially when used prophylactically, applying a "high volume strategy", and in combination with exogenous surfactant from birth can reduce lung injury in premature monkeys 
$(2,3)$. A meta-analysis of randomized controlled trials of elective HFOV, using the high volume strategy, versus conventional mechanical ventilation (CMV) in preterm infants < 36 weeks' gestation showed benefit in survival, and chronic lung disease (4).

In animal models of hyaline membrane disease, tidal liquid ventilation (TLV) compares favourably to CMV with respect to gas exchange, lung mechanics, lung histology and biochemical markers of lung injury (5). TLV has therefore been suggested as a promising tool for the prevention of lung injury in preterm newborns (6). The addition of exogenous surfactant before liquid ventilation further reduces interfacial tension, and further increases compliance, therefore lower inflation pressures are needed $(7,8)$.

Likewise, animal studies demonstrated a gas exchange superiority of partial liquid ventilation (PLV) over gas ventilation in neonatal respiratory distress syndrome (9). Pretreatment with exogenous surfactant offers an additional benefit to PLV alone $(10,11)$. The improved oxygenation and ventilation, but also the attenuation of histological lung injury and inflammation were however similar in preterm lambs treated with either PLV or HFOV (12).

Compared to HFOV alone, gas exchange improved more during HFOV superimposed on a liquid-filled lung (HF-PLV) in preterm lambs with respiratory distress syndrome (13). Gothberg et al reported an improved response to inhaled nitric oxide during HF-PLV, which may imply enhanced recruitment (14). A dose-dependent relationship between the perfluorocarbon (PFC) liquid quantity and oxygenation known during PLV with CMV (15), could however not be found during HF-PLV (16). It was speculated that in HF-PLV perfluorocarbon facilitates rapid expansion of alveoli, while HFOV maintains the achieved inflation. In addition, intratracheal perflubron at doses far less than the functional residual capacity (FRC) significantly reduces pulmonary inflammation (17).

Finally, lung mechanics and histological outcome seem to be more favourable for tidal liquid ventilation when compared to partial liquid ventilation $(10,18)$. As yet, a comparison between TLV and HFOV has not been undertaken.

The goal of our study was to investigate whether, in hyaline membrane disease, TLV, HFOV, or CMV would differently influence gas exchange during, and lung histology-morphometry after $\mathbf{5}$ hours of mechanical ventilation. The inclusion of a CMV group was motivated by previous work in a porcine lung lavage model, showing no clinically relevant differences between CMV, HFOV, and PLV (19). Since small amounts of PFC showed favourable mechanical (10) as well as anti-inflammatory properties (17), we opted for a low dose of liquid $(5 \mathrm{~mL} . \mathrm{kg}$ 1) to assist HFOV. We postulated that liquid assisted HFOV (LA-HFOV) would be equally effective as TLV and superior to CMV in supporting gas exchange. In either comparison, TLV would be superior in protecting the immature lung from ventilator induced lung injury.

\section{MATERIAL AND METHODS}

All surgical procedures and experimental protocols were reviewed and approved by the Institutional Animal Care and Use Committee at the University of Maastricht.

Fourteen time-dated, Texel breed twin-pregnant ewes were anaesthetized between 124 and 126 days gestation (term $147 \pm 3$ days) using thiopentone $1 \mathrm{~g} / 70 \mathrm{~kg}$ IV for induction, and $0.8 \%$ halothane in $50 \%$ nitrous oxide and $50 \%$ oxygen for maintenance. Before they were delivered, the 28 lambs were prospectively assigned to an unventilated fetal control group $(F)$ or one of three treatment groups, to be managed for 5 hours according to a different ventilatory strategy. Under sterile conditions, the fetal head and neck were exposed through a midline laparotomy and hysterotomy. Appropriately sized catheters were placed in the right jugular vein and carotid artery through a mid-cervical incision. Six fetal controls had their trachea ligated in order to fix the lungs with the lung liquid in situ. Immediately after cord clamping they were sacrificed. In the lambs belonging to one of the treatment groups an endotracheal tube $(4.5 \mathrm{~mm} I D)$, provided with a pressure canal ending at the tip (Vygon, France), was placed under direct laryngoscopy and tied into the trachea. After delivery, these lambs were weighed, dried, and placed on a heating pad, under a radiant heater to maintain rectal temperature within a range of $38.5-39.5^{\circ} \mathrm{C}$. No hand-bag ventilation was used before the endotracheal tube was connected to the allocated ventilator. Two hundred $\mathrm{mg}$ of natural surfactant (Alveofact, Boehringer Ingelheim Pharma KG, Biberach, Germany) was then slowly instilled into the trachea at the tip of the ETT (estimated birth weight $2 \mathrm{~kg}$ ). Analgesia was provided by slow IV injection of $0.01 \mathrm{mg} / \mathrm{kg}$ buprenorphine. Anaesthesia and muscle paralysis were maintained using a continuous infusion of pentobarbital (4 $\left.\mathrm{mg} \cdot \mathrm{kg}^{-1} \cdot \mathrm{hr}^{-1}\right)$ and pancuronium bromide $\left(0.1 \mathrm{mg} \cdot \mathrm{kg}^{-1} \cdot \mathrm{hr}^{-1}\right)$ 
respectively. Maintenance fluids (dextrose $10 \%$ ) were infused at a rate of $4 \mathrm{~mL} \cdot \mathrm{kg}^{-1} \cdot \mathrm{hr}^{-1}$. The carotid artery catheter was connected to a pressure transducer, calibrated and zero-referenced to midchest level. Hypotension was defined as a mean arterial pressure $<40$ $\mathrm{mm} \mathrm{Hg}$ and treated with normal saline infusion. Metabolic acidosis $(\mathrm{pH}<7.20$ with $\mathrm{BE}<-8 \mathrm{mmol} / \mathrm{L})$ was corrected using sodium bicarbonate. A pulse oximeter (NPB-290, Nellcor Puritan Bennett Europe BV) monitored saturation at the ear-lobe. All postnatal procedures were performed under sterile conditions, in order to avoid inflammatory response induced by infection. After five hours of ventilation the lambs were killed with an overdose of pentobarbital IV (100 $\left.\mathrm{mg}^{\mathrm{kg}}{ }^{-1}\right)$.

In the CMV group, the endotracheal tube was connected to a continuous flow, time cycled, pressure-limited Bourns BP-200 ventilator. The inspired gases were humidified and warmed at $38^{\circ} \mathrm{C}$ by means of a standard heated humidifier (Concha-Therm Humidifier, Respiratory Care, Inc., Arlington Heights, IL). Initially the lambs were ventilated with a flow of $12 \mathrm{~L} \cdot \mathrm{min}^{-1}, \mathrm{~A}, \mathrm{O}_{2}=1.0$, a PIP of $25 \mathrm{~cm} \mathrm{H}_{2} \mathrm{O}$ and a PEEP of 5 $\mathrm{cm} \mathrm{H}_{2} \mathrm{O}$; the respirator rate was $60 \mathrm{~min}^{-1}$ and $\mathrm{I}: E=1: 2$. $\mathrm{Al}, \mathrm{O}_{2}$ was adjusted to keep pulse-oxymetry at $0.86-0.93$, while PEEP was increased up to $8 \mathrm{~cm} \mathrm{H}_{2} \mathrm{O}$ to minimize oxygen need. Peak inspiratory pressure was changed to maintain $\mathrm{Pa}_{2} \mathrm{CO}_{2}$ between 5-7 kPa. PIP > $35 \mathrm{~cm} \mathrm{H}_{2} \mathrm{O}$ was however not allowed due to the high risk of pneumothorax.

The HFOV group received high frequency oscillation delivered by the sensor Medics 3100A oscillator. Inspired gas temperature was kept at $38^{\circ} \mathrm{C}$ by a Fisher-Paykel humidifier (model MR 500, Fisher \& Paykel, Auckland, New Zealand). A loading dose of intratracheal FC-75 liquid (3M Company, Belgium) of $5 \mathrm{~mL} \cdot \mathrm{kg}^{-1}$ was instilled over 5 minutes. In order to compensate for PFC liquid evaporation, a continuous endotracheal infusion of FC-75 was subsequently given at a rate of about $12 \mathrm{~mL} \cdot \mathrm{kg}^{-1} \cdot \mathrm{h}^{-1}$. At $25^{\circ} \mathrm{C}$, this industrial PFC liquid has a density of 1.78 g. $\mathrm{mL}^{-1}$, a surface tension of $15 \mathrm{mN} \cdot \mathrm{m}^{-1}$ (15 dynes. $\left.\mathrm{cm}^{-1}\right)$. and an $\mathrm{O}_{2}$ and $\mathrm{CO}_{2}$ solubility of 52 and $160 \mathrm{~mL}^{\mathrm{dL}-1}$ respectively. The vapour pressure is $8.4 \mathrm{kPa}$ at $37^{\circ} \mathrm{C}$. To achieve optimal lung inflation the "high MAP approach" (2, 20,21 ) was used. Mean airway pressure (MAP) was set initially at $12 \mathrm{~cm} \mathrm{H} \mathrm{H}_{2} \mathrm{O}$ and adjusted to maintain pulseoximetry at $0.86-0.93$, while aiming at an $\mathrm{Al}_{1} \mathrm{O}_{2}$ as low as 0.30 . MAP was however limited to $25 \mathrm{~cm} \mathrm{H}_{2} \mathrm{O}$. In case of rising $\mathrm{Pa}, \mathrm{CO}_{2}$, or when blood pressure decreased, overdistension of the lungs was considered and a lower MAP was tried out. Oscillatory frequency was maintained at $10 \mathrm{~Hz}$. The amplitude was altered as necessary to keep $\mathrm{Pa}_{2} \mathrm{CO}_{2}$ between 5 and $7 \mathrm{kPa}$.

In the $T L V$ group the lungs were filled over approximately 15 minutes with perfluorocarbon liquid up to functional residual capacity (FRC) while on CMV. In practice, we infused warmed and preoxygenated $\mathrm{FC}-75$ perfluorocarbon liquid, withdrawn from the tidal liquid ventilator circuit, until a liquid meniscus was visible in the endotracheal tube at ZEEP. Then, the endotracheal tube was connected to a volume - limited time-cycled liquid ventilator. This prototype ventilator makes use of a microcomputer feedback system adjusting each inspired tidal volume based on the endexpiratory alveolar pressure, in order to maintain a stable FRC (Degraeuwe PLJ et al. A feedback controller for the maintenance of FRC during tidal liquid ventilation: theory, implementation, and testing. Int J Artif Organs 2000; 23 (10): 680-8). The inspired perfluorocarbon temperature was kept at $38^{\circ} \mathrm{C}$. The initial ventilator settings were: frequency $5 \mathrm{~min}^{-1}$, tidal volume $\left(\mathrm{V}_{\mathrm{T}}\right)$ 15-20 mL. $\mathrm{kg}^{-1}, \mathrm{~A}_{1} \mathrm{O}_{2}$ 1.0, and I:E ratio 1:2. $\mathrm{V}_{\mathrm{T}}$ was adjusted to maintain $\mathrm{Pa}, \mathrm{CO}_{2}$ between 5-7 $\mathrm{kPa}$. The $\mathrm{A} \cdot \mathrm{O}_{2}$ of the sweep gas, and hence the inspiratory $P, O_{2}$ was weaned to achieve $0.86-0.93$ oxygen saturation.

\section{Physiologic measurements and calculations}

In CMV and LA-HFOV animals, proximal airway pressure was measured by a pressure transducer placed at the side port of the endotracheal tube connector. During TLV, supra-carinal tracheal pressure was monitored by a liquid-filled pressure transducer connected to the distal monitoring port (the surfactant canal) of the endotracheal tube. Arterial blood gases and $\mathrm{pH}$ were taken every 30 minutes for five hours and measured within 5 minutes of collection using the AVL993 blood gas analyser (Radiometer, Copenhagen, Denmark) correcting for body temperature. During TLV, simultaneous inspiratory PFC liquid $\mathrm{P}_{1} \mathrm{O}_{2}$ was obtained using a $\mathrm{ABL}^{\mathrm{TM}} 3$ blood gas analyser (Radiometer, Copenhagen, Denmark).

Oxygenation was assessed using the alveolar-arterial pressure difference for $\mathrm{O}_{2}$ calculated as follows: $P(A-a), \mathrm{O}_{2}=$ $\mathrm{P}, \mathrm{O}_{2}-\mathrm{Pa}_{\mathrm{a}, \mathrm{CO}_{2}}-\mathrm{Pa}_{\mathrm{a}, \mathrm{O}_{2}}$. This classical formula assumes a respiratory exchange ratio of 1 , and no diffusion impediment $\left(\mathrm{Pa}_{\mathrm{a}} \mathrm{CO}_{2}-\mathrm{Pa}_{\mathrm{a}} \mathrm{CO}_{2}\right)$. For TLV animals the inspiractory partial pressure of oxygen $\left(P_{1}, \mathrm{O}_{2}\right)$ used, was the measured one. For gas ventilated animals the $P \mathrm{O}_{2}$ was calculated by the equation: $\mathrm{P}, \mathrm{O}_{2}=\mathrm{F}_{1} \mathrm{O}_{2} \times\left(\mathrm{PB}_{\mathrm{B}}-\mathrm{PH}_{2} \mathrm{O}\right.$ $P F C-75)$. The $F C-75$ vapor pressure term $\left(8.7 \mathrm{kPa}\right.$ at $\left.38^{\circ} \mathrm{C}\right)$ was only subtracted for LA-HFOV animals. 


\section{Postmortem studies}

After sacrifice, a chest autopsy was performed. The left stem bronchus and the left pulmonary vessels were tied off and lung biopsies, taken from the left lung were frozen in liquid nitrogen for future biochemical analysis. The ductus arteriosus was ligated, the right ventricle opened and a catheter secured in the main pulmonary artery. The left auricle was opened to allow the perfusate to escape. The right lung was then flushed with buffered $10 \%$ formalin at a pressure of $30 \mathrm{~cm} \mathrm{H}_{2} \mathrm{O}$ for 30 minutes as it was held at it's mean airway pressure recorded at the end of the 5 hour ventilation period. Immediately thereafter, the inflated lung was tied off, removed, and further perfused overnight at the same pressure and immerged in a fixative-bath. Lung specimens for morphology and morphometry were taken from the ventral and dorsal aspects of the cranial, middle, and caudal regions of the right lung. Blocks of tissue (approximately $2 \times 1 \times 0.3 \mathrm{~cm}$ ) were prepared from these six regions, embedded in paraffin, sectioned at $5 \mu \mathrm{m}$, and stained with haemotoxylin and eosin. The lung sections were coded and examined by conventional light microscopy, blinded to treatment group allocation. The following histologic features were analysed using a threepoint, severity-based scoring system (19): desquamation of bronchial and bronchiolar epithelium, septal oedema, lymphangiectasis, septal haemorrhage, intra-alveolar exudate, alveolar haemorrhage, hyaline membrane formation, alveolar neutrophil infiltration, interstitial oedema, interstitial haemorrhage, interstitial neutrophil infiltration, congestion-hyperaemia, granulocyte sticking. trombocytic aggregation, fibrin deposition. The pathologic changes were graded as negative or slight $=0$, moderate $=1$, and severe $=2$. A semiquantitative morphometric analysis was carried out in the following way. Alveolar dimensions or distal lung expansion were scored as: severe atelectasis (2-), mild atelectasis (1-), normal (0), mild distention $(1+)$, and severe distention $(2+)$. Airway distention was scored as normal if mucosal folds were present $(0)$, slightly dilated when mucosa folds were smoothed $(1+)$, obviously dilated with protrusion of mucosa through cartilage $(2+)$. Interstitium was scored as normal $(0)$, moderately distended $(1+)$, and severely distended $(2+)$. The reference for a normal score was the most prevailing appearance in fetal control lungs. The relative occurrence of each morphometric score was semiquantitatively expressed as 1 through 6 if $0-5,6-25$.
$26-50,51-75,76-95$, or $96-100 \%$ of the biopsy surface met the criteria mentioned.

\section{Statistical analysis}

Data are expressed as median (interquartile range) unless otherwise stated. Differences between groups were analysed by Kruskal-Wallis one-way ANOVA and Mann-Whitney $U$ test. Intra-group differences were evaluated by Friedman two-way ANOVA and the Wilcoxon signed rank test.

Whether the distribution of semiquantitative morphometric scores was the same in different treatment groups was tested by the Kolmogorov-Smirnov twosample test (22). This nonparametric test takes into account both dispersion and position variations of two samples. The Bonferroni correction was used for multiple comparisons. Statistical significance was accepted as (two-tailed) $\mathrm{p}<0.05$.

\section{RESULTS}

Of the 28 lambs entered into the study, 23 completed the protocol. One CMV and one LA-HFOV animal died after 2.5 hours as a consequence of tension pneumothorax. During one TLV experiment a fluorothorax occurred within 15 minutes after starting liquid ventilation and two other TLV experiments had to be stopped owing to major technical problems. The general characteristics of the studied animals are shown in Table I. No significant intergroup differences existed with respect to gestational age, birth weight, volume expander and buffer requirements. Except for a lower base deficit during TLV when compared to CMV at 1 and $\mathbf{5}$ hours, no other significant intergroup differences in $\mathrm{pH}, \mathrm{Pa}_{\mathrm{a}} \mathrm{CO}_{2}$, or $\mathrm{BE}$ were observed at any time point in the study (Tab. II). The mean airway pressure during LA-HFOV was significantly higher when compared to $C M V$ at 1,2 , and 3 hours (Tab. II). Liquid tidal volume increased slightly but significantly from $17.0(16.7-20.5) \mathrm{mL} . \mathrm{kg}^{-1}$ at 1 hour to 21.1 $(20.0-22.1) \mathrm{mL} \mathrm{kg}^{-1}$ at 5 hours.

Compared to the CMV group, $P(A-a), O_{2}$ was significantly lower in the TLV group throughout the 5 hour study period. The same gas exchange advantage of TLV versus LAHFOV was only significant at 1,2 and 5 hours (Fig. 1 and Tab. II).

Total lung injury scores were lower in fetal controls than in all ventilated groups. The lungs of TLV animals demonstrated significantly less injury than both CMV and 


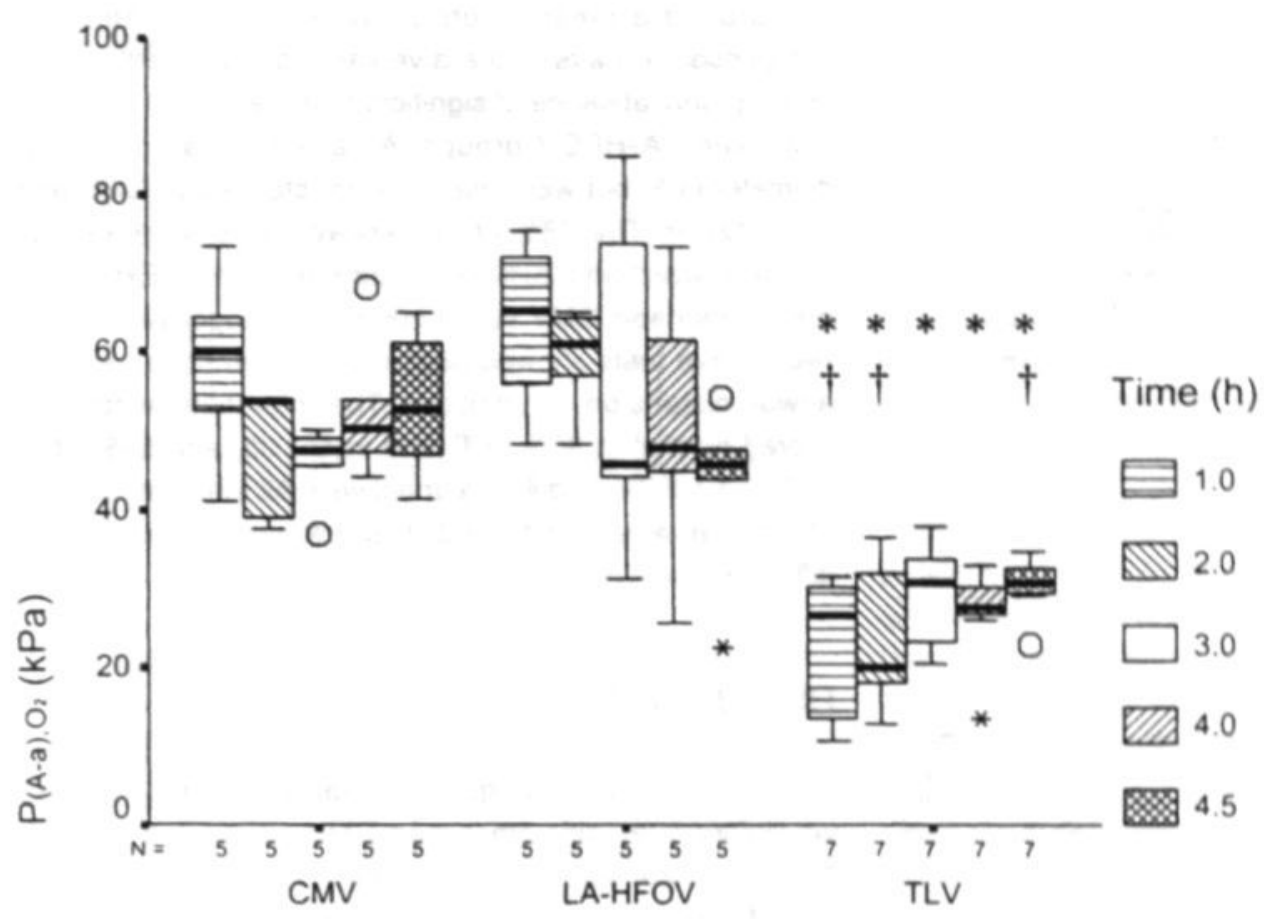

Fig. 1 - Clustered box-andwhiskers plot representing the alveolar-arterial pressure difference for $\mathrm{O}_{2}\left(\mathrm{P}(\mathrm{A}-\mathrm{a}), \mathrm{O}_{2}\right)$ over time in the CMV $L A$. HFOV, and TLV treatment groups. The box extends from the 25th percentile to the 75th percentile with a horizontal line at the median. Whiskers extend down to the smallest and up to the largest observed value that is not outlier. Outliers (o) and extremes (*) have values between 1.5 and 3. or more than 3 box lengths, from the upper or lower edge of the box, respectively. Data were analysed by KruskalWallis and Mann-Whitney test. (*) Significant difference from $C M V ;+$ significant difference from LA-HFOV.

Ventilatory strategy

LA-HFOV treated animals (Fig. 2). Within each ventilatory strategy there were no significant differences between total lung injury scores in dorsal and ventral aspect biopsies. Subanalysis of airway, septal, alveolar, interstitial, and vascular injury scores revealed that the protective effect of TLV was chiefly due to significant lower airway and alveolar scores (TLV vs CMV and TLV vs LA-HFOV: p 5.001 ).
Figures 3 a-c show the distribution of mean values for alveolar, airway, and interstitial morphometric scores per ventilatory strategy. On average, fetal control lungs showed normal alveolar expansion in $77 \%$ of the studied area. CMV and LA-HFOV showed only 7 and $9 \%$ normal alveolar expansion, respectively, whereas more than $50 \%$ of alveoli demonstrated either pronounced collapse or

TABLE I- GESTIONAL AGE, BIRTH WEIGHT, VOLUME EXPANSION WITH SALINE, AND BUFFER REQUIREMENTS WERE SIMILAR IN THE STUDIED GROUPS. NUMBERS ARE MEDIAN (INTERQUARTILE RANGE). KRUSKAL-WALLIS STATISTICS DID NOT REVEAL ANY INTERGROUP DIFFERENCE

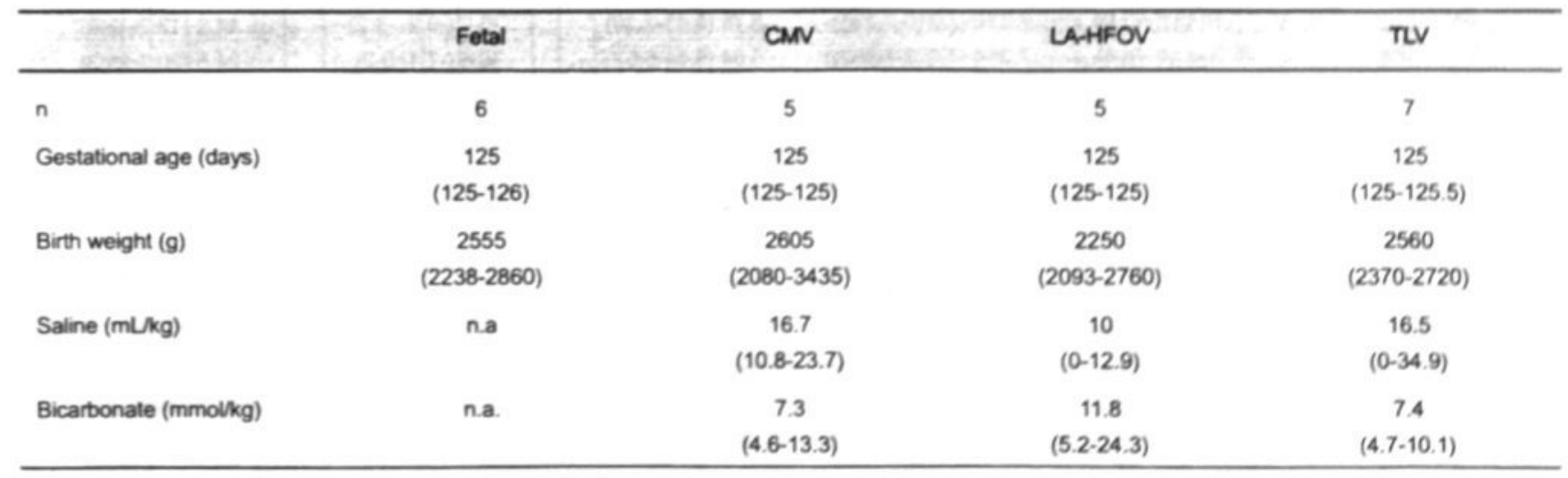




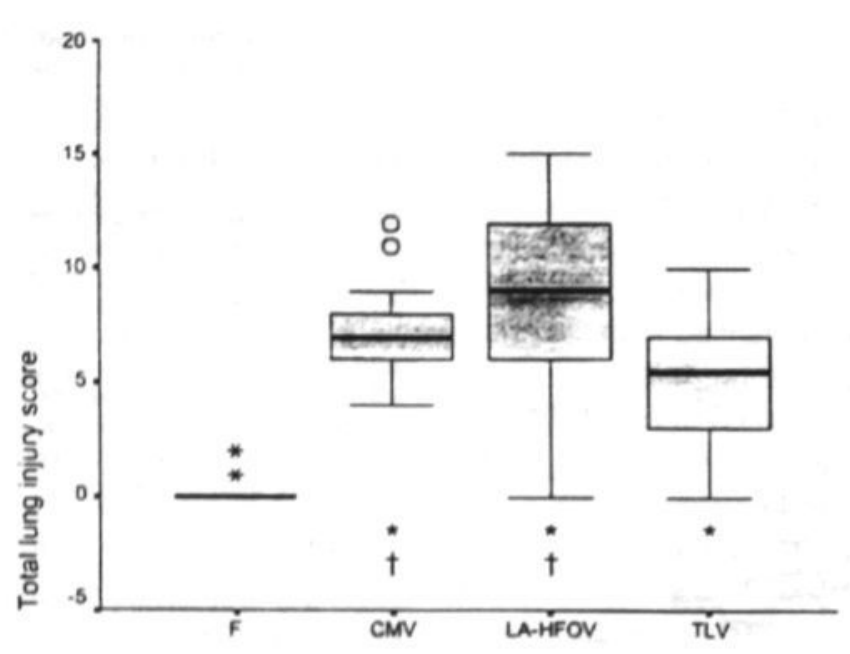

Ventilatory strategy

Fig. 2 - Boxplot for total lung injury scores for the categories F, CMV, LA-HFOV, and TLV. The boxplots show the median, quartiles, and extreme values. There was less lung injury in the $F$ group than in the treatment groups ( $\$ P<0.05$ vs. F) and TLV animals were less lunginjured than both CMV or LA-HFOV group ( $t P<0.05$ vs. TLV).

overinflation. In contrast, $52 \%$ of the alveoli were normally expanded in TLV. There seemed to be a normal distribu- tion around a mean, slightly overexpanded state. The comparison in pairs of the alveolar expansion distribution showed only absence of significant difference between the CMV and LA-HFOV groups. All airways had a normal diameter in $\mathrm{F}$, but were mainly overdistended in $\mathrm{CMV}$ and LA-HFOV. In TLV $68 \%$ of the airways were estimated as normally sized and $29 \%$ as moderately dilated. Except for the comparison CMV vs LA-HFOV, Kolmogorov-Smirnov two-sample tests showed absence of differences between airway distension distributions. The interstitial width was scored normal in $95 \%$ of $F$, and in 66,55 , and $59 \%$ after CMV, LA-HFOV, and TLV respectively. All four distributions of interstitial width tested in pairs were significantly different.

\section{DISCUSSION}

Studies comparing liquid ventilation techniques with ventilatory strategies other than $\mathrm{CMV}$ are scarce $(12,13$, 16, 19, 23-25) and non existent for TLV. The efficacy of high frequency ventilation and PLV, whether using conventional or high frequency ventilation, seems similar in neonatal RDS (12). Partial liquid ventilation, initially

TABLE II-GAS EXCHANGE AND MEAN AIRWAY PRESSURE (MAP) DATA OF CMV, LA-HFOV AND TLV TREATMENT GROUPS OVER TIME. DATAARE MEDIAN (INTERQUARTILE RANGE)

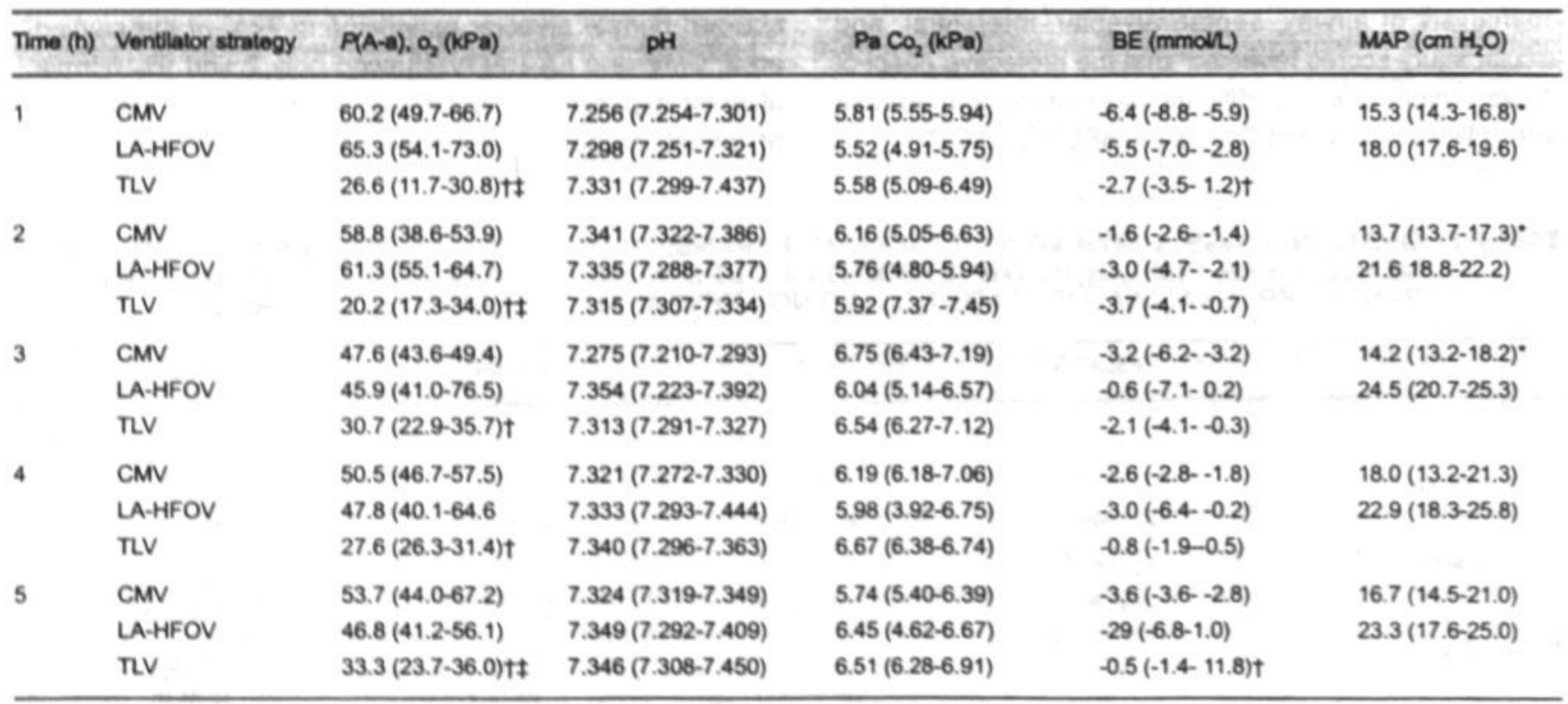

$C M V=$ conventional mechanical ventilation; $\mathrm{LA-HFOV}=$ liquid-assisted high-frequency oscillatory ventilation; TLV = tidal liquid ventiation. Inter-group differences: " $p<0.05$ CMV vs LA-HFOV; $\uparrow p<0.05$ CMV vs TLV; $\ddagger p<0.05$ LA-HFOV vs TLV (by Mann-Whitney U test). 

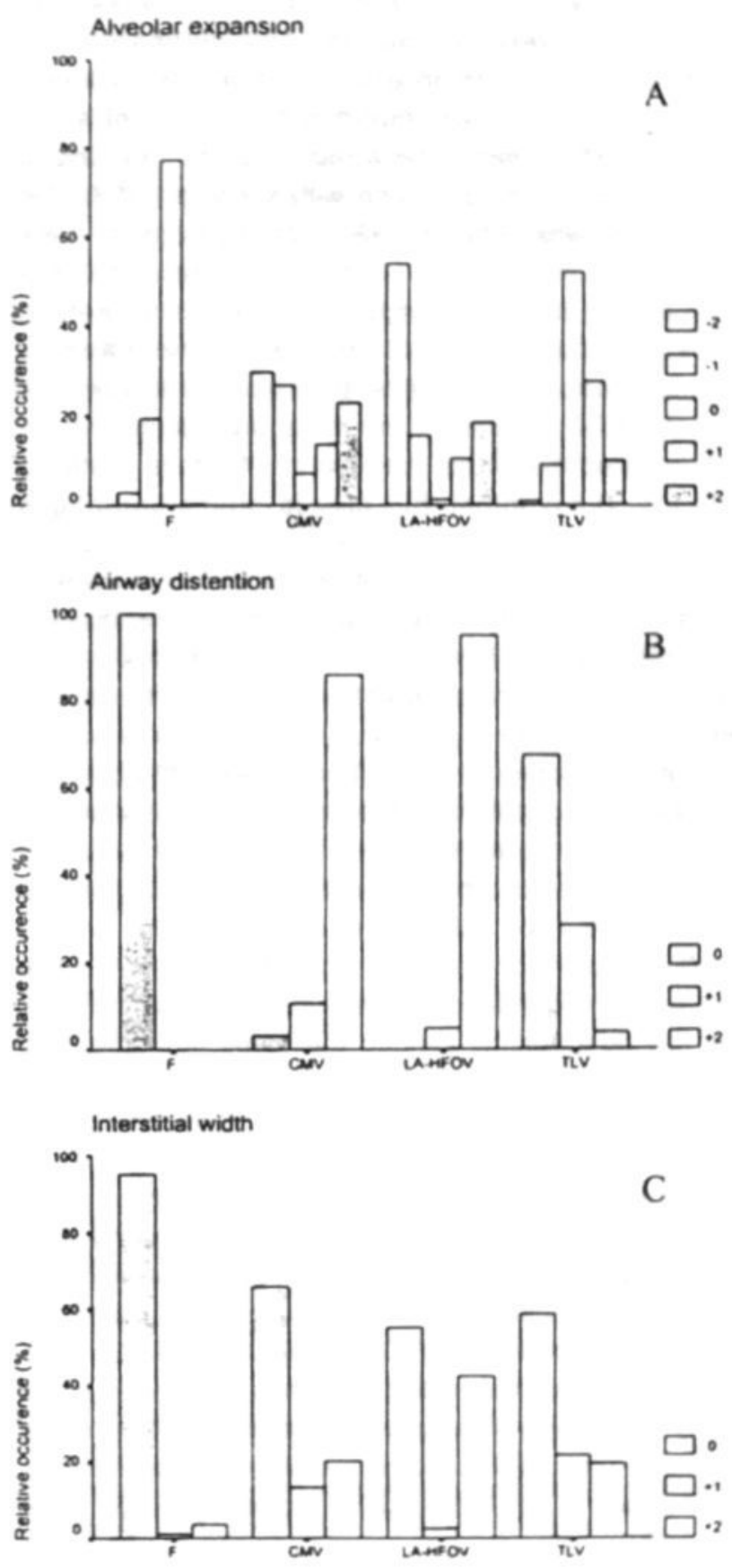

Ventiatory strategy

Fig. 3 - Bar graphs representing the mean percentage of lung biopsy area fitting the semiquantitative scores for alveolar expansion (A). ainway distension (B), and interstitial width (C). See text for decription and discussion. The lack of significant differences in the distributions of morphometric scores was only present between CMV and LA-HFOV grups for alveolar expansion and ainway distention. considered as offering the same advantages as TLV, but free of its disadvantages, may provide less lung protection than $\operatorname{TLV}(18,26)$. We therefore considered a comparison of CMV, HFOV, and TLV. The beneficial effect of adding PFC liquid to HFV is controversial. To match HFOV and TLV animals for the anti-inflammatory effect of a PFC liquid per se, we instilled small amounts of FC-75 in the HFOV animals (liquid assisted HFOV). The main findings of this study were that early TLV compares favourably to either gas ventilation strategy with relation to gas exchange, histological lung injury, and uniformity of ventilation.

When comparing TLV with CMV, our data corroborate previous work of Wolfson and coworkers (5). The worse gas exchange, especially in their CMV group, is most likely due to the lower gestational age (111 \pm 1 days), the lack of exogenous surfactant therapy, and the lower PEEP used. The use of a severity based lung injury score, and the inclusion of nonventilated fetal control lungs in our study confirms Wolfson's histological findings and adds other elements as well. TLV lungs show less ventilator induced lung injury than gas ventilated lungs, but are themselves injured compared to fetal controls. This lung injury may have occurred during the first quarter of gas ventilation, since CMV but also PLV are not devoid of voluor baro-trauma (27). Prophylactic TLV from birth would however only be feasible in the setting of an ex utero intrapartum treatment (EXIT) procedure. The vascular perfusion at existing mean airway pressure used by our group, guarantees the fixation of the in vivo situation. avoiding artefacts such as post mortem atelectasis, which may occur more easily in gas ventilated lungs. Therefore, we feel confident in the results of our semiquantitative morphometric analysis, demonstrating not only pronounced atelectasis but also hyperinflated gas exchange areas in gas ventilated lungs. These findings suggest a combination of both low and high $V^{\prime} / \mathrm{A}^{\prime}$ regions resulting in disturbed oxygenation. Liquid ventilated lungs on the other hand, show a normal distribution of the gas exchange areas. Comparison of this distribution with that in fetal control animals, once again, points out the relativity of this finding. The TLV situation is obviously different from the fetal situation, which is likely to be the ideal situation for a growing lung. The mean alveolar expansion during TLV was indeed in excess of the alveolar distension seen in unventilated fetal lambs, and the distribution was wider. The morphometric analysis of airway dimensions yielded the same profile of findings: the majority of airways ( $>90 \%)$ 
in gas ventilated lungs was overdistended, only one third in liquid ventilated lungs, but none in fetal control lungs. We wonder whether these intermediate morphometric findings in TLV lungs might imply an incomplete protective effect of liquid ventilation. As with PLV, the potential reduction in incidence or in severity of bronchopulmonary dysplasia in still speculative. The proportion of distended to normal interstitial width was similar in the three therapeutic groups, but significantly larger in treated than in fetal control animals. Widened interstitium may be the manifestation of postnatal lung liquid resorption, pulmonary interstitial emphysema or interstitial PFC liquid (28).

The lack of significant differences in outcome variables between CMV and LA-HFOV animals was surprising since animal research but also human data support the use of HFOV in neonatal RDS. Most animal studies investigating HFOV in neonatal RDS used the preterm baboon model (29). In this model, HFOV was found to diminish the pathological findings of small airway overdistention, atelectasis, oedema, hyaline membranes, and pulmonary interstitial emphysema, but increased bronchoalveolar haemorrhages when compared to CMV (30). It was recognized that overexpansion, the cause of circulatory compromise and air leak, should be avoided (2).

The prematurely delivered lamb, although an accepted model of hyaline membrane disease, has not been used as frequently in CMV versus HFOV comparative studies. Lately, Kinsella et al (12) reported a study using extremely preterm lambs (115 days) which makes comparison with our data difficult. Using a PEEP level of $6 \mathrm{~cm} \mathrm{H} \mathrm{H}_{2} \mathrm{O}$ in the $\mathrm{CMV}$ strategy, $\mathrm{Pa}, \mathrm{O}_{2}$ equalled $41 \pm 7 \mathrm{~mm} \mathrm{Hg}$ at the 3-h time point; this corresponds to a $P(A-a), O_{2}$ of $\pm 67 \mathrm{kPa}$ (assuming a $P_{B}$ of $650 \mathrm{~mm} \mathrm{Hg}$ in Denver, $1,600 \mathrm{~m}$ ). Likewise the $P(A-a), O_{2}$ at 3 hours during HFOV was $\pm 46 \mathrm{kPa}$. All CMV lambs in our study had their PEEP increased to $8 \mathrm{~cm} \mathrm{H}_{2} \mathrm{O}$, and demonstrated a $P(A-a), O_{2}$ of $47.6(43.6-49.4) \mathrm{kPa}$ at 3 hours; the $P(A-a), O_{2}$ in LA-HFOV lambs was 45.9 (41.076.5) $\mathrm{kPa}$. Solimano and coworkers (31) studied both ventilation modalities in much older, natural surfactant treated, premature lambs (133-136 days). From Figure 1 in their paper we estimate a $P(A-a), O_{2}$ of around 65 and $60 \mathrm{kPa}$ for CMV and HFOV respectively. Moreover, a large protein leak was demonstrated, independent of the ventilation strategy used. In premature lambs (126-133 days' gestation) treated with surfactant before birth, Walther and coworkers demonstrated a significant larger alveolar surface area in HFOV (superimposed onto backup CMV) than in CMV animals. However, no differences were found in gas exchange or histopathology (32). In an experiment lasting six hours, Jefferies and coworkers reported the effects of either HFOV or CMV in lambs delivered at 129 to 133 days of gestation, and treated at birth with surfactant (33). The oxygenation was better in HFOV animals only at the 4 and 6 hour time point. Other researchers have experienced similar "disappointing" results in preterm lambs aged 130 days (S. Bambang Oetomo, personal communication). In general the disease severity of neonatal RDS appears to be more pronounced in the preterm lamb than in the baboon at 140 days gestation or in the VLBW infant. But also in premature infants (gestational age $<30$ weeks), neither albumin, interleukin 8 , or leukotriene B4 concentration in tracheal aspirate (34), nor the incidence of chronic lung disease were different in a large randomized controlled trial of high frequency ventilation (35). Gentle ventilation and permissive hypercapnia may have improved the respiratory outcome of babies treated with IPPV (1). The importance of lung volume recruitment and maintenance during conventional ventilatory management was also recently emphasized by Rimensberger in a lung lavage rabbit model (36). PEEP was set above the critical closing pressure on the deflation limb of the P-V curve after a sustined inflation. Combining this optimal PEEP with low tidal volume yielded the same outcome as a high volume strategy HFOV: improved gas exchange, and similar lung histology and lung inflammation.

A matter of concern and a potential limitation of our study are the high mean airway pressures recorded in the LA-HFOV animals. Although an accepted early lung volume optimization strategy $(37,38)$ was used, lung overdistention, inducing iatrogenic lung injury, may have been present in the LA-HFOV group. Alternatively, nonuniform surfactant distribution may have contributed to the patchy distribution of atelectasis and overinflation of gas exchange units. This also raises the question whether larger doses of PFC-liquid could protect the lungs more effectively.

In conclusion, the CMV and LA-HFOV strategies, used in this study were unable to uniformly recruit the lungs of preterm lambs, prophylactically treated with natural surfactant. Gas exchange was poor and there was major histopathological lung injury. The equal results of CMV and LA-HFOV contradict some previous experience, but are in agreement with other data. Differences in the animal 
model and the ventilatory strategies used may play a role in these discrepancies. With tidal iquid ventilation, gas exchange was markedly improved, the lungs were homogeneously ventilated and showed less ventilator induced lung injury. Although these findings are promising, the presence of histological lung injury should restrain us from putting our expectations too high. Premature clinical use is not yet warranted. Prolonged mechanical ventilation studies in preterm animals could clarify the potential of TLV in preventing bronchopulmonary dysplasia and preserving normal alveolar growth $(39,40)$.

\section{ACKNOWLEDGEMENTS}

The authors thank Boehringer-Ingelheim for generously supplying Alveofact, and $3 \mathrm{M}$ Company Belgium for kindly providing FC-75 perfluocarbon liquid. Nellcor Puritan Bennett Europe BV ('s Hertogenbosch, The Netherlands) placed a NPB-290 puise oximeter and SensorMedics Critical Care (Bilthoven, The Netherlands) a SensorMedics 3100A oscillator at our disposal.

The excellent technical assistance of Theo van der Nagel, Joyce Suyck, May Bost, and Frans Slagen is gratefully acknowledged.
The study was supported by: Boehringer-Ingelheim Pharma KG, Biberach, Germany: Alveofact, 3M Company Belgium: FC-75 perfluorocarbon liquid, Nellcor Puritan Bennett Europe BV ('s Hertogenbosch, The Netherlands): NPB-290 pulse oximeter, Sensor Medics Critcal Care (Bilthoven, The Netherlands): SensorMedics 3100A oscillator.

Reprint requests to:

Pieter L.J. Degraeuwe, MD

University Hospital Maastricht

Department of Paediatrics

P. Debyelaan 25; P.O. Box 5800

NL - 6202 AZ Maastricht

The Netheriands

e-mail: pde@skin.azm.ni

\section{REFERENCES}

1. Mariani GL, Carlo WA. Ventilatory management in neonates. Science or art? Clin Perinatol 1998; 25: 33-48.

2. deLemos RA, Coalson JJ, Meredith KS, Gestmann DR, Null DM, Jr. A comparison of ventilation strategies for the use of high-frequency oscillatory ventilation in the treatment of hyaline membrane disease. Acta Anaesthesiol Scand Suppl 1989; 90: 102-7.

3. Jackson JC. Truog WE, Standaert TA, et al. Reduction in lung injury after combined surfactant and high-frequency ventilation. Am J Respir Crit Care Med 1994; 150: 534-9.
4. Bhuta T, Henderson Smart DJ. Elective high-frequency oscillatory ventilation versus conventional ventilation in preterm infants with pulmonary dysfunction: systematic review and meta-analyses. Pediatrics 1997; 100: E6.

5. Wolfson MR, Greenspan JS, Deoras KS, Rubenstein SD, Shaffer TH. Comparison of gas and liquid ventilation: clinical, physiological, and histological correlates. J Appl Physiol 1992; 72: 1024-31.

6. Jackson JC, Standaert TA, Troug WE, Hodson WA. Full-tidal liquid ventilation with perfluorocarbon for prevention of lung 
injury in newborn non-human primates. Artif Cells Blood Substit Immobil Biotechnol 1994; 22: 1121-32.

7. Valls-i-Soler A, Alvarez FJ, Gomez MA,et al. Is surfactant (SF) needed in perfluorocarbon filled lungs? Pediatr Res 1995; 37: 354A.

8. Tarczy Hornoch P, Hildebrandt J, Mates EA, et al. Effects of exogenous surfactant on lung pressure-volume characteristics during liquid ventilation. J Appl Physiol 1996; 80: 1764-71

9. Leach CL, Fuhrman BP, Morin FC, Rath MG. Perfluorocarbon-associated gas exchange (partial liquid ventilation) in respiratory distress syndrome: a prospective, randomized, controlled study. Crit Care Med 1993; 21: 1270-8.

10. Tarczy Hornoch P, Hildebrandt J, Standaert TA, Jackson JC. Surfactant replacement increases compliance in premature lamb lungs during partial liquid ventilation in situ. J Appl Physiol 1998; 84: 1316-22.

11. Mrozek JD, Smith KM, Bing DR, et al. Exogenous surfactant and partial liquid ventilation: physiologic and pathologic effects. Am J Respir Crit Care Med 1997; 156: 1058-65.

12. Kinsella JP, Parker TA, Galan H, Sheridan BC, Abman SH. Independent and combined effects of inhaled nitric oxide, liquid perfluorochemical, and high-frequency oscillatory ventilation in premature lambs with respiratory distress syndrome. Crit Care Med 1999; 159: 1220-7.

13. Sukumar M, Bommaraju M, Fisher JE, et al. High-frequency partial liquid ventilation in respiratory distress syndrome: hemodynamics and gas exchange. J Appl Physiol 1998; 84: 327-34

14. Gothberg S, Parker TA, Abman SH, Kinsella JP. Highfrequency oscillatory ventilation and partial liquid ventilation after acute lung injury in premature lambs with respiratory distress syndrome. Crit Care Med 2000; 28: 2450-6.

15. Tutuncu AS, Faithfull NS, Lachmann B. Intratracheal perfluorocarbon administration combined with mechanical ventilation in experimental respiratory distress syndrome: dose-dependent improvement of gas exchange. Crit Care Med 1993; 21: 962-9.

16. Baden HP, Mellema JB, Bratton SL, PP OR, Jackson JC. High-frequency oscillatory ventilation with partial liquid ventilation in a model of acute respiratory failure. Crit Care Med 1997; 25: 299-302.

17. Bradley JD, Spooner ML, Rusheen PD, Peters BP, Xu A, Flaim SF. Intratracheal perflubron (PFB) liquid or vapor reduces lung myeloperoxidase (MPO) levels following cobra venom factor (CVF) challenge in rats. FASEB-J 1996; 10 (suppl): A108.

18. Wolfson MR, Friss HE, Kechner NE, Rubenstein SD, Dechadarevian J-P. Shaffer TH. Physiological basis of improved lung stability after perfluorochemical (PFC) liquid rescue of surfactant treated lambs. Pediatr Res 1994; 35: 357A. 19. Degraeuwe PLJ. Thunnissen FBJM, Vos GD, Blanco CE
High-frequency oscillatory ventilation, partial liquid ventilation, or conventional mechanical ventilation in newborn piglets with saline lavage-induced acute lung injury. A comparison of gas-exchange efficacy and lung histomorphology. Biol Neonate 1999; 75: 118-29.

20. Gerstmann DR, deLemos RA, Clark RH. High-frequency ventilation: issues of strategy. Clin Perinatol 1991; 18: 563-80.

21. McCulloch PR, Forkert PG, Froese AB. Lung volume maintenance prevents lung injury during high frequency oscillatory ventilation in surfactant-deficient rabbits. Am Rev Respir Dis 1988; 137: 1185-92.

22. Sokal RR, Rohlf FJ. Biometry: the principles and practice of statistics in biological research. 2nd ed. San Francisco: W.H. Freeman and Company, 1981.

23. Mrozek JD, Bing DR, Meyers PA, Connett JE, Mammel MC. High-frequency oscillation versus conventional ventilation following surfactant administration and partial liquid ventilation. Pediatric Pulmonology 1998; 26: 21-9.

24. Smith KM, Mrozek JD, Simonton SC, et al. Prolonged partial liquid ventilation using conventional and high-frequency ventilatory techniques: gas exchange and lung pathology in an animal model of respiratory distress syndrome. Crit Care Med 1997; 25: 1888-97.

25. Smith KM, Bing DR, Meyers PA, Connett JE, Boros SJ, Mammel MC. Partial liquid ventilation: a comparison using conventional and high-frequency techniques in an naimal model of acute respiratory failure. Crit Care Med 1997; 25: 1179-86.

26. Foust R, Tran NN, Cox C, et al. Liquid assisted ventilation: an alternative ventilatory strategy for acute meconium aspiration injury. Pediatr Pulmon 1996; 21: 316-22.

27. Cox PN, Frndova H, Tan PS, et al. Concealed air leak associated with large tidal volumes in partial liquid ventilation. Am J Respir Crit Care Med 1997; 156: 992-7.

28. Werner HA, Stockwell JA, Lai-Fook SJ. Partial liquid ventilation causes formation of interstitial perivascular cuffs in rabbit lung. Am J Respir Crit Care Med 1996; 153: A531.

29. Clark RH. High-frequency ventilation. J Pediatr 1994; 124 : 661-70.

30. Coalson JJ, deLemos RA. Pathologic features of various ventilatory strategies. Acta Anaesthesiol Scand Suppl 1989; 90: 108-16.

31. Solimano A, Bryan C, Jobe A, lkegami M, Jacobs H. Effects of high-frequency and conventional ventilation on the premature lamb lung. J Appl Physiol 1985; 59: 1571-7.

32. Walther FJ, Kuipers IM, Gidding CE, Willebrand D, Buchholtz RT, Bevers EM. A comparison of high-frequency oscillation superimposed onto backup mechanical ventilation and conventional mechanical ventilation on the distribution of exogenous surfactant in premature lambs. Pediatr Res 1987; 22: 725-9.

33. Jefferies AL, Dunn MS, Possmayer F, Tai KF. $99 \mathrm{mT}$-DTPA clearance in preterm lambs. Effect of surfactant therapy and 
ventilation. Am Rev Respir Dis 1993; 148: 845-51.

34. Thome U, Gotze Speer B, Speer CP. Pohlandt F. Comparison of pulmonary inflammatory mediators in preterm infants treated with intermittent positive pressure ventilation of high frequency oscillatory ventilation. Pediatr Res 1998; 44: 330-7.

35. Thome U, Kossel H. Lipowsky G, et al. Randomized comparison of high-frequency ventilation with high-rate intermittent positive pressure ventilation in preterm infants with respiratory failure. J Pediatr 1999; 135: 39-46.

36. Rimensberger PC, Pache J-C, McKerlie C, Fmdova H, Cox PN. Lung recruitment and lung volume maintenance: a strategy for improving oxygenation and preventing lung injury during both conventional mechanical ventilation and highfrequency oscillation. Intensive Care Med 2000; 26: 745-55.
37. Kalenga M, Battisti O, Francois A, Langhendries JP. Gerstmann DR, Bertrand JM. High-frequency oscillatory ventilation in neonatal RDS: initial volume optimization and respiratory mechanics. J Appl Physiol 1998; 84: 1174-7.

38. Rimensberger PC, Beghetti M, Hanquinet S, Berner M. First intention high-frequency oscillation with early lung volume optimization improves pulmonary outcome in very low birth weight infants with respiratory distress syndrome. Pediatrics 2000; 105: 1202-8.

39. Albertine $\mathrm{KH}$, Jones GP, Starcher BC,et al. Chronic lung injury in preterm lambs. Disordered respiratory tact development. Am J Respir Crit Care Med 1999; 159: 945-58.

40. Coalson JJ. Experimental models of bronchopulmonary dysplasia. Biol Neonate 1997; 71 (suppl 1): S35-8. 


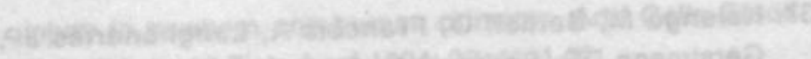

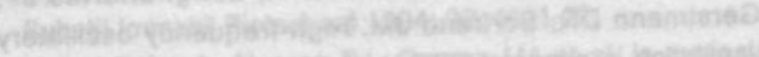

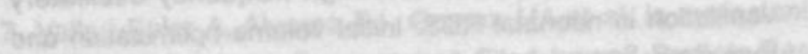

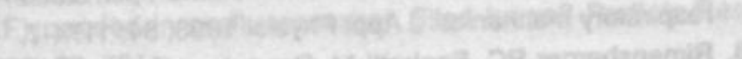

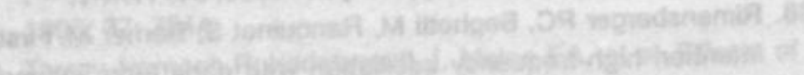

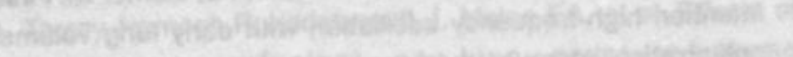

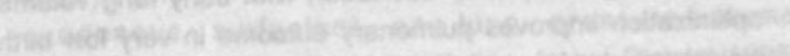

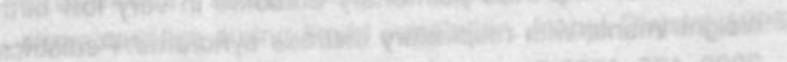

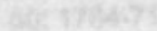

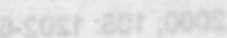

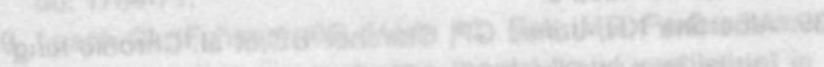

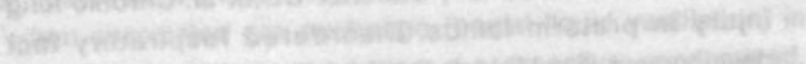

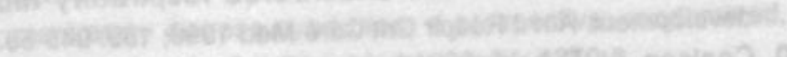

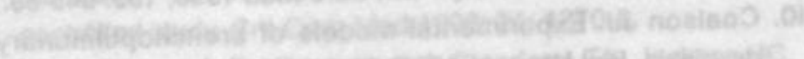

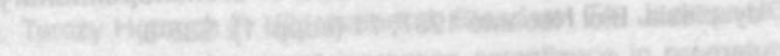

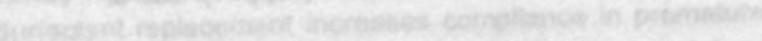

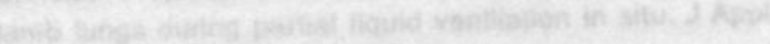

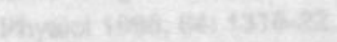

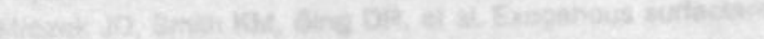

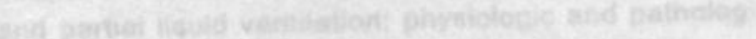

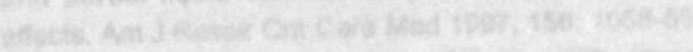

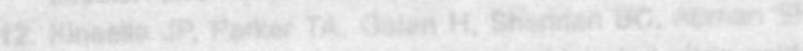

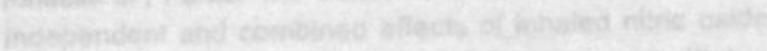

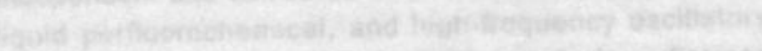

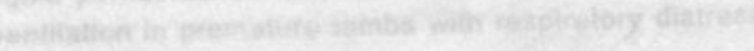

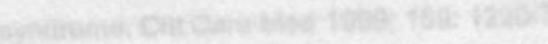

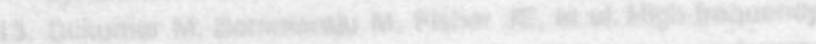

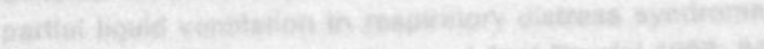

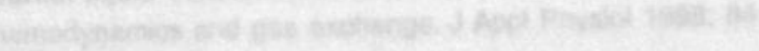
$327-1$

14.

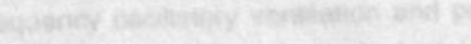

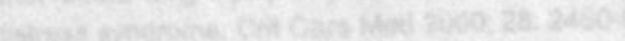

Sw

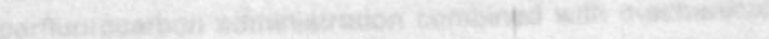

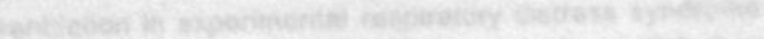

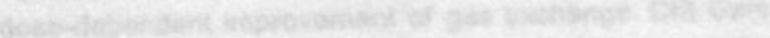

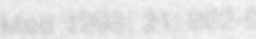

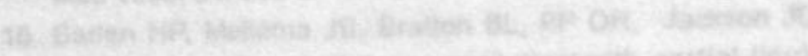

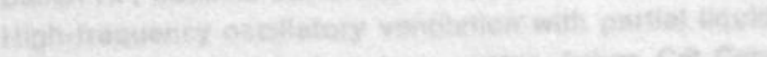

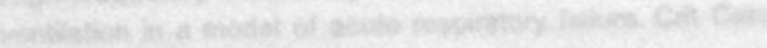

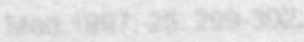

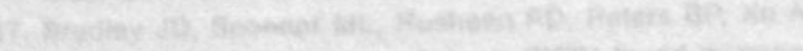

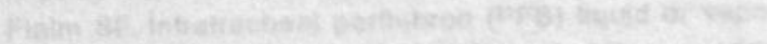

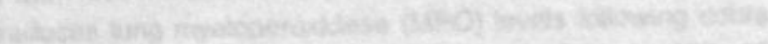

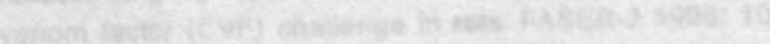
Cuncthata

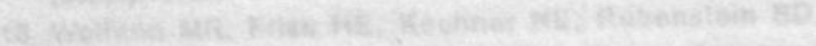

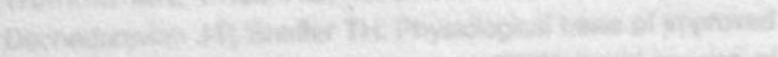

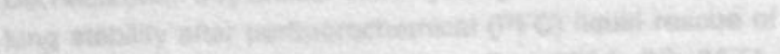

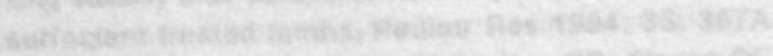

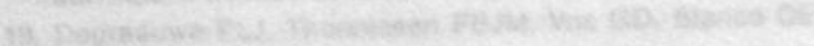

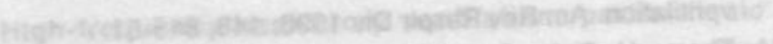

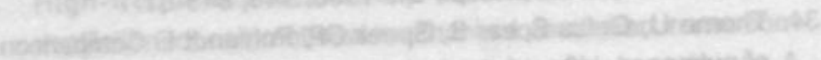

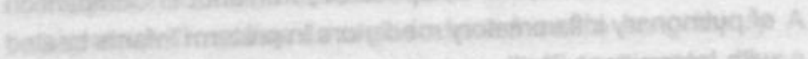

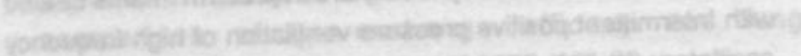

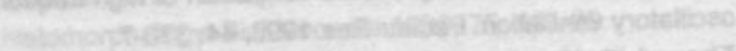

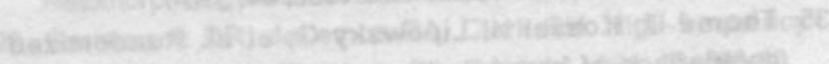

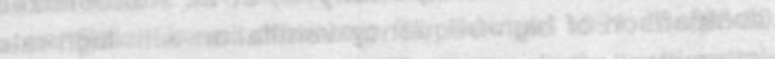

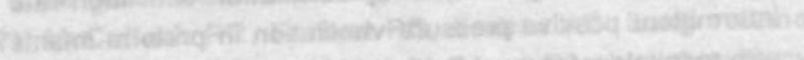

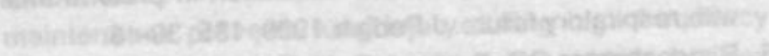

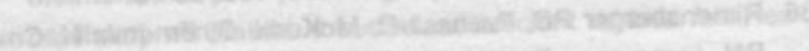

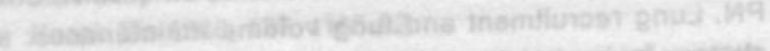

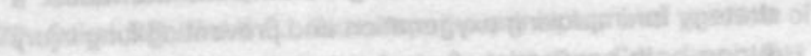

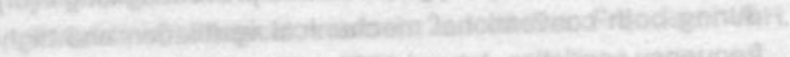

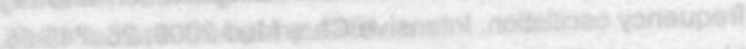

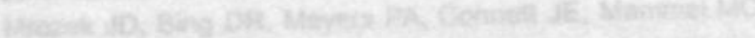

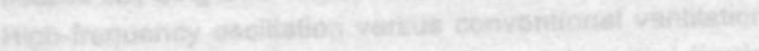

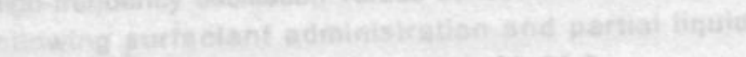

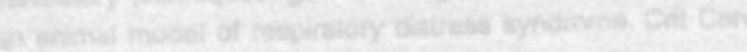

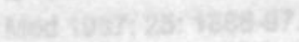

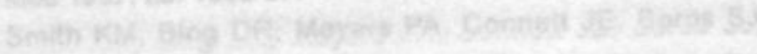

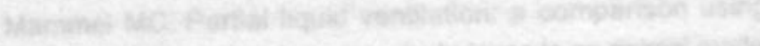

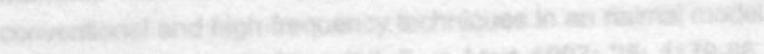

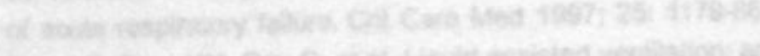

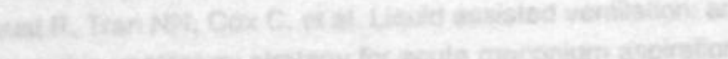

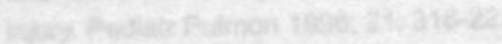

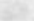

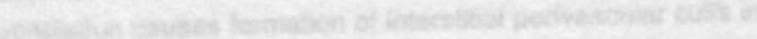

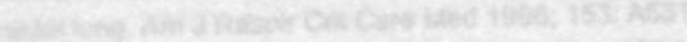

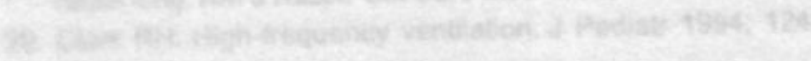

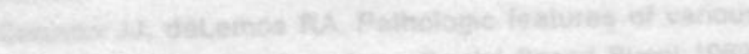

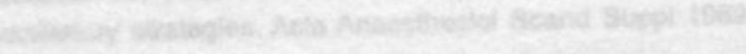

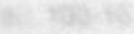

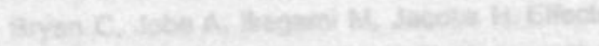

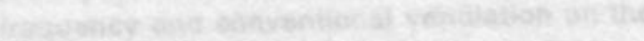

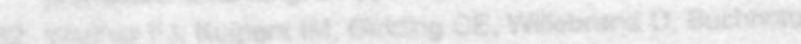

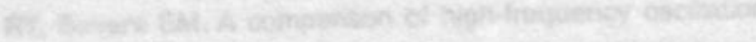

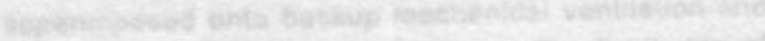

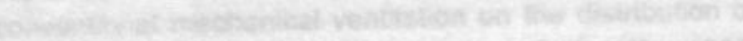

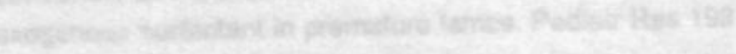
$28+27^{2}-9$

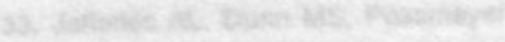

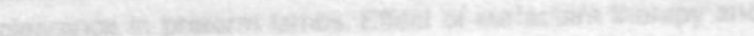


A critical review of the literature on perfluorocarbon liquid ventilation. Hype or hope?

A revised version of:

Degraeuwe PLJ, Vos GD, Blanco CE. Perfluorochemical liquid ventilation: from the animal laboratory to the intensive care unit. Int J Artif Organs 1995;18(10):674-83.

and

Degraeuwe PLJ. Liquid assisted ventilation: a review of controlled animal studies and human experience. Developmental Physiopathology and Clinics 1999;9S:133-137. 
1. The historical origin of tidal perfluorocarbon liquid ventilation

2. Perfluorocarbon liquids as respiratory medium

2.1. Physico-chemical properties of perfluorocarbons

2.2. Biological properties and the use of perfluorocarbons

2.2.1. The fate of inhaled perfluorocarbons

2.2.2. Anti-inflammatory properties: direct and indirect cytoprotection

2.2.3. Effects on airway mucosa

2.2.4. PFC liquids and infection

2.2.5. The effect of perfluorochemicals on lung mechanics and surfactant function

2.3. Other biomedical applications of PFC liquids

3. The liquid-filled lung

4. Lung diseases and pathology that might benefit from liquid-assisted ventilation

4.1. Neonatal respiratory distress syndrome

4.2. Acute respiratory distress syndrome

4.3. Meconium aspiration syndrome

4.4. Congenital diaphragmatic hernia

5. Tidal liquid ventilation

5.1. The technique of tidal liquid ventilation

5.2. Feasibility and other descriptive animal studies on tidal liquid ventilation

5.2.1. Adult (and neonatal) animals with normal lungs

5.2.2. Hyaline membrane disease.

5.2.3. Acute respiratory distress syndrome

5.2.4. Meconium aspiration

5.3. Comparative animal studies

5.3.1. Neonatal respiratory distress syndrome

5.3.2. Acute respiratory distress syndrome

5.3.3. Meconium aspiration syndrome

5.4. Human experience

5.5. Practical guidelines for tidal liquid ventilation

5.6. Haemodynamics during TLV

5.7. Tidal liquid ventilation: action mechanism in the diseased lung (how it improves gas exchange and protects the lungs)

6. Partial liquid ventilation

6.1. The historical origins of partial liquid ventilation

6.2. Feasibility and other descriptive animal studies on partial liquid ventilation

6.2.1. Partial liquid ventilation of the normal lung

6.2.1.1. What happens during PLV?

6.2.1.2. Findings after PLV

6.2.2. PLV in diseased lungs: descriptive (and explanatory) studies

6.3. Studies comparing PLV with CMV

6.3.1. Neonatal respiratory distress syndrome

6.3.2. Acute respiratory distress syndrome

6.3.2.1. Saline lung lavage-induced lung injury

6.3.2.2. Oleic acid infusion-induced acute respiratory distress syndrome 
6.3.2.3. Gastric aspiration-induced acute respiratory distress syndrome

6.3.2.4. Smoke inhalation

6.3.2.5. Hydrocarbon aspiration

6.3.2.6. Pulmonary contusion

6.3.2.7. Neutrophil-mediated lung injury - systemic endotoxaemia

6.3.2.8. Ventilation-induced lung injury

6.3.3. Meconium aspiration syndrome

6.3.4. Congenital diaphragmatic hernia

6.3.5. Pneumonia

6.3.6. Cardiopulmonary bypass and lung transplantation

6.4. PLV combined with or versus other technologies

6.4.1. PLV and exogenous surfactant

6.4.2. PLV and inhaled NO

6.4.3. PLV combined with HFV, ITV, patient triggered ventilation (PTV) and PAV

6.4.4. PLV versus other recruitment strategies (CMV, HFOV)

6.4.5. (Prone) positioning and PLV

6.4.6. Ventilatory strategy (tidal volume, PEEP, and I:E ratio) during PLV

6.4.7. Vaporized or nebulized perfluorocarbons

6.5. Human experience

6.6. Practical guidelines for partial liquid ventilation

6.6.1. Liquid dosing

6.6.2. Liquid dose maintenance

6.6.3. Optimal gas ventilation strategy

6.6.4. PFC conservation during PLV

6.6.5. Suctioning

6.7. Partial liquid ventilation: the proposed action mechanism in the diseased lung (how it improves gas exchange and protects the lungs)

6.7.1. A noncompressible liquid with low surface tension and high spreadability

6.7.2. Decreasing of $\mathrm{V}^{\prime}$ / $/ \mathrm{Q}$ ' mismatch by redistribution of gas ventilation and perfusion

6.7.3. Lavage and tamponade effect

6.7.4. Anti-inflammatory effect or immunomodulation

6.8. Haemodynamics during PLV

7. Appendices

8. References 


$\begin{array}{ll}\text { ALI } & \text { acute lung injury } \\ \text { ARDS } & \text { acute respiratory distress syndrome } \\ \text { BAL(F) } & \text { broncho-alveolar lavage (fluid) } \\ \text { bpm } & \text { breaths per minute } \\ \text { CDH } & \text { congenital diaphragmatic hernia } \\ \text { Cdyn } & \text { dynamic compliance } \\ \text { CMV } & \text { conventional mechanical ventilation } \\ \text { Crs,dyn } & \text { dynamic respiratory system compliance } \\ \text { Crs,stat } & \text { static respiratory system compliance } \\ \text { CTGI } & \text { continuous tracheal gas insufflation } \\ \text { ECLS } & \text { extracorporeal life support } \\ \text { ECMO } & \text { extracorporeal membrane oxygenation } \\ \text { EELV } & \text { end-expiratory lung volume } \\ \text { F } 1, \mathrm{O}_{2} & \text { fraction of inspired oxygen } \\ f \mathrm{R} & \text { respiratory rate } \\ \text { FRC } & \text { functional residual capacity } \\ \text { GV } & \text { gas ventilation } \\ \text { HFOV } & \text { high frequency oscillatory ventilation } \\ \text { HFV } & \text { high frequency ventilation } \\ \text { HMD } & \text { hyaline membrane disease } \\ \text { I:E ratio } & \text { inspiratory expiratory ratio } \\ \text { IL- } & \text { interleukin- } \\ \text { IMV } & \text { intermittent mandatory volume } \\ \text { iNO } & \text { inhaled nitric oxide } \\ \text { ITPV } & \text { intratracheal pulmonary ventilation } \\ \text { ITV } & \text { intratracheal ventilation } \\ \text { LAP } & \text { left atrial pressure } \\ \text { LIP } & \text { lower inflection point } \\ \text { MAP } & \text { mean airway pressure } \\ \text { MAS } & \text { meconium aspiration syndrome } \\ \text { nRDS } & \text { neonatal respiratory distress syndrome } \\ \text { OI } & \text { oxygenation index } \\ P(A-a), O_{2} & \text { alveolo-arterial oxygen tension gradient } \\ \text { Pa, } \mathrm{O}_{2} & \text { partial pressure of arterial oxygen } \\ \text { Pa,CO } & \text { partial pressure of arterial carbon dioxide } \\ \text { PAP } & \text { pulmonary artery pressure } \\ \text { PAV } & \text { proportional assist ventilation } \\ \text { Paw } & \text { airway pressure } \\ \text { PBF } & \text { pulmonary blood flow } \\ \text { PEEP } & \text { positive end-expiratory pressure } \\ \text { PFC } & \text { perfluorocarbon or perfluorochemical } \\ \text { PFOB } & \text { perfluoroctyl bromide } \\ \text { Pl, } \mathrm{O}_{2} & \text { inspired oxygen tension } \\ \text { PIP } & \text { peak inspiratory pressure } \\ & \end{array}$




$\begin{array}{ll}\text { PLV } & \text { partial liquid ventilation } \\ \text { PPHN } & \text { persistent pulmonary hypertension of the newborn } \\ \text { PTV } & \text { patient triggered ventilation } \\ \text { PVR } & \text { pulmonary vascular resistance } \\ \text { SIMV } & \text { synchronized intermittent mandatory volume } \\ \text { SVR } & \text { systemic vascular resistance } \\ \text { TGI } & \text { tracheal gas insufflation } \\ \text { TLV } & \text { tidal liquid ventilation } \\ \text { TNF- } \alpha & \text { tumour necrosis factor alfa } \\ \text { UIP } & \text { upper inflection point } \\ \text { V'A' } & \text { ventilation perfusion ratio } \\ \text { VILI } & \text { ventilator induced lung injury } \\ \text { V }_{\text {T }} & \text { tidal volume } \\ \text { ZEEP } & \text { zero end-expiratory pressure }\end{array}$

\section{Introduction}

Perfluorocarbon liquid assisted ventilation is an experimental respiratory support approach. Two modalities, one derived from the other, make use of perfluorocarbon compounds, but physiologically and in practice the techniques are very different. During tidal liquid ventilation (TLV) the respiratory medium of both functional residual capacity and tidal volume is replaced by neat perfluorocarbon liquid. A liquid ventilator mechanically assists in the delivery of tidal volumes of PFC liquid which is extracorporeally oxygenated, scrubbed of $\mathrm{CO}_{2}$ and warmed to body temperature. Partial liquid ventilation (PLV) refers to gas ventilation of the lungs (partly) filled with a perfluorocarbon liquid.

To identify literature on the topic, we searched the computerized MEDLINE database for articles from 1964 to April 2001, using the key words "Fluorocarbons"/ all subheadings, explode "Respiration-Artificial"/ all subheadings, and explode "Lung"/ all subheadings. Reference lists of retrieved articles were reviewed, and personal files (e.g. abstract books and congress proceedings) were searched.

This review starts with a brief account of the history of liquid ventilation research. Then, the physicochemical and biological properties of perfluorochemical liquids and the physiology of the liquid-filled lung are discussed. We provide a short overview of the major lung diseases that may benefit from liquid ventilation, with focus on their complex pathophysiology and current state of the art therapeutic strategies. Next we discuss descriptive and comparative tidal and partial liquid ventilation research. Explanatory physiological mechanisms are reviewed and efficacy studies are critically analysed.

It is our belief that, in the animal laboratory, TLV is a powerful technique for supporting gas exchange and protecting lung integrity of severely ill or lung damaged test objects. The advantages of PLV over other lung recruitment techniques is far less convincing. Whether either technique can save human lives and improve lung morbidity remains to be tested. 
It should be remembered that the first experimental investigation of liquid ventilation was inspired by earlier observations showing that submerged mice, rats, and dogs could survive for prolonged periods breathing a salt solution equilibrated with oxygen at a pressure of 8 atmospheres $(1,2)$. One of the referenced papers was, in my opinion misleadingly, entitled "Of mice as fish". In spontaneously liquid-breathing animals oxygenation was found to be adequate but retention of carbon dioxide occurred and resumption of gas breathing was impossible unless by vigourous resuscitation. Wash-out of surfactant indeed caused a life threatening respiratory distress. Nevertheless, the prospect of preventing "inert"-gas narcosis and decompression sickness "with a self-contained underwater breathing apparatus" was held out.

In 1966, Kylstra and coworkers reported pulmonary gas exchange data in endotracheally intubated dogs ventilated with hyperbarically oxygenated saline (3). Interestingly, the animals' weight was continuously recorded to generate a fluorocarbon liquid "spirogram", allowing control of liquid functional residual capacity and tidal volume. Diffusion limitation during liquid breathing was elegantly demonstrated, explaining the modest elimination of carbon dioxide while adequate arterial oxygenation was obtained. The authors admitted that the technique of liquid ventilation and the reconversion to gas ventilation needed to be improved. One dog delivered nine healthy pups 44 days after the experiment, suggesting that liquid ventilation did not disturb a normal pregnancy!

Whereas saline required hyperbaric treatment to dissolve enough oxygen, Clark and Gollan subsequently demonstrated that mice and cats could survive while breathing an oxygenated fluorocarbon liquid at atmospheric pressure and survive several weeks after being returned to room air (4). As with saline respiration, and in spite of the higher gas solubility of fluorocarbons, carbon dioxide elimination was impaired. The transition to air breathing appeared to be more successful, but some ill defined lung damage was of concern. Further study of lung pathology in the recovery period was undertaken in newborn puppies (5). After respiration of low vapor pressure perfluorocarbons $\left(0.3 \mathrm{~mm} \mathrm{Hg}\right.$ at $\left.77^{\circ} \mathrm{F}\right)$ evaporation of the liquid lasted several months and cellular infiltration by foamy histiocytes took place. In contrast, animals having inhaled high vapor pressure liquid perfluorocarbons $(260 \mathrm{~mm} \mathrm{Hg}$ at $77^{\circ} \mathrm{F}$ ) developed extreme dilatation of the alveolar spaces. In spite of these side-effects at extreme vapor pressures, the assumption that decompression sickness could be prevented by breathing a noncompressible fluid was confirmed in fluorocarbon liquid breathing mice $(6,7)$ and hamsters (8).

By 1970 the first perfluorocarbon liquid ventilation studies were conducted independently by two research groups. Golan and coworkers demonstrated that, in order to inflate an isolated rabbit lung to the same volume, less pressure was needed in the fluorocarbon fluid filled lung when compared to the air filled state (9). A considerable drop in dynamic compliance during liquid breathing was attributed to the increased frictional resistance of the viscous respiratory medium. The high density and viscosity of liquids indeed limit liquid flow in the airways (10, 11). In gravity assisted mechanically ventilated rabbits, inspired, expired and arterial $\mathrm{PO}_{2}$ determinations pointed at a gas diffusion deficit, which was more pronounced for oxygen than for carbon dioxide (9). Modell et al. reported hypercarbic acidosis in dogs that were liquid ventilated for prolonged periods, unless a mechanical volume ventilator was used generating high peak intratracheal pressures, which may have caused mechanical lung damage and 
pulmonary oedema (12). These first perfluorocarbon liquid ventilation studies have initiated a totally new research era in pulmonary physiology and medicine.

Two unfamiliar aspects of liquid ventilation technology are the use of neat perfluorochemicals as carriers of respiratory gases and the physiological properties of a liquidfilled lung.

\section{Perfluorocarbon liquids as respiratory medium}

The aim of lung ventilation is delivery of oxygen $\left(\mathrm{O}_{2}\right)$ to the alveolo-capillary membrane, and elimination of carbon dioxide $\left(\mathrm{CO}_{2}\right)$ from the alveolar periphery. During spontaneous breathing and conventional mechanical ventilation, mass-transfer of respiratory gases through the lung depends on bulk flow as well as on diffusion. In gas ventilation, nitrogen is the inert carrier of $\mathrm{O}_{2}$ and $\mathrm{CO}_{2}$. During liquid ventilation nitrogen has been replaced by a liquid.

\subsection{Physico-chemical properties of perfluorocarbons}

The differences between gas ventilation and liquid ventilation are due to different physical properties of air and the specific liquid used. In table 1 the physico-chemical properties of air, water or saline, and two perfluorocarbons are compared. Perfluorobutyl perfluorotetrahydrofuran or FC-80 is an industrial perfluorocarbon liquid. Perfluoroctylbromide or perflubron (LiquiVent $(8)$ is a highly purified, medical grade PFC liquid. A variety of other PFC liquids is available. If unknown, some of their physical properties can be predicted with acceptable accuracy using a published quantitative structure-activity relationship (13).

\begin{tabular}{lllll}
\hline & air & water & FC-80* & PFOB \\
\hline density $\left(\mathrm{g} / \mathrm{cm}^{3}\right)$ & 0.001117 & 0.99336 & 1.76 & $1.918^{* *}$ \\
viscosity $(\mathrm{g} / \mathrm{sec} \mathrm{cm})$ & 0.0001904 & 0.006947 & 0.0112 & $0.017^{* *}$ \\
surface tension (dynes/cm) & - & 60 & 15 & 18.1 \\
$\alpha_{\mathrm{O} 2}\left(\mathrm{~cm}^{3} / \mathrm{cm}^{3} \mathrm{mmHg}\right)$ & 0.001316 & 0.0000299 & 0.00064 & \\
$\mathrm{O}_{2}$ solubility $(\mathrm{mL} / 100 \mathrm{~mL})$ & - & 3 & 48 & $53 *$ \\
$\alpha_{\mathrm{CO} 2}\left(\mathrm{~cm}^{3} / \mathrm{cm}^{3} \mathrm{mmHg}\right)$ & 0.001316 & 0.000724 & 0.00211 & \\
$\mathrm{CO}_{2} \mathrm{solubility}(\mathrm{mL} / 100 \mathrm{~mL})$ & - & 55.0 & 160 & $210^{* *}$ \\
$\mathrm{D}_{\mathrm{O} 2}\left(\mathrm{~cm}^{2} / \mathrm{sec}\right)$ & 0.178 & 0.0000322 & 0.0000133 & \\
$\mathrm{D}_{\mathrm{CO} 2}\left(\mathrm{~cm}^{2} / \mathrm{sec}\right)$ & 0.139 & 0.0000255 & 0.0000105 & \\
\hline
\end{tabular}

Table 1. Physical properties of air, water, perfluorobutyl perfluorotetrahydrofuran (FC-80) and perfluoroctyl-bromide (PFOB) or perflubron at 1 atmosphere;

${ }^{\prime}=$ properties at $\mathrm{O}^{\circ} \mathrm{C} ;{ }^{\prime \prime}=$ properties at $37^{\circ} \mathrm{C} ;{ }^{\cdots}=$ properties at $25^{\circ} \mathrm{C} ; \alpha$, solubility coefficient; $\mathrm{D}$, diffusion coefficient 
Perfluorocarbons or perfluorinated hetero-hydrocarbons are organic molecules in which all or nearly all carbon-bound hydrogen atoms have been replaced by fluorine atoms. Due to the tight covalent C-F bounds, they are very stable chemically, non-biotransformable and therefore called wrongly "bioinert" or "virtually non-toxic". PFCs are not ozone-depleting. The presence of the bromine atom makes perflubron (perfluoroctyl bromide) radioopaque. Perfluorocarbon liquids are clear, colourless, and odourless oily liquids that are extremely hydrophobic and have a low lipid solubility. In contrast to saline, lavage with PFC liquid does not appear to deplete the lung of surfactant $(12,14,15)$. Almost all perfluorocarbons have a low (and constant) surface tension and spread easily on almost any surface. A high or positive spreading coefficient means that PFCs adhere to the respiratory epithelium more strongly than they cohere to themselves. Note that the low surface tension of around $15 \mathrm{mN} / \mathrm{m}$, is still much higher than the minimal surface tension of natural surfactant (less than $10 \mathrm{mN} / \mathrm{m}$ ). One of the unique properties of perfluorocarbons is their high solubility for respiratory gases, allowing liquid ventilation under normobaric conditions. Their oxygen-carrying capacity (the dissolved gas or gas content) is directly proportional to the partial pressure of the gas according to Henry's law (16). As a respiratory medium, PFC-liquids have two drawbacks. The diffusion coefficient for respiratory gases is low, and, compared to air, liquids have a high density and viscosity, which both increase the resistance to tidal flow. Both convective and diffusive limitations can be overcome by mechanical ventilation at low frequency, increasing the mean residence time of the liquid in the lung. In adult cats, maximum alveolar ventilation and $\mathrm{CO}_{2}$ elimination was predicted at frequencies between 3 and 5 breaths $/ \mathrm{min}$ (17).

\subsection{Biological properties and the use of perfluorocarbons}

\subsubsection{The fate of inhaled perfluorocarbons}

Perfluorocarbon liquids are minimally absorbed across the respiratory epithelium, distributed throughout the body, scavenged by macrophages and eliminated by volatilization through the lungs (and the skin). Uptake, biodistribution and elimination of PFCs have been extensively studied in normal, diseased and immature lungs $(18,19)$. Perfluorocarbon blood uptake during liquid ventilation is depending on vapour pressure, core temperature, permeability coefficient of the lung, PFC solubility in blood lipid, and V' $/ \mathrm{A}$ ' matching. Tissue uptake depends on tissue-blood partition coefficients, tissue blood flow, and tissue compartment volume $(20,21)$. It should be noticed that the concentrations of PFC measured in blood after intravascular administration of PFC emulsions are several orders of magnitude greater than blood or tissue levels after liquid ventilation $\left(0.25\right.$ to $10 \mu \mathrm{g}$ PFC.mL $\left.{ }^{-1}\right)$.

Although PFC liquids are chemically inert and not biotransformable, they do interfere with biological systems.

\subsubsection{Anti-inflammatory properties: direct and indirect cytoprotection}

Both in vitro and in vivo studies have pointed at anti-inflammatory properties of PFC liquids. On the one side, the PFC may act as a physical barrier between lung cells and inflammatory cells or mediators (direct cytoprotection); on the other hand PFC may exert membrane effects by partitioning into phospholipid bilayers (indirect cytoprotection). 
In vitro studies of alveolar macrophages have shown that exposure to perflubron decreases phagocytosis without loss of viability (22), reduces the stimulated production of reactive oxygen species (as measured by superoxide anion, hydrogen peroxide and chemiluminescence) (23) and cytokines (TNF- $\alpha$, IL-1, IL-6, and IL-8) $(24,25)$. Respiratory burst activity of alveolar macrophages (evaluated by flow cytometry) was also found to be markedly decreased after PLV of healthy animals (26).

Alveolar epithelial cells cultured on polycarbonate porous filter increase their interleukin-8 (IL-8) production when stimulated either at the apical or basolateral side with TNF- $\alpha$. IL-8 production by TNF- $\alpha$ added to the lower chamber was not affected by PFC in the upper chamber, but IL-8 release was blocked when PFC was added to the upper chamber immediately after TNF- $\alpha$ stimulation from that site (27).

Exposure of neutrophils in vitro to perfluorocarbons followed by washing did not interfere with their function, but neutrophils exposed to perfluorochemical blood substitutes were markedly inhibited in their chemotactic and phagocytic responses, and in the presence of perflubron, stimulated human peripheral blood neutrophils showed a decreased superoxide anion generation, chemotaxis, adhesion and injury to epithelial monolayers (28-30).

Similar interactions of perfluorohexane with inflammatory cells have been described in an in vitro model. Perfluorohexane decreased the release of proinflammatory cytokines (TNF- $\alpha$, IL-1 $\beta$ ) by mononuclear blood cells and the expression of tissue factor (a procoagulant protein) in ex vivo stimulated phagocytic cells (monocytes and alveolar macrophages). These effects were not due to a direct perfluorohexane cytotoxicity (31).

Neutrophil binding to endothelial cell monolayers can in vitro also be modulated by indirect exposure to perflubron in a two-chambered BIOCOAT system (mimicking the alveolo-capillary membrane). Endothelial cell monolayers indirectly preexposed to perflubron, before proinflammatory activation, exhibited a diminished and slower neutrophil binding, and decreased expression of cell adhesion molecules E-selectin and ICAM-1 (32). The authors acknowledge that this anti-inflammatory (adhesion lowering) effect during the in vivo situation (PLV) will take some time to manifest because of the relative slow rate of perflubron diffusion into endothelial membranes, and moreover, adhesion molecules do not appear to be essential for neutrophil infiltration from the pulmonary vasculature. Finally, perflubron is known to partition into liposomes and the membrane lipid fraction of erythrocytes, and to intercalate and form an interface between the leaflets of a lipid bilayer. These findings point to a nonspecific membrane stabilizing effect. After incubation with $5 \%$ (vol/vol) PFC, platelet aggregation in response to agonist was reduced with increasing liposolubility of the PFC. Incubation of human RBCs with $10 \%$ (vol/vol) PFC, decreased hypotonic haemolysis. This effect was also directly related to the Log of the PFC lipid solubility (33).

During liquid ventilation, it may be difficult to distinguish mechanical protection from anti-inflammatory effects of PFC liquids. Interestingly however, intraperitoneal FC-77 PFCliquid attenuated the neutrophilic infiltration in the lung after hydrochloric acid aspiration and hyperoxia in rats. Both intraperitoneal FC-77 and intravenous Fluosol decreased the lung permeability and improved pulmonary compliance in this injury model (34).

Nesti et al. showed that exposure to perflubron enhanced healing and reduced inflammation of acute full-thickness burns and the gastrointestinal tract in an animal model of ulcerative colitis $(35,36)$. 
The described effects of PFCs on platelet aggregation and neutrophils may cause harmful side-effects. However, safety studies with intravenous perflubron emulsion in healthy volunteers revealed no adverse effects on haemostasis or cellular immune function $(37,38)$.

\subsubsection{Effects on airway mucosa}

Perflubron has no adverse effect on mucociliary clearance, but mucus secretion was increased in the (non-inflamed) isolated ferret trachea (39).

\subsubsection{PFC liquids and infection}

Perfluorocarbons do not promote bacterial growth, and neither in vitro nor in vivo are they bactericidal $(40,41)$. Some have put forward that PLV with perflubron is unlikely to increase the risk, and may in fact decrease the risk of nosocomial pneumonia (41). Others have shown that perflubron does support growth of nosocomial pathogens, such as Pseudomonas aeruginosa and Staphylococcus aureus, and state that PLV will not decrease the risk of nosocomial pneumonia (42).

\subsubsection{The effect of perfluorochemicals on lung mechanics and surfactant function}

The research group of Buffalo (NY) stated that inhaled perfluorocarbons have no known negative effect on phospholipid metabolism or surfactant function (surface tension) and PLV may even enhance surfactant synthesis and secretion (43-45).

More recently Eckmann et al. demonstrated that PFC is present in the liquid lining of the lung seven days after intravenous administration of Fluosol-DA (perfluorodecalin and perfluorotripropylamine) or Oxygent (perfluoroctyl-bromide) emulsion. Surface tensionsurface area relationship of lung lavage fluid was measured in a Wilhelmy balance system. Loop hysteresis area was greater after Fluosol, but not after Oxygent, than after saline. Loop hysteresis slope was higher after Oxygent than after saline or Fluosol (46). In a companion paper lung mechanics were investigated. After Fluosol administration FRC was greater, vital capacity lower, and lung compliance lower than after Oxygent or saline (47). Thus, the presence of PFC in the lung surface lining layer does modify surfactant dynamic mechanical behaviour. This concept was recently confirmed and further investigated by Schürg et al. using a modified captive bubble surfactometer. Vapor pressure and spreadability of the PFC seem to be important in determining the minimal surface tension during the PLV situation (48).

\subsection{Other biomedical applications of PFC liquids}

Besides the use in liquid ventilation, several other biomedical applications of perfluorochemicals are under (clinical) investigation (49). They will not be discussed in detail: emulsions for blood substitute and pump-priming fluids for cardiopulmonary bypass (50), vitreous fluid replacement (ophthalmologic tools) $(51,52)$, diagnostic imaging agents (bronchography, ultrasound contrast agent, ....), organ perfusates for organ preservation, diagnostic $(53)$ and therapeutic $(54,55)$ bronchoalveolar lavage, prevention of ischemia/reperfusion mucosal injury during mesenteric ischemia (by a continuous 
intraluminal flow of oxygenated perflubron (Imagent GI) (56), liquid-based airway distention $(57,58)$, cell culture media supplements, etc. Pulmonary administration of drugs (PAD) by liquid ventilation has been described for gentamicin (59); $(60)$, vasoactive drugs such as priscoline (61), geneproducts (62) and halothane (63). Finally, liquid ventilation has been used for induction of hypothermia (64-66) and rapid cardiopulmonary rewarming (67).

\section{The liquid-filled lung}

Replacing the respiratory gas carrier nitrogen by a liquid has consequences for both pulmonary mechanics and perfusion.

\section{Pulmonary compliance}

In a land-mark study, von Neergaard et al. demonstrated that less pressure was needed to inflate a lung with a gum arabic-saline solution than with air (68). It was hypothesized, as predicted by the LaPlace's law, that the surface component of the lung's recoil pressure, e.g. the surface tension at the air-lung interface, was eliminated by liquid filling (69).

Also in the PFC-liquid-filled lung the gas-lung interface is replaced by a liquid-lung interface, lowering the lung recoil pressure and increasing the collapse volume $(9,70,71)$. The lung mechanics during TLV have been extensively investigated in a preterm excised lamb lung model of surfactant deficiency by Tarczy-Hornoch et al. Comparing surfactant deficient lungs, surfactant repleted lungs, PFC-filled surfactant deficient lungs, and PFC-filled lungs pretreated with surfactant, they noticed an increasingly reduction of transpulmonary pressures on inflation, and, by inference, a decreasing sequence of interfacial tension. Surfactant improved deflation stability in both gas and liquid ventilation (71).

The lung mechanics during gas ventilation of the liquid containing lung (PLV situation) were studied in similar in vitro experiments (72). In both the surfactant deficient and the surfactant repleted situation, compliance was worse than during TLV, but more favourable than during gas ventilation. Indeed different surface active forces are playing a role in the three situations: a summation of gas-lung and gas-PFC interfacial tension during PLV, PFClung interfacial tension during TLV, and gas-lung interfacial tension during gas ventilation. Surfactant offers additional mechanical benefit to both PLV and TLV since surfactant reduces both gas-lung interfacial tension and PFC-lung interfacial tension. It was estimated that, in the PLV condition, PFC is present in a droplet/lens configuration at low lung volumes. As lung volume and/or lung surface tension rises, the PFC is pulled into a lens shape until the PFC spreads out into a film covering the alveolar surface.

\section{Lung perfusion and ventilation}

Another interesting difference between the gas-filled and the liquid filled lung is the topographical distribution of ventilation and perfusion. The blood flow decreases from the bottom (dependent) to the top (non-dependent) of the upright air-filled lung. An almost evenly distributed blood flow was demonstrated by West et al. in saline-filled isolated dog lungs. It was assumed that the hydrostatic pressure difference in the blood vessels was balanced by corresponding pressures in the airways. The vertical distribution of ventilation was also approximately uniform in the saline-filled lung (73). However, both ventilation (73) and blood 
flow (74) show proximal to peripheral stratification along the terminal gas exchanging regions of the liquid filled lung.

Using radioactive microspheres in an in situ perfused gas- or fluorocarbon-filled lung preparation, but also in vivo, Shaffer and coworkers confirmed that PFC-liquid ventilation decreases dependent and increases non-dependent pulmonary blood flow, in this manner distributing pulmonary blood flow more uniformly throughout the lung $(75,76)$.

\section{Lung diseases and pathology that might benefit from liquid-assisted ventilation}

Although liquid ventilation got its first impetus from the potential use during diving and acceleration (aviation), the main field of application is nowadays the support of gas exchange in the diseased or injured lung. These clinical entities will be briefly reviewed, calling special attention to the pathophysiology and the "conventional" treatment modalities.

\subsection{Neonatal respiratory distress syndrome}

The physiopathology of neonatal respiratory distress syndrome (nRDS) is complex, combining structural lung immaturity, atelectasis due to surfactant deficiency (77), decreased lung fluid reabsorption (78), lung inflammation with pulmonary oedema (loss of intravascular proteins into the lung interstitium and alveoli or transvascular leak of albumin) $(79,80)$, and elevation of the pulmonary vascular resistance $(81,82)$. Prenatal glucocorticoid treatment of women at risk for preterm delivery decrease the risk and severity of respiratory distress syndrome $(83,84)$. Several meta-analyses from The Cochrane Neonatal Collaborative Review Group have demonstrated the short- and long-term benefits of intratracheal administration of surfactant for the treatment and prevention of neonatal RDS. Prophylaxis yielded better outcomes than rescue treatment (85-91).

Recent studies have also indicated that volutrauma compromises the effect of subsequent surfactant therapy (92-94). On the other hand, positive end-expiratory pressure optimises the response to surfactant and preserves the biophysically active large-aggregate surfactant pool (95).

Inhaled nitric oxide in an ovine model of hyaline membrane disease effectively reduced pulmonary vascular resistance and improved oxygenation $(82,96)$. In (severely hypoxemic) preterm infants nitric oxide inhalation appeared to be safe, but, apart from some improvement in arterial oxygenation, no benefit was demonstrated $(97,98)$.

Various ventilatory techniques have been proposed as an alternative to CMV in an effort to improve gas exchange efficacy and reduce ventilation induced lung injury during neonatal RDS.

The use of high frequency ventilation, primarily high frequency oscillatory ventilation is supported by extensive research in the preterm baboon model (99-110). In this model, HFOV was found to improve gas exchange and diminish the pathological findings of small airway overdistention, atelectasis, oedema, hyaline membranes, and pulmonary interstitial emphysema, but bronchoalveolar haemorrhages were increased when compared to CMV. Lately, Yoder et al. compared the prolonged use of HFOV with low tidal volume positive pressure ventilation in antenatally steroid-treated, surfactant-treated immature baboons. HFOV was associated with sustained improved respiratory mechanics and lung histology, although enhanced alveolarization was not observed (111). A meta-analysis of randomized 
controlled trials of elective HFOV, using the high volume strategy, versus conventional mechanical ventilation (CMV) in preterm infants $<36$ weeks' gestation showed benefit in survival, and chronic lung disease (112). Hypocapnia during the first days of life in babies on CMV for $\mathrm{nRDS}$ was associated with an increased incidence of bronchopulmonary dysplasia $(113,114)$. However, a recent randomized trial did not demonstrate a lower incidence of BPD with "gentle ventilation" allowing mild hypercapnia $\left(\mathrm{Pa}_{\mathrm{a}} \mathrm{CO}_{2}\right.$ 6-7.3 $\left.\mathrm{kPa}\right)(115)$.

Other ventilatory support techniques such as intratracheal pulmonary ventilation (ITP) (synonym: continuous tracheal gas insufflation or CTGI) and proportional assist ventilation (PAV) are under investigation $(116,117)$. A recent prospective randomized trial in preterm babies of $<30$ weeks gestational age, suffering from HMD, confirmed that CTGI can decrease peak inflation pressures. Moreover the CTGI group needed less inotropic drugs and the duration of mechanical ventilation was shorter. However, no significant reduction in chronic lung disease was noticed in this study with small sample size (118).

\subsection{Acute respiratory distress syndrome}

Independently of the underlying etiology or pathophysiology, acute respiratory distress syndrome (ARDS) is defined as an acute onset respiratory failure $\left(\mathrm{Pa}_{\mathrm{a}} \mathrm{O} / \mathrm{Fl}, \mathrm{O}_{2} \leq 200\right.$ torr $)$, occurring in the absence of clinical evidence of cardiogenic pulmonary oedema, and characterised by bilateral infiltrates on frontal chest radiograph (119). In addition, some clinical studies require a lung injury score according to Murray and coworkers of $\geq 2.5$ (120). This descriptive clinical definition has recently been criticized since it is too broad and insufficiently specific to account for the patient heterogeneity (121). The causes of ARDS are classified as direct (aspiration, diffuse pulmonary infection, near-drowning, toxic inhalation or lung contusion) or indirect lung injury (sepsis syndrome, severe nonthoracic trauma, hypertransfusion, cardiopulmonary bypass) (119).

Mechanical ventilation can contribute considerably to the progression of this disease characterised by an inhomogeneous ventilated lung with collapsed dependent lung areas and small aerated lung volume ("baby lung model"). High shear forces caused by end-inspiratory stretch due to high peak inspiratory pressure or high tidal volume (barotrauma and volutrauma), but also repetitive opening of collapsed lung units (atelectrauma) may mechanically disrupt epithelium and endothelium eventually causing release of inflammatory mediators, lung inflammation, and systemic inflammatory response (biotrauma) (122).

Based on these pathophysiological insights, lung protective ventilatory strategies have been proposed and tested in animal models and clinical studies (123-129).

A new ventilatory strategy consisting of tidal ventilation between the lower and upper inflection point on the pressure-volume curve of the respiratory system, avoiding both recruitment/derecruitment of collapsed alveoli and pulmonary overstretching, is now favoured (129). Promoting and maintaining of alveolar recruitment by PEEP is combined with low tidal volumes.

Five randomized trials, evaluating (somewhat different) lung protective strategies in ALI or (high risk for) ARDS have been published. Three did not detect a difference in mortality $(130-132)$, whereas two did $(133,134)$. A lung-protective ventilatory strategy tailored with a volume-pressure curve was able to attenuate the cytokine response (both BALF and serum) in ARDS patients (135). The ventilatory strategy used in the large ARDS network study 
(enrolling 861 patients) will likely become the gold standard against which future ventilation strategies have to be tested.

Several other modes of ventilation or therapeutic adjuvants have shown promising results in the animal laboratory or in clinical series: intratracheal pulmonary ventilation (ITPV) (136), proportional assist ventilation (PAV) (137), prone positioning (improving ventilationperfusion matching) (138), inhaled nitric oxide (iNO) (139), high-frequency ventilation (140, $141)$, and exogenous surfactant (142-145). Although some of these therapies may prove efficacious in selected patients and avoid extracorporeal life support $(146,147)$, none of them affected clinical outcome during prospective trials in adults (148). The improved outcome of HFOV in the pediatric RCT, (lower proportion of patients requiring supplemental oxygenation at 30 days) has to be confirmed; the relevance is questionable. Recent animal research suggests that, on condition that lung volume is recruited and maintained, CMV and HFOV are equally effective and protective in lung lavage-induced ARDS (149-152). However, Rotta et al. found CMV (PEEP $10 \mathrm{~cm} \mathrm{H}_{2} \mathrm{O}$ and $\mathrm{V}_{\mathrm{T}} 10 \mathrm{~mL} \cdot \mathrm{kg}^{-1}$ ) not as effective as HFOV in preserving oxygenation and lung compliance $(153,154)$.

Various animal models of ARDS are used to evaluate therapeutic strategies: the surfactant washout model, oleic acid injury, gastric acid aspiration, endotoxaemia and reperfusion injury. One should be aware of the pathophysiological differences of these models and the dissimilarities with human pathology (155).

\subsection{Meconium aspiration syndrome}

Neonatal meconium aspiration syndrome (MAS) has been defined as respiratory distress in an infant born through meconium stained amniotic fluid whose symptoms cannot be otherwise explained (156). Various factors are involved in the pathophysiology of MAS: mechanical obstruction of the airways, pulmonary inflammatory response or chemical pneumonitis, inhibition of surfactant function, and pulmonary vasoconstriction. In the established clinical picture requiring mechanical ventilation several new supplementary techniques have been proposed and tested. In animal models of MAS some investigators have demonstrated effectiveness of surfactant treatment (157-161) but others found no improvement (162). The use of boluses of exogenous surfactant in infants with MAS is supported by the reduction in the need for ECMO found in two randomized trials $(163,164)$. In order to prevent the need for ECMO, the number needed to treat was 6 and 4 respectively. Nevertheless, one authority argues that surfactant therapy for MAS has yet to be subjected to rigorous investigation, and most investigators have stressed the need for further clinical trials $(156,165)$. Several animal studies $(158,166-168)$, and one human pilot study (169) indicate that surfactant lung lavage with or without a subsequent surfactant bolus is a promising mode of treatment. After meconium instillation in piglets, the technique of intratracheal pulmonary ventilation (ITPV) allows effective oxygenation and ventilation at lower mean airway pressures, lower peak inspiratory pressures, and with less lung injury than conventional ventilation (170). Finally, adding polymers such as polyethylene glycol (PEG) to surfactant prevents or reverses surfactant inactivation. In preliminary experiments with meconium injury in adult rats, treatment with PEG/beractant (a modified bovine surfactant extract) $\left(50 \mathrm{mg}^{-\mathrm{kg}^{-1}}\right)$ improved oxygenation and pressure-volume curves more than treatment with beractant (Survanta 8$)(50$ or $100 \mathrm{mg} \cdot \mathrm{kg}^{-1}$ ) alone (171). 
The use of high-frequency ventilation in MAS is supported by some animal studies (172$174)$ but found ineffective in others $(162,175)$. In newborns with severe PPHN due to MAS, a significantly higher percentage babies supported by HFOV responded to iNO when compared to iNO plus conventional ventilation (176). A better alveolar recruitment during HFOV was supposed. On the contrary, The Neonatal Inhaled Nitric Oxide Study Group (NINOS) found improved oxygenation in MAS infants on CMV with iNO, but more importantly, there was no significant difference in mortality or the need for ECMO (177).

Finally, the animal model of meconium instillation has been criticized as a model for human MAS (178). Indeed, in the neonatal baboon, meconium instillation with or without acute perinatal asphyxia, did not elicited persistent pulmonary hypertension and abnormal pulmonary arteriolar muscularization as seen in severe human MAS.

\subsection{Congenital diaphragmatic hernia}

In congenital diaphragmatic hernia $(\mathrm{CDH})$ an incomplete closure of the diaphragm is associated with a primary or secondary disturbance of lung growth and maturation. Structural parenchymal abnormalities at the level of the airways, alveoli, and pneumocytes are associated with functional abnormalities of the surfactant and antioxidant enzyme system (179). The structural development and vasoreactivity of the pulmonary vasculature are abnormal as well (180). The postnatal management of the respiratory insufficiency due to pulmonary hypoplasia and persistent pulmonary hypertension of the newborn is challenging.

In the surgically created lamb model of $\mathrm{CDH}$, prophylactic (but not rescue) surfactant replacement therapy improved lung compliance and gas exchange for at least 4 hours (181, 182). Moreover, Karamanoukian et al. have shown that prophylactic surfactant therapy is needed for iNO to be effective. (183). Lately, Schnitzer et al. demonstrated an improved $\mathrm{CO}_{2}$ elimination obtained without increasing airway pressures, when using the technique of intratracheal pulmonary ventilation in this lamb CDH model (184). Two human cases have also been reported (185) and clinical trials are underway.

In babies with $\mathrm{CDH}$, a gentle ventilation strategy, with permissive hypercarbia, seems to improve survival and decrease the need for ECMO (186-188). Others favour high frequency ventilation for preoperative stabilization (189-192). In term and near-term infants with congenital diaphragmatic hernia, a randomized, double-masked, controlled multicenter study could not demonstrate a significant benefit of inhaled nitric oxide (iNO): oxygenation did not improve and there was no reduction in the occurrence of death and/or the initiation of extracorporeal membrane oxygenation (ECMO) (193). In another multicenter study investigating iNO and HFOV in severe PPHN, the combination of HFOV with iNO was not more efficient (expressed as the \% of patients responding to the treatment) than either treatment alone in $\mathrm{CDH}$ babies (176). Finer et al. recently underscored that the different treatment aspects (ventilation mode, surfactant therapy, and pulmonary vasodilation) and their combinations still need prospective evaluation in the newborn with $\mathrm{CDH}$ (194). 


\subsection{The technique of tidal liquid ventilation}

A variety of mechanical ventilators with increasing complexity has been used over the years in TLV research. The components of a typical TLV system are a (closed) circuit incorporating a liquid reservoir, a pump or pumps, a gas exchanger, a heater, a liquid regenerator, valves to limit and direct the liquid flow, and a control system (195). Gravity (3, $9,196)$, positive and negative pressure generated over the entire body surface by a waterimmersion respirator (197), diaphragm or bellows pumps $(198,199)$, roller pump(s) $(200)$, or a dual piston pump $(64,195,201,202)$ have been used as driving force. Some systems have combined mechanically assisted inspiration with gravity assisted expiration (203-206). However, gravity dependent expiration was found to be an important risk factor for fluorothorax $(204,207)$. Interesting innovations have been the introduction of the stop-flow technique for intermittent measurement of alveolar pressures (208), and the estimation of FRC and tidal volume by continuous measuring the weight of the liquid reservoir in stead of the animal (209). Spray bubblers and membrane oxygenators have been characterized as gas exchangers, and condenser technology has been assessed (210). In 1983, Harris described a digital control system which automatically actuated inspired- and expired-line solenoid valves, depending on the signal from a force platform supporting the ventilated animal. Computer-assisted lung mechanics analysis is becoming an integral part of tidal liquid ventilators $(201,211)$. Recently, Heckman et al. reported on computer software designed to operate a tidal liquid ventilator (212). The operator can measure alveolar pressures and determine the PFC-flow waveform. Control algorithms maintain lung volumes and/or airway pressures within ranges set by the operator. Although determination of lung volumes by weighing the animal or the liquid reservoir is a unique opportunity during TLV, we were concerned about confounders. Therefore we introduced the idea of measuring breath-bybreath end-expiratory occlusion pressures as a representative input signal for a closed-loop system controlling liquid balance during TLV. This system can guarantee an acceptable steady state stability and successful compensation for transient disturbances in liquid balance (213).

Some other technical aspects of TLV have been addressed in the literature as well. It was verified that the resistance of (neonatal) endotracheal tubes to liquid flow is not only depending on internal diameter but also on liquid flow, density, and viscosity $(214,215)$. The pressure-flow characteristics of airway access devices depend on their geometry and can be described in one number, the M-number, which can be determined from experimentally obtained pressure-flow data. There is also a known relationship between M-number, fluid viscosity, fluid density, pressure drop and flow. Therefore, if M-number of the device and fluid's viscosity and density are known, one can predict the relationship between flow and pressure drop (216).

\subsection{Feasibility and other descriptive animal studies on tidal liquid ventilation}

In order to assess feasibility and toxicity, tidal liquid ventilation was first tested in normal animals. Then the applicability in disease models was evaluated. 


\subsubsection{Adult (and neonatal) animals with normal lungs}

Since the early 1970s, PFC liquid ventilation has been studied in adult animals. Unpurified, industrial liquids were used. Adequate gas exchange was supported for up to 8 hours (196). After resumption to gas ventilation transient and short lasting disturbances in respiratory mechanics $(\leq 72 \mathrm{hrs}-1 \mathrm{wk})(199,217-219)$, gas exchange $(196,217)$ and haematologybiochemistry $(\leq 1 \mathrm{wk})(220,221)$ have been observed. Histologic studies showed acute inflammation three hours after liquid ventilation, followed by a macrophagic response which was most prominent at 72 hours. A return to normal was apparent at ten days (217). Trace amounts of PFC were detected by chromatography in all tissues studied for at least 5 years. The highest levels were found in the lungs and regional lymph nodes. No histologic evidence of the presence of PFC was seen except for local accumulation of vacuolated macrophages in the lung and regional lymphnodes. These morphological signs of residual PFC had disappeared in two dogs 10 years after liquid ventilation (222). Calderwood et al. stated that the presence of perfluorochemical did not cause any obvious structural or functional damage $(220,221)$.

Recent comparative studies in adult cats $(209,223)$ confirmed the feasibility and efficacy of PFC liquid ventilation in the normal lung. A lower arterial oxygen tension $\left(\mathrm{Pa}_{\mathrm{a}} \mathrm{O}_{2}\right)$ during PFC liquid ventilation was noticed but this finding was expected because of the relative reduced inspired partial pressure of oxygen in PFC liquid. Other parameters such as $\mathrm{O}_{2}$ delivery, $\mathrm{CO}_{2}$ elimination, respiratory quotient, arterial carbon dioxide tension $\left(\mathrm{Pa}_{\mathrm{a}} \mathrm{CO}_{2}\right), \mathrm{pH}$, heart rate or mean systemic blood pressure were not different.

Full-term neonatal lambs were tidal liquid ventilated up to 24 hours. Adequate gas exchange was present throughout the study period and no microscopic evidence of barotrauma was present (19). The same authors demonstrated that newborn lambs can be safely returned from TLV to PLV and spontaneous gas breathing (224).

An electron microscopic study published in abstract form (225) concluded that the ultrastructure of the newborn rabbit lung remains unimpaired after one hour of perfluorocarbon liquid ventilation. But the text also mentioned that: "Closer examination of the various cell types revealed evidence of pinocytotic vesicles along the borders of alveolar type I as well as endothelial cells."

Adequate gas exchange was also achieved in premature and term newborn monkeys. Two of those near term baboons, who were liquid ventilated from birth for 3 hours, were followedup. Sequential neurodevelopmental and pulmonary testing through 11 months of age have shown no abnormalities. Functional residual capacity (FRC) and total lung capacity were normal. Chest radiography showed persistence of scattered densities, compatible with interstitial radiodense PFC. Lung and other organ histology was normal (205).

In a recent report Wolfson et al. showed that effective gas exchange during TLV was possible in sheep despite a wide range of ages, body weights and thoracic dimensions: from preterm ( $70 \%$ of term) to adult (4-6 years), 0.5 to $36 \mathrm{~kg}$, and anterior-posterior thoracic diameters of 21 to $64 \mathrm{~cm}$. Therefore the technique should be suitable to support human patients from adults to preterm babies (226). 
Early pioneering studies in immature minipigs and rabbits revealed an improved survival and oxygenation when liquid ventilation was compared to gas ventilation $(227,228)$. Subsequently, PFC liquid ventilation was shown to be feasible and effective in ever younger, premature lambs with established respiratory distress syndrome: Shaffer and coworkers demonstrated adequate gas exchange (229-231) and evidence of improved compliance (229, 231). Pulmonary gas exchange, acid-base status, and cardiovascular stability were supported even in very preterm lambs, as young as 102 days gestational age (200). Adequate gas exchange and circulatory stability could be obtained in preterm lambs (gestational age 132 days) while on tidal liquid ventilation for periods up to 72 hours (232).

\subsubsection{Acute respiratory distress syndrome}

In 1994, Hirschl and coworkers used for the first time TLV in young sheep requiring ECLS because of severe lung injury induced by oleic acid injection followed by saline pulmonary lavage. Animals treated with full tidal liquid ventilation were compared with animals receiving standard ECMO "lung rest" gas ventilation ( $\mathrm{PIP}=20 \mathrm{~cm} \mathrm{H}_{2} \mathrm{O}$; PEEP $=4 \mathrm{~cm} \mathrm{H}_{2} \mathrm{O}$; 10 breaths per minute). After 3 hours of TLV sheep demonstrated lower pulmonary shunt and higher pulmonary compliance. The ECMO flow required to maintain a target $P_{\mathrm{a}, \mathrm{O}_{2}}$ was lower (233). This improvement in oxygenation and pulmonary compliance resulting from TLV during ECLS was confirmed in two other reports using the same severe animal model of ARDS. $(209,234)$. It was hypothesized that by improving lung function on ECLS, TLV may shorten the ECMO run, possibly resulting in decreased morbidity and costs (233).

\subsubsection{Meconium aspiration}

In meconium distressed lambs, liquid ventilation increased oxygenation, ventilation was adequate, and because of the increased dynamic lung compliance, peak tracheal as well as peak alveolar pressures were significantly reduced. Additionally, a more uniform distribution of pulmonary blood flow during liquid ventilation was demonstrated (76). In severe meconium aspiration lung injury, necessitating ECLS, TLV improved oxygenation, $\mathrm{CO}_{2}$ removal and pulmonary compliance when compared to pretreatment values or compared to "lung rest" gas ventilation. Meconium plugs were removed by tidal flow of PFC liquid (235).

\subsection{Comparative animal studies}

The efficacy of TLV has been studied in animal models of neonatal RDS (appendix 1), acute RDS (appendix 2), and meconium aspiration syndrome (appendix 3 ).

\subsubsection{Neonatal respiratory distress syndrome}

The first study comparing TLV with CMV in naturally occurring hyaline membrane disease dates from 1973-1974. Immature mini-pigs, born after 95 and 100 days' gestation (full term is 112 days), maintained adequate gas exchange for 210 minutes supported by a liquid ventilator operating on the principle of the iron lung. In contrast: "Gaseous $\mathrm{O}_{2}$ ventilation at 
95 days was nearly impossible, with $75 \%$ of the animals dying within 15 minutes. At 100 days it was possible to maintain animals for about 90 minutes but with great difficulty"(227, 236).

Schwieler and Robertson studied artificial ventilation in surfactant deficient, immature newborn rabbits (27.5-27.75 days; full term $31 \pm 1$ days). Oxygenation, as revealed by skin colour and ECG, appeared to be better in liquid ventilated animals when compared to gas ventilated littermates. Histologic examination of the lungs (at end-expiration) after liquid ventilation showed less necrosis and desquamation of the bronchiolar epithelium and less hyaline membranes in the preterminal airspaces. Bronchioles and alveolar ducts were usually dilated (228).

More recently, Wolfson et al. studied the preterm lamb model of respiratory distress syndrome in a (randomized) controlled fashion (237). Liquid ventilated animals demonstrated consistently better oxygenation and $\mathrm{CO}_{2}$ removal despite lower airway pressures. Respiratory compliance was higher during liquid ventilation compared to gas ventilation. Liquid ventilation seemed to minimize pulmonary barotrauma. In contrast to atelectasis, proteinaceous exudate, haemorrhage, and hyaline membranes seen after gas ventilation, liquid ventilated lungs showed homogeneously expanded alveoli, clear of exudate, haemorrhage, or hyaline membranes, and bordered by thinner walls. Morphometry revealed a larger area of gas exchange. In a more recent study, biochemical evidence was added to the concept of minimized pulmonary barotrauma. Urinary excretion of desmosine, an index of proteolytic destruction of lung elastin, was reduced during TLV (238). Apoptosis does not nearly occur in fetal sheep lungs. The ventilatory strategy used in animals suffering from neonatal RDS seems to define the pattern of apoptosis in the lung. In preterm lambs treated with CMV apoptotic cells were mainly localized within the lumen, whereas in TLV animals apoptotic cells were observed in the epithelial cells lining the airspaces $(239,240)$. In the desmosine and apoptosis studies, only available in abstract form, no details on CMV settings are given, and no surfactant was administered.

All previously mentioned studies were prophylactic in nature. As a rescue therapy too, TLV was superior to CMV in surfactant treated preterm lambs (241). Our recent study comparing TLV, CMV, and HFOV was undertaken to evaluate efficacy, protective properties, and possible side-effects of these three ventilatory strategies applied from birth in surfactant treated preterm lambs. Despite the higher PEEP levels used in CMV, and the aggressive recruitment strategy in HFOV animals, TLV was superior to both gas ventilation strategies with respect to gas exchange and lung injury score. TLV was characterized by a more homogeneous ventilation of the lung (242).

\subsubsection{Acute respiratory distress syndrome}

The first report on the use of TLV in saline lavage-induced lung injury came from the group of Adolfo Valls-i-Soler. Rats made respiratory insufficient by repeated bronchoalveolar saline lavage were randomised to receive either CMV or TLV; for comparison, a group of healthy rats was liquid ventilated as well. In the diseased animals, oxygenation was improved significantly during TLV when compared to CMV, and approximated oxygenation in healthy liquid ventilated animals (243).

Mazzoni and coworkers also compared TLV with CMV in swine (15-20 kg) after inducing respiratory failure by successive saline lung lavages. Despite of lower peak airway and 
alveolar pressures, TLV-treated animals had significantly higher $\mathrm{Pa}_{\mathrm{a}} \mathrm{O}_{2}$ and $\operatorname{similar} \mathrm{Pa}_{\mathrm{a}} \mathrm{CO}_{2}$ levels (244).

In an oleic acid and saline lung lavage sheep model requiring ECLS, Hirschl et al (245) compared gas ventilation with liquid ventilation. During 2.5 hours of either therapy, lung mechanics and gas exchange were significantly better in TLV animals. After discontinuation of ECLS, all gas ventilated animals died, whereas all TLV animals demonstrated effective gas exchange. Lung biopsies after liquid ventilation showed a marked reduction in alveolar haemorrhage, lung fluid accumulation, and inflammatory infiltration. In another paper, using the same lung injury model, physiological and histological data after one hour of gas and liquid ventilation were compared. Liquid ventilation significantly improved $P_{a}, O_{2}$, mixed venous oxygen saturation, lung compliance and physiologic shunt fraction. Postmortem computer tomography attenuation studies showed non homogeneous distribution of gas and homogeneous distribution of perflubron. Histologic lung injury was reduced after liquid ventilation when compared to gas ventilation (246).

Meinhardt et al. reported in abstract form a comparative study of TLV versus CMV in rabbits subjected to oleic acid lung injury. There were no significant differences between the groups with respect to arterial blood gases, mean arterial and central venous pressure, but the difference between peak inspiratory minus end-expiratory pressure was lower during TLV (247).

At the ATS International Conference in May 2000, Wolfson et al. presented a multicenter randomized controlled trial comparing TLV and CMV in oleic acid injured adult sheep. The control animals were ventilated according to the high PEEP, low tidal volume concept. During and after a four hours lasting treatment period, TLV performed better in all cardiopulmonary and histomorphological parameters studied: $\mathrm{Pa}_{\mathrm{a}} \mathrm{O}_{2}, \mathrm{~Sv}_{\mathrm{O}} \mathrm{O}_{2}$, cardiac output, stroke volume, $\mathrm{DO}_{2}$, compliance, oxygen consumption, and ventilatory efficiency index, minute ventilation, physiologic shunt (Qps/Qt), and lactate, alveolar area, \% gas exchange space, and expansion index, \% parenchymal space and composite total lung injury score (TLI) (248).

\subsubsection{Meconium aspiration syndrome}

A first comparative study of meconium instillation injury in rats, demonstrated improved oxygenation and mean arterial blood pressure after 1 and 2 hours in liquid ventilated rats as compared to gas ventilated controls. After 2 hours the mortality in both groups was 3/7 (249).

In subsequent research, newborn lambs, made respiratory insufficient by endotracheal instillation of $25 \%$ meconium solution, were randomized to four therapeutic strategies: exogenous surfactant, PLV, TLV, or control CMV. Each treatment improved oxygenation, with none being superior to another. TLV improved dynamic compliance more than surfactant or PLV, and on lung histology, the protective effect of TLV was most pronounced (250).

\subsection{Human experience}

The first human trial of PFC liquid ventilation (251-253) was limited in design and demonstrated mainly some improvement in pulmonary function after return to gas ventilation. The procedure of liquid ventilation was said to be well tolerated. Obduction findings in four liquid ventilated infants were compared to randomized sections. Following liquid ventilation, 
lung expansion indices were greater, and liver, spleen, kidney and thymus were histologically indistinguishable from conventionally ventilated infants (254).

\subsection{Practical guidelines for tidal liquid ventilation}

Gas ventilator settings and adjustments aim at optimizing gas exchange while at the same time lung injury and circulatory compromise should be avoided. Only a few data are available with relation to the mechanical properties of the liquid filled lung and the ventilator settings during TLV.

Koen et al. quantified the maximum expiratory flow and the diffusion dead space in cats during FC-80 tidal liquid ventilation. Under these circumstances the theoretically predicted maximal alveolar ventilation and $\mathrm{CO}_{2}$ elimination would occur at a breathing frequency of 3 to $5 \mathrm{~min}^{-1}(17)$. The effect of respirator settings on arterial blood gases was recently evaluated by Parker and coworkers (255). Increased oxygenation and ventilation occurred under the following circumstances: increasing respiratory rate from 4 to $6 \mathrm{~min}^{-1}$, increasing $\mathrm{V}_{\mathrm{T}}$ from 10 to $20 \mathrm{~mL} \cdot \mathrm{kg}^{-1}$, and addition of $95 \mathrm{~mL} \cdot \mathrm{min}^{-1}$ of isovolumetric bias flow. $\mathrm{Pa}_{\mathrm{a}} \mathrm{CO}_{2}$ and $\mathrm{Pa}_{\mathrm{a}} \mathrm{O}_{2}$ both decreased when expiratory to inspiratory ratio decreased from 2.0 to 0.5 .

The optimum liquid FRC has not been clearly defined. The group of Shaffer closely monitors respiratory system mechanics to adjust liquid ventilator settings, but no detailed description of their ventilatory strategy is given. We have used an end-expiratory alveolar pressure of zero or slightly above zero at the level of the highest situated alveoli (242). In a recent abstract, Wolfson et al. compared 3 levels of PEEP during TLV: 4, 8, and $12 \mathrm{~cm} \mathrm{H}_{2} \mathrm{O}$. The lowest PEEP was associated with significantly higher arterial oxygenation, systemic bloodflow and oxygen delivery, as well as a lower PVR/SVR ratio (256).

\subsection{Haemodynamics during TLV}

Earlier liquid ventilation studies have noted an increase in pulmonary vascular resistance (PVR) with a decrease in cardiac index of approximately $40 \%$, resulting in lactic acidosis (75, 257-259). Compression of the great veins and heart (decreased preload) and the aorta (increased afterload) by the heavy PFC-filled lungs has also been proposed as the explanation for the decreased cardiac output. Haemodynamic compromise can however be prevented or corrected by good hydration and careful intravascular volume expansion (260). In a comparative study, CMV versus TLV, Mazzoni et al. found no differences in systemic arterial pressure, but a decreased cardiac output during TLV. She proposed overfilling of the lungs as an alternative explanation (244). Most recent studies have reported no impact on cardiovascular stability or even an improvement of circulatory function during TLV (248).

Several authors have mentioned phasic increases and decreases of systemic and pulmonary arterial blood pressure during TLV. Mechanical interference with venous return and afterload were suggested. We have quantified and compared respiration-synchronous fluctuations in haemodynamic variables during gas ventilation, PLV, and TLV. TLV was associated with an increased within breath variability of left ventricular stroke volume, systemic blood pressure, and systemic perfusion pressure (206). The candidate explanatory mechanisms are (an interplay of) decreased systemic venous return (right ventricular preload), changes in afterload, increased ventricular interdependence, and longer inspiratory times associated with liquid inspiration compared to gas inspiration. 
In a recently published abstract, Meinhardt et al. compared haemodynamic parameters between inspiration and expiration in health rabbits randomized to either CMV or TLV. In neither ventilatory strategy was there a difference between inspiratory or expiratory cardiac output, PAP, CVP, or LAP. It was not stated whether right or left sided cardiac was measured. During TLV systemic arterial pressure was lower during expiration (261).

5.7. Tidal liquid ventilation: action mechanism in the diseased lung (how it improves gas exchange and protects the lungs)

The basic research into the favourable effects on gas exchange and lung protection of TLV is limited. It is generally thought that the $\mathrm{V}$ ' $\mathrm{A} / \mathrm{Q}$ ' distribution is improved due to more homogeneous distribution of ventilation $(73,246,262)$ and blood flow $(73,75,76)$ in a liquid ventilated (diseased) lung. Since PFC liquid reduces the interfacial tension in the lung $(9,70$, $71)$, FRC is easily reestablished (263) and alveolar pressures lowered $(76,208,244)$. Mobilisation of alveolar exudate, secretions or inhaled meconium may be another beneficial effect of TLV (76). A tamponade effect has been suggested and as with PLV the antiinflammatory properties of PFC liquids may act.

From the cited animal studies, it is indisputable that TLV was superior to every tested control strategy including optimized CMV, HFOV, and PLV.

\section{Partial liquid ventilation}

\subsection{The historical origins of partial liquid ventilation}

Already in 1974 Rüfer investigated the transition from liquid to gas ventilation. In immature 95-days-old mini-pigs, the lung compliance was markedly increased compared to unventilated and gas ventilated controls, and approached that of the mature (110 days) lung. It was suggested that a film of low surface tension PFC acted as a stable surfactant substitute, and could be useful in the treatment of neonatal RDS (227)! Subsequently, many other investigators have confirmed that following tidal liquid ventilation or PFC lung lavage, surfactant deficient animals demonstrate improved respiratory mechanics and gas exchange compared to pretreatment values $(76,229,230,264,265)$ It was speculated that the improved lung function was due to residual low surface tension PFC, lining the alveoli and acting as an artificial surfactant. Indeed, Mercurio (266) and Gladstone (267), showed that PFC liquids in low doses, increase dynamic compliance and oxygenation in surfactant deficient premature rabbits and lambs. Unlike in surfactant treated animals the FRC was not increased by lowdosed PFC liquid. In contrast to natural surfactant which has a surface area dependent surface tension, PFC has a constant low surface tension that is independent of the alveolar volume. Therefore PFC in low dose can not prevent end-expiratory alveolar collapse. However, the high gas solubility of PFC should not mitigate against intratracheal dosing as large as FRC.

In 1991, Fuhrman at al. described a new technique, called perfluorocarbon-associated gas exchange (PAGE): a volume of perfluorocarbon equivalent to the normal FRC was instilled into the trachea, and gas ventilation resumed for 1 hour. PAGE was well tolerated and its efficiency approached that of conventional gas ventilation in normal piglets (268). Based on the same principles, Lachmann et al. proposed the combination of intratracheal perflubron 
instillation with mechanical ventilation as an alternative treatment of acute respiratory failure in adult animals (269). PAGE is mostly called "partial" liquid ventilation (PLV).

After feasibility and safety studies, the technique of PLV was applied in several disease models and tested against conventional mechanical ventilation and other respiratory support techniques. Meanwhile nearly all variables of the technique have been explored: liquid volume (from full FRC to perfluorocarbon vapour), and various gas ventilation strategies (CMV with different PEEP levels, PAV, ITV, and HFV) in prophylactic and rescue applications.

The physiology turned out to be more complex than initially thought, and monitoring the desired PFC liquid volume in the lungs requires analysis of the evaporative losses (270). The principles of PFC distribution and elimination (271) had to be studied.

It is astonishing that it became known only very recently that the presence of PFC vapour in the gas flowing through pneumotachometers gives falsely high tidal volume measurements $(272,273)$. In the Davies study, the overestimation was 7.2 to $16.1 \%$ using a differential pressure transducer, and 34.5 to $40.7 \%$ with a hot-wire anemometer. Unless taking into account this deviation or unless (re)calibration of the pneumotachograph with a gas composition to be measured, lung compliance calculations are of course subject to the same error.

6.2. Feasibility and other descriptive animal studies on partial liquid ventilation

\subsubsection{Partial liquid ventilation of the normal lung}

Several studies have investigated gas exchange, lung mechanics, and lung histology during and after PLV of the normal lung. We summarize this knowledge in short.

\subsubsection{What happens during PLV?}

\section{Gas exchange}

When measured at equal ventilator and $\mathrm{Fl}, \mathrm{O}_{2}$ settings, arterial oxygen tension is lower during PLV than during gas ventilation $(26,268,274-277)$. Overbeck and coworkers noticed this same finding only in prone but not in supine adult animals (278). Alveolo-arterial differences [(A-a)D's] of respiratory gases are increased proportional to the volume of fluid in the lungs (279). This gas exchange impairment is most likely due to a combination of increased ventilation heterogeneity, $V^{\prime}{ }_{A} / Q$ ' heterogeneity, creation of true shunt regions consisting of flooded unventilated alveoli as well as heterogeneously distributed diffusion limitation (280-282). Imaging regional Q' and V' demonstrated a decrease of $Q$ ' and $V^{\prime}{ }_{A} / Q$ ' during PLV in the dependent lung regions of supine ventilated sheep (283).

\section{Effect of gas ventilation strategy}

The effect of the ventilator settings on gas exchange during PLV has been neglected for quite a while. It is now known that both tidal volume and end-inspiratory pressure influence oxygenation during PLV in normal animals $(284,285)$. 
Interesting data were recently provided by Uchida et al. who compared respiratory gas tensions in arterial blood samples and in central and distal (fourth generation) airway PFC liquid samples. The distal $\mathrm{PFC} \mathrm{PO}_{2}$ was lower than the proximal $\mathrm{PFC} \mathrm{PO}_{2}$, and the distal PFC $\mathrm{PCO}_{2}$ was higher than the proximal PFC $\mathrm{PCO}_{2}$. When increasing $\mathrm{V}_{\mathrm{T}}$ from 30 to $50 \mathrm{~mL}$, or PEEP from 0 to $10 \mathrm{~cm} \mathrm{H}_{2} \mathrm{O}$, the arterial $P_{\mathrm{O}_{2}}$ became higher than the distal liquid $\mathrm{PO}_{2}$ (286). It is assumed that increasing $\mathrm{V}_{\mathrm{T}}$ and PEEP increase the surface area of gas liquid interface and recruit the nondependent lung (287).

\section{Pulmonary mechanics}

Filling the normal lung with PFC liquid alters the static pressure-volume relationship (268, $288,289)$. In adult animals, the decrease in static lung compliance was shown to be inversely correlated with increasing perflubron dose (278). Fujino et al. explicited the effect of PLV on the inflection points of the pressure-volume curve in healthy sheep and found a decrease in the capacity of the lungs for gas. Indeed, filling the lungs with PFOB elicited a lower inflection point (LIP), not present before filling, in a dose-dependent manner, whereas the upper inflection point decreased significantly (290). Likewise, Goldner et al., using He-dilution technique, demonstrated a dose-dependent decrease of aerated lung volume with incremental PFC volumes in normal dogs (291).

Dynamic compliance was also shown to be decreased in healthy animals on PLV (275, $277,292)$. In contrast to TLV, expiratory airway resistance and respiratory time constant are not substantially affected by PLV (268), but inspiratory airway resistance turned out to be higher during PLV than during CMV (275). Kuhlen et al. found dynamic resistance increased with all tested PFC doses ranging from 7.5 to $30 \mathrm{~mL} \cdot \mathrm{kg}^{-1}$ (293)

Ferreyra et al. systematically investigated the effect of (incremental) PEEP levels on gas ventilation during PLV in healthy sheep. Low PEEP has a negative effect on gas delivery to the lung during PLV. (1) During pressure control ventilation with low PEEP, peak airway pressures (above PEEP) exceeded set values and peak flow was markedly decreased (as was $\mathrm{V}_{\mathrm{T}}$ ). (2) During volume control ventilation with low PEEP, peak airway pressures (above PEEP) are increased and peak gas flow was delayed and exceeded set values. The airway resistance was increased. The alterations of pressure and flow waveforms disappeared with PEEP equal to the lower inflection point (LIP). These findings were interpreted as follows: Low PEEP allows PFC liquid residing in the large airways thereby impeding gas ventilation. High PEEP moves PFC liquid out of conducting airways, thereby reducing impedance to gas ventilation (294). Using fluorine-19 MRI technology, Uchida et al. demonstrated that, indeed, only at airway pressures above the LIP a gas-liquid interface is established (295).

Feasibility of prolonged PLV (24 hours) and resumption of gas ventilation was demonstrated in normal animals (296). Even spontaneous breathing with partly perflubron filled lungs was well tolerated for up to 24 hours in normal rabbits (297). This is in agreement with data on lung mechanics in healthy spontaneous breathing lambs revealing no differences in work of breathing (WOB) at different levels of PFC filling (298). But, it was also noted that CPAP during spontaneous PLV improved oxygenation, and reduced the increase in respiratory rate related to the PFC instillation (299).

Since PCF preferentially distributes to dependent lung regions, PLV may increase the normal vertical pleural pressure gradient. Dorsal pleural pressure indeed increased with increasing PFC liquid instillation (291). 
Regional gas ventilation and pulmonary blood flow distribution are influenced by PFC liquid instilled into the lung.

Since PFC liquid has a high specific gravity, it tends to pool in the dependent lung regions and gas ventilation is preferentially distributed to the non-dependent lung.

Inspection of the lung during PLV of open-chest animals showed initially gas inflation of nondependent lung regions before inflation of the dependent portions $(268,300)$. This simple clinical observation was corroborated by $\mathrm{CT}$ examination and magnetic resonance imaging: gas ventilation is directed preferentially to the non-dependent part of the lung until significant airway pressures are reached, directing gas ventilation to the dependent lung regions ( 295 , $301)$.

\section{Regional PBF in normal animals}

Using radioactive microspheres, Kallas et al. studied the regional pulmonary blood flow (PBF) distribution in healthy ventilated supine sheep. Intratracheal instillation of perflubron resulted in a dose dependent decrease in relative PBF (rPBF) in dorsal (dependent) aspects of the right lower lobe and left lower lobe. Concomitantly, there was a dose dependent increase in $\mathrm{rPBF}$ in the right anterior lobe, right middle lobe and left anterior lobe, which was greatest in dorsal regions and occurred even in lung pieces located in the same horizontal plane as right and left lower lobe regions which decreased their rPBF. The redistribution of PBF away from the lower lobes was attributed the preferential filling of these lobes. (302)

In comparable experiments, Doctor et al. also found significant redistribution in the pattern of rPBF. In lambs on CMV there was a dependent-favoured regional flow pattern in the vertical plane (confined to the apical and upper hilar sections) and a slight apicaldiaphragmatic gradient (across the transverse plane). After initiation of PLV there was a doseindependent reduction of $\mathrm{rPBF}$ in the diaphragmatic regions of the lung, and a doseaugmented gradient favouring the apical lung developed. Redistribution of flow in the vertical axis, with reversal of the gradient to a pattern favouring flow to nondependent (ventral) lung was less consistent (276). The anatomical position of the animals was such that the dorsal surface of the lung formed an angle of approximately 20 degrees with respect to the horizontal, resulting in preferential filling of the dependent lung adjacent to the diaphragm well before filling of the dependent lung at the apex.

In normal neonatal piglets, ventilated in supine position, PLV decreased the rPBF to the most dependent (dorsal) lung segments (303). Also in an ex vivo isolated lung preparation, apical lung perfusion increased, whereas basal lung perfusion decreased after instillation of perfluorocarbons (304).

The effects of sodium nitroprusside and inhaled NO on local ventilation/perfusion during PLV have been assessed in normal animals. The results suggest that the decreased basal lung perfusion may not exclusively be due to the high specific weight of PFCs but may be caused, at least in part, by hypoxic pulmonary vasoconstriction secondary to local hypoventilation (283).

Finally, the distribution of regional lung perfusion during PLV depends on the time point in the respiratory cycle. Diversion of lung perfusion away from dependent lung regions is seen at end-expiratory pressure. At end inspiration, $\mathrm{PFC}$ and gas are more evenly distributed 
throughout the lung and the effect of the liquid density on pulmonary blood flow is reduced. At end-inspiratory pressure a diversion of perfusion back towards the dependent lung is seen $(277,305)$.

\section{Alveolar permeability and fluid absorption}

Ricard et al. investigated alveolar liquid clearance in an in vivo rat model. The absorption of instilled Ringer solution was increased when followed by PLV with perflubron. The passive epithelial permeability increased during alveolar flooding. Instillation of $2 \mathrm{~mL}$ perflubron prevented this increase in permeability, but $1 \mathrm{~mL}$ did not (306).

\section{Histology}

Histological findings following PLV have been divergent: focal overdistended alveoli but well-preserved lung architecture (296), interstitial, perivascular fluid cuffs (307), and intracellular oedema and mitochondrial membrane disintegration in alveolar macrophages, type I and type II cells (26). BALF analysis demonstrated increased total protein in partial liquid ventilated lungs (26).

Stretch injury. Even in healthy animals, PLV can not prevent lung injury induced by low PEEP $\left(5 \mathrm{~cm} \mathrm{H}_{2} \mathrm{O}\right)$ and high $\mathrm{V}_{\mathrm{T}}$ ventilation $\left(51 \mathrm{~mL} \cdot \mathrm{kg}^{-1}\right.$ achieving a plateau pressure of $>50$ $\mathrm{cm} \mathrm{H}_{2} \mathrm{O}$ ) when compared to tidal ventilation within lower and upper inflexion points on the pressure-volume curve. Low PEEP high $\mathrm{V}_{\mathrm{T}}$ ventilation resulted in impaired gas exchange, histologic changes and increased mortality when compared to high PEEP-low $\mathrm{V}_{\mathrm{T}}$ ventilation $(308,309)$.

\section{Haemodynamics}

In healthy pigs, PLV (full-FRC and PEEP) did not affect cardiac output, mean arterial pressure, glomerular filtration rate, diuresis, natriuresis, plasma renin activity, plasma aldosterone concentration, or atrial natriuretic factor (310).

\subsubsection{Findings after PLV}

After PLV or PFC instillation, during evaporation of the liquid, a decrease in dynamic compliance was reported, and higher PEEP levels were required to maintain a stable arterial oxygenation (296). Similar findings were reported in the 1970s during gas breathing following TLV $(196,199,217-219)$. At the long-term, pulmonary function seems to be preserved (275).

In the isolated hamster lung (311) as well as in the intact rabbit (275) and mice (312) the permeability of the alveolo-capillary membrane seems to be increased after PLV.

Pathologically, different findings have been reported: interstitial swelling in perivascular areas and alveolar damage consisting of septal swelling with abundant cells and exudate in the alveoli (312), focal atelectasis in otherwise normal lungs (296), and severe local emphysema in non-dependent regions, suggesting overdistention of non-dependent ventilated areas (313). BALF analysis revealed increased cells (foamy macrophages ( $>90 \%$ at $3 \mathrm{~h}$ ) and neutrophils 
$(>40 \%$ at $24 \mathrm{~h})$ ) and a decreased ratio of SP-B to protein concentration (due to the increased protein concentration) (312).

Sekins et al reported no adverse effects in three near term baboons (165-171 days gestational age; term is 182 days), who were maintained on PLV for 96 hours, followed by 24 hours of CMV. Except for some vacuolated alveolar macrophages, no histological abnormalities were seen (314).

\subsubsection{PLV in diseased lungs: descriptive (and explanatory) studies}

Lachmann et al. proposed for the first time the combination of intratracheal perflubron instillation with mechanical ventilation as an alternative treatment of acute respiratory failure caused by repeated saline lung lavage in adult rabbits $(269,315)$. PLV seemed to improve gas exchange and lung mechanics both in saline lung-lavaged animals and in oleic acid lung injury $(316,317)$. Incremental or increasing doses perflubron pointed out a dose-independent increase in compliance and a dose-dependent increase in oxygenation $(316,318-323)$. Hence it appeared that, unless the evaporative PFC losses were replaced, the favourable effect on oxygenation was time-dependent $(324,325)$. Recently, Max. et al. described a time-dependent decrease of oxygenation even when losses due to evaporation were compensated. They speculate that the liquid $\mathrm{PO}_{2}$ at the alveolar level is high immediately after instillation but subsequently drops due to diffusion limitation. Maximal improvement in oxygenation (the "best fill") required more complete lung filling, which, however, was accompanied by a modest decrease in lung compliance (in large animals with OA lung injury) $(316,323,326)$. As in healthy animals, expiratory resistance did not increase due to PLV $\left(30 \mathrm{~mL} \cdot \mathrm{kg}^{-1}\right)(327)$.

In 1997, Cox et al. gave a fair warn against the use of full FRC PLV with high tidal volume - low PEEP ventilation, a combination with an apparent high risk for air leak syndrome (328). Since then, much has been learned about liquid filling and gas ventilation strategy during PLV (vide infra).

\subsection{Studies comparing PLV with CMV}

The efficacy of PLV has been tested in a multitude of animal models. The studies are summarised hereafter. Details are given in appendices for neonatal RDS (appendix 4), ARDS (appendix 5-7), meconium aspiration syndrome (appendix 8), and congenital diaphragmatic hernia (appendix 9).

\subsubsection{Neonatal respiratory distress syndrome}

The first prospective, randomized, controlled study of PLV in premature lambs with established respiratory distress syndrome made mention of dramatically improved lung mechanics and facilitated oxygenation and $\mathrm{CO}_{2}$ removal (329). By protocol, tidal volume in the PLV animals was increased from $7-8 \mathrm{~mL} \cdot \mathrm{kg}^{-1}$ to $15 \mathrm{~mL} . \mathrm{kg}^{-1}$. In a covering editorial, the study was criticized because of the absence of a true, matched control group, the short duration, and the lack of pulmonary histopathology (330).

deLemos and coworkers compared management with PLV for 96 hours with CMV in preterm baboons (gestational age 140 days, term is 180 days) showing $\mathrm{X}$-ray and clinical 
evidence of neonatal RDS. Animals on PLV demonstrated improved gas exchange and lung mechanics (331).

The same beneficial effects on gas exchange and lung mechanics were documented in premature lambs (125 days gestation) treated with exogenous surfactant at the end of the first hour, and randomized at two hours of life to receive 4 hours of either CMV or PLV (332).

In a second randomized controlled animal study, Leach and coworkers compared four groups of preterm lambs with nRDS (125-127 days): CMV, Exosurf® at 30 minutes, PLV from 30 minutes, and Exosurf® at 30 minutes followed by PLV from 45 minutes. Independent of Exosurf® pretreatment, gas exchange and lung mechanics were superior during PLV (using perflubron) when compared to CMV or surfactant + CMV. Gross examination of the lungs post mortem revealed no parenchymal cysts or haemorrhages after PLV (43).

Similarly, Moya et al. reported that repeated intratracheal administration of FC-100 in surfactant deficient lambs (125 days of gestation) improved gas exchange and lung function more than did Exosurf( treatment (333).

Preterm lambs (125-127 days), treated with beractant (Survanta $®$ ) at 1 hour, demonstrated sustained improvement of gas exchange and respiratory compliance after perflubron rescue at 2 hours. Different strategies were used: lung filling 30 or $10 \mathrm{~mL} \cdot \mathrm{kg}^{-1}$ and ventilator frequency $60 \mathrm{or} 30 \mathrm{bpm}$. A strategy using $30 \mathrm{~mL} \cdot \mathrm{kg}^{-1}$ perflubron and a ventilator frequency of $60 \mathrm{bpm}$ yielded greater lung expansion, less barotrauma, and reduced regional differences in lung perflubron content (300).

In preterm rabbits (27 days gestation), Heldt and Henderson showed that $5 \mathrm{~mL} . \mathrm{kg}^{-1}$ of endotracheal beractant (Survanta ${ }^{\circledR}$ ) did not improve respiratory system compliance. After 10 minutes of ventilation, the respiratory system compliance was higher after $5 \mathrm{~mL} . \mathrm{kg}^{-1}$ perfluoroctylbromide instilled than after surfactant. In comparison with surfactant alone, a partially emulsified mixture of beractant and PFC significantly improved respiratory system compliance at 10 and 20 minutes. The authors speculate that PFC may improve the distribution of surfactant (334).

Different recruitment strategies (PLV, HFOV, and combined PLV-HFOV) were compared in extremely premature lambs (115 days gestation) after prophylactic surfactant. PLV was better than CMV with respect to gas exchange, and myeloperoxidase activity in lung tissue when the strategies were used in a prophylactic fashion (96). As a rescue treatment, PLV improved oxygenation in 115-118 days' gestation lambs, but lung histology and myeloperoxidase activity were similar (335).

Tokieda et al. investigated the effects of oropharyngeal administration of FC-75 perfluorocarbon liquid to neonatal homozygous surfactant protein B deficient mice. Normally, these animals die rapidly, failing to inflate their lungs and oxygenate. PFC liquid administration significantly prolonged survival, improved lung mechanics and oxygenation. Compared to room air or $40 \%$ oxygen treated controls, PFC treatment was associated with more histologic damage to epithelial, vascular, and alveolar structures after only 30 minutes. After longer times, lung damage was also evident in heterozygous and wild type mice treated with FC-75 (336). 


\subsubsection{Acute respiratory distress syndrome}

\subsubsection{Saline lung lavage-induced lung injury}

The efficacy of full FRC (18 mL. $\mathrm{kg}^{-1}$ of perflubron) PLV versus CMV in saline lunglavaged adult rabbits was first reported in 1993 (337). Using the same ventilator settings, PLV resulted in an improved $\mathrm{Pa}_{\mathrm{a}} \mathrm{O}_{2}$, and increased respiratory system compliance. No significant morphologic abnormalities were observed at microscopic examination in the PLV lungs. Houmes et al. confirmed a dose-dependent increase in $\mathrm{Pa}_{\mathrm{a}} \mathrm{O}_{2}$ in large pigs randomized to CMV or incremental doses of perflubron; PLV had no deleterious effect on haemodynamic parameters (338).

The improvements in arterial oxygenation and lung mechanics were reproducible using other perfluorocarbons, namely FC 3280 (320, 339), FC-77 (340), and APF-140M (341). In the latter study the beneficial effect on oxygenation and lung mechanics was only transient which could be attributed to the lack of substitution of PFC evaporative losses.

PLV with small volumes of FC $3280\left(15 \mathrm{~mL} \cdot \mathrm{kg}^{-1}\right)$ in lung-lavaged pigs improved survival significantly. However, $\mathrm{Pa}_{\mathrm{a}} \mathrm{O}_{2}$, dynamic compliance, and lung injury scores were not significantly different between treatment and control animals (342). Neither in this study were the PFC evaporative losses replaced.

In a controlled study of saline lung-lavaged swine, Bradley et al. demonstrated a dosedependent improvement of $\mathrm{Pa}_{\mathrm{a}} \mathrm{O}_{2}$, and a dose-independent increase of pulmonary compliance during PLV (322).

Sawada et al. confirmed the beneficial effect of PLV on oxygenation and pulmonary compliance; light microscopic findings consistent with ARDS were significantly reduced after PLV when compared to CMV control lungs $(343,344)$.

Once again in a rabbit acute lung injury model, van Eeden et al. demonstrated that PLV improved arterial oxygenation when compared to CMV. PLV reduced lung damage as evidenced by a significant reduction in alveolar haemorrhage, oedema, hyaline membrane formation, and alveolar wall damage. In gravity-dependent lung regions there was less inflammatory response (less sequestration and migration of polymorphonuclear leukocytes). Type II alveolar cells were damaged and reduced by CMV $(345,346)$.

Following this series of studies favouring PLV, some papers questioned the superiority of PLV to CMV.

In a porcine lung lavage model we could not demonstrate any gas exchange advantage of PLV over an optimized CMV strategy using a high PEEP and temporarily increased peak inspiratory pressures. Moreover, neither histological lung injury scores nor lung expansion, as measured by mean linear intercept, were significantly different between the PLV and CMV animals (347).

Comparing different treatment strategies in lung-lavaged rats, Hartog et al. noticed better oxygenation in the group ventilated with high PEEP $\left(18 \mathrm{~cm} \mathrm{H}_{2} \mathrm{O}\right) \mathrm{CMV}$ when compared to PLV. The high PEEP group showed however significantly more lung injury than the PLV animals (348).

Another intriguing but unexplained observation was reported by Hartog et al. who demonstrated marked differences in the effect on lung mechanics and gas exchange efficacy of four perfluorocarbons (APF-140, APF-215, APF-175A or FC 3280) (349). 
Lately, in a sheep saline lung lavage model, gas ventilation and PLV were compared with respect to their effects on gas exchange, haemodynamics, respiratory mechanics, and lung histology. However different from all previous research the authors used a lung protective ventilatory strategy in both groups (350). PEEP was set at $1 \mathrm{~cm} \mathrm{H}_{2} \mathrm{O}$ above the LIP on the inspiratory limb of the P-V curve; peak inspiratory pressure was altered to achieve normocapnia but was limited to the UIP or $35 \mathrm{~cm} \mathrm{H}_{2} \mathrm{O}$. Applied PEEP was 18.9 (1.4) and 11.5 (2.5) $\mathrm{cm} \mathrm{H}_{2} \mathrm{O}$ in the GV and PLV group, respectively. $\mathrm{Pa}_{\mathrm{a}} \mathrm{O}_{2}$ increased in both groups but was not significantly different between groups. Quasistatic lung compliance improved significantly by both strategies, but only tended to improve earlier and to a greater extend with PLV. In GV animals tidal volume decreased significantly, whereas $\mathrm{Pa}_{\mathrm{a}} \mathrm{CO}_{2}$ and dead space/tidal volume ratio were markedly increased. There were no significant between group differences in overall (weighted) histologic scores. But the severity and extend of histologic lesions were higher in the dependent lung regions of GV compared to PLV animals. The lungs were inflated to a pressure of $23 \mathrm{~cm} \mathrm{H}_{2} \mathrm{O}$ with fixative solution. The authors state that "The method that was chosen for tissue fixation may have lowered the differences". We would argue that an identical airway pressure during fixation favoured alveolar recruitment in the PLV lungs.

\subsubsection{Oleic acid infusion-induced acute respiratory distress syndrome}

The first paper on partial liquid ventilation in oleic acid-injured animals demonstrated that intratracheal administration of perflubron at volumes substantially less than liquid FRC significantly improved arterial oxygenation and static lung compliance with no impairment in $\mathrm{CO}_{2}$ elimination or cardiac index. Maximal improvement in oxygenation required more complete lung filling, which was accompanied by a modest decrease in lung compliance. Lung histology was not different between control or PLV animals, independent of the prophylactic or therapeutic application $(316,351)$.

In oleic acid - lung lavage injured sheep on extracorporeal life support, Hirschl et al. observed also improved gas exchange, pulmonary function, and, moreover, reduction in lung pathology $(352,353)$.

The technique of partial liquid ventilation improved arterial oxygenation also in large animals with oleic acid induced ARDS, but pulmonary compliance was not significantly different when PLV and CMV ventilation were compared (326).

Quintel et al. confirmed the gas exchange benefit of PLV in oleic acid injured adult sheep, and objectively quantified histomorphometric benefit of PLV: lower diffuse alveolar damage score, larger mean alveolar diameter, and lower number of alveoli per high-power field, decreased septal wall thickness, and mean capillary diameter (354). Using in vivo chest CT studies, the same authors demonstrated that perflubron was predominantly distributed to the dependent regions of the lung, and although gas was distributed throughout the lung with each inspiration, more gas than perflubron went to the nondependent lung regions (355). Endexpiratory lung volume was measured using an electron beam tomography scanner. At a PEEP level of 5 mbar, lung volume was reduced by the oleic acid injury but reestablished by $10 \mathrm{~mL} . \mathrm{kg}^{-1}$ perflubron. At $30 \mathrm{~mL} \cdot \mathrm{kg}^{-1} \mathrm{PFOB}$, the lung volume significantly exceeded baseline values (356).

After induction of acute lung injury by oleic acid infusion, neonatal piglets supported by PLV had improved gas exchange, static lung compliance, and survival than their peers on 
conventional ventilation. Lung histology was markedly preserved after PLV (357) The same authors also reported that alveolar protein leak was significantly reduced in the same ARDS model when PLV was instituted before lung injury (358). PLV instituted early in the course of acute lung injury did not reduce intra-alveolar protein leak in one study (359), but did decreased the alveolar-capillary permeability in another (360).

Other comparative studies in the oleic acid model have further explored the potential mechanisms explaining the improvement of gas exchange during PLV. Gauger et al. reported that the improvement in gas exchange during PLV coincided with an increased end-expiratory lung volume (composite of gas and liquid) (361). Also observed was an attenuation of the increase in total lung water (especially in the dependent lung regions) (362). After PLV, the number of inflammatory cells in BAL fluid was less than after CMV (363), and biochemical markers of oxidative damage to lipids (thiobarbituric acid reactive substances or TARBS) were reduced in lung tissue homogenates (364).

In contrast to all previous studies using the oleic acid lung injury model, Romera et al. did not find any beneficial affect of PLV on gas exchange or respiratory mechanics in a randomized controlled trial in pigs (365). The fact that an $F, \mathrm{O}_{2}$ of 0.5 was used can not explain their findings. Lately, Lange et al. studied the effect of PLV on pulmonary vascular permeability and lung water concentration in dog with oleic acid injury. PLV and CMV animals were ventilated with a PEEP of $7.5 \mathrm{~cm} \mathrm{H}_{2} \mathrm{O}$. Five and 21 hours after lung injury, PLV animals had a significantly worse oxygenation than CMV treated dogs, showing a $\mathrm{Pa}_{\mathrm{a}} \mathrm{O}_{2}$ similar to base-line. The authors speculated that PEEP opened dorsal atelectasis during CMV, whereas during PLV PFC liquid impeded gas exchange in the dependent lung (366).

\subsubsection{Gastric aspiration-induced acute respiratory distress syndrome}

When started 60 minutes after tracheal instillation of gastric aspirate, PLV resulted in better arterial oxygenation than CMV during the inflammatory phase ( 2.5 to 6 hours after injury) of the provoked ARDS in piglets. Macroscopic and microscopic lung injury was less pronounced in PLV treated lungs but not quantified. In the abstract the authors summarize that "histologic evidence for ARDS ... was lacking" (367). The ameliorated oxygenation was also demonstrated in large acid-injured sheep (284).

The protective mechanisms involved during PLV were further explored in a hydrochloric acid aspiration and large tidal volume $\left(\mathrm{V}_{\mathrm{T}} \geq 15 \mathrm{ml} / \mathrm{kg}\right)$ induced lung injury model in rats. PLV starting at 30 minutes after acid instillation, improved $\mathrm{Pa}_{\mathrm{a}} \mathrm{O}_{2}$, and decreased peak inspiratory pressures; serum tumour necrosis factor- $\alpha$ was significantly lower after 2,3 , and 4 hours of PLV compared with control CMV. Tracheal fluid TNF- $\alpha$ concentrations were not significantly different in this study (368). In an identical study, PLV decreased TNF- $\alpha$ concentration both in aspired tracheal fluid as in serum. TNF- $\alpha$ m-RNA in lung tissue was not different between the ventilation strategies, suggesting an inhibition of the cytokine gene translation and not at the transcription level (369).

\subsubsection{Smoke inhalation}

Smoke inhalation injury is a threatening complication in burn patients. PLV significantly improved gas exchange and survival in a neonatal piglets subjected to severe smoke inhalation injury. The ventilator strategy used in this first animal study was somewhat surprising: to 
maintain physiological $\mathrm{pH}$ and blood gases the lowest tidal volume, but also the lowest rate (30 bpm), and end-expiratory pressure (PEEP $4 \mathrm{~cm} \mathrm{H}_{2} \mathrm{O}$ ) possible were used (370). In an ovine model of smoke inhalation, Cindrick et al. randomized the animals to receive a bronchoscopic lavage with $200 \mathrm{~mL}$ of perflubron or saline at $2,6,12$, and 24 hours after injury. The use of a perfluorocarbon as lavage fluid attenuated the postprocedure hypoxemia, but overall there was no therapeutic benefit associated with PFC lavages (371).

\subsubsection{Hydrocarbon aspiration}

Low-viscosity hydrocarbons (e.g. kerosene) cause fulminant pneumonitis and ARDS following aspiration. In lambs with kerosene pneumonitis, Clayton et al. randomized the animals to baseline gas ventilation (group 1), and gas ventilation adjusted to optimize gas exchange without (group 2) or with $20 \mathrm{~mL}^{\mathrm{kg}} \mathrm{kg}^{-1}$ intratracheal perflubron (group 3). $\mathrm{Pa}, \mathrm{O}_{2}$ and dynamic compliance were higher in group 3 when compared to group 1 animals, but these outcome measures only tended to be higher in group 3 than in group 2 (372). Kahai et al. demonstrated that PLV can improve oxygenation and reduce histologic and biochemical evidence of lung injury in rabbits given intratracheal kerosene (373). Burns and coworkers investigated whether a brief (1 to 2 minutes) period of PLV with $20 \mathrm{~mL} \cdot \mathrm{kg}^{-1} \mathrm{FC}-77$ could improve survival in a rat model of severe hydrocarbon aspiration. Mortality was however significantly greater in the PLV-treated animals. The authors discussed possible explanations: increased dispersal of kerosene by the PFC, increased alveolar permeability caused by the PFC, increased work of breathing, or the short period of positive-pressure ventilation (374).

\subsubsection{Pulmonary contusion}

Pulmonary contusion after blunt thoracic trauma may be complicated by ARDS with high mortality. In a severe pulmonary contusion model, Moomey et al. compared the cardiopulmonary effects of CMV with PEEP or PLV without PEEP. Five hours after a blunt chest injury was delivered (by a captive bolt gun) to mongrel pigs, these animals were randomized for a study period lasting 2 hours. In gas ventilated animals PEEP was build up in increments of $5 \mathrm{~cm} \mathrm{H}_{2} \mathrm{O}$ and 30-minute interval up to $25 \mathrm{~cm} \mathrm{H}_{2} \mathrm{O}$. Both PLV and PEEP ventilation improved gas exchange but $\mathrm{PEEP} \geq 20 \mathrm{~cm} \mathrm{H}_{2} \mathrm{O}$ was better at increasing $\mathrm{Pa}, \mathrm{O}_{2} / F \mathrm{I}, \mathrm{O}_{2}$ ratio and only PEEP $\geq 10 \mathrm{~cm} \mathrm{H}_{2} \mathrm{O}$ seemed capable at lowering dead space ventilation. Both strategies improved $\mathrm{Pa}_{\mathrm{a}, \mathrm{CO}_{2}}$, compliance and shunt fraction. Stroke index, cardiac index, and oxygen delivery decreased with higher PEEP levels. A histologic lung injury score was lower in the contralateral uninjured lungs when treated with PLV (375). The authors suggest that PLV might be a promising novel ventilatory strategy for pulmonary contusion. Several study limitations make the conclusion indeed conditional.

\subsubsection{Neutrophil-mediated lung injury - systemic endotoxaemia}

Accumulation of neutrophils in the lung and the release of reactive oxygen species by activated leukocytes sequestered in the lung contribute to the pathogenesis of the acute inflammatory phase of ARDS. These inflammatory phenomena can be studied in appropriate animal models: cobra venom factor (CVF) challenge, haemorrhagic shock and $\mathrm{E}$. Coli endotoxaemia. 
PLV used as a rescue therapy in rats subjected to cobra venom-induced lung injury showed reduced MPO activity in the lungs (376).

In the same disease model, Colton et al. showed that PLV (full FRC $=10 \mathrm{~mL} . \mathrm{kg}^{-1}$ perflubron) started either before or after administration of CVF was associated with a significant reduction of albumin permeability index (377). In another study the same authors investigated the effect of four strategies on pulmonary neutrophil accumulation: PLV (full $\mathrm{FRC}=10 \mathrm{~mL} \cdot \mathrm{kg}^{-1}$ perflubron $)$ and gas ventilation with PEEP $\left(5 \mathrm{~cm} \mathrm{H}_{2} \mathrm{O}\right)$, each technique either used prophylactically or as rescue. When compared to gas ventilated controls (PEEP = 0 ), the neutrophil count was reduced in the four study groups. The total lung myeloperoxidase concentrations were lower in the study groups, but this difference reached significance only after prophylactic application. The authors conclude that PLV and PEEP are associated with a similar decrease in the pulmonary accumulation of neutrophils (378).

Haemorrhagic shock and reperfusion induces lung injury involving neutrophil sequestration. During resuscitation from haemorrhagic shock, rats were randomized to gas ventilation or PLV with $5 \mathrm{~mL} \cdot \mathrm{kg}^{-1}$ perflubron. PLV resulted in a significant reduction of lung myeloperoxidase activity reflecting reduced neutrophil accumulation in the lung. There was also a trend towards decreased capillary leak (379).

Following the IV administration of E. Coli endotoxin to rabbits, animals prophylactically supported with PLV demonstrated lower $\mathrm{Pa}_{\mathrm{a}, \mathrm{O}_{2}}$ but less metabolic acidosis than CMV treated animals. PLV per se induced a shift to the right of the pressure volume curve, but attenuated the worsening of the static compliance induced by endotoxin infusion and ventilation (289). The global histologic lung injury scores after PLV were lower than after CMV, and this was mainly due to a reduction of tissue injury in the dependent regions of the lung (380). Furthermore, PLV significantly decreased neutrophil accumulation, myeloperoxidase activity, and indicators for lipid peroxidation and oxidative damage to proteins $(289,381)$. Interestingly, HFOV and PLV turned out to be equally effective in improving the lung injury score, and decreasing leukostasis and MPO activity in the lungs (381).

\subsubsection{Ventilation-induced lung injury}

Dreyfuss et al. tested the effect of a low dose of perflubron $\left(3.3 \mathrm{~mL} \cdot \mathrm{kg}^{-1}\right)$ on permeability pulmonary oedema induced by (extreme) hyperventilation after alveolar flooding in rats. On average, instillation of perflubron antagonized the microvascular permeability changes induced by the injury model. Perfluorocarbon reduced the LIP, shifted the whole quasi-static pressure volume curve to the left, and reduced the end-inspiratory pressure. There was a good correlation between the LIP pressure and the albumin distribution space (an index of pulmonary microvascular injury) (382). It was concluded that PLV at low doses can protect against VILI by improving the mechanical properties of the lung.

After 2 hours of mechanical ventilation with high $\mathrm{V}_{\mathrm{T}}\left(42 \mathrm{~mL} . \mathrm{kg}^{-1}\right)$ and $\mathrm{ZEEP}$, lung injury was present in rats (increased BAL protein concentration) but BAL TNF- $\alpha$ was not increased. When LPS was injected before ventilation, TNF- $\alpha$ in BALF was significantly increased. In both injury models, intratracheal perflubron decreased protein but not TNF- $\alpha$ concentration in BALF (383). 


\subsubsection{Meconium aspiration syndrome}

Compared with CMV at the same ventilator settings, or compared with artificial surfactant, PLV provided better oxygenation and survival in young piglets after instillation of a $33 \%$ slurry of pooled human meconium (384). Likewise, other researchers have demonstrated increased arterial oxygenation and improved pulmonary mechanics when applying PLV in neonatal lambs with meconium aspiration $(385,386)$. In a comparable study Foust et al. demonstrated improved $\mathrm{Pa}_{\mathrm{a}} \mathrm{O}_{2}$ and histological changes which were "less evident" in the PLV lungs (250). Also in the newborn piglet MAS model, PLV using the PFC-liquid perfluorodecalin improved oxygenation, and dynamic respiratory system compliance (387), but the histological lung injury was reported to be unchanged (388).

\subsubsection{Congenital diaphragmatic hernia}

The efficacy of PLV was compared with CMV using the congenital diaphragmatic hernia $(\mathrm{CDH})$ lamb model by two research groups. PLV increased survival, and both gas exchange and dynamic compliance were significantly improved (389-392). Started after 30 minutes, PLV was however not able to prevent perivascular emphysema $(391,392)$.

PLV and CMV were also compared in newborn rat pups with Nitrofen induced CDH. After endotracheal instillation of $15 \mathrm{~mL} \cdot \mathrm{kg}^{-1}$ of Rimar 101, gas exchange ameliorated, and postmortem lung mechanics improved (lower opening pressures and higher static lung compliance) $(393,394)$. Interestingly, four hours after birth, more heat shock protein 70 mRNA (HSP-70 mRNA) was expressed in CMV than in PLV treated lungs.

Immunohistochemically, both HSP-70 and HSP-27 staining was more intense after CMV than after PLV. The authors speculated that decreased expression of these stress proteins may stand for decreased trauma to the hypoplastic CDH lungs during PLV (395).

\subsubsection{Pneumonia}

In rats with a lethal pneumococcal pneumonia, PLV for 15 minutes started 4 hours after intratracheal bacterial instillation, improved 5-day survival significantly compared with survival in gas ventilated control animals (396). In a subsequent study survival up to 10 days was not altered by 20 minutes of spontaneous submerged liquid breathing. FC-77 did not inhibit bacterial growth, neither in vitro, nor in vivo (40). In a third study, infected rats were allocated to one of 5 groups: no treatment, penicillin alone, gas ventilation, PLV alone, or PLV plus penicillin. Ventilation was started 24 hours after tracheal inoculation with type III pneumococcal solution, and lasted only 10 minutes. The 10 -day survival was $0,40,0,0$, and $80 \%$ respectively. The lack of efficacy of PLV as solo therapy was attributed to the longer treatment delay, the shorter ventilation period, and the longer period of observation. The authors suggest that PLV in combination with antibiotics may be an effective therapeutic modality (397). They suppose that antiinflammatory properties of PFCs and/or the increased surfactant production or low surface tension of the PFC themselves are the most likely explanation for their findings.

Sajan and Steinhorn confirmed that perflubron is not bactericidal, and demonstrated that PLV with perflubron (only) tended to decrease bacterial growth after intentional inoculation 
of the airways. In vitro bacterial adhesion was decreased by exposure to perflubron and FC77, but unaffected by Rimar 101 (41).

Intratracheal administration of antibiotics with PLV has been explored as another therapeutic option for bacterial pneumonia. Four or five hours after an single dose of gentamicin or vancomycin, lung tissue antibiotic concentrations were higher after pulmonary drug administration when compared to intravenous administration of an equal dose (398, 399). In the lethal pneumococcal pneumonia rat model, a single dose of intramuscular penicillin and the intratracheal administration of penicillin with a PFC emulsion were equally effective in reducing mortality (400).

\subsubsection{Cardiopulmonary bypass and lung transplantation}

Cardiopulmonary bypass (CPB) is frequently harmful to pulmonary vascular mechanics and cardiac output, eventually leading to increased morbidity and mortality. PLV using perflubron, and started before $\mathrm{CPB}$, can decrease input pulmonary resistance, pulmonary characteristic impedance, and pulmonary artery pressure, while improving transpulmonary vascular efficiency, cardiac output, and static lung compliance (401). CPB-induced neutrophil sequestration in the lung was reduced by both prophylactic and therapeutic PLV (402). With respect to cardiac output and oxygen delivery full FRC PLV was more effective than half FRC PLV (403).

As long ago as 1970, it was already demonstrated that the deterioration of a transplant lung could be alleviated by ventilating it with oxygenated perfluorocarbon liquid during the preservation period (404). The effect of PLV on acute graft dysfunction, a form of ischemiareperfusion injury, was more recently studied in adult mongrel dogs undergoing left single lung allotransplantation. Oxygenation deteriorated in control animals and remained stable during PLV. The histology of dorsal lung biopsies appeared better preserved after PLV (405).

\subsection{PLV combined with or versus other technologies}

\subsubsection{PLV and exogenous surfactant}

Since PFC liquids may act as an artificial surfactant, several experiments have been designed in order to compare exogenous surfactant therapy with PLV.

Partial liquid ventilation versus surfactant. PLV with perflubron was found to be more effective than Exosurf $\circledast$ or Infasurf $(\mathbb{B}$ as rescue therapy in preterm lambs with severe advanced respiratory distress syndrome $(43,406)$. Repeated low doses of FC-100 were also more effective than Exosurf® (333). In saline lung-lavaged newborn piglets, Mrozek noted similar results with beractant (Survanta $(8)$ : the improvement in oxygenation was less sustained in surfactant than in PLV treated animals and the improvement in respiratory system compliance was greater in PLV than after surfactant treatment. The latter finding was confirmed by others (407). In addition, Mrozek demonstrated reduced pathologic lung injury in the lower lobes of PLV-treated animals (408). Hartog reported nearly opposite findings in lung-lavaged adult rats. In this disease model, natural surfactant therapy had a more favourable profile than PLV: no increased protein concentration in BAL fluid, no decreased lung volume at pressures $<15 \mathrm{~cm} \mathrm{H}_{2} \mathrm{O}$ on the deflation limb of the pressure-volume curve, no increased ratio of small to large surfactant aggregates, and lower lung injury score (348). In 
meconium aspiration injury PLV was more effective than artificial surfactant (384), but not significantly different from beractant (Survanta $(2)$ (250).

PLV with and without surfactant. From a physiological (and clinical) point of view, the question "PFC-liquid or exogenous surfactant?" has become irrelevant. Indeed the mechanical properties of the lung are optimized by instillation of PFC liquid after surfactant therapy. This was nicely shown in in vitro experiments (72) as well as in lung-lavaged piglets. Compared to PLV-only treated animals, pathologic lung injury was reduced throughout the lungs in animals treated with beractant (Survanta $($ ) followed by PLV. Lohbrunner et al. recently reported exactly the same findings in large pigs treated with either PF5080 or Curosurf followed by PF5080 (409). Taken together, these findings suggest pretreatment with natural surfactant offers an additional benefit to PLV alone (408). In a recent study by Kelly et al., there was no apparent additional benefit from combined therapy with surfactant and PLV with FC 5080 (410). An improvement in gas exchange was again demonstrated when PLV was preceded by surfactant lavage in meconium lung injury (411). Mertz et al. recently published an intriguing and unexplained finding, when comparing PLV with and without surfactant (Alveofact $(8)$ pretreatment in lung-lavaged piglets treated for 24 hours. There were two subgroups which were ventilated with either CMV or high frequency ventilation. At 18 and 24 hours, gas exchange was worse in surfactant treated animals. Moreover, histological lung injury was most pronounced in surfactant treated high frequency ventilated FC77 filled lungs (412).

\subsubsection{PLV and inhaled NO}

Increased pulmonary vascular resistance frequently contributes to the pathophysiology of lung disease and respiratory insufficiency. Therefore, the use of $\mathrm{iNO}$, a potent and selective pulmonary vasodilator, was investigated during PLV.

In healthy lambs with U46619-elicited pulmonary hypertension, iNO exhibited the same pharmacokinetics and pharmacodynamics during PLV as during CMV. In addition, there seemed to be no increased risk of toxicity $\left(\mathrm{NO}_{2}\right.$ and methaemoglobin levels) $(413,414)$. It was hypothesized that since PFC-liquid causes alveolar recruitment, the response to iNO would be augmented in parenchymal lung disease treated with PLV. This augmented response to iNO was shown to be true in ovine neonatal RDS $(96,335)$, saline lung lavage injury, $(415-$ $419)$, oleic acid lung injury (420), meconium aspiration $(385,387)$, and congenital diaphragmatic hernia $(390,421)$. Using coloured microspheres, Uchida et al. studied pulmonary blood flow (PBF) in saline lung-lavaged rabbits positioned in right lateral decubitus. PLV shifted PBF to the non-dependent left lung. Subsequent iNO therapy significantly accentuated the shift of PBF to the left lung, suggesting that iNO acts predominantly in gas-ventilated alveoli (419).

In the oleic acid lung injury model, intratracheal instillation of prostaglandin $\mathrm{E}_{1}\left(\mathrm{PGE}_{1}\right)$ or prostacyclin $\left(\mathrm{PGI}_{2}\right)$ during PLV had an additive effect at improving oxygenation $(422,423)$.

In U46619-induced pulmonary vasoconstriction, alkalosis was as effective during PLV as during CMV in decreasing PVR (424). In these experiments, instillation of epoprostenol $\left(\mathrm{PGI}_{2}\right)$ during PLV decreased PVR and pulmonary arterial pressure but also decreased arterial oxygenation (425). 


\subsubsection{PLV combined with HFV, ITV, patient triggered ventilation (PTV) and PAV}

Gas ventilation of the PFC liquid filled lung using techniques other than CMV are attractive since the advantages of liquid and alternative gas ventilation mode might be combined and additive.

Conventional $P L V$ versus high frequency $P L V$. Partial liquid ventilation using high frequency techniques does not provide gas exchange advantage to PLV using conventional techniques (426-428). Neither was there additional pathologic protection when high frequency ventilation was used in conjunction with PLV as compared with PLV-CMV alone (335, 428430).

PLV using intratracheal pulmonary ventilation (ITPV). The technique of intratracheal pulmonary ventilation, also known as tracheal gas insufflation (TGI), with reverse thrust catheter (RTC), was developed to reduce dead space ventilation. In healthy animals, RTCITPV allowed lowering tidal volume $\left(\mathrm{V}_{\mathrm{T}}\right)$ to as low as $1.0 \mathrm{~mL} \cdot \mathrm{kg}^{-1}$, at respiratory rates up to $120 \mathrm{~min}^{-1}$, while maintaining normocapnia $(431,432)$.

In sheep with high pressure ventilator-induced acute lung injury, low PEEP-low $V_{T}$ ITPV compared favourable to CMV: normocapnia could be sustained, weaning to room air was possible, and histopathologic lung injury was less severe (433). In oleic acid lung injured sheep, TGI combined with continuous positive airway pressure (CPAP) significantly lower dead space, minute ventilation, pressure time product, and work of breathing (434). In lunglavaged rabbits, and in a porcine near-drowning model, ventilation and oxygenation were achieved at significantly lower ventilator settings using ITPV compared with conventional ventilation, or $\mathrm{CO}_{2}$ clearance and oxygenation improved at the same ventilator settings (435439). Preliminary case studies suggest efficacy in neonatal and pediatric patients with uncontrollable hypercapnia (440).

The increase in $\mathrm{PCO}_{2}$ induced by PLV in the normal lung can be significantly reduced by superimposing TGI (441).

Since the gaseous lung volume is low during PLV, ITPV may be an attractive gas ventilation strategy to combine with. In newborn piglets with meconium aspiration syndrome, treated with PLV, ITPV enabled to use significantly lower MAP and PIP when compared to CMV (442).

Patient triggered ventilation. Patient triggered ventilation (PTV) or synchronous intermittent mandatory ventilation (SIMV) was favoured over conventional ventilation by three reviewers of the Cochrane Collaboration because, in a meta-analysis, PTV and SIMV were associated with a reduction in airleaks and a shorter duration of ventilation (443). However, two large recent trials, not yet included in the meta-analysis found no advantage for PTV. In a commentary in the Lancet, Roger Soll stated that patient-triggered ventilators should be refined or abandoned (444).

Patient-triggered partial liquid ventilation was feasible in spontaneously breathing, normal piglets, but an increased work of breathing, due to PFC liquid in the lung, was suggested (higher minute ventilation and lower dynamic respiratory system compliance). Whether supported by CPAP, IMV, SIMV, or AC, these normal animals maintained normal gas exchange by increasing minute ventilation. In lung-injured piglets, the subject effort, as 
estimated by the patient-effort index (PEI), was not increased by PLV. Fully synchronized and assisted mode of ventilation resulted in the lowest subject effort when compared to IMV or SIMV $(445,446)$. The effect of different PTV modes on ventilator-induced histologic lung injury was not investigated.

PLV combined with proportional assist ventilation (PAV). Proportional assist ventilation (PAV) is a mode of partial ventilatory support designed to relieve the resistive and elastic workload of the respiratory system proportional to the patient's breathing effort, i.e. the generated flow or volume. A potential advantage, namely the reduction of peak airway pressures required to sustain ventilation (447), was confirmed in adult patients (448) and in low birth weight neonates (117).

Hummler and coworkers compared gas ventilation with PLV in spontaneously breathing animals supported by PAV under different lung conditions. In healthy rabbits PLV did not preclude stable ventilation and gas exchange (449). In animals with surfactant depletion and meconium aspiration the combination of PLV-PAV improved gas exchange and lung compliance. Moreover, in a meconium aspiration study increased survival and improved lung histology were demonstrated (450-452). Finally, haemodynamics were compared between spontaneous breathing animals supported by PLV-PAV and paralysed animals supported by controlled ventilation PLV. Whether the lungs were healthy or surfactant depleted, the former group demonstrated a higher cardiac output and oxygen-delivery $(453,454)$.

\subsubsection{PLV versus other recruitment strategies (CMV, HFOV)}

High frequency gas ventilation versus high frequency $P L V$. At least eight studies have compared high frequency gas ventilation (HFV) with HFV superimposed on a PFC-filled lung (HF-PLV). In preterm lambs with respiratory distress syndrome (RDS) Leach and Sukumar found gas exchange improved during HF-PLV $(455,456)$. This conclusion was not shared by Gothberg who noticed no differences (335). In a saline lung-lavage model, Sakurai and coworkers (457) described improved gas exchange during HF-PLV, but Doctor et al. (458) found no significant differences (neither in gas exchange nor in lung histology), while Manaligod found less lung injury after HF-PLV but similar gas exchange, independent of the perflubron dose $(427,430)$. Baden (459) noticed a more rapid improvement in oxygenation with the addition of a small $\left(3 \mathrm{~mL} \cdot \mathrm{kg}^{-1}\right)$ volume of PFC during HFOV. However, larger doses of perflubron ( 15 and $30 \mathrm{~mL} \cdot \mathrm{kg}^{-1}$ ) were not more effective than continuation of HFOV alone. Doctor et al. also noticed a transiently improved oxygenation with $5 \mathrm{~mL} \cdot \mathrm{kg}^{-1}$ perflubron in supine and $5 \mathrm{~mL} \cdot \mathrm{kg}^{-1}$ perflubron in prone position. This low dose PFC liquid attenuated lung injury in the dependent lung (460). Merz et al. confirmed the equivalent gas exchange efficacy of HF-PLV and HFOV (plus surfactant) and after 24 hours their HF-PLV animals also presented significantly less histological lung injury (428). In another study on HF-PLV, these investigators found no effect of the initial PFC liquid dosing $\left(5\right.$ or $\left.30 \mathrm{~mL} \cdot \mathrm{kg}^{-1}\right)$ on gas exchange or pulmonary mechanics (461). Since the absolute value and the differences in PFC evaporative rate are unknown in HFV circumstances, no definite conclusions can be drawn as to the optimal filling volume during HFOV.

$P L V$ versus $H F O V$. Kinsella treated immature lambs prophylactically with surfactant followed by conventional mechanical ventilation (CMV), PLV or high frequency oscillatory ventilation (HFOV) using a high volume strategy. HFOV and PLV caused similar improvement in gas 
exchange, lung histology and equivalent attenuation of lung inflammation (96). Gothberg found similar results when in the same disease model high frequency oscillatory ventilation and partial liquid ventilation were used as rescue treatment (335). We found HFOV slightly more effective than PLV in a lung lavage model, but lung injury scores were non different (347). Manaligod and Merz would agree on the gas exchange equivalence, but after an experimental time span of 20 or 24 hours, liquid ventilated lungs looked more healthy (428, 430). In addition, Merz demonstrated a reduced concentration of IL-6, leukotrien B4 (LTB4), and 6-keto-prostaglandin F1 in BALF of PLV treated animals (462).

\subsection{5. (Prone) positioning and PLV}

The physiological mechanisms by which prone positioning improves gas exchange in ARDS have been studied extensively. It was shown that turning from supine to prone reduces the positive pleural pressure in dependent regions, and reduces the gravitational pleural pressure gradient resulting in the requirement of less airspace presssure to generate airspace opening, and more uniform inflation. Lung perfusion is preferentially distributed to the dorsal lung units regardless of body position. Using single-photon emission-computed tomography, it was demonstrated that the prone posture decreased V' $A$ /Q' heterogeneity. And this improvement in $\mathrm{V}$ ' $\mathrm{A} / \mathrm{Q}$ ' matching in the prone position is secondary to increased homogeneity of the $\mathrm{V}$ ' ${ }_{A}$ distribution and increased correlation of regional V' ${ }_{A}$ and Q' (463, 464). Despite the strong experimental foundation, prone ventilation benefits have not yet been translated in improved morbidity or mortality (465).

In normal adult sheep PLV decreased oxygenation in supine, but not in prone positioned animals (278).

In oleic acid injured animals (sheep and dogs) on PLV, oxygenation and compliance acutely improved when changing from supine to prone position $(466,467)$. These findings were confirmed in the saline lung lavage model of acute lung injury $(468,469)$.

Continuous bed rotation during PLV did not influence gas exchange in a study by Curtis et al (470), whereas Urlesberger noticed an improved $\mathrm{CO}_{2}$ removal (471).

\subsubsection{Ventilatory strategy (tidal volume, PEEP, and I:E ratio) during PLV}

\section{Tidal volume}

As in normal animals oxygenation improves with incremental increases of gas $\mathrm{V}_{\mathrm{T}}(323)$. Positive end-expiratory pressure

For decades, PEEP has been known to prevent end-expiratory alveolar collapse and PEEP is also used to recruit atelectatic lung units. The function of PEEP during PLV has only recently been appreciated fully.

Some early PLV studies acknowledge the necessity of some PEEP avoid early inspiratory pressure surges caused by PFC liquid moving back into the large airways during expiration $(284,319)$

The first indication that PEEP was also important for gas exchange was reported by Kaizers et al. In saline lung-lavaged pigs supported with PLV, increasing levels of PEEP (from 0.5 to $1.5 \mathrm{kPa}$ ) resulted in further improvement of oxygenation (472).

The effects of PEEP during PLV (30 mL. $\mathrm{kg}^{-1}$ RIMAR 101) were also studied in sheep after oleic acid injury and saline lung lavage by setting PEEP at random at $0,5,10$, or $15 \mathrm{~cm} \mathrm{H}_{2} \mathrm{O}$. 
At PEEP levels of 10 and $15 \mathrm{~cm} \mathrm{H}_{2} \mathrm{O}$ there was an additional benefit on oxygenation $\left(\mathrm{Pa}_{\mathrm{a}} \mathrm{O}_{2}\right.$, and $\mathrm{Qs} / \mathrm{Qt}$ ), dead space ventilation, and expiratory airway resistance. At PEEP levels of 5 and $10 \mathrm{~cm} \mathrm{H}_{2} \mathrm{O}$ mean airway resistance, dynamic and static compliance showed additional improvement. At $15 \mathrm{~cm} \mathrm{H}_{2} \mathrm{O}$, mean arterial pressure, cardiac output and oxygen delivery decreased. The increase in mean airway resistance was explained by liquid refluxing in the large airways (473).

The oxygenation and static respiratory compliance of rabbits, made respiratory insufficient by repeated saline lung lavage, improved by instillation of $12 \mathrm{~mL} \cdot \mathrm{kg}^{-1}$ of perfluorodecalin. Stepwise increasing PEEP from 2 to $10 \mathrm{~cm} \mathrm{H}_{2} \mathrm{O}$ caused a dose-dependent linear increase in $\mathrm{P}_{\mathrm{a}, \mathrm{O}_{2}}$. A concomitant increase in static compliance peaked at a PEEP of $8 \mathrm{~cm} \mathrm{H}_{2} \mathrm{O}(474)$.

Saline lung-lavaged rabbits received volume-targeted, time-cycled positive pressure ventilation and perflubron instillation up to FRC volume. Five episodes of 30 minutes were successively carried out with PEEP settings of $4,8,12,8$, and $4 \mathrm{~cm} \mathrm{H}_{2} \mathrm{O}$ respectively. Oxygenation and ventilation parallelled PEEP and EELV measurement changes. Dynamic compliance did not increase with increasing PEEP but increased with decreasing PEEP to values higher than baseline. At the end of the study oxygenation was lower than at baseline (475). Limitations in the study design (especially the lack of replacement of evaporative losses) precludes adequate interpretation of the data.

A research group of Boston under the leadership of Dr. Kacmarek also investigated the effects of (combined) PLV and PEEP. Filling the saline lavaged lung with PFC liquid shifts the inspiratory P-V curve to the left, improving compliance and decreasing the LIP. At moderate to high doses of PFC liquid ( 15 to $\left.30 \mathrm{~mL} \cdot \mathrm{kg}^{-1}\right)$, PEEP set $1 \mathrm{~cm} \mathrm{H}_{2} \mathrm{O}$ above the LIP further increased oxygenation, reduced physiological dead space ventilation, and improved total respiratory system compliance when compared with a PEEP of $5 \mathrm{~cm} \mathrm{H}_{2} \mathrm{O}$ (476). This synergistic effect of PEEP on oxygenation during PLV was independent of the mode of ventilation or I:E ratio (477). In a final study, gas exchange and histologic lung injury were compared in saline lung-lavaged sheep; the animals were randomised to CMV or full-FRC PLV but both groups were treated with the same "lung protective strategy": PEEP $1 \mathrm{~cm} \mathrm{H}_{2} \mathrm{O}$ above the LIP on the inspiratory P-V curve and PIP limited to $35 \mathrm{~cm} \mathrm{H}_{2} \mathrm{O}$. Both groups achieved the same oxygenation improvement, but dead space ventilation increased significantly in the CMV group. The extent and the severity of lung injury in the dependent regions was greater in the CMV group (350).

The impact of airway pressure on the distribution of the gas-liquid interface during PLV was nicely demonstrated using fluorine-19 magnetic resonance imaging (MRI).

Perfluorocarbons liquids are an excellent MRI contrast medium and their MR signal is attenuated at the gas-liquid interface. In post mortem rabbits, either with normal lungs or after oleic acid injury, total lung fluorine-19 intensity decreased with increasing airway pressures above the lower infection point. The signal reduction occurred from non-dependent to dependent lung regions and in a dose-dependent manner. Thus, only at Paw above the LIP, a gas-liquid interface seems to be established (295).

In a saline lavage lung injury model, Goddon et al. systematically searched for the optimal mean airway pressure during HFO-PLV (perflubron $10 \mathrm{~mL}^{-\mathrm{kg}^{-1}}$ ). The pressure corresponding to the point of maximal curvature (PMC, $26 \pm 0.8 \mathrm{~cm} \mathrm{H}_{2} \mathrm{O}$ ) on the expiratory limb of the static $\mathrm{P}-\mathrm{V}$ curve turned out to yield the best oxygenation without impairing cardiac output (478). Oxygenation was also affected by oscillatory frequency, amplitude and I:E ratio. Low frequency $(4 \mathrm{~Hz})$, high amplitude $\left(60 \mathrm{~cm} \mathrm{H}_{2} \mathrm{O}\right)$, and $\mathrm{I}: \mathrm{E} 1: 1$ resulted in the best oxygenation 
(479). A combination of this low frequency and high amplitude can generate a $\mathrm{V}_{\mathrm{T}}$ of 5.5 (1.0) $\mathrm{mL} \cdot \mathrm{kg}^{-1}(480)$.

\section{Inspiratory to expiratory time ratio}

In rabbits with saline lung lavage lung injury and ventilated with a low PEEP $\left(2 \mathrm{~cm} \mathrm{H}_{2} \mathrm{O}\right)$ and high $\mathrm{V}_{\mathrm{T}}\left(18 \mathrm{~mL} \cdot \mathrm{kg}^{-1}\right)$ strategy, Lim et al. demonstrated that extending the $\mathrm{I}: \mathrm{E}$ ratio during PLV improves oxygenation and ventilation. The effect on oxygenation was more pronounced during PLV than during gas ventilation (481). Unfortunately, no comparison was made with the effect of raising PEEP to levels above the LIP.

\subsubsection{Vaporized or nebulized perfluorocarbons}

The effect of PFC vapour has been evaluated in different disease models.

In a dose-response study, lung neutrophil sequestration following cobra venom factor challenge, as measured by lung myeloperoxidase levels, was significantly reduced by PLV with 10,5 , and $1 \mathrm{~mL} \cdot \mathrm{kg}^{-1}$ PFOB. MPO levels were reduced in a PFOB-vapour treated group of rats (376).

Lung dysfunction secondary to intestinal ischemia/reperfusion manifests itself by increased pulmonary vascular resistance and microvascular permeability. This neutrophil associated lung injury can be prevented by PFC vapour ventilation (482).

Vaporized perfluorohexane for 30 minutes improved oxygenation and lung compliance for two hours in sheep with oleic acid injured lungs (483).

Kelly et al. used the classical saline lung lavage model to compare the effects of PLV with perfluorocarbon PF 5080, nebulized PF 5080, natural surfactant (poractant- $\alpha$ ), artificial surfactant (pumactant), and the combinations poractant- $\alpha$ and PLV, and pumactant and PLV. Nebulized PF 5080 had no effect on oxygenation, dynamic compliance and survival, whereas PLV, poractant- $\alpha$, and combinations of surfactant and PLV were all equally effective (410) The authors argue that, using a continuous flow ventilator, the dose of PFC delivered to the lungs may have been to small.

A recent report compared the effects of inhaled PFC or full-FRC PLV on gas exchange, lung mechanics, and cytokine expression in lung-lavaged piglets. Both therapeutic modalities had a similar favourable effect on oxygenation, $\mathrm{CO}_{2}$ elimination, and dynamic compliance at the end of two hours of PFC dosing. These improvements were sustained after 4 supplemental hours of IMV. Compared to control animals, the m-RNA expression of IL-1 $\beta$, IL-6, IL-8 and TGF $\beta$ were significantly lower in the inhaled PFC group. The PLV group showed a lower mRNA expression of IL-1 $\beta$ than the controls $(484,485)$.

\subsection{Human experience}

The published data on PLV in humans which we could retrieve are listed in table 2. On the web-site of Alliance Pharmaceutical Corp., San Diego, CA, it is reported that to date approximately 280 patients have received LiquiVent in a clinical study [Wedel MK http://www.allp.com/LiquiVent/LV_SUMM.HTM accessed March 25th 2001].

All but one reported studies are uncontrolled, limiting their message. Necropsies in nine patients managed with PLV on ECMO in a phase II study did not reveal any unique histologic findings in the lungs (486). In the controlled, multi-centre trial in adult patients with severe respiratory failure but not requiring extracorporeal life support, no significant deleterious 
effects attributable to PLV were found. There was no difference between survival rate or ventilator free days between the groups. However, there was a preponderance of elderly patients randomized to PLV. When patients less than 55 years of age were examined, the survival was better and the ventilator free days longer in the PLV group $(487,488)$. More recently, a multicenter pilot study randomized 16 patients with ALI or ARDS to receive PLV with a PFC liqud dose near full-FRC or approximately $50 \%$ FRC. The authors concluded that it is possible to use pre-defined algorithms to maintain these two dosing levels, as well as ventilation and weaning protocols, during PLV (489). An international Phase II/III FDA trial of PLV in ARDS/ALI, which will enroll > 260 adult patients is currently underway. The endpoints of this three-arm study (CMV, PLV with FRC dose, and PLV with approximately onehalf of the FRC dose) is "ventilator-free days" within 28 days after initiation of therapy. The secondary end-point is 28-day mortality.

\begin{tabular}{llll}
\hline Patients & Number & Perfluorocarbon & Reference \\
\hline Preterm neonatal RDS & 3 & Rimar 101 & $(251,252)$ \\
MAS-PPHN; pneumonia; RDS & 3 & Rimar 101 & $(253)$ \\
Infant on ECMO & 2 & perflubron & $(490)$ \\
Infants (4), children (6) and adult-ECMO (10) & 20 & perflubron & $(491-494)$ \\
Infants (divers pathology): CMV and HFV & 13 & Rimar 101 & $(495)$ \\
Children ARDS & 6 & & $(496)$ \\
Child with PC pneumonia & 1 & perflubron & $(497)$ \\
Preterm nRDS & 13 & perflubron & $(498)$ \\
Children ARDS & 10 & perflubron & $(499)$ \\
Infant-ECMO (2 CDH, 4 ARDS) & 6 & perflubron & $(500)$ \\
Adult-ARDS & 9 & perflubron & $(501)$ \\
Adult-ARDS (RCT) & 65 & perflubron & $(487,488$, \\
& & & $502,503)$ \\
Newborn (PIE, PTX): HFV & 1 & Rimar 101 & $(504)$ \\
Newborns & 7 & Rimar 101 & $(505)$ \\
Infants & 4 & & $(506)$ \\
Alveolar proteinosis & 1 & perflubron & $(55)$ \\
Alveolar proteinosis & 1 & perfluorodecalin & $(507)$ \\
\hline
\end{tabular}

Table 2. Published human partial liquid ventilation experience 
Although PLV was proposed as a simple technique consisting of gas ventilation to a PFC liquid-filled lung, the practical application turned out to be more complex. Several questions needed to be answered: 1 . What is the ideal liquid amount to be instilled and maintained? 2 . How can the residual PFC volume in the lungs be assessed? 3. Which gas ventilatory strategies is most effective? 4. How can the PFC vapor in the expired gas be captured?

\subsubsection{Liquid dosing}

The optimal PFC liquid volume is still controversial. The dose-dependency of oxygenation would suggest that a full FRC dose is preferable, but some studies revealed a decrease in aerated lung volume and compliance near FRC.

Some studies favour a high liquid dose. In the sheep nRDS model, the best gas exchange, respiratory mechanics, and more homogeneous lung expansion was found in the group of animals treated with a high-dose $\left(30 \mathrm{~mL} \cdot \mathrm{kg}^{-1}\right)$ and a high respirator frequency $\left(60 \mathrm{~min}^{-1}\right)$ (300). The protective effect of PLV on cardiac output and oxygen delivery during experimental cardiopulmonary bypass was better with full FRC than with half FRC PLV (403).

Other studies argue against a high liquid dose. Lim et al studied the effect of liquid dose on respiratory mechanics in saline lung-lavaged rabbits. At PFC doses greater than $9-12 \mathrm{~mL} . \mathrm{kg}^{-1}$ (1/2 to $2 / 3$ FRC) dynamic and static respiratory system compliance decrease below values noticed below this dose (508). In an oleic acid lung injury model, Constantin compared the gas exchange efficacy of PLV after instillation of 5,10, or $15 \mathrm{~mL} \cdot \mathrm{kg}^{-1}$ Rimar 101 while using a "best PEEP" level based on the LIP. Oxygenation was not significantly better with a PFC dose above $10 \mathrm{~mL} \cdot \mathrm{kg}^{-1}(509,510)$.

During HF-PLV the effect of PFC liquid dose is also controversial, although most studies found no difference between low and high doses $(427,430,459,461)$. Doctor et al. found significantly better oxygenation after dosing $15 \mathrm{~mL} . \mathrm{kg}^{-1}$ than after 5 or $20 \mathrm{~mL} \cdot \mathrm{kg}^{-1}(511)$.

PFC is more uniformly dispersed when dosed in a rotating fashion (alternating supine to prone versus supine), independent of mode of ventilation (HFOV versus CMV) (512). The better distribution of PFC in the lung resulted in a transiently improved oxygenation (460).

\subsubsection{Liquid dose maintenance}

If the amount of PFC in the lungs is to be kept stable during PLV (513), quantification of evaporative losses is of vital importance in order to adjust replacement dosing.

In 1997, Shaffer et al. introduced and validated the use of a thermal conductivity analyzer to measure PFC saturation of mixed expired gas in order to evaluate the evaporation loss of PFC in the lung (270). Since then, the device underwent further improvements in design and operation (514). Others have demonstrated the accuracy of infrared quantification of perflubron evaporative loss (515). Adsorbent silicon-rich zeoliths are suitable to absorb evaporative PFC losses and have been proposed as a method of quantification (516).

PFC evaporation is influenced by several factors: the physical properties of the PFC (vapor pressure), size of the initial dose, lung condition (injury), amount of PFC in the respiratory system, distribution of PFC in the lung, ventilatory strategy (minute ventilation and PEEP), 
body temperature and postural (re)positioning $(270,271,517-522)$. Evaporative loss can be reduced by using heat and moisture exchangers $(523,524)$.

\subsubsection{Optimal gas ventilation strategy}

The importance of ventilator setting in gas exchange and lung protection have been discussed in section 6.4.6.

Lung compliance transiently increases during instillation of liquid, rapidly improves during PLV, and again decreases during weaning and evaporation. The clinician may need online measurements of lung mechanics to adjust gas ventilation (525).

\subsubsection{PFC conservation during PLV}

Fluorophilic heat-and-moisture exchangers have been developed, and a closed rebreathing system for PFC conservation during PLV has been described (526).

\subsubsection{Suctioning}

Because lung oedema, exudate, and debris have a lower density than PFC liquid they tend to be displaced to the central airways. Tenacious material may cause endotracheal tube obstruction. Aggressive suctioning has been recommended.

6.7. Partial liquid ventilation: the proposed action mechanism in the diseased lung (how it improves gas exchange and protects the lungs)

In the normal lung, the efficacy of gas exchange is impaired by PLV. The causes for this have been shown to be increased ventilation-perfusion ( $V^{\prime} / Q^{\prime}$ ') heterogeneity, increased shunt, and diffusion impairment. On the contrary, PLV improves gas exchange in diseased or injured lungs. Several explanatory mechanisms have been postulated or demonstrated.

\subsubsection{A noncompressible liquid with low surface tension and high spreadability}

Since liquid perfluorochemicals have a low surface tension and a high spreading coefficient, they are supposed to facilitate the recruitment of atelectatic (or consolidated) lung units. In diseased lungs, perfluorocarbons indeed reduce the LIP, and shift the inspiratory pressure-volume curve to the left, improving respiratory system compliance $(382,476)$. These surfactant like properties may not prevent end-expiratory collapse, since the surface tension of PFCs is low $(15 \mathrm{mN} / \mathrm{cm})$ but not surface dependent and considerably higher than the minimal surface tension of surfactant. End-expiratory stabilization of alveoli or avoidance of derecruitment is however possible by the incompressible nature of a PFC liquid (mechanical stenting of alveoli). End-expiratory lung volume (composite of gas and liquid) is reestablished or increased by PLV $(356,361)$. Whether the liquid FRC substantially participates in gas exchange is disputed. The low diffusion coefficient of PFC and the decreased perfusion of dependent lung regions may limit effective gas exchange through liquid filled alveoli. 
The reduction of interfacial tension allows a reduction of inflation pressures, decreasing barotrauma to the lung. On the other hand, heavy PFC liquid tends to settle in the dependent lung regions. This is associated with less histologic lung injury in these areas $(354,380,429)$.

\subsubsection{Decreasing of $V_{A}^{\prime} / Q^{\prime}$ mismatch by redistribution of gas ventilation and perfusion}

Already in 1996 Lamm et al. measured regional $\mathrm{V}_{\mathrm{A}} / \mathrm{QQ}^{\prime}$ using single photon computed tomography and regional Q' using radiolabeled microspheres in oleic acid-induced ALI before and after PLV $\left(20 \mathrm{~mL}^{-\mathrm{kg}^{-1}}\right)$. Pre-PLV, large areas of shunt and low V/Q were located in dorsal regions. Post-PLV, shunt and low V/Q were improved as were ABGs. PLV also redistributed Q' to ventral lung regions. The authors concluded that PLV improves oxygenation by redistributing $Q^{\prime}$ from dorsal to ventral lung regions thereby improving $V^{\prime} / Q^{\prime}$ matching (527).

Redistribution of regional pulmonary blood flow from dependent (poorly ventilated) to less dependent lung segments was also demonstrated by other investigators in oleic acid lung injury $(303,362)$. In the study of Lange et al. regional pulmonary blood flow during PLV showed only a trend toward redistribution of blood away from the dorsal regions (366). In saline lung-lavaged pigs, Max et al. did not find any statistically significant effect of PLV on pulmonary blood flow distribution (528).

More recently, Willey-Courand et al. imaged relative ventilation and perfusion in Tween 80 -saline lung-lavaged sheep using positron emission tomography. They also concluded that PLV improved oxygenation by converting dependent areas of shunt into areas of low V ' $A$ ' ' (529). Lim et al. used the multiple inert gas elimination technique in saline lung-lavaged rabbits. PLV decreased oxygen shunt by transforming shunt units in low V ' $/ Q^{\prime}$ ' and normal $V_{A}^{\prime} / Q$ ' units (530)(531).

\subsubsection{Lavage and tamponade effect}

PLV has a broncho-alveolar lavage effect, mobilizing cellular debris, mucus, and alveolar oedema $(265,493,498)$. Endotracheal tube obstruction by mucus plugs may be a side-effect of this for which the clinician should be prepared.

PLV may attenuate intra-alveolar oedema formation by increasing intra-alveolar hydrostatic forces. PLV indeed redistributed total lung water from dependent to less dependent lung segments and ameliorated the continued accumulation of total lung water in oleic acid injured dogs (362). However, in an intermediate-term study (21 hours), Lange et al. could not demonstrate any difference in pulmonary vascular leak or lung water accumulation between CMV and PLV dogs with oleic acid injury. In this study a PEEP of $7.5 \mathrm{~cm} \mathrm{H}_{2} \mathrm{O}$ was used in all animals (366).

\subsubsection{Anti-inflammatory effect or immunomodulation}

Numerous studies have shown that PLV is associated with a decrease in pulmonary leukostasis, inflammatory mediator release, and reactive oxygen species induced tissue damage. Whether this in vivo effect is due to the immunomudulatory properties of PFC liquids per se, or by the attenuation of baro- or volu-trauma is not clear. Anyway, the reduction of neutrophil sequestration by PLV is equivalent to that obtained by a high volume HFOV strategy $(96,381)$. 
Studies with an ex-vivo isolated lung preparation have convincingly demonstrated that, under zone 3 flow conditions (LAP>Paw), PLV has no effects on haemodynamic variables (pressure-flow relationships, vascular compliance, capillary pressure, and filtration coefficients) (532). The authors therefore assumed that PLV has no effects on right ventricular afterload. However, the in vivo situation may be more complicated.

Haemodynamics in normal piglets were compared between PLV and CMV. There were no differences, except for an increased pulmonary arterial pressure (PAP) and pulmonary vascular resistance (PVR) at a low $\mathrm{Fl}, \mathrm{O}_{2}$ of 0.3 (274). Similar findings were noted in larger pigs, without lung injury. Cardiac output (measured by thermodilution) and systemic vascular resistance (SVR) were unchanged after instillation of a volume of perfluorocarbon liquid equivalent to the FRC. Pulmonary vascular resistance (PVR) and pulmonary arterial pressure (PAP) measured at end-expiration increased during PLV when compared to base-line (277). It should be acknowledged that PLV decreased arterial and mixed venous $\mathrm{PO}_{2}$.

Numerous comparative studies in lung diseased animals have explicitly studied the effects of PLV on haemodynamics, and have, in general, not found any deleterious effect on measured systemic haemodynamic parameters. $(284,320,337,338,354,357,361,362,364$, $367,533)$. It should be noted that with high doses of perfluorocarbon liquid $\left(>30 \mathrm{~mL} \cdot \mathrm{kg}^{-1}\right)$ cardiac compromise has been noted (326).

Two echocardiographic studies are worth mentioning.

In surfactant-treated preterm lambs, PLV did not induce any change in heart rate, systemic arterial pressure, central venous pressure, systemic vascular resistance, stroke volume, aortic and pulmonary blood flow, left-to-right ductal flow, or left ventricular shortening and ejection fraction. Interestingly, end-systolic meridian wall stress, end-systolic circumferential wall stress, and end-systolic and end-diastolic left ventricular internal diameter were significantly reduced. The decrease in left ventricular wall stress at a maintained cardiac output implies a decrease of myocardial oxygen consumption (534).

In saline lung-lavaged sheep, right sided haemodynamics were assessed after successive administration of $10 \mathrm{~mL} \cdot \mathrm{kg}^{-1}$ perflubron (cumulative dose $40 \mathrm{~mL} \cdot \mathrm{kg}^{-1}$ ). The techniques used were Swan-Ganz catheter and transoesophageal doppler-echocardiography (acceleration time, ejection time, and pre-ejection period). With liquid doses $220 \mathrm{~mL} \cdot \mathrm{kg}^{-1}$, progressive right ventricular dysfunction and signs of pulmonary hypertension appeared, although this was not confirmed by pulmonary artery pressure measurements (535). A recent study demonstrated that PLV does not affect the accuracy of capillary wedge pressure or thermodilution cardiac output measurements made by pulmonary artery catheter (536).

\section{Cerebral circulation}

In healthy two-week old lambs, PLV had no significant effect on carotid blood flow or cerebral metabolic rates of oxygen, glucose and lactate when compared to gas ventilation (537). Near infra red spectroscopy measurements during PFC filling demonstrated dose- and velocity-dependent effects on cerebral total and oxy-haemoglobin (538). Therefore, a slow instillation of PFC liquid should be preferred. 
7. Appendices

The following details of comparative liquid ventilation studies were tabulated: the animal model; whether the therapeutic intervention was prophylactic or rescue $(\mathrm{P} / \mathrm{R})$; the experimental duration (ED) (hours); the ventilator settings; the effects of the experimental therapy on oxygenation, $\mathrm{CO}_{2}$ removal, respiratory mechanics, histology and biological or biochemical markers. The ventilator settings are represented as: PFC liquid filling (if applicable); respiratory frequency $x$ PIP/PEEP $\left(\mathrm{cm} \mathrm{H}_{2} \mathrm{O}\right)$ or $\mathrm{V}_{\mathrm{T}}\left(\mathrm{mL} . \mathrm{kg}^{-1}\right)$ and PEEP; I:E ratio; $\mathrm{Fl}, \mathrm{O}_{2}$; liquid $\mathrm{FRC}$ if applicable. 
Appendix 1. Comparative studies of TLV in nRDS

\begin{tabular}{|c|c|c|c|c|c|c|c|c|c|}
\hline Animal model & $\mathrm{P} / \mathrm{R}$ & ED & CMV & TLV & oxygenation & $\begin{array}{l}\mathrm{CO}_{2} \\
\text { removal }\end{array}$ & $\begin{array}{l}\text { lung- } \\
\text { mechanics }\end{array}$ & histology \& biochemistry & References \\
\hline $\begin{array}{l}\text { preterm } \\
\text { mini-pigs } \\
(95,100,110 d)\end{array}$ & $\mathbf{P}$ & 53 & $?$ & ? & $\mathrm{TLV}>\mathrm{CMV}$ & $?$ & $?$ & $?$ & $(227,236)$ \\
\hline $\begin{array}{l}\text { preterm rabbits } \\
(27.5-27.75 \mathrm{~d})\end{array}$ & $\mathbf{P}$ & $\leq 3$ & $\begin{array}{l}50 \times 25-30 / ? \mathrm{~mm} \mathrm{Hg} \\
? ; 1.0\end{array}$ & $\begin{array}{l}5-7 \mathrm{x} \pm 17 \mathrm{ml} \cdot \mathrm{kg}^{-1} \\
? ; ?\end{array}$ & $\mathrm{TLV}>\mathrm{CMV}$ & $?$ & ? & $\begin{array}{l}\text { TLV }<\mathrm{CMV} \text { : necrosis and desquamation of } \\
\text { bronchiolar epithelium; hyaline membranes }\end{array}$ & (228) \\
\hline $\begin{array}{l}\text { preterm lambs } \\
(108-116 \mathrm{~d})\end{array}$ & $\mathbf{P}$ & 3 & $\begin{array}{l}40-70 \times 6-10 \mathrm{~mL}^{-} \mathrm{kg}^{-1} \\
\text { PEEP } 2-6 \mathrm{~cm} \mathrm{H}_{2} \mathrm{O} \\
1.0\end{array}$ & $\begin{array}{l}3-8 \times 10-20 \mathrm{~mL} \cdot \mathrm{kg}^{-1} \\
1: 1.5-1: 3 \\
\text { FRC: } 20-40 \mathrm{~mL} \cdot \mathrm{kg}^{-1}\end{array}$ & $\mathrm{TLV}>\mathrm{CMV}$ & $\mathrm{TLV}>\mathrm{CMV}$ & $\begin{array}{l}\text { Crs,dyn: } \\
\text { TLV>CMV }\end{array}$ & $\begin{array}{l}\text { CMV: atelectasis, proteinaceous exudate, } \\
\text { haemorrhage, and hyaline membranes } \\
\text { TLV: homogeneously expanded alveoli, clear of } \\
\text { exudate, haemorrhage, or hyaline membranes, } \\
\text { and bordered by thinner walls }\end{array}$ & (237) \\
\hline $\begin{array}{l}\text { preterm lambs } \\
\text { (125 d) }\end{array}$ & $\mathbf{R}$ & 1 & $?$ & $?$ & $\mathrm{TLV}>\mathrm{CMV}$ & $\mathrm{TLV}<\mathrm{CMV}$ & $\begin{array}{l}\text { Crs: } \\
\text { TLV }<\mathrm{CMV}\end{array}$ & $?$ & (241) \\
\hline $\begin{array}{l}\text { immature lambs } \\
(117 \pm 1.4 \mathrm{~d})\end{array}$ & $\mathbf{P}$ & 4 & 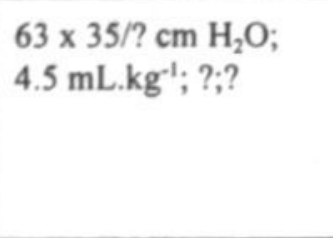 & $4.9 \times 19.3 \mathrm{~mL} . \mathrm{kg}^{-1}$ & $\mathrm{TLV}>\mathrm{CMV}$ & $?$ & $\begin{array}{l}\text { TLV: lower } \\
\text { ventilatory } \\
\text { pressures }\end{array}$ & $\begin{array}{l}\text { TLV: intact and homogeneously expanded } \\
\text { lungs with larger gas exchange areas; less } \\
\text { urinary DES excretion: reduced elastin turnover } \\
\text { CMV: patchy expansion, disruption of alveolo- } \\
\text { capillary membranes across all regions }\end{array}$ & (238) \\
\hline $\begin{array}{l}\text { preterm lambs } \\
(110-120 \mathrm{~d})\end{array}$ & $\mathbf{P}$ & $\leq 4$ & $?$ & $?$ & $\mathrm{TLV}>\mathrm{CMV}$ & $?$ & ? & $\begin{array}{l}\text { CMV: apoptotic cells within the lumen } \\
\text { TLV: apoptotic cells in epithelial lining cells }\end{array}$ & $(239,240)$ \\
\hline $\begin{array}{l}\text { preterm lambs } \\
(124-126 \mathrm{~d})\end{array}$ & $\mathbf{P}$ & 5 & $60 \times 35 / 8 \times 1: 2$ & $\begin{array}{l}5 \times 19.7 \mathrm{~mL} . \mathrm{kg}^{-1} \\
1: 2\end{array}$ & $\mathrm{TLV}>\mathrm{CMV}$ & $\mathrm{TLV}=\mathrm{CMV}$ & NA & $\begin{array}{l}\text { Total lung injury score: TLV }<\text { CMV; less } \\
\text { collapse and overdistention; normally expanded } \\
\text { alveoli }\end{array}$ & (242) \\
\hline
\end{tabular}


Appendix 2. Comparative studies of TLV in ARDS

\begin{tabular}{|c|c|c|c|c|c|c|c|c|c|c|}
\hline \multicolumn{2}{|c|}{ Animal model } & \multirow{2}{*}{$\begin{array}{l}\mathrm{P} / \mathrm{R} \\
\mathrm{R}\end{array}$} & \multirow{2}{*}{$\frac{\text { ED }}{1}$} & \multirow{2}{*}{$\begin{array}{l}\text { CMV } \\
30 \times 25 / 5 ; 1: 2 ; 1.0\end{array}$} & \multirow{2}{*}{$\begin{array}{l}\text { TLV } \\
6-7 \times 25 \mathrm{~mL} \cdot \mathrm{kg}^{-1} ; 1: 2 ; \\
>400 \mathrm{~mm} \mathrm{Hg}\end{array}$} & \multirow{2}{*}{$\frac{\text { oxygenation }}{\mathrm{TLV}>\mathrm{CMV}}$} & \multirow{2}{*}{$\begin{array}{l}\mathrm{CO}_{2} \text { removal } \\
\mathrm{TLV}=\mathrm{CMV}\end{array}$} & \multirow{2}{*}{$\begin{array}{l}\text { lung-mechanics } \\
?\end{array}$} & \multirow{2}{*}{$\begin{array}{l}\text { histology \& biochemistry } \\
?\end{array}$} & \multirow{2}{*}{$\begin{array}{l}\text { References } \\
(243)\end{array}$} \\
\hline $\begin{array}{l}\text { Saline } \\
\text { lung }\end{array}$ & rats & & & & & & & & & \\
\hline & $\begin{array}{l}\text { swine } \\
15-20 \mathrm{~kg}\end{array}$ & R & $?$ & $\begin{array}{l}13-16 \times 14-16 \mathrm{~mL}^{. \mathrm{kg}^{-1}} \text {; } \\
\text { PEEP } 5 \mathrm{~cm} ; ? ; 1.0\end{array}$ & $\begin{array}{l}4-5 \times 15-18 \mathrm{~mL} \cdot \mathrm{kg}^{-1} \\
25-50 \% ; 100 \%\end{array}$ & $\mathrm{TLV}>\mathrm{CMV}$ & $\mathrm{TLV}=\mathrm{CMV}$ & $\begin{array}{l}\text { TLV: PIP and } \\
\text { Palv lower }\end{array}$ & ? & (244) \\
\hline \multirow[t]{3}{*}{$\begin{array}{l}\text { Oleic } \\
\text { acid } \\
\text { injury }\end{array}$} & $\begin{array}{l}\text { sheep } \\
17.3 \pm 4.2 \mathrm{~kg}\end{array}$ & $\mathbf{R}$ & 1 & $\begin{array}{l}30 \times 20 \mathrm{~mL}^{-\mathrm{kg}^{-1}} \text {; } \\
\text { PEEP } 5 \mathrm{~cm} \mathrm{H}_{2} \mathrm{O}\end{array}$ & $\begin{array}{l}5 \times 20 \mathrm{~mL}^{. \mathrm{kg}^{-1}} \\
1: 2 \\
\text { FRC: } 35 \mathrm{~mL} \cdot \mathrm{kg}^{-1}\end{array}$ & $\mathrm{TLV}>\mathrm{CMV}$ & & Cst: $\mathrm{TLV}>\mathrm{CMV}$ & $\begin{array}{l}\text { intraalveolar haemorrhage } \\
\text { and oedema, and } \\
\text { inflammatory infiltrate: } \\
\text { TLV }<\text { CMV }\end{array}$ & (246) \\
\hline & rabbits & R & 2.75 & $? \times 25 / 5 ; ? ; ?$ & $\begin{array}{l}5.5 \times 18 \mathrm{~mL} \cdot \mathrm{kg}^{-1} \\
1: 2 \\
\text { FRC: } 30 \mathrm{~mL} \cdot \mathrm{kg}^{-1}\end{array}$ & $\mathrm{TLV}=\mathrm{CMV}$ & $\mathrm{TLV}=\mathrm{CMV}$ & $\begin{array}{l}\text { PIP-PEEP: } \\
\text { CMV }>\text { TLV }\end{array}$ & $?$ & (247) \\
\hline & adult sheep & $\mathbf{R}$ & 4 & $\begin{array}{l}20-40 \times \leq 40 / 13 \mathrm{~cm} \mathrm{H}_{2} \mathrm{O} \\
\leq 10 \mathrm{~mL}^{-\mathrm{kg}^{-1}} ; ? ; 1.0\end{array}$ & $\begin{array}{l}3-6 \times \leq 25 \mathrm{~mL} \cdot \mathrm{kg}^{-1} \\
? ; 1.0\end{array}$ & $\mathrm{TLV}>\mathrm{CMV}$ & $\mathrm{TLV}>\mathrm{CMV}$ & ? & $\begin{array}{l}\text { TLV: better lungexpansion; } \\
\text { less lung injury }\end{array}$ & (248) \\
\hline
\end{tabular}


Appendix 3. Comparative studies of TLV in MAS

\begin{tabular}{|c|c|c|c|c|c|c|c|c|c|}
\hline Animal model & $\mathbf{P} / \mathbf{R}$ & ED & CMV & TLV & oxygenation & $\mathrm{CO}_{2}$ removal & lung-mechanics & histology \& biochemistry & References \\
\hline rats & early $R\left(15^{\prime}\right)$ & 2 & $\begin{array}{l}\text { ventilatory strategy based } \\
\text { on optimizing pulmonary } \\
\text { mechanics and } A B G \\
\text { profile }\end{array}$ & $\begin{array}{l}\text { ventilatory strategy } \\
\text { based on optimizing } \\
\text { pulmonary mechanics } \\
\text { and ABG profile }\end{array}$ & $\mathrm{TLV}>\mathrm{CMV}$ & $\mathrm{TLV}=\mathrm{CMV}$ & NA & NA & (249) \\
\hline $\begin{array}{l}\text { newborn lambs } \\
3.5-5.6 \mathrm{~kg}\end{array}$ & early R $\left(30^{\prime}\right)$ & 4 & $\begin{array}{l}\text { as previous; PIP/PEEP } \\
<40 / 7 \mathrm{~cm} \mathrm{H} \mathrm{H}_{2} \mathrm{O}\end{array}$ & $\begin{array}{l}5 \times ? \mathrm{~mL}^{-\mathrm{kg}^{-1}} \\
1: 3 ; 1.0\end{array}$ & $\mathrm{TLV}=\mathrm{CMV}$ & $\mathrm{TLV}=\mathrm{CMV}$ & $\begin{array}{l}\text { Crs,dyn: } \\
\text { TLV }>\text { CMV }\end{array}$ & TLV: less injury & (250) \\
\hline
\end{tabular}

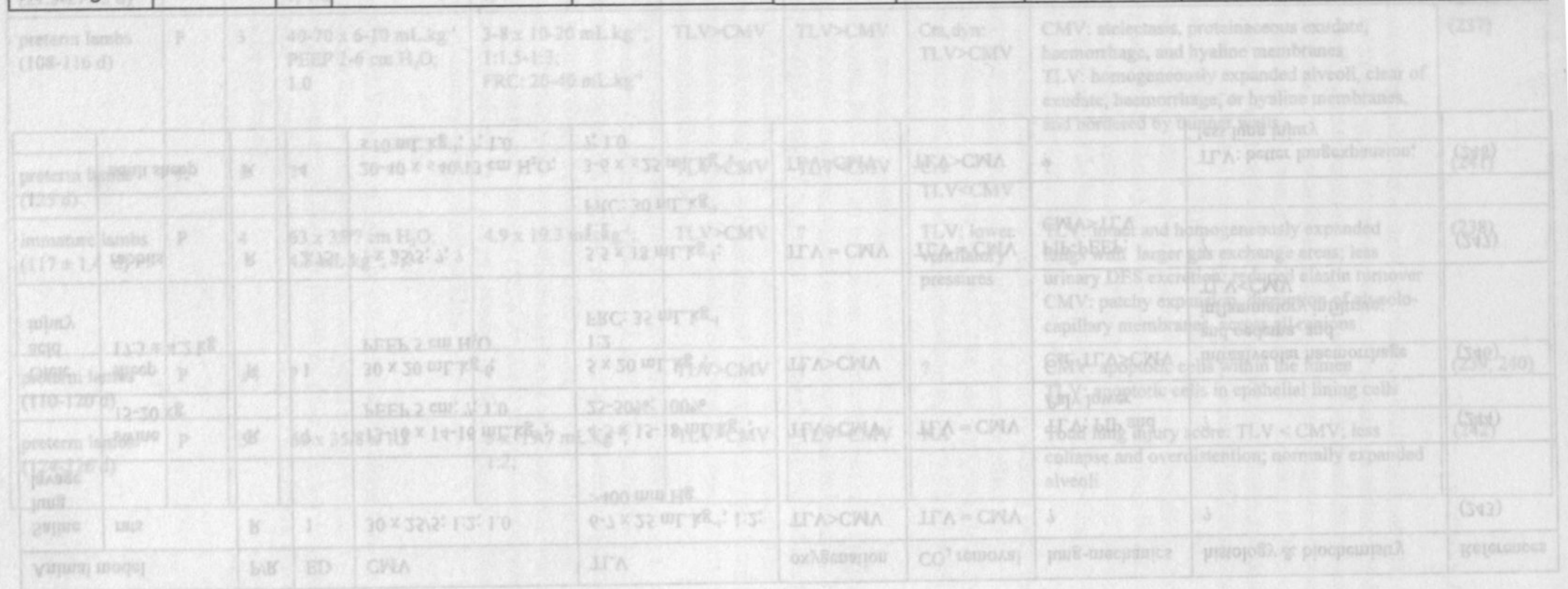


Appendix 4. Comparative studies of PLV in nRDS

\begin{tabular}{|c|c|c|c|c|c|c|c|c|c|c|}
\hline Animal model & P/R & ED & CMV & & PLV & oxygenation & $\mathrm{CO}_{2}$ removal & lung-mechanics & histology \& biochemistry & References \\
\hline $\begin{array}{l}\text { preterm baboons } \\
(140 \mathrm{~d})\end{array}$ & $\begin{array}{l}R \\
\text { (2 hrs) }\end{array}$ & 96 & 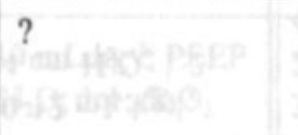 & 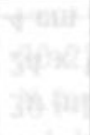 & 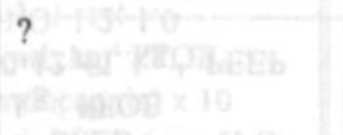 & $\mathrm{PLV}>\mathrm{CMV}$ & ? & PLV $>$ CMV & 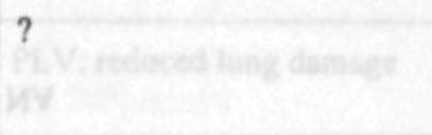 & (331) \\
\hline $\begin{array}{l}\text { lambs } \\
(125-127 d)\end{array}$ & $\begin{array}{l}\text { early R } \\
\left(30^{\prime}\right)\end{array}$ & 4.5 & $\begin{array}{l}50-60 \times 30-38 / 4 \times \\
0.33-0.50^{\prime \prime} ; 1.0 \\
V_{T} 3.6-4.9 \mathrm{~mL} . \mathrm{kg}^{-1}\end{array}$ & & $\begin{array}{l}20-25 \times 30 \text { and lower } \\
/ 4 ; 0.75^{\prime \prime} ; \\
V_{T} 11.8 \mathrm{~mL} \cdot \mathrm{kg}^{-1}\end{array}$ & $\mathrm{PLV}>\mathrm{CMV}$ & PLV $>$ CMV & $\begin{array}{l}\text { Crs,dyn: } \\
\text { PFOB>Exosurf }\end{array}$ & 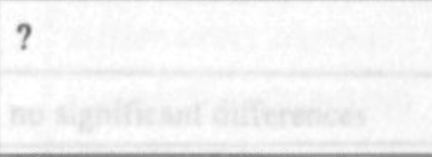 & (43) \\
\hline $\begin{array}{l}\text { lambs } \\
(125 \mathrm{~d})\end{array}$ & $\begin{array}{l}\text { early R } \\
\left(15^{\prime}\right)\end{array}$ & 6 & $\begin{array}{l}40 \times \max 40 / 3 \times 0.4 \\
1.0\end{array}$ & 4"; & $\begin{array}{l}40 \times \max 40 / 3 \times 0.4 " ; \\
1.0\end{array}$ & $\mathrm{PLV}>\mathrm{CMV}$ & PLV $>$ CMV & $\begin{array}{l}\text { Cdyn: } \\
\text { FC100>Exosurf }\end{array}$ & 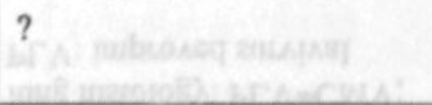 & (333) \\
\hline $\begin{array}{l}\text { lambs } \\
(125-127 d)\end{array}$ & $\begin{array}{l}R \\
\text { (2 hrs) }\end{array}$ & 2 & $\begin{array}{l}\leq 60 \times \leq 35 / 3-5 ; \leq 0.5 \\
1.0\end{array}$ & $5 "$ & $\begin{array}{l}30 \text { or } 60 \mathrm{x} \leq 35 / 3-5 \\
\leq 0.5^{\prime \prime} ; 1.0\end{array}$ & $\mathrm{PLV}>\mathrm{CMV}$ & PLV $>$ CMV & $\begin{array}{l}\text { Crs,dyn: } \\
\text { PLV>CMV }\end{array}$ & $\begin{array}{l}\text { trend to lower lung injury } \\
\text { score in PLV }\end{array}$ & (300) \\
\hline $\begin{array}{l}\text { preterm rabbits } \\
(27 \mathrm{~d})\end{array}$ & $\mathbf{P}$ & 1 & $?+49+10^{\prime}=$ & & 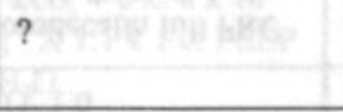 & ? & $?$ & $\begin{array}{l}\text { Crs: } \\
\text { PFOB }>\text { beractant }\end{array}$ & $?$ & (334) \\
\hline $\begin{array}{l}\text { preterm lambs } \\
\text { (115 d) }\end{array}$ & $P$ & 4 & $\begin{array}{l}30-60 \times 35-25 / 4-6 ; \\
1.0\end{array}$ & $1: 1$ & $\begin{array}{l}\text { PFOB: full FRC } \\
30-60 \times 35-25 / 4-6 ; \\
1: 1 ; 1.0\end{array}$ & $\mathrm{PLV}>\mathrm{CMV}$ & $\begin{array}{l}\mathrm{PLV}=\mathrm{CMV} \\
\text { by protocol }\end{array}$ & $\begin{array}{l}\text { PIP and MAP: } \\
\text { PLV }<\text { CMV }\end{array}$ & $\begin{array}{l}\text { PLV: augmented response to } \\
\text { iNO } \\
\text { MPO activity: } \text { PLV }<\text { CMV }\end{array}$ & (96) \\
\hline $\begin{array}{l}\text { preterm lambs } \\
\text { (115-118 d) }\end{array}$ & R (2 hrs) & 2 & $\begin{array}{l}30-40 \times 20-35 / 4-7 \\
1.0\end{array}$ & $1: 1$ & $\begin{array}{l}\text { PFOB: ful FRC } \\
30-40 \times 20-35 / 4-7 ; \\
1: 1 ; 1.0\end{array}$ & $\mathrm{PLV}>\mathrm{CMV}$ & $\begin{array}{l}\mathrm{PLV}=\mathrm{CMV} \\
\text { by protocol }\end{array}$ & $\begin{array}{l}\text { PIP and MAP: } \\
\text { PLV }<C M V\end{array}$ & $\begin{array}{l}\text { Histology and MPO-activity } \\
\text { similar }\end{array}$ & (335) \\
\hline $\begin{array}{l}\text { newborn SP-B } \\
\text { deficient mice }\end{array}$ & $\mathbf{P}$ & 0.5 & $?$ & & $?\left(b^{\prime}\left(00^{\prime}+6(3)\right)^{\prime}\right.$ & PLV $>$ CMV & $?$ & $\mathrm{PLV}>\mathrm{CMV}$ & $\begin{array}{l}\text { Histologic damage: } \\
\text { "PLV">CMV!! }\end{array}$ & (336) \\
\hline
\end{tabular}


Appendix 5. Comparative studies of PLV in saline lavage induced lung injury

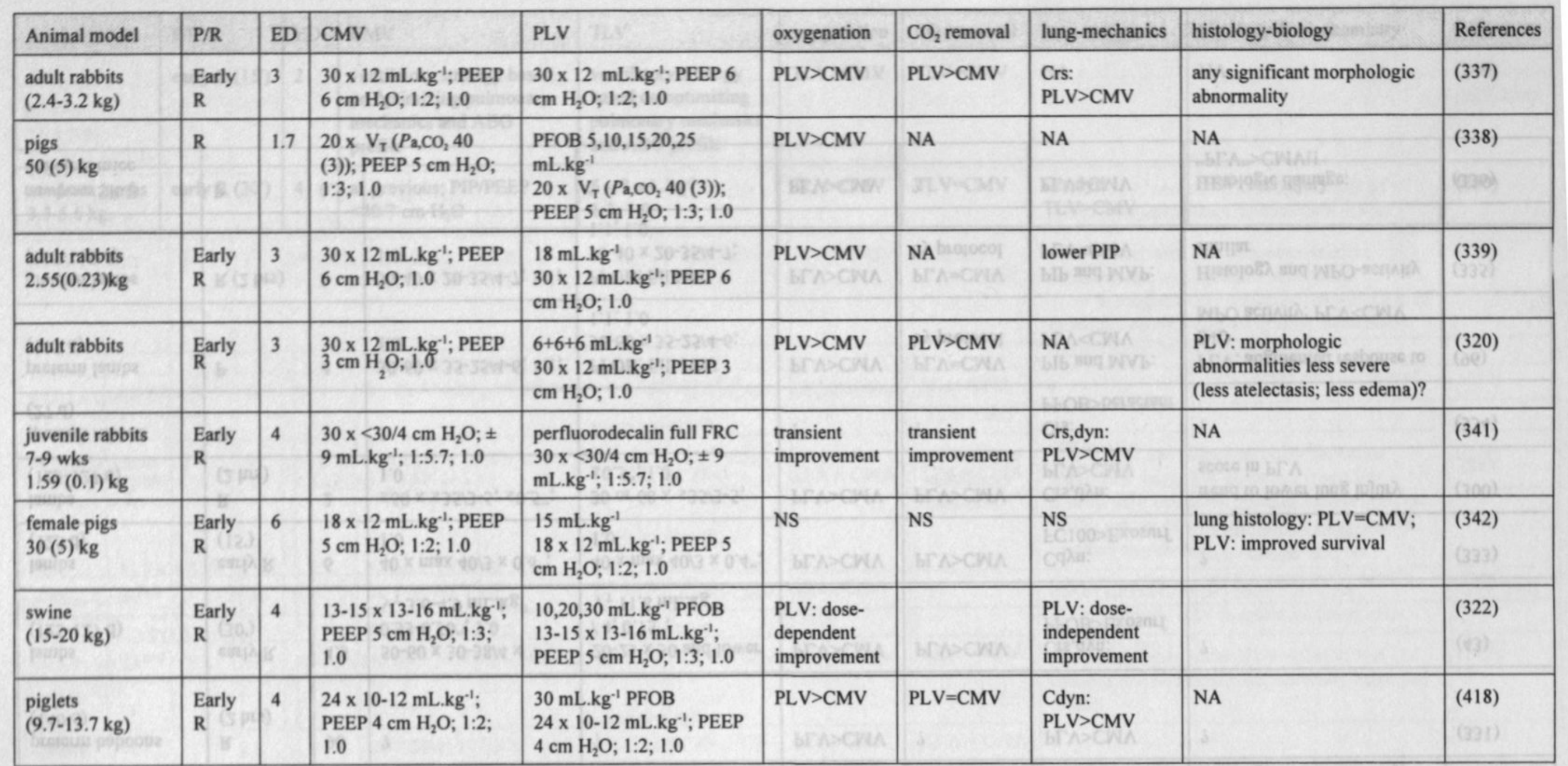




\begin{tabular}{|c|c|c|c|c|c|c|c|c|c|c|}
\hline $\begin{array}{l}\text { rabbits } \\
(2.7-3.4 \mathrm{~kg})\end{array}$ & 1 & $\begin{array}{l}\text { Early } \\
\text { R }\end{array}$ & 2 & $\begin{array}{l}25 \times 10 \mathrm{~mL} . \mathrm{kg}^{-1} ; \text { PEEP } \\
5 \mathrm{~cm} \mathrm{H} \mathrm{H}_{2} \mathrm{O} ; 1: 1 ; 1.0\end{array}$ & $\begin{array}{l}15 \mathrm{~mL} \cdot \mathrm{kg}^{-1} \text { PFOB } \\
25 \times 10 \mathrm{~mL}^{-1} \mathrm{~kg}^{-1} \text {; PEEP } 5\end{array}$ & \multirow[t]{2}{*}{$\mathrm{PLV}>\mathrm{CMV}$} & \multirow[t]{2}{*}{$\mathrm{PLV}>\mathrm{CMV}$} & $\begin{array}{l}\text { Cdyn: } \\
\text { PLV }>\text { CMV }\end{array}$ & $\begin{array}{l}\text { reduction in the severity of } \\
\text { the lung damage }\end{array}$ & \multirow[t]{2}{*}{ (344) } \\
\hline & & & & & $\mathrm{N}_{2} \mathrm{U}, 1.1,1.0$ & & & & & \\
\hline $\begin{array}{l}\text { rabbits } \\
(2.5-3.5 \mathrm{~kg})\end{array}$ & 8 & $\begin{array}{l}\text { Early } \\
\text { R }\end{array}$ & 4 & \multirow{2}{*}{$\begin{array}{l}35 \times 10 \mathrm{~mL}^{\mathrm{kg}}{ }^{-1} ; \text { PEEP } \\
6 \mathrm{~cm} \mathrm{H}_{2} \mathrm{O} ; 1: 1 ; \mathrm{SaO}_{2} \\
>85 \%\end{array}$} & \multirow{2}{*}{$\begin{array}{l}20-25 \mathrm{~mL}^{\mathrm{kg}}{ }^{-1} \text { PFOB } \\
\mathrm{N} \text { (normocapnia) x } 10 \\
\mathrm{~mL} \cdot \mathrm{kg}^{-1} ; \text { PEEP } 6 \mathrm{~cm} \mathrm{H}_{2} \mathrm{O} \\
1: 1 ; \mathrm{SaO}_{2} \geq 85 \%\end{array}$} & \multirow[t]{2}{*}{$\mathrm{PLV}>\mathrm{CMV}$} & nY & \multirow[t]{2}{*}{ NA } & \multirow[t]{2}{*}{ PLV: reduced lung damage } & $(345,346)$ \\
\hline 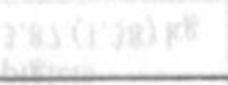 & & & & & & & & & & \\
\hline piglets & 14 & Early & 4 & \multirow{2}{*}{\multicolumn{2}{|c|}{\begin{tabular}{|l|l}
$40 \times 30 / 8 ; 1: 1 ; 1.0$ & $\begin{array}{l}30 \mathrm{~mL} \cdot \mathrm{kg}^{-1} \mathrm{FC}-75 \\
40 \times 26 / 6 ; 1: 1 ; 1.0\end{array}$ \\
& \\
& \\
\end{tabular}}} & \multirow[t]{2}{*}{$\mathrm{PLV}<\mathrm{CMV}$} & \multirow[t]{2}{*}{$=$} & \multirow{2}{*}{$\begin{array}{l}\text { Crs,E,st: } \\
\text { PLV<CMV } \\
\text { area in } \\
\text { hysteresis loop: } \\
\text { PLV }<\text { CMV }\end{array}$} & no significant differences & $(347)$ \\
\hline $\begin{array}{l}8-16 \text { days } \\
2.8-4.0 \mathrm{~kg}\end{array}$ & 8 & & & & & & & & 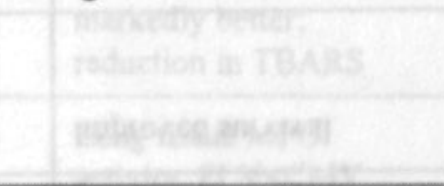 & $(25+3)$ \\
\hline rabbits & & Early & 12 & $\mathrm{~N}$ to $\mathrm{Pa}, \mathrm{CO}_{2} 4-6 \mathrm{kPa} \mathrm{x}$ & $20-25 \mathrm{~mL} \cdot \mathrm{kg}^{-1}$ PF 5080 & $\mathrm{PLV}>\mathrm{CMV}$ & & \multirow{3}{*}{$\begin{array}{l}\text { Cdyn: } \\
\text { PLV }>\text { CMV }\end{array}$} & survival improved & $(410)$ \\
\hline $3.46(0.40) \mathrm{kg}$ & 15) & & & $\begin{array}{l}10 \mathrm{~mL} \mathrm{~kg}^{-1} \times \mathrm{I}: 1 \times 1.0 \\
\text { PEEP } 4 \mathrm{~cm} \mathrm{H} \mathrm{H}_{2} \mathrm{O}\end{array}$ & $\begin{array}{l}\mathrm{N} \text { to } \mathrm{Pa}_{2} \mathrm{CO}_{2} 4-6 \mathrm{kPa} \times 10 \\
\mathrm{~mL} \cdot \mathrm{kg}^{-1} \mathrm{X} 1: 1 \times 1.0 ; \text { PEEP }\end{array}$ & $\operatorname{arn} A \times c h$ & hV & & 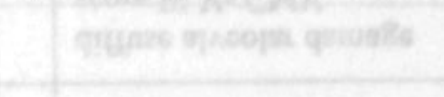 & $(300)$ \\
\hline & & & & & $4 \mathrm{~cm} \mathrm{H}_{2} \mathrm{O}$ & & & & & \\
\hline $\begin{array}{l}\text { sheep } \\
27.4(5.6) \mathrm{kg}\end{array}$ & b & $\begin{array}{l}\text { Early } \\
\text { R }\end{array}$ & 5 & \multirow{2}{*}{$\begin{array}{l}20 \times \mathrm{PIP}<\mathrm{UIP} \text { or } 35 \mathrm{~cm} \\
\mathrm{H}_{2} \mathrm{O} ; \mathrm{PEEP}=\mathrm{LIP}+1 \\
\mathrm{~cm} \mathrm{H}_{2} \mathrm{O} ; 1: 1 ; 1.0\end{array}$} & $\begin{array}{l}22 \mathrm{~mL} . \mathrm{kg}^{-1} \text { PFOB; } \\
20 \times \text { PIP }<\text { UIP or } 35 \mathrm{~cm}\end{array}$ & \multirow[t]{2}{*}{ no difference } & \multirow{2}{*}{$\begin{array}{l}\text { better } \\
\text { ventilation } \\
\text { with PLV }\end{array}$} & $\begin{array}{l}\text { improved } \\
\text { quasi-static }\end{array}$ & \multirow{2}{*}{$\begin{array}{l}\text { less alveolar collapse in } \\
\text { dependent lung regions after } \\
\text { PLV }\end{array}$} & $(350)$ \\
\hline $28.8(7.2) \mathrm{kg}$ & & & & & $\begin{array}{l}\mathrm{H}_{2} \mathrm{O} ; \text { PEEP LIP }+1 \mathrm{~cm} \\
\mathrm{H}_{2} \mathrm{O} ; 1: 1 ; 1.0\end{array}$ & & & $\begin{array}{l}\text { lung } \\
\text { compliance }\end{array}$ & & \\
\hline
\end{tabular}


Appendix 6. Comparative studies of PLV in oleic acid lung injury

\begin{tabular}{|c|c|c|c|c|c|c|c|c|c|c|}
\hline Animal model & P/R & & ED & CMV & PLV & oxygenation & $\mathrm{CO}_{2}$ removal & lung-mechanics & histology-biology & References \\
\hline $\begin{array}{l}\text { dogs } \\
17.9(2.5) \mathrm{kg}\end{array}$ & & and $R$ & $2.5-4$ & $\begin{array}{l}20 \times \mathrm{V}_{\mathrm{T}}\left(\mathrm{Pa}_{2} \mathrm{CO}_{2}=35-\right. \\
45) ; \mathrm{PEEP} 6 \mathrm{~cm} \mathrm{H} \mathrm{H}_{2} \mathrm{O} \\
1: 1 ; 1.0\end{array}$ & $\begin{array}{l}\text { perflubron } 10-20-30-40-50-60 \\
\text { mL.kg-1 } \\
20 \mathrm{x} \mathrm{V}_{\mathrm{T}}\left(P_{\mathrm{a}}, \mathrm{CO}_{2}=35-45\right) \\
\text { PEEP } 6 \mathrm{~cm} \mathrm{H}_{2} \mathrm{O} ; 1: 1 ; 1.0\end{array}$ & $\mathrm{PLV}>\mathrm{CMV}$ & $\begin{array}{l}\text { decided by } \\
\text { protocol }\end{array}$ & $\begin{array}{l}\text { PLV: increased } \\
\text { compliance until } \\
40 \mathrm{~mL}^{-\mathrm{kg}^{-1}}\end{array}$ & lung histology similar & (316) \\
\hline $\begin{array}{l}\text { sheep } \\
17.2(1.8) \mathrm{kg}\end{array}$ & $\mathbf{R}$ & & 2.5 & $\mathrm{~V}_{\mathrm{T}} 15 \mathrm{~mL} \cdot \mathrm{kg}$ & $\begin{array}{l}\text { PFOB } 35 \mathrm{~mL} \cdot \mathrm{kg}^{-1} \\
\mathrm{~V}_{\mathrm{T}} 15 \mathrm{~mL} \cdot \mathrm{kg}^{-1}\end{array}$ & $\mathrm{PLV}>\mathrm{CMV}$ & NA & Crs: PLV $>C M V$ & & (352) \\
\hline $\begin{array}{l}\text { sheep } \\
17.1(1.8) \mathrm{kg}\end{array}$ & $\mathbf{R}$ & 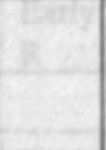 & 2.5 & $\begin{array}{l}30 \mathrm{x}<50 / 4 \mathrm{~cm} \mathrm{H}_{2} \mathrm{O} ; \text {; } \\
1.0\end{array}$ & $\begin{array}{l}\text { PFOB } 30 \mathrm{~mL}^{-\mathrm{kg}^{-1}} \\
30 \mathrm{x}<50 / 4 \mathrm{~cm} \mathrm{H}_{2} \mathrm{O} ; ? ; 1.0\end{array}$ & $\mathrm{PLV}>\mathrm{CMV}$ & NA & $\begin{array}{l}\text { Crs,st: } \\
\text { PLV }>\text { CMV }\end{array}$ & $\begin{array}{l}\text { reduction of } \\
\text { inflammatory response } \\
\text { reduction in lung injury }\end{array}$ & (353) \\
\hline $\begin{array}{l}\text { sheep } \\
54.0(3.4)\end{array}$ & $\mathbf{R}$ & $\operatorname{lin} 2$ & 2.5 & $\begin{array}{l}15 \times 15 \mathrm{~mL} . \mathrm{kg} ; \text { PEEP } \\
6 \mathrm{~cm} \mathrm{H} \mathrm{H}_{2} \mathrm{O} ; ? ; 1.0\end{array}$ & $\begin{array}{l}\text { PFOB 10-20-30-40-50 mL.kg-1 } \\
15 \times 15 \mathrm{~mL} . \mathrm{kg} ; \text { PEEP } 6 \mathrm{~cm} \\
\mathrm{H}_{2} \mathrm{O} ; ? ; 1.0\end{array}$ & $\mathrm{PLV}>\mathrm{CMV}$ & NS & $\begin{array}{l}\text { Crs,st: } \\
\text { PLV=CMV }\end{array}$ & 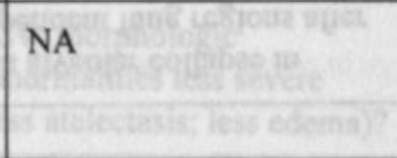 & $(326)$ \\
\hline $\begin{array}{l}\text { sheep } \\
64.9(6.4)\end{array}$ & $\mathbf{R}$ & (2) & 1.5 & $\begin{array}{l}12 \times 12-15 \mathrm{~mL} . \mathrm{kg} ; \\
\text { PEEP } 5 \mathrm{~cm} \mathrm{\textrm {H } _ { 2 } \mathrm { O } ;} ; \\
1.0\end{array}$ & $\begin{array}{l}\text { PFOB } 30 \mathrm{~mL} \cdot \mathrm{kg}^{-1} \\
12 \times 12-15 \mathrm{~mL} \cdot \mathrm{kg}^{\prime} \text { PEEP } 5 \mathrm{~cm} \\
\mathrm{H}_{2} \mathrm{O} ; ? ; 1.0\end{array}$ & PLV $>$ CMV & NA & NA & $\begin{array}{l}\text { diffuse alveolar damage } \\
\text { score PLV }<\text { CMV } \\
\text { morphometrics improved }\end{array}$ & $(354)$ \\
\hline $\begin{array}{l}\text { neonatal } \\
\text { piglets } \\
2.6(0.32) \mathrm{kg}\end{array}$ & $\mathbf{R}$ & 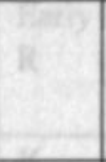 & 3 & $\begin{array}{l}25 \times 10-15 \mathrm{~mL} . \mathrm{kg} ; \\
\text { PEEP } 5 \mathrm{~cm} \mathrm{H} \mathrm{H}_{2} \mathrm{O} ; \mathrm{I}: 3 \\
1.0\end{array}$ & $\begin{array}{l}\text { PFOB } 30 \mathrm{~mL} . \mathrm{kg}^{-1} \\
25 \times 10-15 \mathrm{~mL} . \mathrm{kg}^{-} \text {PEEP } 5 \mathrm{~cm} \\
\mathrm{H}_{2} \mathrm{O} ; 1: 3 ; 1.0\end{array}$ & $\mathrm{PLV}>\mathrm{CMV}$ & $\mathrm{PLV}>\mathrm{CMV}$ & $\begin{array}{l}\text { Crs,st: } \\
\text { PLV }>\text { CMV }\end{array}$ & improved survival & (357) \\
\hline $\begin{array}{l}\text { neonatal } \\
\text { piglets } \\
3.87(1.38) \mathrm{kg}\end{array}$ & P & $2=4$ & 3 & $\begin{array}{l}25 \times 10-15 \mathrm{~mL} . \mathrm{kg} ; \\
\text { PEEP } 5 \mathrm{~cm} \mathrm{H} \mathrm{H}_{2} \text {; } 1: 3 \text {; } \\
1.0\end{array}$ & $\begin{array}{l}\text { PFOB } 30 \mathrm{~mL} \cdot \mathrm{kg}^{-1} \\
25 \times 10-15 \mathrm{~mL} \cdot \mathrm{kg}^{-} \text {PEEP } 5 \mathrm{~cm} \\
\mathrm{H}_{2} \mathrm{O} ; 1: 3 ; 1.0\end{array}$ & 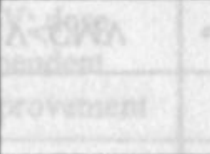 & & Elitonet & alveolar protein reduced & (358) \\
\hline $\begin{array}{l}\text { sheep } \\
22-29 \mathrm{~kg}\end{array}$ & $\mathbf{R}$ & 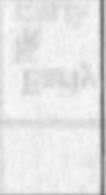 & 1.5 & $\begin{array}{l}\text { 10-16 x } 15 \mathrm{~mL} . \mathrm{kg} ; \\
\text { PEEP } 5-7 \mathrm{~cm} \mathrm{H}_{2} \mathrm{O} ; \\
1: 1 ; 1.0\end{array}$ & $\begin{array}{l}\text { PFOB } 30 \mathrm{~mL} \cdot \mathrm{kg}^{-1} \\
10-16 \times 15 \mathrm{~mL} . \mathrm{kg} ; \text { PEEP } 5-7 \\
\mathrm{~cm} \mathrm{H}_{2} \mathrm{O} ; 1: 1 ; 1.0\end{array}$ & $\mathrm{PLV}>\mathrm{CMV}$ & NA & $\begin{array}{l}\text { PLV: end- } \\
\text { expiratory lung } \\
\text { volume } \\
\text { increased }\end{array}$ & NA & $(361)$ \\
\hline
\end{tabular}

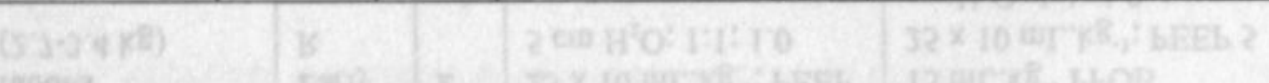

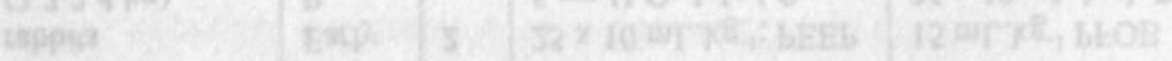

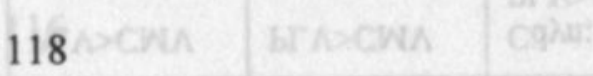




\begin{tabular}{|c|c|c|c|c|c|c|c|c|c|}
\hline $\begin{array}{l}\text { mongrel dogs } \\
13.6-23.2 \mathrm{~kg}\end{array}$ & R 2 & 0.75 & $\begin{array}{l}\text { 10-18 x } 15 \mathrm{~mL}_{.} \mathrm{kg}^{-1} \\
\text { PEEP } 5-7 \mathrm{~cm} \mathrm{H}_{2} \text {; } \\
1: 1 ; 1.0\end{array}$ & $\begin{array}{l}\text { PFOB } 30 \mathrm{~mL}^{-\mathrm{kg}^{-1}} \\
10-18 \text { x } 15 \mathrm{~mL}^{-1} \mathrm{~kg}^{-1} \\
\text { PEEP } 5-7 \mathrm{~cm} \mathrm{H}_{2} \mathrm{O} ; 1: 1 ; 1.0\end{array}$ & $\mathrm{PLV}>\mathrm{CMV}$ & NA & NA & $\begin{array}{l}\text { PLV: less increase in } \\
\text { TLW }\end{array}$ & (362) \\
\hline beagle dogs & early $R$ & 5 & & full FRC perfluorodecalin & $\mathrm{PLV}>\mathrm{CMV}$ & PLV $>$ CMV & $\mathrm{PLV}=\mathrm{CMV}$ & $\begin{array}{l}\text { number of inflammatory } \\
\text { cells in BALF: } \\
\text { PLV<CMV } \\
\text { PLV: decreased } \\
\text { inflammatory response }\end{array}$ & (363) \\
\hline $\begin{array}{l}\text { piglets } \\
3.55(0.73) \mathrm{kg}\end{array}$ & early R & 3 & $\begin{array}{l}20 \times 12-15 \mathrm{~mL} . \mathrm{kg} ; \\
\text { PEEP } 4 \mathrm{~cm} \mathrm{H} \text {; } \\
1.0\end{array}$ & $\begin{array}{l}\text { PFOB } 30 \text { mL.kg-1 } \\
20 \times 12-15 \text { mL.kg; PEEP } 4 \mathrm{~cm} \\
\mathrm{H}_{2} \mathrm{O} ; ? ; 1.0\end{array}$ & $\mathrm{PLV}>\mathrm{CMV}$ & NA & $\begin{array}{l}\text { improved } \\
\text { survival }\end{array}$ & $\begin{array}{l}\text { histological appearance } \\
\text { markedly better; } \\
\text { reduction in TBARS }\end{array}$ & (364) \\
\hline $\begin{array}{l}\text { mongrel dogs } \\
(18.0-25.6 \mathrm{~kg})\end{array}$ & $\mathbf{R}$ & 21 & $\begin{array}{l}\mathrm{N}\left(\text { normal } P_{2}, \mathrm{CO}_{2}\right) \times 15 \\
\mathrm{~mL} . \mathrm{kg} ; \text { PEEP } 7.5 \mathrm{~cm} \\
\mathrm{H}_{2} \mathrm{O} ; ? ; 1.0\end{array}$ & $\begin{array}{l}\text { PFOB } 10 \text { or } 30 \mathrm{~mL} . \mathrm{kg}^{-1} \\
\mathrm{~N}\left(\text { normal } \mathrm{Pa}_{\mathrm{a}} \mathrm{CO}_{2} \text { ) } \times 15 \mathrm{~mL} . \mathrm{kg} ;\right. \\
\text { PEEP } 7.5 \mathrm{~cm} \mathrm{H}_{2} \mathrm{O} ; ? ; 1.0\end{array}$ & $\mathrm{PLV}<\mathrm{CMV}$ & $\begin{array}{l}\mathrm{PLV}=\mathrm{CMV} \\
\text { by protocol }\end{array}$ & NA & $\begin{array}{l}\text { Lung tissue MPO } \\
\text { activity: PLV }<\text { CMV }\end{array}$ & (366). \\
\hline
\end{tabular}


Appendix 7. Comparative studies of PLV in gastric acid aspiration lung injury

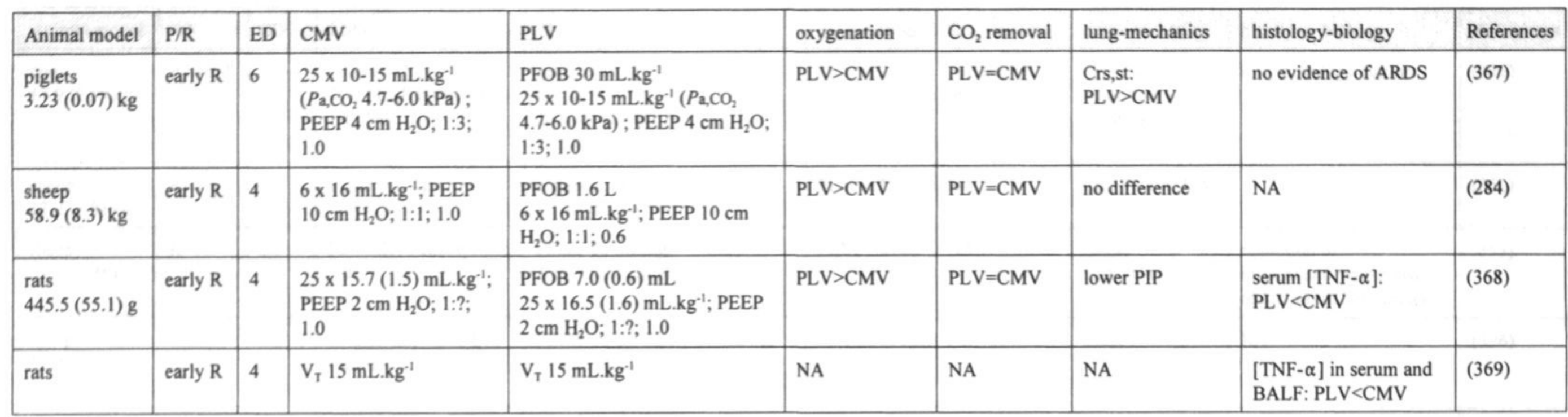


Appendix 8. Comparative studies of PLV in meconium aspiration syndrome

\begin{tabular}{|c|c|c|c|c|c|c|c|c|c|}
\hline Animal model & $\mathrm{P} / \mathrm{R}$ & ED & $\mathrm{CMV}$ & PLV & oxygenation & $\mathrm{CO}_{2}$ removal & lung-mechanics & histology-biochemical & References \\
\hline $\begin{array}{l}\text { neonatal } \\
\text { piglets } \\
\leq 10 \text { days }\end{array}$ & early $R$ & 5 & ? & $=\mathrm{CMV}$ & $\mathrm{PLV}>\mathrm{CMV}$ & NA & $?$ & $?$ & (384) \\
\hline $\begin{array}{l}\text { term newly } \\
\text { born lambs }\end{array}$ & $\mathbf{R}$ & 3 & $\begin{array}{l}\text { ? } \times \text { ?; PEEP } 3-4 \mathrm{~cm} \mathrm{H}_{2} \mathrm{O} \\
1: ? ; 1.0\end{array}$ & PFOB ? mL & $\mathrm{PLV}>\mathrm{CMV}$ & NA & Crs,dyn: PLV>CMV & $?$ & (385) \\
\hline $\begin{array}{l}\text { newborn lambs } \\
3.5-5.6 \mathrm{~kg}\end{array}$ & $\begin{array}{l}\text { early R } \\
\left(30^{\prime}\right)\end{array}$ & 4 & $\begin{array}{l}\text { ventilatory strategy based } \\
\text { on optimizing pulmonary } \\
\text { mechanics and arterial } \\
\text { blood gas profile; } \\
\text { PIP/PEEP }<40 / 7 \mathrm{~cm} \mathrm{H}_{2} \mathrm{O}\end{array}$ & $=\mathrm{CMV}$ & $\mathrm{PLV}>\mathrm{CMV}$ & $\mathrm{PLV}=\mathrm{CMV}$ & $\begin{array}{l}\text { Crs,dyn: } \\
\text { PLV=CMV }\end{array}$ & $\begin{array}{l}\text { atelectasis - over- } \\
\text { expansion less evident } \\
\text { in PLV }\end{array}$ & (250) \\
\hline $\begin{array}{l}\text { newborn lambs } \\
4.8(1.1) \mathrm{kg}\end{array}$ & early $R$ & $?$ & $?$ & $?$ & $\mathrm{PLV}>\mathrm{CMV}$ & $\mathrm{PLV}>\mathrm{CMV}$ & $?$ & $?$ & (386) \\
\hline $\begin{array}{l}\text { newborn } \\
\text { piglets } \\
1.2-2.0 \mathrm{~kg}\end{array}$ & early $R$ & 4 & $\begin{array}{l}\leq 80 x<30 \mathrm{~cm} \mathrm{H}_{2} \mathrm{O} \\
\text { PEEP } 4 \mathrm{~cm} \mathrm{H} \mathrm{H}_{2} \mathrm{O} ; 1: ? ; \\
0.90 \\
P_{\mathrm{a}, \mathrm{CO}_{2}} 5.3-8.0 \mathrm{kPa}\end{array}$ & $\begin{array}{l}\text { perfluorodecalin } \\
\text { s } 80 \times<30 \mathrm{~cm} \mathrm{H}_{2} \mathrm{O} ; \text { PEEP } \\
2 \mathrm{~cm} \mathrm{H} \mathrm{H}_{2} \mathrm{O} ; 1: ? ; 0.90 ? \\
\mathrm{~Pa}_{2}, \mathrm{CO}_{2} 5.3-8.0 \mathrm{kPa}\end{array}$ & $\mathrm{PLV}>\mathrm{CMV}$ & $\mathrm{PLV}>\mathrm{CMV}$ & $\begin{array}{l}\text { dynamic respiratory } \\
\text { system compliance } \\
\text { improved } \\
\text { Crs,dyn: } \mathrm{PLV}>\mathrm{CMV}\end{array}$ & $\begin{array}{l}\text { injury scores not } \\
\text { different }\end{array}$ & $(387,388)$ \\
\hline
\end{tabular}


Appendix 9. Comparative studies of PLV in congenital diaphragmatic hernia

\begin{tabular}{|c|c|c|c|c|c|c|c|c|c|}
\hline Animal model & $\mathrm{P} / \mathrm{R}$ & ED & CMV & PLV & oxygenation & $\mathrm{CO}_{2}$ removal & lung-mechanics & histology-biochemistry & References \\
\hline $\begin{array}{l}\text { near term lambs }(141 \mathrm{~d}) \\
\text { CMV: } 3.68(0.17) \mathrm{kg} \\
\text { PLV: } 4.25(0.36) \mathrm{kg}\end{array}$ & early $R$ & 3.75 & $\begin{array}{l}60 \times 25 / 4 \mathrm{~cm} \mathrm{H}_{2} \mathrm{O} ; \\
1: ? ; 1.0\end{array}$ & $\begin{array}{l}\text { PFOB full FRC } \\
60 \times 25 / 4 \mathrm{~cm} \mathrm{H}_{2} \mathrm{O} ; 1: ? \\
1.0\end{array}$ & PLV $>$ CMV & $\mathrm{PLV}>\mathrm{CMV}$ & Cdyn: PLV $>$ CMV & NA & (389) \\
\hline $\begin{array}{l}\text { near term lambs }(141 \mathrm{~d}) \\
\text { CMV: } 3.14(1.07) \mathrm{kg} \\
\text { PLV: } 4.17(0.49) \mathrm{kg}\end{array}$ & early $R$ & 3.75 & $\begin{array}{l}60 \times 30 / 5 \mathrm{~cm} \mathrm{H}_{2} \mathrm{O} ; \\
1: ? ; 0.9\end{array}$ & $\begin{array}{l}\text { PFOB full FRC } \\
60 \times 30 / 5 \mathrm{~cm} \mathrm{H} \mathrm{H}_{2} \mathrm{O} ; 1: ? \\
0.9\end{array}$ & $\mathrm{PLV}>\mathrm{CMV}$ & $\mathrm{PLV}>\mathrm{CMV}$ & Cdyn: PLV $>$ CMV & NA & (390) \\
\hline $\begin{array}{l}\text { near term lambs (139 d) } \\
4.07(0.29) \mathrm{kg}\end{array}$ & $\mathbf{R}$ & 3 & $\begin{array}{l}60-100 \times 25-30 / 3-5 \\
\mathrm{~cm} \mathrm{H}_{2} \mathrm{O} ; 1: ? ; 1.0\end{array}$ & $\begin{array}{l}\text { PFOB } 10-12 \mathrm{~mL} \cdot \mathrm{kg}^{-1} \\
60-100 \times 25-30 / 3-5 \mathrm{~cm} \\
\mathrm{H}_{2} \mathrm{O} ; 1: 2 ; 1.0\end{array}$ & $\begin{array}{l}\mathrm{PLV}>\mathrm{CMV} \\
\text { transiently }\end{array}$ & $\mathrm{PLV}>\mathrm{CMV}$ & $\begin{array}{l}\text { Cdyn: } \\
\text { PLV }>\text { CMV }\end{array}$ & $\begin{array}{l}\text { no differences in } \\
\text { histology }\end{array}$ & $(391,392)$ \\
\hline term rat pups & $\mathbf{R}$ & 4 & $\begin{array}{l}40 \times 25-17 / 3 \mathrm{~cm} \mathrm{H}_{2} \mathrm{O} ; \\
1: ? ; 1.0\end{array}$ & $\begin{array}{l}\text { Rimar-101 } 15 \mathrm{~mL} . \mathrm{kg}^{-1} \\
40 \times 25-17 / 3 \mathrm{~cm} \mathrm{H}_{2} \mathrm{O} \text {; } \\
1: ? ; 1.0\end{array}$ & NA & $\mathrm{NA}$ & $\begin{array}{l}\text { increased total lung } \\
\text { volume; } \\
\text { improved opening } \\
\text { pressure }\end{array}$ & $\begin{array}{l}\text { PLV: improved } \\
\text { aeration pattern; } \\
\text { increased expression of } \\
\text { HSP-70 and } 27 \text { in } \\
\text { CMV }\end{array}$ & $\begin{array}{l}(393-395, \\
539,540)\end{array}$ \\
\hline
\end{tabular}


1. Kylstra JA, Tissing MO, van der Maen A. Of mice as fish. Trans ASAIO 1962;8:378-383.

2. Kylstra JA. Survival of submerged mammals. N Engl J Med 1965;272(4):198-200.

3. Kylstra JA, Paganelli CV, Lanphier EH. Pulmonary gas exchange in dogs ventilated with hyperbarically oxygenated liquid. J Appl Physiol 1966;21(1):177-84.

4. Clark LC, Jr., Gollan F. Survival of mammals breathing organic liquids equilibrated with oxygen at atmospheric pressure. Science 1966;152(730):1755-6.

5. Gollan F, Clark RM. Experimental pathology after respiration and injection of various fluorocarbon liquids. Exp Med Surg 1968;26(4):249-62 .

6. Gollan F, Clark LC. Prevention of bends by breathing an organic liquid. Trans Assoc Am Physicians 1967;80:102-10.

7. Gollan F, Clark LC, Jr. Rapid decompression of mice breathing fluorocarbon liquid at 500 PSI. Ala J Med Sci 1967;4(3):336-7.

8. Lynch PR, Wilson JS, Shaffer TH, Cohen N. Decompression incidence in air- and liquid-breathing hamsters. Undersea Biomed Res 1983;10(1):1-10.

9. Gollan F, McDermott J, Johnson AE, Namon R. Compliance and diffusion during respiration with fluorocarbon fluid. Fed Proc 1970;29(5):1725-30.

10. Leith DE, Jere M. Maximum expiratry flow in liquid-filled lungs. Fed Proc 1966;25:506.

11. Hamosh P, Luchsinger PC. Maximum expiratory flow in isolated liquid-filled lungs. J Appl Physiol 1968;25(5):485-8.

12. Modell JH, Gollan F, Giammona ST, Parker D. Effect of fluorocarbon liquid on surface tension properties of pulmonary surfactant. Chest 1970;57(3):263-5.

13. Gabriel JL, Miller TF, Jr., Wolfson MR, Shaffer TH. Quantitative structure-activity relationships of perfluorinated hetero-hydrocarbons as potential respiratory media. Application to oxygen solubility, partition coefficient, viscosity, vapor pressure, and density. ASAIO J 1996;42(6):968-73.

14. Ruefer R. [Alveolar surface forces in ventilation of liquids] Alveolare Oberflachenkrafte bei Flussigkeitsatmung. Pflugers Arch 1969;307(2):R14.

15. Ruefer R. Surfactant and alveolar surface forces after breathing of an inert fluorinated liquid. Fed Proc 1970;29(5): 1813-5.

16. Wesseler EP, LIltis R, Clark LC. The solubility of oxygen in highly fluorinated liquids. J Fluor Chemistry 1977;9:137-146.

17. Koen PA, Wolfson MR, Shaffer TH. Fluorocarbon ventilation: maximal expiratory flows and $\mathrm{CO} 2$ elimination. Pediatr Res 1988;24(3):291-6.

18. Shaffer TH, Wolfson MR, Greenspan JS, Hoffman RE, Davis SL, Clark LC, Jr. Liquid ventilation in premature lambs: uptake, biodistribution and elimination of perfluorodecalin liquid. Reprod Fertil Dev 1996;8(3):409-16.

19. Stavis RL, Wolfson MR, Cox C, Kechner N, Shaffer TH. Physiologic, biochemical, and histologic correlates associated with tidal liquid ventilation. Pediatr Res 1998;43(1):132-8.

20. Shaffer TH, Wolfson MR. Liquid ventilation. In: Polin RA, Fox WA, editors. Fetal and neonatal physiology. 2nd ed. Philadelphia: W.B. Saunders Company; 1998. p. 1219-1242.

21. Mandl M, Harris K, Wolfson MR, Shaffer TH. Body temperature dependent differences in perfluorochemical (PFC) tissue and blood content during partial liquid ventilation (PLV). Pediatr Res 2000;47(4):59A.

22. Steinhorn DM, Smith TM, Fuhrman BP. Liquid perfluorocarbon affects phagocytosis by alveolar macrophages after in vitro exposure. Crit Care Med 1995;23(1 suppl):A213.

23. Smith TM, Steinhorn DM, Thusu K, Fuhrman BP, Dandona P. A liquid perfluorochemical decreases the in vitro production of reactive oxygen species by alveolar macrophages. Crit Care Med 1995;23(9):1533-9.

24. Thomassen MJ, Buhrow LT, Wiedemann HP. Perflubron decreases inflammatory cytokine production by human alveolar macrophages. Crit Care Med 1997;25(12):2045-7.

25. Smith D, Neslund G, Flaim SF. Perflubron (Liquivent) partially inhibits the human macrophage response to LPS in vitro. In: Liquid ventilation: a symposium; 1996 September 19; Ann Arbor, MI; 1996. p. 25. 
26. Sterner-Kock A. Partial liquid ventilation with perfluorocarbons induces structural pulmonary changes and alters the respiratory burst in alveolar macrophages. Am J Respir Crit Care Med 1998;157:A369.

27. Baba A, Kim YK, Zhang H, Liu M, Slutsky AS. Perfluorocarbon blocks tumor necrosis factor-alphainduced interleukin-8 release from alveolar epithelial cells in vitro. Crit Care Med 2000;28(4):1113-8.

28. Virmani R, Fink LM, Gunter K, English D. Effect of perfluorochemical blood substitutes on human neutrophil function. Transfusion 1984;24(4):343-7.

29. Varani J, Hirschl RB, Dame M, Johnson K. Perfluorocarbon protects lung epithelial cells from neutrophil-mediated injury in an in vitro model of liquid ventilation therapy. Shock 1996;6(5):339-44.

30. Rossman JE, Caty MG, Rich GA, Karamanoukian HL, Azizkhan RG. Neutrophil activation and chemotaxis after in vitro treatment with perfluorocarbon. J Pediatr Surg 1996;31(8):1147-50.

31. Koch T, Ragaller M, Haufe D, Hofer A, Grosser M, Albrecht DM, et al. Perfluorohexane attenuates proinflammatory and procoagulatory response of activated monocytes and alveolar macrophages. Anesthesiology 2001;94(1):101-109.

32. Woods CM, Neslund G, Kornbrust E, Flaim SF. Perflubron attenuates neutrophil adhesion to activated endothelial cells in vitro. Am J Physiol Lung Cell Mol Physiol 2000;278(5):L1008-17.

33. Obraztsov VV, Neslund GG, Kornbrust ES, Flaim SF, Woods CM. In vitro cellular effects of perfluorochemicals correlate with their lipid solubility. Am J Physiol Lung Cell Mol Physiol 2000;278(5):L1018-24.

34. Nader ND, Knight PR, Davidson BA, Safaee SS, Steinhorn DM. Systemic perfluorocarbons suppress the acute lung inflammation after gastric acid aspiration in rats. Anesth Analg 2000;90(2):356-61.

35. Nesti F, Cosio C, Bu JC, Walding D, Smith O. Modulation of epidermal wound healing with perflubron in full thickness burns of the rat. Crit Care Med 1996;24(1 suppl):A139.

36. Nesti F, Cosio C, Walding D, Bu JC, Smith O. Modulation of inflammation with perflubron in the murine model of dextran sulfate sodium induced ulcerative colitis. Crit Care Med 1996;24:A33.

37. Leese PT, Noveck RJ, Shorr JS, Woods CM, Flaim KE, Keipert PE. Randomized safety studies of intravenous perflubron emulsion. I. Effects on coagulation function in healthy volunteers. Anesth Analg 2000;91(4):804-11.

38. Noveck RJ, Shannon EJ, Leese PT, Shorr JS, Flaim KE, Keipert PE, et al. Randomized safety studies of intravenous perflubron emulsion. II. Effects on immune function in healthy volunteers. Anesth Analg 2000;91(4):812-22.

39. Kishioka C, Dorighi MP, Rubin BK. Perfluorooctyl bromide (perflubron) stimulates mucin secretion in the ferret trachea. Chest 1999;115(3):823-8.

40. Dickson EW, Heard SO, Brueggemann AB, Doern GV. Spontaneous perfluorocarbon ventilation as a treatment for lethal pneumococcal pneumonia in mice. Crit Care Med 1996;24(suppl 1):A106.

41. Sajan I, Scannapieco FA, Fuhrman BP, Steinhorn DM. The risk of nosocomial pneumonia is not increased during partial liquid ventilation. Crit Care Med 1999;27(12):2741-7.

42. Jung R, Pendland SL, Martin SJ. The effect of partial liquid ventilation with perfluoroctylbromide on bacterial growth. Crit Care Med 1998;26(1 Suppl):A101.

43. Leach CL, Holm B, Morin FC, Fuhrman BP, Papo MC, Steinhorn D, et al. Partial liquid ventilation in premature lambs with respiratory distress syndrome: efficacy and compatibility with exogenous surfactant. J Pediatr 1995;126(3):412-20.

44. Leach CL, Holm BA, Morin FC, Fuhrman BP, Papo MC, Hernan LJ. Partial liquid ventilation with LiquiventTM increases endogenous surfactant production in premature lambs with respiratory distress syndrome (RDS). Pediatr Res 1995;37:220A.

45. Steinhorn DM, Leach CL, Fuhrman BP, Holm BA. Partial liquid ventilation enhances surfactant phospholipid production. Crit Care Med 1996;24(7):1252-6.

46. Eckmann DM, Swartz MA, Gavriely N, Glucksberg MR, Grotberg JB. Influence of intravenous perfluorocarbon administration on the dynamic behavior of lung surfactant. Artif Cells Blood Substit Immobil Biotechnol 1998;26(4):359-66.

47. Eckmann DM, Swartz MA, Glucksberg MR, Gavriely N, Grotberg JB. Perfluorocarbon induced alterations in pulmonary mechanics. Artif Cells Blood Substit Immobil Biotechnol 1998;26(3):25971.

48. Schurch S, Amato M, Valls-i-Soler A, Green FHY. Surface properties od surfactant-perfluorocarbon fluid combinations related to partial and total liquid ventilation. In: 2nd European Symposium on Liquid Ventilation; 2000 October 2-3, 2000; Bilbao; 2000. p. 15. 
49. Riess JG. Overview of progress in the fluorocarbon approach to in vivo oxygen delivery. Biomater Artif Cells Immobilization Biotechnol 1992;20(2-4):183-202.

50. Lowe KC. Perfluorinated blood substitutes and artificial oxygen carriers. Blood Rev 1999;13(3):17184.

51. Peyman GA, Schulman JA, Sullivan B. Perfluorocarbon liquids in ophthalmology. Surv Ophthalmol 1995;39(5):375-95.

52. Wong D, Lois N. Perfluorocarbons and semifluorinated alkanes. Semin Ophthalmol 2000;15(1):2535 .

53. Redding GJ, Standaert TA, Jackson JC. Perfluorocarbon as a vehicle for diagnostic bronchoalveolar lavage (BAL). Am J Respir Crit Care Med 1994;149(4(2)):A935.

54. Marraro G, Bonati M, Ferrari A, Barzaghi MM, Pagani C, Bortolotti A, et al. Perfluorocarbon broncho-alveolar lavage and liquid ventilation versus saline broncho-alveolar lavage in adult guinea pig experimental model of meconium inhalation. Intensive Care Medicine 1998;24(5):501-508.

55. Tsai WC, Lewis D, Nasr SZ, Hirschl RB. Liquid ventilation in an infant with pulmonary alveolar proteinosis. Pediatr Pulmonol 1998;26(4):283-6.

56. O' Donnell KA, Caty MG, Zheng S, Rossman JE, Azizkhan RG. Oxygenated intraluminal perfluorocarbon protects intestinal muscosa from ischemia/reperfusion injury. J Pediatr Surg 1997;32(2):361-5.

57. Nobuhara KK, Fauza DO, DiFiore JW, Hines MH, Fackler JC, Slavin R, et al. Continuous intrapulmonary distension with perfluorocarbon accelerates neonatal (but not adult) lung growth. Journal Of Pediatric Surgery 1998;33(2):292-297.

58. Nobuhara KK, Ferretti ML, Siddiqui AM, Kim SS, Treves ST, Wilson JM. Long-term effect of perfluorocarbon distension on the lung. Journal Of Pediatric Surgery 1998;33(7):1024-1028.

59. Fox WW, Weis CM, Cox C, Farina C, Drott H, Wolfson MR, et al. Pulmonary administration of gentamicin during liquid ventilation in a newborn lamb lung injury model. Pediatrics 1997;100(5):e51-e57.

60. Zelinka MA, Wolfson MR, Calligaro I, Rubenstein SD, Greenspan JS, Shaffer TH. A comparison of intratracheal and intravenous administration of gentamicin during liquid ventilation. Eur J Pediatr 1997;156(5):401-4.

61. Wolfson MR, Greenspan JS, Shaffer TH. Pulmonary administration of vasoactive substances by perfluorochemical ventilation. Pediatrics 1996;97(4):449-55.

62. Lisby DA, Ballard PL, Fox WW, Wolfson MR, Shaffer TH, Gonzales LW. Enhanced distribution of adenovirus-mediated gene transfer to lung parenchyma by perfluorochemical liquid. Hum Gene Ther 1997;8(8):919-28.

63. Kimless Garber DB, Wolfson MR, Carlsson C, Shaffer TH. Halothane administration during liquid ventilation. Respir Med 1997;91(5):255-62.

64. Shaffer TH, Forman DL, Wolfson MR. Physiological effects of ventilation with liquid fluorocarbon at controlled temperatures. Undersea Biomed Res 1984;11(3):287-98.

65. Forman DL, Bhutani VK, Tran N, Shaffer TH. A new approach to induced hypothermia. J Surg Res 1986;40(1):36-42.

66. Darwin MG, Russell SR, Rasch C, O'Farrell J, Harris SB. A novel method of rapidly inducing or treating hypothermia or hyperpyrexia, by means of "mixed-mode" (gas and liquid) ventilation using perfluorochemicals. Critical Care Medicine 1999;27(1 suppl):A81 .

67. Dickson EW, Sivilotti MLA, Mangolds G, Renzi FP, Heard SO, Mori K, et al. Core rewarming via warm lavage liquid ventilation in a swine model of hypothermia-associated ventricular fibrillation. Academic Emergency Medicine 2001;8(1):82-84.

68. von Neergaard K, Wirtz K. Ueber eine Methode zur Messung der Lungenelastizităt am lebenden Menschen, insbesondere beim Emphysem. Z Klin Med 1926;105:35-50.

69. Mead J, Whittenberger JL, Radford EP. Surface tension as a factor in pulmonary volume-pressure hysteresis. J Appl Physiol 1957;10:191-196.

70. Kylstra JA, Schoenfisch WH. Alveolar surface tension in fluorocarbon-filled lungs. J Appl Physiol 1972;33(1):32-5.

71. Tarczy Hornoch P, Hildebrandt J, Mates EA, Standaert TA, Lamm WJ, Hodson WA, et al. Effects of exogenous surfactant on lung pressure-volume characteristics during liquid ventilation. J Appl Physiol 1996;80(5):1764-71. 
73. West JB, Dolle CT, Matthews CME, Zardini P. Distribution of blood flow and ventilation in salinefilled lung. J Appl Physiol 1965;20(6):1107-1117.

74. West JB, Maloney JE, Castle BL. Effect of stratified inequality of blood flow on gas exchange in liquid-filled lungs. J Appl Physiol 1972;32(3):357-61.

75. Lowe CA, Shaffer TH. Pulmonary vascular resistance in the fluorocarbon-filled lung. J Appl Physiol 1986;60(1):154-9.

76. Shaffer TH, Lowe CA, Bhutani VK, Douglas PR. Liquid ventilation: effects on pulmonary function in distressed meconium-stained lambs. Pediatr Res 1984;18(1):47-52.

77. Avery ME, Mead J. Surface properties in relation to atelectasis and hyaline membrane disease. Am J Dis Child 1959;97:517-523.

78. O'Brodovich HM. Immature epithelial $\mathrm{Na}+$ channel expression is one of the pathogenetic mechanisms leading to human neonatal respiratory distress syndrome. Proc Assoc Am Physicians 1996; 108(5):345-55.

79. Jefferies AL, Coates G, O'Brodovich H. Pulmonary epithelial permeability in hyaline-membrane disease. N Engl J Med 1984;311(17):1075-80.

80. Zimmerman JJ. Bronchoalveolar inflammatory pathophysiology of bronchopulmonary dysplasia. Clin Perinatol 1995;22(2):429-56.

81. Halliday H, Hirschfeld S, Riggs T, Liebman J, Fanaroff A, Bormuth C. Respiratory distress syndrome: echocardiographic assessment of cardiovascular function and pulmonary vascular resistance. Pediatrics 1977;60(4):444-9.

82. Kinsella JP, Ivy DD, Abman SH. Inhaled nitric oxide improves gas exchange and lowers pulmonary vascular resistance in severe experimental hyaline membrane disease. Pediatr Res 1994;36(3):402-8.

83. Crowley P, Chalmers I, Keirse MJ. The effects of corticosteroid administration before preterm delivery: an overview of the evidence from controlled trials. Br J Obstet Gynaecol 1990;97(1):11-25.

84. Crowley PA. Antenatal corticosteroid therapy: a meta-analysis of the randomized trials, 1972 to 1994. Am J Obstet Gynecol 1995;173(1):322-35.

85. Yost CC, Soll RF. Early versus delayed selective surfactant treatment for neonatal respiratory distress syndrome. Cochrane Database Syst Rev 2000(2):Cd001456.

86. Soll RF. Synthetic surfactant for respiratory distress syndrome in preterm infants. Cochrane Database Syst Rev 2000(2):Cd001149.

87. Soll RF. Prophylactic synthetic surfactant for preventing morbidity and mortality in preterm infants. Cochrane Database Syst Rev 2000(2):Cd001079.

88. Soll RF. Prophylactic natural surfactant extract for preventing morbidity and mortality in preterm infants. Cochrane Database Syst Rev 2000(2):Cd000511.

89. Soll RF, Morley CJ. Prophylactic versus selective use of surfactant for preventing morbidity and mortality in preterm infants. Cochrane Database Syst Rev 2000(2):Cd000510.

90. Soll RF. Natural surfactant extract versus synthetic surfactant for neonatal respiratory distress syndrome. Cochrane Database Syst Rev 2000(2):Cd000144.

91. Soll RF. Multiple versus single dose natural surfactant extract for severe neonatal respiratory distress syndrome. Cochrane Database Syst Rev 2000(2):Cd000141.

92. Werner O, Bjorklund LJ. Resuscitation strategy and surfactant therapy. Biol Neonate 1997;71 Suppl 1:32-4.

93. Bjorklund LJ, Ingimarsson J, Curstedt T, John J, Robertson B, Werner O, et al. Manual ventilation with a few large breaths at birth compromises the therapeutic effect of subsequent surfactant replacement in immature lambs. Pediatr Res 1997;42(3):348-55.

94. Wada K, Jobe AH, Ikegami M. Tidal volume effects on surfactant treatment responses with the initiation of ventilation in preterm lambs. J Appl Physiol 1997;83(4):1054-61.

95. Michna J, Jobe AH, Ikegami M. Positive end-expiratory pressure preserves surfactant function in preterm lambs. Am J Respir Crit Care Med 1999;160(2):634-9.

96. Kinsella JP, Parker TA, Galan H, Sheridan BC, Abman SH. Independent and combined effects of inhaled nitric oxide, liquid perfluorochemical, and high-frequency oscillatory ventilation in premature lambs with respiratory distress syndrome. Am J Respir Crit Care Med 1999;159(4 Pt 1):1220-7. 

oxide in moderately hypoxaemic neonates with respiratory failure: a randomised controlled trial. Lancet 1999;354(9184):1066-71.

98. Kinsella JP, Walsh WF, Bose CL, Gerstmann DR, Labella JJ, Sardesai S, et al. Inhaled nitric oxide in premature neonates with severe hypoxaemic respiratory failure: a randomised controlled trial. Lancet 1999;354(9184):1061-5.

99. Ackerman NB, Jr., Coalson JJ, Kuehl TJ, Stoddard R, Minnick L, Escobedo MB, et al. Pulmonary interstitial emphysema in the premature baboon with hyaline membrane disease. Crit Care Med 1984;12(6):512-6.

100. Bell RE, Kuehl TJ, Coalson JJ, Ackerman N, Null DM, Jr., Escobedo MB, et al. High-frequency ventilation compared to conventional positive-pressure ventilation in the treatment of hyaline membrane disease in primates. Crit Care Med 1984;12(9):764-8.

101. Clark RH, Wiswell TE, Null DM, deLemos RA, Coalson JJ. Tracheal and bronchial injury in highfrequency oscillatory ventilation compared with conventional positive pressure ventilation. J Pediatr 1987;111(1):114-8.

102. Coalson JJ, deLemos RA. Pathologic features of various ventilatory strategies. Acta Anaesthesiol Scand Suppl 1989;90:108-16.

103. deLemos RA, Coalson JJ, Gerstmann DR, Null DM, Jr., Ackerman NB, Escobedo MB, et al. Ventilatory management of infant baboons with hyaline membrane disease: the use of high frequency ventilation. Pediatr Res 1987;21(6):594-602.

104. deLemos RA, Coalson JJ, Meredith KS, Gerstmann DR, Null DM, Jr. A comparison of ventilation strategies for the use of high-frequency oscillatory ventilation in the treatment of hyaline membrane disease. Acta Anaesthesiol Scand Suppl 1989;90:102-7.

105. deLemos RA, Coalson JJ, deLemos JA, King RJ, Clark RH, Gerstmann DR. Rescue ventilation with high frequency oscillation in premature baboons with hyaline membrane disease. Pediatr Pulmonol 1992;12(1):29-36.

106. Gerstmann DR, deLemos RA, Coalson JJ, Clark RH, Wiswell TE, Winter DC, et al. Influence of ventilatory technique on pulmonary baroinjury in baboons with hyaline membrane disease. Pediatr Pulmonol 1988;5(2):82-91.

107. Jackson JC, Truog WE, Standaert TA, Juul SE, Murphy JH, Chi EY, et al. Effect of high-frequency ventilation on the development of alveolar edema in premature monkeys at risk for hyaline membrane disease. Am Rev Respir Dis 1991;143(4 Pt 1):865-71.

108. Jackson JC, Truog WE, Standaert TA, Murphy JH, Juul SE, Chi EY, et al. Reduction in lung injury after combined surfactant and high-frequency ventilation. Am J Respir Crit Care Med 1994;150(2):534-9.

109. Kinsella JP, Gerstmann DR, Clark RH, Null DM, Jr., Morrow WR, Taylor AF, et al. High-frequency oscillatory ventilation versus intermittent mandatory ventilation: early hemodynamic effects in the premature baboon with hyaline membrane disease. Pediatr Res 1991;29(2):160-6.

110. Yoder BA, Kuehl TJ, de Lemos RA, Null DM, Jr., Ackerman NB, Jr. Patent ductus arteriosus during high-frequency ventilation for hyaline membrane disease. Crit Care Med 1987;15(6):587-90.

111. Yoder BA, Siler Khodr T, Winter VT, Coalson JJ. High-frequency oscillatory ventilation - Effects on lung function, mechanics, and airway cytokines in the immature baboon model for neonatal chronic lung disease. Am J Respir Crit Care Med 2000;162(5):1867-1876.

112. Bhuta T, Henderson Smart DJ. Elective high-frequency oscillatory ventilation versus conventional ventilation in preterm infants with pulmonary dysfunction: systematic review and meta-analyses. Pediatrics 1997;100(5):E6.

113. Garland JS, Buck RK, Allred EN, Leviton A. Hypocarbia before surfactant therapy appears to increase bronchopulmonary dysplasia risk in infants with respiratory distress syndrome. Arch Pediatr Adolesc Med 1995;149(6):617-22.

114. Kraybill EN, Runyan DK, Bose CL, Khan JH. Risk factors for chronic lung disease in infants with birth weights of 751 to 1000 grams. J Pediatr 1989;115(1):115-20.

115. Mariani G, Cifuentes J, Carlo WA. Randomized trial of permissive hypercapnia in preterm infants. Pediatrics 1999;104(5 Pt 1):1082-8.

116. Bancalari E. Intratracheal pulmonary ventilation in neonatal respiratory failure. Crit Care Med $1999 ; 27(1): 18-9$. 
117. Schulze A, Gerhardt T, Musante G, Schaller P, Claure N, Everett R, et al. Proportional assist ventilation in low birth weight infants with acute respiratory disease: A comparison to assist/control and conventional mechanical ventilation. J Pediatr 1999;135(3):339-44.

118. Dassieu G, Brochard L, Benani M, Avenel S, Danan C. Continuous tracheal gas insufflation in preterm infants with hyaline membrane disease. A prospective randomized trial. Am J Respir Crit Care Med 2000;162(3 Pt 1):826-31.

119. Bernard GR, Artigas A, Brigham KL, Carlet J, Falke K, Hudson L, et al. The American-European Consensus Conference on ARDS. Definitions, mechanisms, relevant outcomes, and clinical trial coordination. Am J Respir Crit Care Med 1994;149(3 Pt 1):818-24.

120. Murray JF, Matthay MA, Luce JM, Flick MR. An expanded definition of the adult respiratory distress syndrome. Am Rev Respir Dis 1988;138(3):720-3.

121. Abraham E, Matthay MA, Dinarello CA, Vincent JL, Cohen J, Opal SM, et al. Consensus conference definitions for sepsis, septic shock, acute lung injury, and acute respiratory distress syndrome: time for a reevaluation. Crit Care Med 2000;28(1):232-5.

122. Ware LB, Matthay MA. The acute respiratory distress syndrome. N Engl J Med 2000;342(18):133449.

123. Dreyfuss D, Saumon G. Ventilator-induced lung injury: lessons from experimental studies. Am J Respir Crit Care Med 1998;157(1):294-323.

124. Bigatello LM, Hurford WE, Pesenti A. Ventilatory management of severe acute respiratory failure for Y2K. Anesthesiology 1999;91(6):1567-70.

125. Ranieri VM, Slutsky AS. Respiratory physiology and acute lung injury: the miracle of Lazarus. Intensive Care Med 1999;25(10):1040-3.

126. Hudson LD. Progress in understanding ventilator-induced lung injury. JAMA 1999;282(1):77-8.

127. Slutsky AS, Tremblay LN. Multiple system organ failure. Is mechanical ventilation a contributing factor? Am J Respir Crit Care Med 1998;157(6 Pt 1):1721-5.

128. Slutsky AS. Lung injury caused by mechanical ventilation. Chest 1999;116(1 Suppl):9s-15s.

129. Lewandowski K. Small tidal volumes - large benefit? Intensive Care Med 1999;25(8):771-4.

130. Brochard L, Roudot Thoraval F, Roupie E, Delclaux C, Chastre J, Fernandez Mondejar E, et al. Tidal volume reduction for prevention of ventilator-induced lung injury in acute respiratory distress syndrome. The Multicenter Trail Group on Tidal Volume reduction in ARDS. Am J Respir Crit Care Med 1998;158(6):1831-8.

131. Brower RG, Shanholtz CB, Fessler HE, Shade DM, White P, Jr., Wiener CM, et al. Prospective, randomized, controlled clinical trial comparing traditional versus reduced tidal volume ventilation in acute respiratory distress syndrome patients. Crit Care Med 1999;27(8):1492-8.

132. Stewart TE, Meade MO, Cook DJ, Granton JT, Hodder RV, Lapinsky SE, et al. Evaluation of a ventilation strategy to prevent barotrauma in patients at high risk for acute respiratory distress syndrome. Pressure- and Volume-Limited Ventilation Strategy Group. N Engl J Med 1998;338(6):355-61.

133. Amato MB, Barbas CS, Medeiros DM, Magaldi RB, Schettino GP, Lorenzi Filho G, et al. Effect of a protective-ventilation strategy on mortality in the acute respiratory distress syndrome. N Engl J Med 1998;338(6):347-54.

134. The_Acute_Respiratory_Distress_Syndrome_Network. Ventilation with lower tidal volumes as compared with traditional tidal volumes for acute lung injury and the acute respiratory distress syndrome. N Engl J Med 2000;342(18):1301-8.

135. Ranieri VM, Suter PM, Tortorella C, De Tullio R, Dayer JM, Brienza A, et al. Effect of mechanical ventilation on inflammatory mediators in patients with acute respiratory distress syndrome: a randomized controlled trial. JAMA 1999;282(1):54-61.

136. Baumgart S, Spitzer AR. Intratracheal pulmonary ventilation, the latest new ventilation technique for supporting diffuse lung injury: do we jump on the bandwagon? Crit Care Med 2000;28(5):1674-5.

137. Kuhlen R, Rossaint R. Proportional assist ventilation. Intensive Care Med 1999;25(9):1021-3.

138. Lamm WJ, Graham MM, Albert RK. Mechanism by which the prone position improves oxygenation in acute lung injury. Am J Respir Crit Care Med 1994;150(1):184-93.

139. Rossaint R, Falke KJ, Lopez F, Slama K, Pison U, Zapol WM. Inhaled nitric oxide for the adult respiratory distress syndrome. N Engl J Med 1993;328(6):399-405. 
140. Imai $\mathrm{Y}$, Kawano T, Miyasaka K, Takata M, Imai T, Okuyama K. Inflammatory chemical mediators during conventional ventilation and during high frequency oscillatory ventilation. Am J Respir Crit Care Med 1994;150(6 Pt 1):1550-4.

141. Amold JH, Hanson JH, Toro Figuero LO, Gutierrez J, Berens RJ, Anglin DL. Prospective, randomized comparison of high-frequency oscillatory ventilation and conventional mechanical ventilation in pediatric respiratory failure. Crit Care Med 1994;22(10):1530-9.

142. Robertson B. Surfactant inactivation and surfactant replacement in experimental models of ARDS. Acta Anaesthesiol Scand Suppl 1991;95:22-8.

143. Robertson B. Surfactant inactivation and surfactant therapy in acute respiratory distress syndrome (ARDS). Monaldi Arch Chest Dis 1998;53(1):64-9.

144. Zhu GF, Sun B, Niu SF, Cai YY, Lin K, Lindwall R, et al. Combined surfactant therapy and inhaled nitric oxide in rabbits with oleic acid-induced acute respiratory distress syndrome. Am J Respir Crit Care Med 1998;158(2):437-43.

145. Gregory TJ, Steinberg KP, Spragg R, Gadek JE, Hyers TM, Longmore WJ, et al. Bovine surfactant therapy for patients with acute respiratory distress syndrome. Am J Respir Crit Care Med 1997;155(4):1309-15.

146. Lewandowski K, Rossaint R, Pappert D, Gerlach H, Slama KJ, Weidemann H, et al. High survival rate in 122 ARDS patients managed according to a clinical algorithm including extracorporeal membrane oxygenation. Intensive Care Med 1997;23(8):819-35.

147. Ullrich R, Lorber C, Roder G, Urak G, Faryniak B, Sladen RN, et al. Controlled airway pressure therapy, nitric oxide inhalation, prone position, and extracorporeal membrane oxygenation (ECMO) as components of an integrated approach to ARDS. Anesthesiology 1999;91(6):1577-86.

148. Dellinger RP. Inhaled nitric oxide versus prone positioning in acute respiratory distress syndrome. Crit Care Med 2000;28(2):572-4.

149. Vazquez de Anda GF, Hartog A, Verbrugge SJ, Gommers D, Lachmann B. The open lung concept: pressure-controlled ventilation is as effective as high-frequency oscillatory ventilation in improving gas exchange and lung mechanics in surfactant-deficient animals. Intensive Care Med 1999;25(9):990-6.

150. Gommers D, Hartog A, Schnabel R, De Jaegere A, Lachmann B. High-frequency oscillatory ventilation is not superior to conventional mechanical ventilation in surfactant-treated rabbits with lung injury. Eur Respir J 1999;14(4):738-44.

151. Rimensberger PC, Pache J-C, McKerlie C, Findova H, Cox PN. Lung recruitment and lung volume maintenance: a strategy for improving oxygenation and preventing lung injury during both, conventional mechanical ventilation and high-frequency oscillation. Intensive Care Med 2000;26(6):745-755.

152. Vazquez de Anda GF, Gommers D, Verbrugge SJ, De Jaegere A, Lachmann B. Mechanical ventilation with high positive end-expiratory pressure and small driving pressure amplitude is as effective as high-frequency oscillatory ventilation to preserve the function of exogenous surfactant in lung-lavaged rats. Crit Care Med 2000;28(8):2921-5.

153. Rotta AT, Chilungu M, Gunnarsson B, Steinhorn DM. The effects of lung-recruiting ventilatory strategies in acutely injured atelectasis-prone rabbits. Critical Care Medicine 1999;27(1 suppl):A 133 .

154. Rotta AT, Dowhy M, Frisicaro P, Gunnarsson B, Steinhorn DM. Mechanical ventilation strategies influence pulmonary mechanics in atelectasis-prone rabbits. Critical Care Medicine 1999;27(1 suppl):A92.

155. Rosenthal C, Caronia C, Quinn C, Lugo N, Sagy M. A comparison among animal models of acute lung injury. Crit Care Med 1998;26(5):912-6.

156. Cleary GM, Wiswell TE. Meconium-stained amniotic fluid and the meconium aspiration syndrome. An update. Pediatr Clin North Am 1998;45(3):511-29.

157. al Mateen KB, Dailey K, Grimes MM, Gutcher GR. Improved oxygenation with exogenous surfactant administration in experimental meconium aspiration syndrome. Pediatr Pulmonol 1994;17(2):75-80.

158. Paranka MS, Walsh WF, Stancombe BB. Surfactant lavage in a piglet model of meconium aspiration syndrome. Pediatr Res 1992;31(6):625-8.

159. Sun B, Curstedt T, Song GW, Robertson B. Surfactant improves lung function and morphology in newborn rabbits with meconium aspiration. Biol Neonate 1993;63(2):96-104.

160. Sun B, Herting E, Curstedt T, Robertson B. Exogenous surfactant improves lung compliance and oxygenation in adult rats with meconium aspiration. J Appl Physiol 1994;77(4):1961-71. 
161. Sun B, Curstedt T, Robertson B. Exogenous surfactant improves ventilation efficiency and alveolar expansion in rats with meconium aspiration. Am J Respir Crit Care Med 1996;154(3 Pt 1):764-70.

162. Wiswell TE, Peabody SS, Davis JM, Slayter MV, Bent RC, Merritt TA. Surfactant therapy and highfrequency jet ventilation in the management of a piglet model of the meconium aspiration syndrome. Pediatr Res 1994;36(4):494-500.

163. Findlay RD, Taeusch HW, Walther FJ. Surfactant replacement therapy for meconium aspiration syndrome. Pediatrics 1996;97(1):48-52.

164. Lotze A, Mitchell BR, Bulas DI, Zola EM, Shalwitz RA, Gunkel JH. Multicenter study of surfactant (beractant) use in the treatment of term infants with severe respiratory failure. Survanta in Term Infants Study Group. J Pediatr 1998;132(1):40-7.

165. Soll RF, Dargaville P. Surfactant for meconium aspiration syndrome in full term infants. Cochrane Database Syst Rev 2000(2):Cd002054.

166. Cochrane CG, Revak SD, Merritt TA, Schraufstatter IU, Hoch RC, Henderson C, et al. Bronchoalveolar lavage with KL4-surfactant in models of meconium aspiration syndrome. Pediatr Res 1998;44(5):705-15.

167. Ohama Y, Itakura Y, Koyama N, Eguchi H, Ogawa Y. Effect of surfactant lavage in a rabbit model of meconium aspiration syndrome. Acta Paediatr Jpn 1994;36(3):236-8.

168. Ohama Y, Ogawa Y. Treatment of meconium aspiration syndrome with surfactant lavage in an experimental rabbit model. Pediatr Pulmonol 1999;28(1):18-23.

169. Lam BC, Yeung CY. Surfactant lavage for meconium aspiration syndrome: a pilot study. Pediatrics 1999;103(5 Pt 1):1014-8.

170. Handman H, Rais Bahrami K, Rivera O, Seale WR, Short BL. Use of intratracheal pulmonary ventilation versus conventional ventilation in meconium aspiration syndrome in a newborn pig model. Crit Care Med 1997;25(12):2025-30.

171. Lu KW, William Taeusch H, Robertson B, Goerke J, Clements JA. Polymer-surfactant treatment of meconium-induced acute lung injury. Am J Respir Crit Care Med 2000;162(2 Pt 1):623-8.

172. Calkovska A, Sun B, Curstedt T, Renheim G, Robertson B. Combined effects of high-frequency ventilation and surfactant treatment in experimental meconium aspiration syndrome. Acta Anaesthesiol Scand 1999;43(2):135-45.

173. Hachey WE, Eyal FG, Curtet Eyal NL, Kellum FE. High-frequency oscillatory ventilation versus conventional ventilation in a piglet model of early meconium aspiration. Crit Care Med 1998;26(3):556-61.

174. Huang QW, Sun B, Gao F, Zhang Y, Wu Y, Zhu LW, et al. Effects of inhaled nitric oxide and highfrequency ventilation in rabbits with meconium aspiration. Biol Neonate 1999;76(6):374-82.

175. Patrinos ME, Balaraman V, Ku T, Meister J, Rubin BK, Stenzler A, et al. Promoting meconium clearance from the lungs of the neonatal piglet with asymmetric high frequency oscillation. Pediatr Res 1997;42(3):342-7.

176. Kinsella JP, Truog WE, Walsh WF, Goldberg RN, Bancalari E, Mayock DE, et al. Randomized, multicenter trial of inhaled nitric oxide and high-frequency oscillatory ventilation in severe, persistent pulmonary hypertension of the newborn. J Pediatr 1997;131(1 Pt 1):55-62.

177. The_Neonatal_Inhaled_Nitric_Oxide_Study_Group_(NINOS). Inhaled nitric oxide in full-term and nearly full-term infants with hypoxic respiratory failure. N Engl J Med 1997;336(9):597-604.

178. Cornish JD, Dreyer GL, Snyder GE, Kuehl TJ, Gerstmann DR, Null DM, Jr., et al. Failure of acute perinatal asphyxia or meconium aspiration to produce persistent pulmonary hypertension in a neonatal baboon model. Am J Obstet Gynecol 1994;171(1):43-9.

179. Wilcox DT, Irish MS, Holm BA, Glick PL. Pulmonary parenchymal abnormalities in congenital diaphragmatic hernia. Clin Perinatol 1996;23(4):771-9.

180. O'Toole SJ, Karamanoukian HL, Morin FC, Holm BA, Egan EA, Azizkhan RG, et al. Surfactant decreases pulmonary vascular resistance and increases pulmonary blood flow in the fetal lamb model of congenital diaphragmatic hernia. J Pediatr Surg 1996;31(4):507-11.

181. Wilcox DT, Glick PL, Karamanoukian H, Rossman J, Morin FC, 3rd, Holm BA. Pathophysiology of congenital diaphragmatic hernia. V. Effect of exogenous surfactant therapy on gas exchange and lung mechanics in the lamb congenital diaphragmatic hernia model. J Pediatr 1994;124(2):289-93.

182. O'Toole SJ, Karamanoukian HL, Sharma A, Morin FC, 3rd, Holm BA, Azizkhan RG, et al. Surfactant rescue in the fetal lamb model of congenital diaphragmatic hernia. J Pediatr Surg 1996;31(8):1105-8. 
183. Karamanoukian HL, Glick PL, Wilcox DT, Rossman JE, Holm BA, Morin FC, 3rd. Pathophysiology of congenital diaphragmatic hernia. VIII: Inhaled nitric oxide requires exogenous surfactant therapy in the lamb model of congenital diaphragmatic hernia. J Pediatr Surg 1995;30(1):1-4.

184. Schnitzer JJ, Thompson JE, Hedrick HL. A new ventilator improves $\mathrm{CO} 2$ removal in newborn lambs with congenital diaphragmatic hernia. Crit Care Med 1999;27(1):109-12.

185. Wilson JM, Thompson JR, Schnitzer JJ, Bower LK, Lillehei CW, Perlman ND, et al. Intratracheal pulmonary ventilation and congenital diaphragmatic hernia: a report of two cases. J Pediatr Surg 1993;28(3):484-7.

186. Wung JT, Sahni R, Moffitt ST, Lipsitz E, Stolar CJ. Congenital diaphragmatic hernia: survival treated with very delayed surgery, spontaneous respiration, and no chest tube. J Pediatr Surg 1995;30(3):4069.

187. Wilson JM, Lund DP, Lillehei CW, Vacanti JP. Congenital diaphragmatic hernia--a tale of two cities: the Boston experience. J Pediatr Surg 1997;32(3):401-5.

188. Kays DW, Langham MR, Jr., Ledbetter DJ, Talbert JL. Detrimental effects of standard medical therapy in congenital diaphragmatic hernia. Ann Surg 1999;230(3):340-8.

189. Tamura M, Tsuchida Y, Kawano T, Honna T, Ishibashi R, Iwanaka T, et al. Piston-pump-type high frequency oscillatory ventilation for neonates with congenital diaphragmatic hernia: a new protocol. J Pediatr Surg 1988;23(5):478-82.

190. Miguet D, Claris O, Lapillonne A, Bakr A, Chappuis JP, Salle BL. Preoperative stabilization using high-frequency oscillatory ventilation in the management of congenital diaphragmatic hemia. Crit Care Med 1994;22(9 Suppl):S77-82.

191. Reyes C, Chang LK, Waffarn F, Mir H, Warden MJ, Sills J. Delayed repair of congenital diaphragmatic hernia with early high-frequency oscillatory ventilation during preoperative stabilization. J Pediatr Surg 1998;33(7):1010-4.

192. Somaschini M, Locatelli G, Salvoni L, Bellan C, Colombo A. Impact of new treatments for respiratory failure on outcome of infants with congenital diaphragmatic hernia. Eur J Pediatr 1999;158(10):780-4.

193. The_Neonatal_Inhaled_Nitric_Oxide_Study_Group_(NINOS). Inhaled nitric oxide and hypoxic respiratory failure in infants with congenital diaphragmatic hernia. Pediatrics 1997;99(6):838-45.

194. Finer NN, Tierney A, Etches PC, Peliowski A, Ainsworth W. Congenital diaphragmatic hernia: developing a protocolized approach. J Pediatr Surg 1998;33(9):1331-7.

195. Sekins KM, Nugent L, Mazzoni M, Flanagan C, Neer L, Rozenberg A, et al. Recent innovations in total liquid ventilation system and component design. Biomed Instrum Technol 1999;33(3):277-84.

196. Modell JH, Newby EJ, Ruiz BC. Long-term survival of dogs after breathing oxygenated fluorocarbon liquid. Fed Proc 1970;29(5):1731-6.

197. Sass DJ, Nolan AC, Wood EH. Digital computer analysis of circulatory and respiratory pressures in water-immersed dogs breathing liquid in force environments of 1 and $7 \mathrm{~Gy}$. Aerosp Med 1974;45(1):1-11.

198. Moskowitz GD. A mechanical respirator for control of liquid breathing. Fed Proc 1970;29(5):1751-2.

199. Shaffer TH, Moskowitz GD. Demand-controlled liquid ventilation of the lungs. J Appl Physiol 1974;36(2):208-13.

200. Wolfson MR, Tran N, Bhutani VK, Shaffer TH. A new experimental approach for the study of cardiopulmonary physiology during early development. J Appl Physiol 1988;65(3):1436-43.

201. Larrabe JL, Gómez MA, Alvarez FJ, Gastiasoro E, Arnaiz A, Fernández MB, et al. Development of total liquid ventilation technology. A practical approach. In: 1st European Symposium on Liquid Ventilation; 1999 November 26-27, 1999; Berlin; 1999. p. 31.

202. Meinhardt JP, Quintel M, Hirschl RB. Development and application of a double-piston configured, total-liquid ventilatory support device. Crit Care Med 2000;28(5):1483-8.

203. Harris DJ, Coggin RR, Roby J, Feezor M, Turner G, Bennett PB. Liquid ventilation in dogs: an apparatus for normobaric and hyperbaric studies. J Appl Physiol 1983;54(4):1141-8.

204. Baba Y, Taenaka Y, Akagi H, Nakatani T, Masuzawa T, Tatsumi E, et al. A volume-controlled liquid ventilator with pressure-limit mode: imperative expiratory control. Artif Organs 1996;20(9):1052-6.

205. Jackson JC, Standaert TA, Truog WE, Hodson WA. Full-tidal liquid ventilation with perfluorocarbon for prevention of lung injury in newborn non-human primates. Artif Cells Blood Substit Immobil Biotechnol 1994;22(4):1121-32. 

ventilation on cardiac output and blood pressure variability in neonatal piglets with respiratory insufficiency. Pediatr Pulmonol 2000;30(2):114-24.

207. Meinhardt JP, Sawada S, Quintel M, Hirschl RH. Comparison Of Static Airway Pressures During Total Liquid Ventilation While Applying Different Expiratory Modes And Time Patterns. Am J Respir Crit Care Med 1999;159(4 Pt 2):79.

208. Curtis SE, Fuhrman BP, Howland DF. Airway and alveolar pressures during perfluorocarbon breathing in infant lambs. J Appl Physiol 1990;68(6):2322-8.

209. Hirschl RB, Merz SI, Montoya JP, Parent A, Wolfson MR, Shaffer TH, et al. Development and application of a simplified liquid ventilator. Crit Care Med 1995;23(1):157-63.

210. Wolfson MR, Miller TF, Peck G, Shaffer TH. Multifactorial analysis of exchanger efficiency and liquid conservation during perfluorochemical liquid-assisted ventilation. Biomed Instrum Technol 1999;33(3):260-7.

211. Alvarez FJ, Gastiasoro E, Gomez MA, Larrabe JL, Arnaiz A, Fernandez B, et al. Real-Time Measurement of Pulmonary Mechanics during Perfluorocarbon (PFC) Tidal Liquid Ventilation (TLV). Pediatr Res 2000;54(4):350A.

212. Heckman JL, Hoffman J, Shaffer TH, Wolfson MR. Software for real-time control of a tidal liquid ventilator. Biomed Instrum Technol 1999;33(3):268-76.

213. Degraeuwe PLJ, Dohmen LRB, Geilen JM, Blanco CE. A feedback controller for the maintenance of FRC during tidal liquid ventilation: theory, implementation, and testing. International Journal of Artificial Organs 2000;23(10):680-688.

214. Fox WW, Cox C, Weis C, Wolfson MR, Shaffer TH. Neonatal endotracheal tubes: variation in airway resistance with different perfluorochemical liquids. Artif Cells Blood Substit Immobil Biotechnol 1994;22(4):1397-402.

215. Fox WW, Cox CA, Weis CM, Wolfson MR, Shaffer TH. Comparison of perfluorochemical fluids used for liquid ventilation: effect of endotracheal tube flow resistance. Pediatr Pulmonol 1997;23(6):449-56.

216. Chambers S, Laberteaux K, Hirschl R. Demonstration of a method to characterize and develop airway access devices for total liquid ventilation. Artif Cells Blood Substit Immobil Biotechnol 1998;26(2):123-32.

217. Modell JH, Hood CI, Kuck EJ, Ruiz BC. Oxygenation by ventilation with fluorocarbon liquid (FX80). Anesthesiology 1971;34(4):312-20.

218. Saga S, Modell JH, Calderwood HW, Lucas AJ, Tham MK, Swenson EW. Pulmonary function after ventilation with fluorocarbon liquid P-12F (caroxin-F). J Appl Physiol 1973;34(2):160-4.

219. Tuazon JG, Modell JH, Hood Cl, Swenson EW. Pulmonary function after ventilation with fluorocarbon liquid (Caroxin-D). Anesthesiology 1973;38(2):134-40.

220. Calderwood HW, Modell JH, Rogow L, Tham MK, Hood CI. Morphologic and biochemical changes in dogs after ventilation with caroxin-D fluorocarbon. Anesthesiology 1973;39(5):488-95.

221. Calderwood HW, Ruiz BC, Tham MK, Modell JH, Saga SA, Hood CI. Residual levels and biochemical changes after ventilation with perfluorinated liquid. J Appl Physiol 1975;39(4):603-7.

222. Hood $\mathrm{Cl}$, Modell JH. A morphologic study of long-term retention of fluorocarbon after liquid ventilation. Chest 2000;118(5):1436-1440.

223. Hirschl RB, Grover B, McCracken M, Wolfson MR, Shaffer TH, Bartlett RH. Oxygen consumption and carbon dioxide production during liquid ventilation. J Pediatr Surg 1993;28(4):513-8.

224. Stavis RL, Cox CA, Wolfson MR, Cullen AB, Roache RF, Hipp S, et al. Tidal liquid ventilation (TLV) transition to spontaneous breathing (SB): 24 hour follow-up of physiologic and radiologic correlates. Pediatr Res 1998;43(4 (Pt 2)):298A.

225. Forman DL, Bhutani VK, Hilfer SR, Shaffer TH. A fine structure study of the liquid-ventilated newborn rabbit. Fed Proc 1984;43:647.

226. Wolfson MR, Cox CA, Shaffer TH. Tidal Liquid Ventilation: Is Lung Size Or Age A Physiological Limitation? Am J Respir Crit Care Med 1998;157(4):A460.

227. Ruefer R, Spitzer HL. Liquid ventilation in the respiratory distress syndrome. Chest 1974;66(0):suppl:29s-30s.

228. Schwieler GH, Robertson B. Liquid ventilation in immature newborn rabbits. Biol Neonate 1976;29(5-6):343-53. 

base balance in premature lambs during liquid ventilation since birth. Pediatr Res 1976;10(4):227-31.

230. Shaffer TH, Douglas PR, Lowe CA, Bhutani VK. The effects of liquid ventilation on cardiopulmonary function in preterm lambs. Pediatr Res 1983;17(4):303-6.

231. Shaffer TH, Tran N, Bhutani VK, Sivieri EM. Cardiopulmonary function in very preterm lambs during liquid ventilation. Pediatr Res 1983;17(8):680-4.

232. Stavis RL, Wolfson MR, Cox CA, Foust R, Miller TF, Kechner NE, et al. Prolonged total liquid ventilation in premature lambs. Pediatr Res 1997;41(4 (Pt 2)):180A.

233. Hirschl RB, Parent A, Tooley R, Shaffer T, Wolfson M, Bartlett RH. Lung management with perfluorocarbon liquid ventilation improves pulmonary function and gas exchange during extracorporeal membrane oxygenation (ECMO). Artif Cells Blood Substit Immobil Biotechnol 1994;22(4):1389-96.

234. Wolfson MR, Friss HE, Billmire D, Hirschl RB, Shaffer TH. Combined technologies: Liquid ventilation (LV) and extracorporeal life support (ECLS) for treatment of severe neonatal lung injury. In: The 10th Annual Children's National Medical Center ECMO Symposium; 1994 Feb 27 - Mar 3; Keystone, Colorado; 1994. p. \#49.

235. Wolfson MR, Robinson N, Ginda M, Friss HE, Taulane J, Cox C, et al. Combined technologies: Liquid ventilation (LV) and extracorporeal life support (ECLS) for treatment of meconium aspiration injury. In: The 11 th Annual Children's National Medical Center Symposium on ECMO \& Advanced Therapies for respiratory failure; 1995 Feb 26 - Mar 2; Keystone, Colorado; 1995. p. \#99.

236. Ruefer R, Gross H, Elssner-Beyer T. Artificial respiration of fetal minipigs (Kuenstliche Beatmung von Zwergschweinfeten). Pfluger Arch 1973;339(Suppl):R41.

237. Wolfson MR, Greenspan JS, Deoras KS, Rubenstein SD, Shaffer TH. Comparison of gas and liquid ventilation: clinical, physiological, and histological correlates. J Appl Physiol 1992;72(3):1024-31.

238. Wolfson MR, Cox C, Starcher B, Foust R, Miller TF, Miller TF, et al. Biochemical and histological indices of reduced pulmonary trauma during perfluorochemical (PFC) liquid ventilation. Pediatr Res 1996;39:356A.

239. Horowitz S, Foust R, Zhang W, Shaffer T, Wolfson MR, Davis JM. Distinct Patterns Of Apoptosis during total liquid ventilation (TLV) vs. conventional ventilation (CV). Pediatr Res 1997:41(4 Pt 2):255A.

240. Mantell LL, Wolfson M, Shaffer T, Scott W, Horowitz S. Distinct Patterns Of Apoptosis In Lungs Of Sheep During Liquid And Gas Ventilation. Am J Respir Crit Care Med 1999;159(4 Pt 2):602A.

241. Wolfson MR, Friss HE, Kechner NE, Rubenstein SD, Dechadarevian J-P, Shaffer TH. Physiological basis of improved lung stability after perfluorochemical (PFC) liquid rescue of surfactant treated lambs. Pediatr Res 1994;35(4):357A.

242. Degraeuwe PLJ, Thunnissen FBJM, Jansen NJG, Dormaar JT, Dohmen LRB, Blanco CE. Conventional gas ventilation, liquid-assisted high-frequency oscillatory ventilation, and tidal liquid ventilation in surfactant-treated preterm lambs. International Journal of Artificial Organs 2000;23(11):754-764.

243. Alvarez FJ, Gómez MA, López-Heredia J, Gastiasoro E, Arnaiz A, Alfonso LF, et al. Perfluorocarbon tidal liquid ventilation (TLV) in experimental respiratory distress. In: Hot topics '94 in neonatology; 1994 December 4-6, 1994; Washington, DC; 1994. p. 333.

244. Mazzoni M, Spooner M, Hoffman JK, Bradley J, Sekins KM, Flaim SF. Gas exchange and cardiopulmonary function in a large injury model during total liquid ventilation with perflubron. In: Liquid ventilation: a symposium; 1996 September 19; Ann Arbor, MI; 1996. p. 13.

245. Hirschl RB, Parent A, Tooley R, McCracken M, Johnson K, Shaffer TH, et al. Liquid ventilation improves pulmonary function, gas exchange, and lung injury in a model of respiratory failure. Ann Surg 1995;221(1):79-88.

246. Hirschl RB, Overbeck MC, Parent A, Hernandez R, Schwartz S, Dosanjh A, et al. Liquid ventilation provides uniform distribution of perfluorocarbon in the setting of respiratory failure. Surgery 1994;116(2):159-67.

247. Meinhardt JP, Quintel M, Hirschl RH. Reduction of intratracheal pressure in total liquid ventilated rabbits after oleic acid lung injury. FASEB-J 1999;13(5 Pt 2):A828.

248. Wolfson MR, Jackson JC, Foley DS, Hirschl RB, Gauvin F, Lamm WJ, et al. Multi-Center Comparative Study Of Conventional Mechanical (CMV) To Tidal Liquid Ventilation (TLV) In Oleic Acid (OA) Injured Sheep. Am J Respir Crit Care Med 2000;161(3):A46. 
249. Foust R, Kechner N, Wolfson MR, Shaffer TH. Comparison between gas ventilation and liquid perfluorocarbon ventilation in acute meconium lung injury. FASEB-J 1993;7 suppl:A230.

250. Foust R, Tran NN, Cox C, Miller TF, Greenspan JS, Wolfson MR, et al. Liquid assisted ventilation: an alternative ventilatory strategy for acute meconium aspiration injury. Pediatr Pulmonol 1996;21(5):316-22.

251. Greenspan JS, Wolfson MR, Rubenstein SD, Shaffer TH. Liquid ventilation of preterm baby. Lancet 1989;2(8671): 1095 .

252. Greenspan JS, Wolfson MR, Rubenstein SD, Shaffer TH. Liquid ventilation of human preterm neonates. J Pediatr 1990;117(1 Pt 1):106-11.

253. Shaffer TH, Wolfson MR, Greenspan JS, Rubenstein SD, Stern RG. Perfluorochemical liquid as a respiratory medium. Artif Cells Blood Substit Immobil Biotechnol 1994;22(2):315-26.

254. Deoras KS, Coppola D, Wolfson MR, Greenspan JS, Rubenstein SD, Shaffer TH. Liquid ventilation of neonates: tissue histology and morphometry. Pediatr Res 1990;27(4 (Pt 2)):29A.

255. Parker JC, Thomas J, Hamm CR. Optimized blood gases during total liquid ventilation in piglets. FASEB-J 2000;14(4):A609.

256. Wolfson MR, Davidson A, Shaffer TH, Roache R, Merwin J, Pucella J. PEEP sensitivity during tidal liquid ventilation. Pediatr Res 1999;45(4):326A.

257. Lowe C, Tuma RF, Sivieri EM, Shaffer TH. Liquid ventilation: cardiovascular adjustments with secondary hyperlactatemia and acidosis. J Appl Physiol 1979;47(5):1051-7.

258. Lowe CA, Shaffer TH. Increased pulmonary vascular resistance during liquid ventilation. Undersea Biomed Res 1981;8(4):229-38.

259. Sivieri EM, Moskowitz GD, Shaffer TH. Instrumentation for measuring cardiac output by direct Fick method during liquid ventilation. Undersea Biomed Res 1981;8(2):75-83.

260. Curtis SE, Fuhrman BP, Howland DF, DeFrancisis M, Motoyama EK. Cardiac output during liquid (perfluorocarbon) breathing in newborn piglets. Crit Care Med 1991;19(2):225-30.

261. Meinhardt JP, Tsagogiorgias C, Quintel M, van Ackern K. Influence of liquid and gas tidal volumes on hemodynamic function in rabbits during total liquid ventilation. Intensive Care Medicine 2000;26(Suppl 3):S217.

262. Tarczy Hornoch P, Hildebrandt J, Jackson JC. Gravitational effects on volume distribution in a model of partial and total liquid ventilation. Respir Physiol 2000;120(2):125-38.

263. Tooley R, Hirschl RB, Parent A, Bartlett RH. Total liquid ventilation with perfluorocarbons increases pulmonary end-expiratory volume and compliance in the setting of lung atelectasis. Crit Care Med 1996;24(2):268-73.

264. Bhutani VK, Wolfson MR, Tran NN, Shaffer TH. Liquid ventilation: postnatal cardiopulmonary conditioning of very preterm lambs. In: Jones CT, editor. Fetal and neonatal development. 1988 ed: Perinatology Press; 1988. p. 304.

265. Richman PS, Wolfson MR, Shaffer TH. Lung lavage with oxygenated perfluorochemical liquid in acute lung injury. Crit Care Med 1993;21(5):768-74.

266. Mercurio MR, Fiascone JM, Lima DM, Jacobs HC. Surface tension and pulmonary compliance in premature rabbits. J Appl Physiol 1989;66(5):2039-44.

267. Gladstone IM, Ray AO, Salafia CM, Perez Fontan J, Mercurio MR, Jacobs HC. Effect of artificial surfactant on pulmonary function in preterm and full-term lambs. J Appl Physiol 1990;69(2):465-72.

268. Fuhrman BP, Paczan PR, DeFrancisis M. Perfluorocarbon-associated gas exchange. Crit Care Med 1991;19(5):712-22.

269. Lachmann B, Tutuncu AS, Bos JAH, Faithfull NS, Erdmann W. Intratracheal perfluorooctyl-bromide (PFOB) in combination with mechanical ventilation. In: International Society for Oxygen Transport to Tissues; 1991 Aug 24-30; Willemstand. Curacao; 1991. p. E16.

270. Shaffer TH, Foust Rr, Wolfson MR, Miller TF, Jr. Analysis of perfluorochemical elimination from the respiratory system. J Appl Physiol 1997;83(3):1033-40.

271. Miller TF, Milestone B, Stern R, Shaffer TH, Wolfson MR. Effect of single versus multiple dosing on perfluorochemical distribution and elimination during partial liquid ventilation. Pediatr Pulmonol 1999;27(6):410-8.

272. Proquitté H, Rüdiger M, Krause S, Foitzik B, M. S, Kurzidim L, et al. Impact of different PFC concentrations on flow measurements. European Journal of medical Research 2000;5:76.

273. Davies MW, Dunster KR. The effect of perfluorocarbon vapour on the measurement of respiratory tidal volume during partial liquid ventilation. Physiological Measurement 2000;21(3):n23-n30. 
274. Hernan LJ, Fuhrman BP, Papo MC, Steinhorn DM, Leach CL, Salman N, et al. Cardiorespiratory effects of perfluorocarbon-associated gas exchange at reduced oxygen concentrations. Crit Care Med 1995;23(3):553-9.

275. Tutuncu AS, Houmes RJ, Bos JA, Wollmer P, Lachmann B. Evaluation of lung function after intratracheal perfluorocarbon administration in healthy animals. Crit Care Med 1996;24(2):274-9.

276. Doctor A, Ibla JC, Grenier BM, Zurakowski D, Ferretti ML, Thompson JE, et al. Pulmonary blood flow distribution during partial liquid ventilation. Journal Of Applied Physiology 1998;84(5):15401550.

277. Morris KP, Cox PN, Mazer CD, Fmdova H, McKerlie C, Wolfe R. Distribution of pulmonary blood flow in the perfluorocarbon-filled lung. Intensive Care Medicine 2000;26(6):756-763.

278. Overbeck MC, Pranikoff T, Hirschl RB. Partial liquid ventilation provides effective gas exchange in a large animal model. J Crit Care 1996;11(1):37-42.

279. Mates EA, Jackson JC, Hildebrandt J, Truog WE, Standaert TA, Hlastala MP. Respiratory gas exchange and inert gas retention during partial liquid ventilation. Adv Exp Med Biol 1994;361:42735.

280. Mates EA, Tarczy Hornoch P, Hildebrandt J, Jackson JC, Hlastala MP. Negative slope of exhaled $\mathrm{CO} 2$ profile: implications for ventilation heterogeneity during partial liquid ventilation. Adv Exp Med Biol 1996;388:585-97.

281. Mates EA, Hildebrandt J, Jackson JC, Tarczy Hornoch P, Hlastala MP. Shunt and ventilationperfusion distribution during partial liquid ventilation in healthy piglets. J Appl Physiol 1997;82(3):933-42.

282. Mates vanLobensels E, Anderson JC, Hildebrandt J, Hlastala MP. Modeling diffusion limitation of gas exchange in lungs containing perfluorocarbon. J Appl Physiol 1999;86(1):273-84.

283. Harris RS, Willey-Courand DB, Head CA, Galletti GG, Venegas JG. The effects of pulmonary vasodilation on regional pulmonary perfusion $(\mathrm{Qr})$ and ventilation (Var) during partial liquid ventilation (PLV). Am J Respir Crit Care Med 1998;157:A462.

284. Hernan LJ, Fuhrman BP, Kaiser RE, Penfil S, Foley C, Papo MC, et al. Perfluorocarbon-associated gas exchange in normal and acid-injured large sheep. Crit Care Med 1996;24(3):475-81.

285. Davies K, Campbell RS, Johannigman JA, Hurst JM, Porembka DT, Luchette FA, et al. Effects of tidal volume $\left(\mathrm{V}_{\mathrm{T}}\right)$ on oxygen delivery and gas exchange during partial liquid ventilation (PLV). In: Liquid ventilation: a symposium; 1996 September 19; Ann Arbor, MI; 1996. p. 16.

286. Uchida T, Yokoyama K, Nakazawa K, Makita K. Partial pressure of oxygen and partial pressure of carbon dioxide of perfluorocarbon liquid during partial liquid ventilation: their regional difference and their dependence on tidal volume and positive end-expiratory pressure level. Intensive Care Medicine 2001;27(1):36-41.

287. Kacmarek RM. Partial liquid ventilation: is there a niche? Intensive Care Medicine 2001;27(1):1-2.

288. Patel MM, Patel MK, Szanto P, Alrenga DP, Long DM. Ventilation with synthetic fluids. Surg Clin North Am 1971;51(1):25-36.

289. Rotta AT, Gunnarsson B, Hernan LJ, Fuhrman BP, Steinhorn DM. Partial liquid ventilation with perflubron attenuates in vivo oxidative damage to proteins and lipids. Crit Care Med 2000;28(1):2028.

290. Fujino Y, Kirmse M, Chiche JD, Hromi J, Kacmarek RM. The effect of partial liquid ventilation (PLV) on inflection points of the pressure-volume (P-V) curve in healthy sheep. Am J Respir Crit Care Med 1998;157(3):A463.

291. Goldner. Effect of incremental perfluorocarbon instillation on lung volumes (FRC) and regional pleural pressure. Am J Respir Crit Care Med 1997;153(4):A87.

292. Al-Rahmani A, Awad K, Miller TF, Wolfson MR, Shaffer TH. Effects of partial liquid ventilation (PLV) with perfluorodecalin in the saline injured lung of the juvenile rabbit model. Pediatr Res 1996;39:384A.

293. Kuhlen Rea. Lung mechanics during partial liquid ventilation (PLV) with perfluorocarbon (PFC) in experimental acute lung injury (ALI). Am J Respir Crit Care Med 1997;153:A950.

294. Ferreyra G, Goddon S, Fujino Y, Kacmarek RM. The relationship between gas delivery patterns and the lower inflection point of the pressure-volume curve during partial liquid ventilation. Chest 2000;117(1):191-8. 

distribution of gas-liquid interface during partial liquid ventilation in the oleic acid lung injury model: fluorine-19 magnetic resonance imaging study. Crit Care Med 2000;28(8):2904-8.

296. Salman NH, Fuhrman BP, Steinhorn DM, Papo MC, Hernan LJ, Leach CL, et al. Prolonged studies of perfluorocarbon associated gas exchange and of the resumption of conventional mechanical ventilation. Crit Care Med 1995;23(5):919-24.

297. Rich PB, Reickert CA, Mahler SA, Sawada S, Awad S, Kazerooni EA, et al. Prolonged partial liquid ventilation in spontaneously breathing awake animals. Crit Care Med 1999;27(5):941-5.

298. Heulitt MJ, Holt S, Wilson W. Evaluation of work of breathing of spontaneous breaths during partial liquid ventilation in a healthy animal model. Crit Care Med 1997;25(Suppl 1):A25.

299. Novotny WE, Holbert D. Use of continuous positive airway pressure (CPAP) during partial liquid ventilation (PLV) in spontaneous breathing rabbits. Pediatr Res 1999;54(4):354A.

300. Wolfson MR, Kechner NE, Roache RF, DeChadarevian JP, Friss HE, Rubenstein SD, et al. Perfluorochemical rescue after surfactant treatment: effect of perflubron dose and ventilatory frequency. J Appl Physiol 1998;84(2):624-40.

301. Cox PN, Morris K, Frndova H, Babyn P, Bryan AC. Where does the gas go during a ventilatory cycle in a lung filled to FRC with perfluorocarbon (PFC)? Am J Respir Crit Care Med 1997;155:A951.

302. Kallas HJ, Jackson JC, Glenny RW, Hlastala MP. Alterations in regional pulmonary blood flow distribution during partial liquid ventilation (PLV) in a normal adult sheep lung. In: Liquid ventilation: a symposium; 1996 September 19, 1996; Ann Arbor, MI; 1996. p. 27.

303. Enrione MA, Papo MC, Leach CL, Holm BA, Hernan LJ, Fuhrman BP, et al. Regional pulmonary blood flow during partial liquid ventilation in normal and acute oleic acid-induced lung-injured piglets. Crit Care Med 1999;27(12):2716-23.

304. Loer SA, Schlack W, Ebel D, Tarnow J. Effects of partial liquid ventilation on regional pulmonary blood flow distribution of isolated rabbit lungs. Crit Care Med 2000;28(5):1522-5.

305. Cox PN, Morris KP, Frndova H, Mazer D, McKerlie C. Partial liquid ventilation (PLV) redistributes pulmonary blood flow away from dependent lung regions. Am J Respir Crit Care Med 1998;157:A462.

306. Ricard JD, Martin Lefevre L. Dreyfuss D, Saumon G. Alvoolar permeability and liquid absorption during partial liquid ventilation of rats with perflubron. Am J Respir Crit Care Med 2000;161(1):44-9.

307. Werner HA, Stockwell JA, Lai-Fook SJ. Partial liquid ventilation causes formation of interstitial perivascular cuffs in rabbit lung. Am J Respir Crit Care Med 1996;153:A531.

308. Fujino Y, Kirmse M, Chiche JD, Hromi J, Kacmarek RM. Partial liquid ventilation (PLV) does not protect against high stretch lung injury in healthy sheep. Am J Respir Crit Care Med 1998;157(3):A461.

309. Chiche JD, Fujino Y, Kirmse M, Hromi J, Kacmarek RM. High stretch ventilatory strategies induce alveolar damage during partial liquid ventilation (PLV). Am J Respir Crit Care Med 1998;157(3):A462.

310. Steinau F, Deja M, Krebs MO, U. K, Rossaint R. Positive end-expiratory pressure (PEEP) impaires renal function whereas "liquid PEEP" does not. Intensive Care Medicine 2000;26(Suppl 3):S217.

311. Zier JL, Wangensteen OD, Webers JA, Wilkin MK, Green TP. Effect of perfluorocarbon and ventilation modality on alveolar epithelial permeability. Pediatr Res 1993;33(4):43A.

312. Haberman BE, Wert SE, Whitsett JA, Iwamoto HS. Effects of perfluorocarbon in spontaneous breathing mice. Pediatr Res 1998;43:282A.

313. Hummler H, Thome U, Schulze A, Pohlandt F. Partial liquid ventilation (PLV) combined with Proportional Assist Ventilation (PAV) in spontaneous breathing animals: follow-up of gas exchange and survival over a four week period in a rabbit model. Pediatr Res 1998;43:285A.

314. Sekins KM, Coalson JJ, deLemos RA, Fields TK, Flaim SF, Guerra JM, et al. Long-term partial liquid ventilation (PLV) with perflubron in the near-term baboon neonate. Artif Cells Blood Substit Immobil Biotechnol 1994;22(4):1381-7.

315. Lachmann B, Tutuncu AS, Bos JA, Faithfull NS, Erdmann W. Perflubron (perfluorooctylbromide) instillation combined with mechanical ventilation: an alternative treatment of acute respiratory failure in adult animals. Adv Exp Med Biol 1992;317:409-12.

316. Curtis SE, Peek JT, Kelly DR. Partial liquid breathing with perflubron improves arterial oxygenation in acute canine lung injury. J Appl Physiol 1993;75(6):2696-702. 
317. Jackson JC, M. SK, Standaert TA, Truog WE, Hodson WA. Improved gas exchange and lung compliance after intratracheal perflubron in piglets with acute lung injury. Pediatric Research 1993;33(4):330A.

318. Tutuncu AS, Lachmann B, Faithfull NS, Erdmann W. Dose-dependent improvement of gas exchange by intratracheal perflubron (perfluorooctylbromide) instillation in adult animals with acute respiratory failure. Adv Exp Med Biol 1992;317:397-400.

319. Tutuncu AS, Faithfull NS, Lachmann B. Intratracheal perfluorocarbon administration combined with mechanical ventilation in experimental respiratory distress syndrome: dose-dependent improvement of gas exchange. Crit Care Med 1993;21(7):962-9.

320. Kaisers U, Max M, Schnabel R, Böhm S, Hendrik ER, Rossaint R, et al. Partial liquid ventilation with FC 3280 in experimental lung injury: dose-dependent improvement of gas exchange and lung mechanics. Appl Cardiopulmon Pathophysiol 1996;6:163-170.

321. Penfil S, Hernan LJ, Fuhrman BP, Papo MC, Leach CL, Frisacario P, et al. Relationship between volume of perflubron (PFOB) and arterial oxygenation during partial liquid ventilation. Crit Care Med 1996;24(1):148A.

322. Bradley Jea. Dose/response effect of Liquivent during partial liquid ventilation in a saline-lavaged lung injury model in swine. Am J Respir Crit Care Med 1997;153:A950.

323. Parent AC, Overbeck MC, Hirschl RB. Oxygen dynamics during partial liquid ventilation in a sheep model of severe respiratory failure. Surgery 1997;121(3):320-7.

324. Tutuncu AS, Akpir K, Mulder P, Faithfull NS, Erdmann W, Lachmann B. Gas exchange and lung mechanics during long-term mechanical ventilation with intratracheal perfluorocarbon administration in respiratory distress syndrome. Adv Exp Med Biol 1992;317:401-7.

325. Tutuncu AS, Akpir K, Mulder P, Erdmann W, Lachmann B. Intratracheal perfluorocarbon administration as an aid in the ventilatory management of respiratory distress syndrome. Anesthesiology 1993;79(5): 1083-93.

326. Overbeck MC, Pranikoff T, Yadao CM, Hirschl RB. Efficacy of perfluorocarbon partial liquid ventilation in a large animal model of acute respiratory failure. Crit Care Med 1996;24(7):1208-14.

327. Kirmse M, Fujino Y, Kacmarek RM. The effect of partial liquid ventilation (PLV) on expiratory resistance in lung injured sheep. Am J Respir Crit Care Med 2000;161(3):A388.

328. Cox PN, Fmdova H, Tan PS, Nakamura T, Miyasaka K, Sakurai Y, et al. Concealed air leak associated with large tidal volumes in partial liquid ventilation. Am J Respir Crit Care Med 1997;156(3 Pt 1):992-7.

329. Leach CL, Fuhrman BP, Morin FC, Rath MG. Perfluorocarbon-associated gas exchange (partial liquid ventilation) in respiratory distress syndrome: a prospective, randomized, controlled study. Crit Care Med 1993;21(9):1270-8.

330. Notterman DA. A new PAGE in mechanical ventilation? Crit Care Med 1993;21(9):1257-9.

331. deLemos RA, Winter D, Fields T, Doherty T, Null DJ, Yoder B, et al. Prolonged partial liquid ventilation in the treatment of hyaline membrane disease (HMD) in the premature baboon. Pediatr Res 1994;35:330A.

332. Wolfson MR, Kechner NE, Friss HE, Rubenstein SD, Shaffer TH. Improved gas exchange and pulmonary mechanics during and following slow tracheal instillation of perfluorochemical liquid in neonatal respiratory distress. Am J Respir Crit Care Med 1994;149(4 Pt 2):A545.

333. Moya FR, Llanos AJ, Rios AM, Riquelme RA, Moraga FA, Rubio LA, et al. Repeated doses of the perfluorocarbon FC-100 improve lung function of preterm lambs. Pediatr Res 1997;42(6):893-8.

334. Heldt GP, Henderson GP. Improved respiratory system compliance with the addition of perfluorocarbon to replacement surfactant in preterm rabbits. Pediatr Res 1998;43(4(2)):284A.

335. Gothberg S, Parker TA, Abman SH, Kinsella JP. High-frequency oscillatory ventilation and partial liquid ventilation after acute lung injury in premature lambs with respiratory distress syndrome. Crit Care Med 2000;28(7):2450-6.

336. Tokieda K, Whitsett JA, Clark JC, Weaver TE, Ikeda K, McConnell KB, et al. Pulmonary dysfunction in neonatal SP-B-deficient mice. Am J Physiol 1997;273(4 Pt 1):L875-82.

337. Tutuncu AS, Faithfull NS, Lachmann B. Comparison of ventilatory support with intratracheal perfluorocarbon administration and conventional mechanical ventilation in animals with acute respiratory failure. Am Rev Respir Dis 1993;148(3):785-92.

338. Houmes RJ, Verbrugge SJ, Hendrik ER, Lachmann B. Hemodynamic effects of partial liquid ventilation with perfluorocarbon in acute lung injury. Intensive Care Med 1995;21(12):966-72. 
339. Max M, Kaisers U, Eichhorn V, Böhm S, Rossaint R, Lachmann B. Partial liquid ventilation with the perfluorocarbon FC $3280\left(\mathrm{C}_{8} \mathrm{~F}_{18}\right)$ in an animal model of acute lung injury. Int Care Med 1996;22(suppl 3):S427.

340. Stewart MJ, Davies MW, Souriel M, Kamberi S, Bayley G, Chavasse R, et al. Perfluorochemical associated gas exchange (PAGE) using FC-77: the effect of PAGE and inhaled nitric oxide (INO) on oxygenation, hemodynamics, pulmonary mechanics and lung injury in a surfactant deficient piglet model. Pediatr Res 1998;43:298A.

341. Al Rahmani A, Awad K, Miller TF, Wolfson MR, Shaffer TH. Effects of partial liquid ventilation with perfluorodecalin in the juvenile rabbit lung after saline injury. Crit Care Med 2000;28(5):145964.

342. Kaisers U, Max M, Walter J, Kuhlen R, Pappert D, Falke K, et al. Partial liquid ventilation with small volumes of FC 3280 increases survival time in experimental ARDS. Eur Respir J 1997;10(9):1955-

61.

343. Sawada S, Ichiba S, Itano H, Shoga K. Experimental study of partial liquid ventilation in the setting of acute respiratory failure in a rabbit model. In: Liquid ventilation: a symposium; 1996 September 19; Ann Arbor, MI; 1996. p. 28.

344. Sawada S, Ichiba S, Itano H, Shoga K, Shimizu N. Experimental study of partial liquid ventilation in the setting of acute respiratory failure induced by sea water lung lavage in rabbits. Acta Medica Okayama 1998;52(3):131-137.

345. van Eeden SF, Klut ME, Alexander J, Zonis Z, Skippen P. Partial liquid ventilation with perfluorocarbon improves gas exchange and lung inflammation in acute lung injury. Am J Respir Crit Care Med 1998;157:A461.

346. van Eeden SF, Klut ME, Leal MA, Alexander J, Zonis Z, Skippen P. Partial liquid ventilation with perfluorocarbon in acute lung injury: light and transmission electron microscopy studies. Am J Respir Cell Mol Biol 2000;22(4):441-50.

347. Degraeuwe PLJ, Thunnissen FBJM, Vos GD, Blanco CE. High-frequency oscillatory ventilation, partial liquid ventilation, or conventional mechanical ventilation in newborn piglets with saline lavage-induced acute lung injury. A comparison of gas-exchange efficacy and lung histomorphology. Biol Neonate 1999;75(2):118-29.

348. Hartog A, Vazquez de Anda GF, Gommers D, Kaisers U, Verbrugge SJ, Schnabel R, et al. Comparison of exogenous surfactant therapy, mechanical ventilation with high end-expiratory pressure and partial liquid ventilation in a model of acute lung injury. $\mathrm{Br} \mathrm{J}$ Anaesth 1999;82(1):81-6.

349. Hartog A, Kaisers U, Gommers D, Lachmann B. Comparing the effects of four different perfluorocarbons on gas exchange and lung mechanics in an animal model of acute lung injury. Acp Applied Cardiopulmonary Pathophysiology 1999;8(1):41-46.

350. Fujino Y, Goddon S, Chiche JD, Hromi J, Kacmarek RM. Partial liquid ventilation ventilates better than gas ventilation. Am J Respir Crit Care Med 2000;162(2 Pt 1):650-7.

351. Curtis SE, Peek JT. Effect of progressive intratracheal administration of perflubron during conventional gas ventilation in anesthetized dogs with oleic acid lung injury. Adv Exp Med Biol 1994;345:51-58.

352. Hirschl RB, Tooley R, Parent A, Johnson K, Bartlett RH. Partial liquid ventilation improves gas exchange in the setting of respiratory failure during during extracorporeal life support (ECLS). Surg Forum 1993;44:646-649.

353. Hirschl RB, Tooley R, Parent AC, Johnson K, Bartlett RH. Improvement of gas exchange, pulmonary function, and lung injury with partial liquid ventilation. A study model in a setting of severe respiratory failure. Chest 1995;108(2):500-8.

354. Quintel M, Heine M, Hirschl RB, Tillmanns R, Wessendorf V. Effects of partial liquid ventilation on lung injury in a model of acute respiratory failure: a histologic and morphometric analysis. Crit Care Med 1998;26(5):833-43.

355. Quintel M, Hirschl RB, Roth H, Loose R, vanAckern K. Computer tomographic assessment of perfluorocarbon and gas distribution during partial liquid ventilation for acute respiratory failure. American Journal Of Respiratory and Critical Care Medicine 1998;158(1):249-255.

356. Quintel M, Lucke T, Weiser H, Roth H, Lehmann HJ, Meinhard J, et al. Electron Beam Tomography (EBT) Based Volume Measurements In Healthy And Oleic Acid Injured Adult Sheep Lungs During Partial Liquid Ventilation (PLV). Am J Respir Crit Care Med 1999;159(4 Pt 2):901A. 

associated gas exchange improves oxygenation, lung mechanics, and survival in a model of adult respiratory distress syndrome. Crit Care Med 1996;24(3):466-74.

358. Papo M, Holm B, Fuhrman B, Hernan L, Steinhorn D, Leach C, et al. Perfluorocarbon associated gas exchange (PAGE) instituted prior to lung injury decreases intra-alveolar protein flux. Crit Care Med 1994;22(1):A141.

359. Papo M, Steinhorn DM, Holm B, Enrione M, Leach C, Hernan L, et al. The effect of partial liquid ventilation (PLV) on protein leak and surface tension in a model of acute lung injury. Am J Respir Crit Care Med 1996;153:A392.

360. Romera MA, Rubio JJ, Santos M, Fuente M, Chamorro C, Pardo C, et al. Does partial liquid ventilation improve alveolar permeability in acute respiratory distress syndrome. Intensive Care Med 2000;26(suppl 3):S217.

361. Gauger PG, Overbeck MC, Chambers SD, Cailipan Cl, Hirschl RB. Partial liquid ventilation improves gas exchange and increases EELV in acute lung injury. Journal Of Applied Physiology 1998;84(5): 1566-1572.

362. Gauger PG, Overbeck MC, Koeppe RA, Shulkin BL, Hrycko JN, Weber ED, et al. Distribution of pulmonary blood flow and total lung water during partial liquid ventilation in acute lung injury. Surgery 1997;122(2):313-23.

363. Suh GY, Chung MP, Park SJ, Park JW, Kim HC, Kim H, et al. Partial liquid ventilation with perfluorocarbon improves gas exchange and decreases inflammatory response in oleic acid-induced lung injury in beagles. J Korean Med Sci 1999;14(6):613-22.

364. Steinhorn DM, Papo MC, Rotta AT, Aljada A, Fuhrman BP, Dandona P. Liquid ventilation attenuates pulmonary oxidative damage. J Crit Care 1999;14(1):20-8.

365. Romera MA, Rubio JJ, Santos M, Tendillo FJ, Dominguez de Vittota E, Chamorro C, et al. Partial liquid ventilation in experimental acute lung injury. Inefficacy at reduced oxygen concentrations. Intensive Care Med 1998;24(suppl 1):S80.

366. Lange NR, Kozlowski JK, Gust R, Shapiro SD, Schuster DP. Effect of partial liquid ventilation on pulmonary vascular permeability and edema after experimental acute lung injury. Am J Respir Crit Care Med 2000;162(1):271-7.

367. Nesti FD, Fuhrman BP, Steinhorn DM, Papo MC, Hernan LJ, Duffy LC, et al. Perfluorocarbonassociated gas exchange in gastric aspiration. Crit Care Med 1994;22(9): 1445-52.

368. Kawamae K, Pristine G, Chiumello D, Tremblay LN, Slutsky AS. Partial liquid ventilation decreases serum tumor necrosis factor-alpha concentrations in a rat acid aspiration lung injury model. Crit Care Med 2000;28(2):479-83.

369. Kawamae K, Isomine S, Matsumoto Y, Otsuki M, Tase C, Murakawa M. PLV Suppress The TNFAlpha Production, But Not The Gene Expression In The Lung Injury Model. Am J Respir Crit Care Med 1999;159(4 Pt 2):902.

370. Fitzpatrick JC, Jordan BS, Salman N, Williams J, Cioffi WG, Jr., Pruitt BA, Jr. The use of perfluorocarbon-associated gas exchange to improve ventilation and decrease mortality after inhalation injury in a neonatal swine model. J Pediatr Surg 1997;32(2):192-6.

371. Cindrick LL, Gore DC, Herndon DN, Traber LD, Traber DL. Bronchoscopic lavage with perfluorocarbon decreases postprocedure hypoxemia in an ovine model of smoke inhalation. J Trauma 1999;46(1):129-35.

372. Clayton RG, Wolfson MR, Shaffer TH. Partial liquid ventilation (PLV) in lambs with kerosene pneumonitis. Am J Respir Crit Care Med 1997;153:A950.

373. Kahai J, Rotta A, Quadrani D, Alashari M, Joshi P, Steinhorn D. Partial liquid ventilation (PLV) attenuates lung injury in a hydrocarbon aspiration injury (HAI). 1998;36:427-428.

374. Burns MJ, Dickson EW, Sivilotti ML, Hocker M, Porcaro WA. Enhanced mortality from perfluorocarbon administration in a rat model of kerosene aspiration. J Toxicol Clin Toxicol 1999;37(7):855-9.

375. Moomey CB, Jr., Fabian TC, Croce MA, Melton SM, Proctor KG. Cardiopulmonary function after pulmonary contusion and partial liquid ventilation. J Trauma 1998;45(2):283-90.

376. Bradley JD, Spooner ML, Rusheen PD, Peters BP, Xu A, Flaim SF. Intratracheal perflubron (PFB) liquid or vapor reduces lung myeloperoxidase (MPO) levels following cobra venom factor (CVF) challenge in rats. FASEB-J 1996;10 (suppl):A 108. 

leak in the setting of acute lung injury. J Crit Care 1998;13(3):136-9.

378. Colton DM, Till GO, Johnson KJ, Dean SB, Bartlett RH, Hirschl RB. Neutrophil accumulation is reduced during partial liquid ventilation. Crit Care Med 1998;26(10):1716-24.

379. Younger JG, Taqi AS, Till GO, Hirschl RB. Partial liquid ventilation protects lung during resuscitation from shock. J Appl Physiol 1997;83(5):1666-70.

380. Rotta AT, Gunnarsson B, Hernan LJ, Fuhrman BP, Steinhorn DM. Partial liquid ventilation influences pulmonary histopathology in an animal model of acute lung injury. J Crit Care 1999;14(2):84-92.

381. Rotta AT, Steinhorn DM. Partial liquid ventilation reduces pulmonary neutrophil accumulation in an experimental model of systemic endotoxemia and acute lung injury. Crit Care Med

382. Dreyfuss D, Martin Lefevre L, Saumon G. Hyperinflation-induced lung injury during alveolar flooding in rats: effect of perfluorocarbon instillation. Am J Respir Crit Care Med 1999;159(6):17527.

383. Ricard JD, Dreyfuss D, Saumon G. In Vivo TNF-alpha Production During High Volume Mechanical Ventilation (MV) In Rats: Evidence For the Need Of Priming And Effect Of Partial Liquid Ventilation With Perfluorocarbon (PFC). Am J Respir Crit Care Med 1999;159(4 Pt 2):901A.

384. Thompson AE, Fuhrman BP, Alan J. Perfluorocarbon-associated gas exchange (PAGE) in experimental meconium aspiration (MAS). Pediatr Res 1993;33:238A.

385. Albert GP, Leach CL, Hernan L, Morin FC. Pulmonary mechanics and hemodynamics in a meconium aspiration (MAS) lamb model treated with partial liquid ventilation (PLV) and nitric oxide (NO). Pediatr Res 1996;39:43A.

386. Valls-i-Soler A, Gastiasoro E, Alvarez FJ, Arnaiz A, Fernández-Ruanova B, Alfonso LF, et al. Cardiovascular effects of partial liquid ventilation (PLV) on experimental meconium aspiration syndrome (MAS) in newborn lambs. Pediatr Res 1998;43:301A.

387. Barrington KJ, Singh AJ, Etches PC, Finer NN. Partial liquid ventilation with and without inhaled nitric oxide in a newborn piglet model of meconium aspiration. Am J Respir Crit Care Med 1999;160(6):1922-7.

388. Singh AJea. Partial liquid (PLV) and conventional gas ventilation (GV); histopathologic differences in newborn piglet lungs in a mecomium aspiration syndrome (MAS) model. Pediatr Res 1997;4I(4(2)):268A.

389. Wilcox DT, Glick PL, Karamanoukian HL, Leach C, Morin FCr, Fuhrman BP. Perfluorocarbonassociated gas exchange improves pulmonary mechanics, oxygenation, ventilation, and allows nitric oxide delivery in the hypoplastic lung congenital diaphragmatic hernia lamb model. Crit Care Med 1995;23(11):1858-63.

390. Wilcox DT, Glick PL, Karamanoukian HL, Morin FCr, Fuhrman BP, Leach C. Partial liquid ventilation and nitric oxide in congenital diaphragmatic hernia. J Pediatr Surg 1997;32(8):1211-5.

391. Major D, Cadenas M, Cloutier R, Fournier L, Wolfson MR, Shaffer TH. Combined gas ventilation and perfluorochemical tracheal instillation as an alternative treatment for lethal congenital diaphragmatic hernia in lambs. J Pediatr Surg 1995;30(8):1178-82.

392. Major D, Cadenas M, Cloutier R, Leclerc S, Fournier L, Shaffer TH, et al. Morphometrics of normal and hypoplastic lungs in preterm lambs with gas and partial liquid ventilation. Pediatr Surg Int 1997;12(2-3):121-5.

393. Alshafei M, Albert A, ljsselstijn H, Tibboel D. Liquid ventilation significantly improves compliance in neonatal rats with congenital diaphragmatic hernia (CDH). Am J Respir Crit Care Med 1996;153:A553.

394. Gischler SJ, Vlot J, Albert A, Alshafei M, Tibboel D. Beneficial effects of partial liquid ventilation in neonatal rats with congenital diaphragmatic hernia. In: Liquid ventilation: a symposium; 1996 September 19; Ann Arbor, MI; 1996. p. 18.

395. Okazaki T, Sharma HS, Vlot J, Alshafei M, Tibboel T. Pulmonary stress response in congenital diaphragmatic hernia rats after conventional and partial liquid ventilation. Submitted 2000.

396. Dickson E, Heard S, Fraire A, Feltquate D, Chu B, Chapman G. Partial liquid ventilation in the treatment of rats with lethal pneumococcal pneumonia. Crit Care Med 1995;23:A263.

397. Dickson EW, Heard SO, Chu B, Fraire A, Brueggemann AB, Doern GV. Partial liquid ventilation with perfluorocarbon in the treatment of rats with lethal pneumococcal pneumonia. Anesthesiology $1998 ; 88(1): 218-223$. 
398. Cullen AB, Cox CA, Hipp SJ, Wolfson MR, Shaffer TH. Intra-tracheal delivery strategy of gentamicin with partial liquid ventilation. Respir Med 1999;93(11):770-8.

399. Franz AR, Rőhlke W, Schnabel R, Pohlandt F, Hummler HD. Pulmonary (I.P.) administration of gentamicin- and vancomycin-perfluorocarbon-suspensions during partial liquid ventilation (PLV) improves pulmonary antibiotic tissue concentrations (PATC). In: 2nd European Symposium on Liquid Ventilation; 2000 October 2-3, 2000; Bilbao; 2000. p. 23.

400. Dickson EW, Heard SO, Goodin T, Brueggemann AB, Doern GV. Use of a penicillin containing perfluorocarbon emulsion in the treatment of rats with lethal pneumococcal pneumonia. Crit Care Med 1996;24(suppl 1):A28.

401. Cheifetz IM, Cannon ML, Craig DM, Quick G, Kern FH, Smith PK, et al. Liquid ventilation improves pulmonary function and cardiac output in a neonatal swine model of cardiopulmonary bypass. J Thorac Cardiovasc Surg 1998;115(3):528-35.

402. Williams EA, Welty SE, Geske RS, Hubble CL, Craig DM, Quick G, et al. Liquid lung ventilation reduces neutrophil sequestration in a neonatal swine model of cardiopulmonary bypass. Critical Care Medicine 2001;29(4):789-795.

403. Cannon ML, Cheifetz IM, Craig DM, Hubble CL, Quick G, Ungerleider RM, et al. Optimizing liquid ventilation as a lung protection strategy for neonatal cardiopulmonary bypass: full functional residual capacity dosing is more effective than half functional residual capacity dosing. Crit Care Med 1999;27(6):1140-6.

404. Lowenstein E, Lincoln JC, Modell JH, Austen WG, Laver MB. Preservation of excised canine lungs by ventilation with liquid fluorocarbon. Fed Proc 1970;29(5):1775-7.

405. Itano H, Aoe M, Ichiba S, Yamashita M, Date H, Andou A, et al. Partial liquid ventilation for acute allograft dysfunction after canine lung transplantation. Ann Thorac Surg 1999;67(2):332-9.

406. Peregrino MA, Sukumar M, Bommaraju M, Holm BA, Hernan LJ, Fuhrman BP, et al. High frequency partial liquid ventilation vs infasurf rescue in preterm lambs with respiratory distress syndrome (RDS). Pediatr Res 1998;43:293A.

407. Proquitté H, Flemmer A, Baethmann A, Simbruner G. Effects of surfactant or liquid ventilation with RM 101 on gas exchange (GE) and lung mechanics (LM) in nwb. piglets. Pediatr Res 1997;42(3):413.

408. Mrozek JD, Smith KM, Bing DR, Meyers PA, Simonton SC, Connett JE, et al. Exogenous surfactant and partial liquid ventilation: physiologic and pathologic effects. Am J Respir Crit Care Med 1997;156(4 Pt 1):1058-65.

409. Lohbrunner H, Wolf S, Deja M, Sterner-Kock A, U. K. Partial liquid ventilation (PLV) in combination with low dose surfactant in experimental acute lung injury (ALI). Intensive Care Medicine 2000;26(Suppl 3):S217.

410. Kelly KP, Stenson BJ, Drummond GB. Randomised comparison of partial liquid ventilation, nebulised perfluorocarbon, porcine surfactant, artificial surfactant, and combined treatments on oxygenation, lung mechanics, and survival in rabbits after saline lung lavage. Intensive Care Medicine 2000;26(10):1523-1530.

411. Nakamura T, Matsuzawa S, Sugiura M, Tamura M. A randomised control study of partial liquid ventilation after airway lavage with exogenous surfactant in a meconium aspiration syndrome animal model. Arch Dis Child Fetal Neonatal Ed 2000;82(2):F160-2.

412. Merz U, Kellinghaus M, Hausler M, Pakrawan N, Klosterhalfen B, Hornchen H. Partial liquid ventilation with surfactant: effects on gas exchange and lung pathology in surfactant-depleted piglets. Intensive Care Med 2000;26(1):109-16.

413. Leach CL, Morin FC, Fuhrman BP, Hernan L, Papo M, Steinhorn D, et al. Efficacy and pharmacokinetics of nitric oxide inhalation during partial liquid ventilationsm with perflubron (Liquivent ${ }^{\mathrm{TM}}$ ). Pediatr Res 1994;35(4):394A.

414. Leach CL, Morin FC, Fuhrman BP, Hernan L. Efficacy And Pharmacokinetics Of Nitric Oxide Inhalation During Partial Liquid Ventilationsm With Liquivent R. Am J Respir Crit Care Med 1999;159(4 Pt 2):78A.

415. Houmes RJ, Hartog A, Verbrugge SJ, Bohm S, Lachmann B. Combining partial liquid ventilation with nitric oxide to improve gas exchange in acute lung injury. Intensive Care Med 1997;23(2):163-9.

416. Hartog A, Houmes RJ, Verbrugge SJ, Erdmann W, Lachmann B. Partial liquid ventilation and inhaled nitric oxide have a cumulative effect in improving arterial oxygenation in experimental ARDS. Adv Exp Med Biol 1997;428:281-3. 
417. Max M, Kuhlen R, Falter F, Reyle Hahn M, Dembinski R, Rossaint R. Effect of PEEP and inhaled nitric oxide on pulmonary gas exchange during gaseous and partial liquid ventilation with small volumes of perfluorocarbon. Acta Anaesthesiol Scand 2000;44(4):383-90.

418. Zobel G, Urlesberger B, Dacar D, Rodl S, Reiterer F, Friehs I. Partial liquid ventilation combined with inhaled nitric oxide in acute respiratory failure with pulmonary hypertension in piglets. Pediatr Res 1997;41(2):172-7.

419. Uchida T, Nakazawa K, Yokoyama K, Makita M. Inhaled Nitric Oxide During Partial Liquid Ventilation Shifts Pulmonary Blood Flow To The Non-Dependent Lung Regions. Am J Respir Crit Care Med 1999;159(4 Pt 4):902A.

420. Uchida T, Nakazawa K, Yokoyama K, Makita K, Amaha K. The combination of partial liquid ventilation and inhaled nitric oxide in the severe oleic acid lung injury model. Chest 1998;113(6):1658-66.

421. Wilcox DT, Glick PL, Karamanoukian HL, Morin FC, 3rd, Fuhrman BP, Leach C. Partial liquid ventilation and nitric oxide in congenital diaphragmatic hernia. J Pediatr Surg 1997;32(8):1211-5.

422. Nakazawa K, Uchida T, Matsuzawa Y, Yokoyama K, Makita K, Amaha K. Treatment of pulmonary hypertension and hypoxia due to oleic acid induced lung injury with intratracheal prostaglandin E1 during partial liquid ventilation. Anesthesiology 1998;89(3):686-92.

423. Nakazawa K, Yokoyama K, Matsuzawa Y, Makita K, Amaha K. Pulmonary administration of prostacyclin ( $\mathrm{PGI}(2))$ during partial liquid ventilation in an oleic acid-induced lung injury: inhalation of aerosol or intratracheal instillation? Intensive Care Medicine 2001;27(1):243-250.

424. Eyal FG, Hamm CR, Beals DA, O'Donnell KT, Whitehurst RM. Efficacy of inhaled nitric oxide (NO) and alkalosis during partial liquid ventilation in oleic pulmonary hypertension. Pediatr Res 1997:41(4(2)):253A.

425. Hamm CR, Beals DA, O'Donnell KT, Zayek MM, Whitehurst RM, Eyal FG. Pulmonary administration of Prostacyclin ( $\mathrm{PGI}_{2}$ ) during partial liquid ventilation (PLV) in an animal model of pulmonary hypertension (PHT). Pediatr Res 1998;43(4(2)):284A.

426. Smith KM, Bing DR, Meyers PA, Connett JE, Boros SJ, Mammel MC. Partial liquid ventilation: a comparison using conventional and high-frequency techniques in an animal model of acute respiratory failure. Crit Care Med 1997;25(7):1179-86.

427. Manaligod JM, Bendel-Stenzel EM, Smith KM, Simonton SC, Bing DR, Meyers PA, et al. High frequency oscillatory ventilation and conventional ventilation, exogenous surfactant, and partial liquid ventilation: physiologic effects of prolonged treatment in an animal lung injury model. Pediatr Res 1999;45(4):331A.

428. Merz U, Kellinghaus M, Hausler M, Rose E, Hornchen H, Klosterhalfen B. Effects of prolonged partial liquid ventilation, high frequency ventilation and conventional ventilation on gas exchange and lung pathology in newborn surfactant-depleted piglets. Shock 2000;13(6):472-477.

429. Smith KM, Mrozek JD, Simonton SC, Bing DR, Meyers PA, Connett JE, et al. Prolonged partial liquid ventilation using conventional and high-frequency ventilatory techniques: gas exchange and lung pathology in an animal model of respiratory distress syndrome. Crit Care Med 1997;25(11):1888-97.

430. Manaligod JM, Bendel-Stenzel EM, Smith KM, Simonton SC, Bing DR, Meyers PA, et al. High frequency oscillatory ventilation and conventional ventilation, exogenous surfactant, and partial liquid ventilation: effect of prolonged treatment on lung pathology in an animal lung injury model. Pediatr Res 1999;45(4):331A.

431. Kolobow T, Powers T, Mandava S, Aprigliano M, Kawaguchi A, Tsuno K, et al. Intratracheal pulmonary ventilation (ITPV): control of positive end-expiratory pressure at the level of the carina through the use of a novel ITPV catheter design. Anesth Analg 1994;78(3):455-61.

432. Kolobow T, Giacomini M, Reali Forster C, Trawoger R. The current status of intratracheal-pulmonary ventilation (ITPV). Int J Artif Organs 1995;18(10):670-3.

433. Rossi N, Kolobow T, Aprigliano M, Tsuno K, Giacomini M. Intratracheal pulmonary ventilation at low airway pressures in a ventilator-induced model of acute respiratory failure improves lung function and survival. Chest 1998;114(4):1147-57.

434. Cereda MF, Sparacino ME, Frank AR, Trawoger R, Kolobow T. Efficacy of tracheal gas insufflation in spontaneously breathing sheep with lung injury. Am J Respir Crit Care Med 1999;159(3):845-50. 

ventilation versus conventional mechanical ventilation in a rabbit model of surfactant deficiency. Pediatr Res 1995;38(6):878-85.

436. Burkhead SR, Lally KP, Bristow F, Sandor GJ, Xue H. Intratracheal pulmonary ventilation provides effective ventilation in a near-drowning model. J Pediatr Surg 1996;31(3):337-41.

437. Perez CA, Bui KC, Bustorff Silva J, Atkinson JB. Comparison of intratracheal pulmonary ventilation with hybrid intratracheal pulmonary ventilation in a rabbit model of acute respiratory distress syndrome by saline lavage. ASAIO J 1999;45(5):496-501.

438. Velarde CA, Short BL, Rivera O, Seale W, Howard R, Kolobow T, et al. A comparison of intratracheal pulmonary ventilation to conventional ventilation in a surfactant deficient animal model. Crit Care Med 2000;28(5):1455-8.

439. Perez CA, Bui KC, Bustorff Silva J, Atkinson JB. Comparison of intratracheal pulmonary ventilation and hybrid intratracheal pulmonary ventilation with conventional mechanical ventilation in a rabbit model of acute respiratory distress syndrome by saline lavage. Crit Care Med 2000;28(3):774-81.

440. Makhoul IR, Bar Joseph G, Blazer S, Halberthal MS, Oren R, Sujov P. Intratracheal pulmonary ventilation in premature infants and children with intractable hypercapnia. ASAIO J 1998;44(1):82-8.

441. Meszaros E, Ogawa R. Continuous low-flow tracheal gas insufflation during partial liquid ventilation in rabbits. Acta Anaesthesiol Scand 1997;41(7):861-7.

442. Onasanya BI, Rais-Bahrami K, Rivera O, Seale WR, Short BL. The use of intratracheal pulmonary ventilation (ITPV) and partial liquid ventilation ( $\left(\mathrm{PLV}^{\mathrm{SM}}\right)$ in newborn piglets with meconium aspiration syndrome. In: 15th Annual CNMC ECMO Symposium; 1999 February 21-25; Keystone, CO; 1999.

443. Greenough A, Milner AD, Dimitriou G. Synchronized mechanical ventilation for respiratory support in newborn infants. Cochrane Database Syst Rev 2000(2):Cd000456.

444. Soll R. Patient-triggered ventilation of the newborn. Lancet 2000;356(9224):90-1.

445. Bendel Stenzel EM, Mrozek JD, Bing DR, Meyers PA, Connett JE, Mammel MC. Dynamics of spontaneous breathing during patient-triggered partial liquid ventilation. Pediatr Pulmonol 1998;26(5):319-25.

446. Bendel Stenzel EM, Bing DR, Meyers PA, Connett JE, Mammel MC. Synchronized gas and partial liquid ventilation in lung-injured animals: improved gas exchange with decreased effort. Pediatr Pulmonol 1999;27(4):242-50.

447. Younes M. Proportional assist ventilation, a new approach to ventilatory support. Theory. Am Rev Respir Dis 1992;145(1):114-20.

448. Younes M, Puddy A, Roberts D, Light RB, Quesada A, Taylor K, et al. Proportional assist ventilation. Results of an initial clinical trial. Am Rev Respir Dis 1992;145(1):121-9.

449. Hummler HD, Schulze A, Pohlandt F, Thome U. Dynamics of breathing during partial liquid ventilation in spontaneously breathing rabbits supported by elastic and resistive unloading. Pediatr Res 2000;47(3):392-7.

450. Hummler H, Franz A, Schulze A, Pohlandt F. Spontaneous breathing during partial liquid ventilation (PLV): ventilation, gas exchange and hemodynamics in animals with meconium aspiration syndrome (MAS) supported by elastic and resistive unloading. Pediatr Res 1999;54(4):305A.

451. Hummler HD, Thome U, Franz A, Schulze A, Pohlandt F. Spontaneous respiratory effort during partial liquid ventilation (PLV). European Journal of medical Research 1999;4:206.

452. Hummler HD, Franz A, Thome U, Schulze A, Pohlandt F. Partial liquid ventilation (PLV) in spontaneous breathing subjects supported by assisted mechanical ventilation. In: 2nd European Symposium on Liquid Ventilation; 2000 October 2-3, 2000; Bilbao; 2000. p. 35.

453. Franz AR, Mack C, Reichert J, Pohlandt F, Hummler H. Cardiac output (CO) during partial liquid ventilation (PLV): comparison of spontaneous breathing supported by proportional assist ventilation $(\mathrm{SB}+\mathrm{PAV})$ with controlled ventilation and muscle paralysis $(\mathrm{CV}+\mathrm{MP})$ in normal rabbits. European Journal of medical Research 2000;5:87.

454. Franz AR, Mack C, Reichert J, Pohlandt F, Hummler H. Cardiac output (CO) during partial liquid ventilation (PLV) in rabbits with ARDS: comparison of spontaneous breathing supported by proportional assist ventilation (SB+PAV) with controlled ventilation and muscle paralysis (CV+MP). European Journal of medical Research 2000;5:89. 
455. Leach CL, Sukumar M, Holm BA, Papo M, Morin FC, Steinhorn D, et al. High frequency partial liquid ventilation and surfactant treatment in preterm lambs with respiratory distress syndrome (RDS). Pediatr Res 1996;39(4):50A.

456. Sukumar M, Bommaraju M, Fisher JE, Morin FC, Papo MC, Fuhrman BP, et al. High-frequency partial liquid ventilation in respiratory distress syndrome: hemodynamics and gas exchange. J Appl Physiol 1998;84(1):327-34.

457. Sakurai Y, Fmdova H, Tan P, Cox PN. Perfluorocarbon - The recruiting agent of choice. Am J Respir Crit Care Med 1998;157:A462.

458. Doctor A, Mazzoni MC, BelBalzo U, DiCanzio J, Arnold JH. High-frequency oscillatory ventilation of the perfluorocarbon-filled lung: preliminary results in an animal model of acute lung injury. Crit Care Med 1999;27(11):2500-7.

459. Baden HP, Mellema JD, Bratton SL, PP OR, Jackson JC. High-frequency oscillatory ventilation with partial liquid ventilation in a model of acute respiratory failure. Crit Care Med 1997;25(2):299-302.

460. Doctor A, E. A-K, Tan P, Watson K, Thompson J, Arnold J. Extended high frequency partial liquid ventilation in lung injury: gas exchange and lung injury score. Pediatr Res 2000;47(4):55A.

461. Merz U, Kellinghaus M, Kurth A, Hornchen H. PLV combined with HFOV: influence of the initial perfluorocarbon (PFC) filling volume on gas exchange and lung mechanics in surfactant depleted newborn animals. In: 2nd European Symposium on Liquid Ventilation; 2000 October 2-3, 2000; Bilbao; 2000. p. 44.

462. Merz U, Kellinghaus M, Peschgens T, Klosterhalfen B, Hornchen H. Release of inflammatory mediators in bronchoalveolar lavage (BAL) after prolonged conventional ventilation (CV), high frequency oscillatory ventilation (HFOV) or partial liquid ventilation (PLV) in surfactant-depleted newborn pigs. Pediatr Res 2000;54(4):369A.

463. Sinclair SE, Albert RK. Altering ventilation-perfusion relationships in ventilated patients with acute lung injury. Intensive Care Med 1997;23(9):942-50.

464. Mure M, Domino KB, Lindahl SG, Hlastala MP, Altemeier WA, Glenny RW. Regional ventilationperfusion distribution is more uniform in the prone position. J Appl Physiol 2000;88(3): 1076-83.

465. Albert RK. Prone ventilation. Clinics in Chest Medicine 2000;21(3):511-517,ix.

466. Standaert TA, Lamm WJE, Tarczy-Hornoch P, Hildebrandt J, Mates EA, Jackson JC. Prone position is best during partial liquid ventilation in oleic acid injured sheep. Pediatr Res 1995;37(4(2)):54A.

467. Suh GY, Kang KW, Park SJ, Chung MP, Kim H, Rhee C, et al. The effect of prone positioning during partial liquid ventilation. Am J Respir Crit Care Med 2000;161(3):A387.

468. Max M, Kuhlen R, Lopez F, Reyle Hahn SM, Baumert JH, Rossaint R. Combining partial liquid ventilation and prone position in experimental acute lung injury. Anesthesiology 1999;91(3):796-803.

469. Merz U, Kellinghaus M, Mühlenbach R, Hornchen $H$. Prone position improves pulmonary function in surfactant-depleted newborn piglets during partial liquid ventilation. In: 2nd European Symposium on Liquid Ventilation; 2000 October 2-3, 2000; Bilbao; 2000. p. 43.

470. Curtis SE, Tilden SJ, Bradley WE, Cain SM. Effect of continuous rotation on the efficacy of partial liquid (perflubron) breathing in canine acute lung injury. Adv Exp Med Biol 1994;361:449-56.

471. Urlesberger B, Zobel G, Dacar D, Rodl S, Trafojer U, Trantina A, et al. Partial liquid ventilation combined with kinetic therapy in acute respiratory failure in piglets. Intensive Care Med 1999;25(5):496-502.

472. Kaisers U, Kuhlen R, Keske U, Sommerer A, Mohnhaupt A, Falke KJ, et al. Superimposing positive end-expiratory pressure during partial liquid ventilation in experimental lung injury. Eur Respir J 1998;11(5):1035-42.

473. Zobel G, Rodl S, Urlesberger B, Dacar D, Trafojer U, Trantina A. The effect of positive endexpiratory pressure during partial liquid ventilation in acute lung injury in piglets. Crit Care Med 1999;27(9):1934-9.

474. Suh GY, Chung MP, Park SJ, Koh Y, Kang KW, Kim H, et al. Partial liquid ventilation shows dosedependent increase in oxygenation with PEEP and decreases lung injury associated with mechanical ventilation. Journal of Critical Care 2000;15(3):103-112.

475. Manaligod JM, Bendel Stenzel EM, Meyers PA, Bing DR, Connett JE, Mammel MC. Variations in end-expiratory pressure during partial liquid ventilation: impact on gas exchange, lung compliance, and end-expiratory lung volume. Chest 2000;117(1):184-90. 
Kirmse M, Fujino Y, Hess D, Kacmarek RM. Positive end-expiratory pressure improves gas exchange and pulmonary mechanics during partial liquid ventilation. Am J Respir Crit Care Med 1998;158(5 Pt 1):1550-6.

477. Fujino Y, Kirmse M, Hess D, Kacmarek RM. The effect of mode, inspiratory time, and positive endexpiratory pressure on partial liquid ventilation. Am J Respir Crit Care Med 1999;159(4 Pt 1):108795.

478. Goddon S, Takeuchi M, Hromi J, Kacmarek R. Determination of optimal mean airway pressure in high frequency oscillatory partial liquid ventilation (HFO-PLV) in an ovine model of ARDS. Am J Respir Crit Care Med 2000;161(3):A47.

479. Goddon S, Takeuchi M, Hromi J, Kacmarek R. Effect of frequency, amplitude and I:E ratio on pulmonary gas-exchange in high frequency oscillatory partial liquid ventilation (HFO-PLV). Am J Respir Crit Care Med 2000;161(3):A387.

480. Hromi J, Takeuchi M, Goddon S, Kacmarek R. Tidal volumes during high frequency oscillatory partial liquid ventilation (HFO-PLV) in an ovine model of adult ARDS. Am J Respir Crit Care Med 2000;161(3):A388.

481. Lim CM, Koh Y, Shim TS, Lee SD, Kim WS, Kim DS, et al. The effect of varying inspiratory to expiratory ratio on gas exchange in partial liquid ventilation. Chest 1999;116(4):1032-8.

482. Beals DA, Bosarge PL, Hamm CR, Eyal FG. Ventilation with perfluorocarbon vapor prevents secondary injury due to intestinal ischemia/reperfusion. Crit Care Med 1998;26(1 suppl):Al15.

483. Bleyl JU, Ragaller M, Tscho U, Regner M, Kanzow M, Hubler M, et al. Vaporized perfluorocarbon improves oxygenation and pulmonary function in an ovine model of acute respiratory distress syndrome. Anesthesiology 1999;91(2):461-9.

484. Kandler M, von der Hardt K, Schoof E, Dötsch J, Rascher W. Persistent improvement of gas exchange and lung dynamics by inhaled perfluorocarbon in surfactant depleted piglets. In: 2 nd European Symposium on Liquid Ventilation; 2000 October 2-3, 2000; Bilbao; 2000. p. 36.

485. von der Hardt K, Schoof E, Kandler M, Dötsch J, Rascher W. Inhaled perfluorocarbon suppresses early pulmonary inflammatory response in a surfactant depleted piglet model. In: 2 nd European Symposium on Liquid Ventilation; 2000 October 2-3, 2000; Bilbao; 2000. p. 24.

486. Bruch LA, Flint A, Hirschl RB. Pulmonary pathology of patients treated with partial liquid ventilation. Mod Pathol 1997;10(5):463-8.

487. Bartlett RH, Hirschl RB. Liquid ventilation in ARDS. Acta Anaesthesiol Scand Suppl 1997;111:68-9.

488. Bartlett R, Croce M, Hirschl R, D. G, Wiedemann H, Davis K, et al. A phase II randomized, controlled trial of partial liquid ventilation (PLV) in adult patients with acute hypoxemic respiratory failure (AHRF). Crit Care Med 1997;25(suppl 1):A35.

489. Wiedemann HP, Schuster D, Sandifer D, Fessler H, Mette S, Tutuncu A, et al. A Multicenter, Randomized, Feasibility Study Of Two Doses Of Perflubron Administered For Partial Liquid Ventilation (PLV) In Patients With Acute Respiratory Distress Syndrome (ARDS). Am J Respir Crit Care Med 1999;159(4 Pt 2):80A.

490. Gross GW, Greenspan JS, Fox WW, Rubenstein SD, Wolfson MR, Shaffer TH. Use of liquid ventilation with perflubron during extracorporeal membrane oxygenation: chest radiographic appearances. Radiology 1995;194(3):717-20.

491. Hirschl RB, Pranikoff T, Gauger P, Schreiner RJ, Dechert R, Bartlett RH. Liquid ventilation in adults, children, and full-term neonates. Lancet 1995;346(8984):1201-2.

492. Hirschl RB, Pranikoff T, Wise C, Overbeck MC, Gauger P, Schreiner RJ, et al. Initial experience with partial liquid ventilation in adult patients with the acute respiratory distress syndrome. JAMA 1996;275(5):383-9.

493. Gauger PG, Pranikoff T, Schreiner RJ, Moler FW, Hirschl RB. Initial experience with partial liquid ventilation in pediatric patients with the acute respiratory distress syndrome. Crit Care Med 1996;24(1):16-22.

494. Pranikoff T, Gauger PG, Hirschl RB. Partial liquid ventilation in newborn patients with congenital diaphragmatic hernia. J Pediatr Surg 1996;31(5):613-8.

495. Nekvasil R, Trittenwein R, Fedora M. Perfluorocarbon associated gas exhange (PAGE). Middle European Experiance in human babies. Intensive care Medicine 1996;22:S430.

496. Fedora M, Nekvasil R, Seda M, Klimovic M, Dominik P. Partial liquid ventilation in the therapy of pediatric acute respiratory distress syndrome. Bratisl Lek Listy 1999;100(9):481-5. 

rats with congenital diaphragmatic hernia. In: Liquid ventilation: a symposium; 1996 September 19; Ann Arbor, MI; 1996. p. 26.

498. Leach CL, Greenspan JS, Rubenstein SD, Shaffer TH, Wolfson MR, Jackson JC, et al. Partial liquid ventilation with perflubron in premature infants with severe respiratory distress syndrome. The LiquiVent Study Group. N Engl J Med 1996;335(11):761-7.

499. Toro-Figueroa LO, Meliones JN, Curtis SE, Thompson AE, Hirschl RB, Fackler JC, et al. Perflubron partial liquid ventilation (PLV) in children with ARDS: a safety and efficacy pilot study. Crit Care Med 1996;24(suppl 1):A150.

500. Greenspan JS, Fox WW, Rubenstein SD, Wolfson MR, Spinner SS, Shaffer TH. Partial liquid ventilation in critically ill infants receiving extracorporeal life support. Philadelphia Liquid Ventilation Consortium. Pediatrics 1997;99(1):E2.

501. Hirschl RB, Conrad S, Kaiser R, Zwischenberger JB, Bartlett RH, Booth F, et al. Partial liquid ventilation in adult patients with ARDS: a multicenter phase I-II trial. Adult PLV Study Group. Ann Surg 1998;228(5):692-700.

502. Szekely LA, Thompson BT, Woolf A. Use of partial liquid ventilation to manage pulmonary complications of acute verapamil-sustained release poisoning. J Toxicol Clin Toxicol 1999;37(4):4759.

503. Croce MA, Fabian TC, Patton JH, Jr., Melton SM, Moore M, Trenthem LL. Partial liquid ventilation decreases the inflammatory response in the alveolar environment of trauma patients. J Trauma 1998;45(2):273-80.

504. Dani C, Reali F, Bertini G, Rubaltelli FF. Partial liquid ventilation in an infant treated with HFOV. Pediatr Res 1998;43:279A.

505. Dani C, Reali MF, Bertini G, Rubaltelli FF. Liquid ventilation for management of neonatal respiratory insufficiency. Rivista Italiana Di Pediatria Italian Journal of Pediatrics 1998;24(5):938-946.

506. Gentili M, Pagni R, Gentili S, Ferretti A, Santelli F, Avenali S, et al. [Partial liquid ventilation (PLV) in the newborn and infants: initial experiences in Italy] Ventilazione liquida parziale (PLV) nel neonato e nel lattante: prime esperienze in Italia. Pediatr Med Chir 1998;20(5):315-6.

507. Rajka T, Henrichsen T, Vinorum OG, de Lange C, Erichsen A, Fugelseth D, et al. Partial liquid ventilation and pulmonary lavage with perfluoro chemicals during conventional ventilation. European Journal of medical Research 2000;5:80.

508. Lim CM, Koh Y, Jung BO, Lee SD, Kim WS, Kim DS, et al. An optimal dose of perfluorocarbon for respiratory mechanics in partial liquid ventilation for dependent lung-dominant acute lung injury. Chest 2000;117(1):199-204.

509. Constantin JM, Gindre G, Gonzalez D, Segrell-Therre JD, Bazin JE, Schoeffler P. Determination of the minimum volume required to ensure partial liquid ventilation in the pig with ARDS. Anesthesiology 1998;89(3A):Abstract 1400.

510. Constantin JM, Bazin JE, Schoeffler P. Determination Of The Minimum Volume Required To Ensure Partial Liquid Ventilation In The Pig With ARDS. Am J Respir Crit Care Med 1999;159(4 Pt 2):78A.

511. Doctor A, Price B, Bhargava N, DiCanzio J, Amold JH. High-frequency oscillatory ventilation of the perfluorocarbon-filled lung: Dose-response relationships in an animal model of acute lung injury. Critical Care Medicine 2001;29(4):847-854.

512. Bateman ST, Doctor A, Price B, Murphy MA, Thompson JE, Zurakowski D, et al. Optimizing intrapulmonary perfluorocarbon distribution: Fluoroscopic comparison of mode of ventilation and body position. Critical Care Medicine 2001;29(3):601-608.

513. Merz U, Klosterhalfen B, Kellinghaus M, Peschgens T, Pluschke S, Hoernchen H. Effects of single and multiple doses of perfluorocarbon in comparison with continuous partial liquid ventilation on gas exchange and lung pathology in newborn surfactant-depleted pigs. Critical Care Medicine 2001;29(3):645-651.

514. Philips CM, Weis C, Fox WW, Wolfson MR, Shaffer TH. On-line techniques for perfluorochemical vapor sampling and measurement. Biomed Instrum Technol 1999;33(4):348-55.

515. Mazzoni M, Nugent L, Klein D, Hoffman J, Sekins KM, Flaim SF. Dose monitoring in Partial Liquid Ventilation by infrared measurement of expired perfluorochemicals. Biomed Instrum Technol 1999;33(4):356-64.

516. Proquitté H, Rudiger M, Krause S, Foitzik B, Schmalisch G, Wauer RW. Perfluorocarbon loss during partial liquid ventilation. European Journal of medical Research 2000;5:41. 
517. Weis CM, Fox WW, Philips CM, Wolfson MR, Shaffer TH. Perfluorochemical elimination from the lungs: Effect of initial dose. Pediatr Pulmonol 2000;30(4):324-329.

518. Mandl M, Harris K, Wolfson MR, Shaffer TH. Perfluorochemical (PFC) evaporation from the lungs: effect of body temperature. Pediatr Res 1999;45(4):311A.

519. Trevisanuto D, Jeng M-J, Weis CM, Fox WW, Wolfson MR, Shaffer TH. Positive end- expiratory pressure (PEEP) modulates perfluorochemical (PFC) evaporation from the lungs. Pediatr Res 2000;47(4):436A.

520. Jeng MJ, Trevisanuto D, Weis CM, Fox WW, Cullen AB, Wolfson MR, et al. Role of ventilation strategy on perfluorochemical evaporation from the lungs. Journal of Applied Physiology 2001;90(4):1365-1372.

521. Doctor A, Amold J, Al-Khadra E, Watson K, Thompson J. Perfluorocarbon (PFC) Vapor Loss During High Frequency Ventilation: Effect Of Intrapulmonary PFC Distribution And Volume. Am J Respir Crit Care Med 2000;161(3):A46.

522. Miller TF, Milestone B, Stern R, Shaffer TH, Wolfson MR. Effects of perfluorochemical distribution and elimination dynamics on cardiopulmonary function. Journal of Applied Physiology 2001;90(3):839-849.

523. Mazzoni MC, Sekins KM, Rusheen PD, Spooner ML, Hoffman J, del Balzo U, et al. Decreased perflubron evaporative loss during partial liquid ventilation in swine with heat and moisture exchangers. Am J Respir Crit Care Med 1998;157(4):A461.

524. Nugent LJ, Mazzoni MC, Flaim SF, Hoffman JK, Sekins KM. Dose maintenance for Partial Liquid Ventilation: passive heat-and-moisture exchangers. Biomed Instrum Technol 1999;33(4):365-72.

525. Greenspan JS, Wolfson MR, Rubenstein SD, Antunes M, Kechner N, Shaffer TH. Partial liquid ventilation trials: management implications of serial pulmonary mechanics. Pediatric Research 1995;37(4 (Pt 2)):207A.

526. Schrader B, Westenskow D, Kofoed S, Durst K, Orr J, Flanagan C, et al. A closed rebreathing system for dose maintenance during Partial Liquid Ventilation. Biomed Instrum Technol 1999;33(4):373-82.

527. Lamm WJE, Graham MM, Albert RK. Partial liquid ventilation improves oxygenation by redistributing perfusion to ventral lung regions. Am J Respir Crit Care Med 1996;153(4 Pt 2):A12.

528. Max M, Nowak B, Dembinski R, Schulz G, Kuhlen R, Buell U, et al. Changes in pulmonary blood flow during gaseous and partial liquid ventilation in experimental acute lung injury. Anesthesiology 2000;93(6):1437-1445.

529. Willey-Courand DB, Harris R, Galletti G, Head C, J. V. Partial liquid ventilation (PLV) reduces shunt (Qs/Qt) in the surfactant deficient lung. Am J Respir Crit Care Med 1998;157:A464.

530. Lim C, Domino KB, Glenny RW, Hlastala MP. Va/Q Distribution Changes With Increasing Perfluorocarbon (PFC) Dose In Partial Liquid Ventilation (PLV) For Rabbit Model Of ARDS. Am J Respir Crit Care Med 1999;159(4 Pt 2):902.

531. Lim CM, Domino KB, Glenny RW, Hlastala MP. Effect of increasing perfluorocarbon dose on $\mathrm{V}$ (over dot)A/Q(over dot) distribution during partial liquid ventilation in acute lung injury. Anesthesiology 2001;94(4):637-642.

532. Loer SA, Tarnow J. Effects of partial liquid ventilation with perfluorocarbons on pressure-flow relationships, vascular compliance, and filtration coefficients of isolated blood-perfused rabbit lungs. Critical Care Medicine 1998;26(12):2037-2041.

533. Max M, Kuhlen R, Dembinski R, Rossaint R. Time-dependency of improvements in arterial oxygenation during partial liquid ventilation in experimental acute respiratory distress syndrome. Critical Care 2000;4(2):114-119.

534. Davidson A, Heckman JL, Donner RM, Miller TF, Shaffer TH, Wolfson MR. Cardiopulmonary interaction during partial liquid ventilation in surfactant-treated preterm lambs. Eur J Pediatr 1998;157(2):138-45.

535. Willey-Courand DB, Kirmse M, Fujino Y, Nathan N, Venegas J, Kacmarek RM. Alterations in cardiovascular function during partial liquid ventilation (PLV) as detected by echocardiography. Am J Respir Crit Care Med 1998;157(3):A528.

536. Fessler HE, Pearse D. Accuracy Of Hemodynamic Monitoring During Partial Liquid Ventilation (PLV) In Sheep. Am J Respir Crit Care Med 1999;159(159):901A.

537. Dimmitt RA, Beckman SA, Halamek LP, Moss RL, Mickas NA, Amii LA, et al. Cerebral Blood Flow and Metabolism During Partial Liquid Ventilation in Neonatal Lambs. Pediatr Res 2000;54(4):356A. 
538. Rudiger M, Proquitte H, Burkhardt W, Krause S, Schmidt M, Wauer RR. Cerebral hemoglobin concentration is affected by mode of PFC administration in partial liquid ventilation. Pediatr Res 2000;54(4):430A.

539. Okazaki T. Pulmonary expression of heat shock proteins in congenital diaphragmatic hernia rats after conventional and partial liquid ventilation. Am J Respir Crit Care Med 1997;153:A949.

540. Okazaki T. Clinical and molecular aspects of stress on the developing lungs [PhD]. Rotterdam: Erasmus University Rotterdam; 1999. 
Perfluorocarbon liquid assisted ventilation is an intriguing experimental respiratory support technique investigated over the last 35 years. This thesis collects personal studies and a comprehensive review on this research topic. Our own contribution to the study of liquid ventilation is summarised below. Then, the present knowledge on liquid ventilation is analysed critically. Some suggestions for further research are given.

\section{Summary of own experimental work}

Complex interactions between the cardiovascular and pulmonary system exist. Mechanical ventilation induces both steady-state and phasic influences on cardiac output and blood pressure. In chapter 1 we systematically explored the phasic respiratory-induced haemodynamic alterations during gas ventilation, PLV, and TLV in lung lavaged piglets. TLV was associated with increased within-breath variability of left stroke volume, systemic blood pressure and systemic perfusion pressure. The clinical implications for the immature brain are unknown and more research is needed to understand the underlying mechanisms.

In chapter 2 we report on a preclinical comparison between PLV, HFOV, and CMV in piglets with saline lavage-induced acute lung injury. All three ventilation strategies improved oxygenation and ventilation, and an equal severity of histologic lung injury was noticed. Eventually, PLV animals demonstrated impaired oxygenation and lung mechanics. It was speculated that the animal model is less stable than previously thought; impairment of oxygenation and lung mechanics is typical for PLV of the normal lung.

During TLV, the balance between in- and outflow liquid volumes should be maintained precisely in equilibrium in order to avoid overdistention or collapse of the lungs. Chapter 3 describes the development and testing of a microcomputer feedback system using endexpiratory occlusion pressures as a representative input signal for a closed-loop system. Bench tests and animal experiments testing the automated control revealed a small bias, and clinically acceptable oscillations of the end-expiratory lung volume.

Finally, in chapter 4, we compared TLV, high-volume, liquid-assisted HFOV, and highPEEP CMV in preterm, surfactant treated lambs. TLV compared favourable to either gas ventilation strategy by its more uniform ventilation, reduced histologic lung injury, and improved gas exchange.

\section{General discussion, criticism on liquid ventilation research, and future prospective}

When artificial ventilation or respiratory support is needed, the strategy used should provide adequate pulmonary gas exchange while avoiding pulmonary trauma or impairment of the circulatory system. Before introducing an innovative technique in clinical practice, it should be tested against the best therapeutic option already available. The benefit demonstrated in preclinical testing should have clinical relevance. Gas exchange, respiratory mechanics, and lung histology are only surrogate outcomes. For the patient and his family, only survival and quality of life (long term pulmonary and neurodevelopmental outcome) are meaningful endpoints. 
Liquid ventilation has been repeatedly represented as an exciting, promising innovation in respiratory medicine. We should refrain from this premature conclusion since the current scientific data do not support unshaded enthusiasm.

\section{Tidal liquid ventilation.}

The superiority of TLV in supporting gas exchange and/or in protecting lung histomorphology has been demonstrated in every published comparative study. This was also the case when TLV was tested against so-called lung protective strategies $(1,2)$.

So far, no clinical trials have investigated the efficacy of TLV in human diseases. It is therefore unknown whether TLV will also be able to improve "ventilator free days" and survival in children or adults suffering from ARDS or ALI. In the neonatal context, one would like to know whether TLV improves survival and/or reduces the risk for ECMO in near-term and term babies with severe respiratory insufficiency. With the widespread use of antenatal steroids, prophylactic or early surfactant treatment and gentle lung protective ventilation support, mortality due to neonatal RDS is rare. There is doubt whether a preterm target population can be selected to demonstrate improved survival in an adequately powered trial. Finally, the possibility that TLV could decrease the incidence and severity of chronic lung disease in preterm babies is still questionable. It is known that bronchopulmonary dysplasia is not only characterised by problems of tissue damage and repair, but that alveolar and vascular lung growth are impaired in very preterm animals after chronic artificial ventilation (3-6). This disruption of lung development can be influenced favourably by low tidal volume CMV (7), but HFOV did not further enhance alveolarisation (8). Only similar chronic ventilation studies may support or refute the hypothesis that normal (fetal) lung growth can be preserved in immature animals during TLV. In the fetus, continuous and intermittent lung distention are important for lung growth, alveolar differentiation and surfactant system maturation (9). The role of fetal breathing in normal lung growth was also demonstrated in vitro by elongating gelfoam sponges on which fetal rat lung cell were maintained in organotypic culture. $\left[{ }^{3} \mathrm{H}\right]$ thymidine incorporation and rate of cell division were affected by the amplitude, frequency, periodicity, and duration of the applied stretch (10). Interestingly, foam elongation of $5 \%(p<0.001)$ and $10 \%(p<0.05)$ resulted in increased DNA synthesis but $1 \%$ elongation did not. However, a stretch of $10 \%$ was also associated with increased cytotoxicity, as assessed by release of $\left[{ }^{14} \mathrm{C}\right]$ adenine into the culture medium. Other in vitro studies have stressed that deformation-induced injury to alveolar epithelial cells varies significantly with both peak magnitude and deformation amplitude (11). It remains to be demonstrated whether TLV, characterized by large tidal volumes, can mimic the fetal growth promoting environment.

An equally unexplored area of TLV application is the condition of lung hypoplasia (due to e.g. congenital diaphragmatic hernia, or oligohydramnion sequence). Since very immature lambs can be supported by TLV (12), the technique may better than gas ventilation strategies support babies with hypoplastic lungs.

The technical complexity of TLV has been frequently invoked against its clinical use and technical problems have certainly delayed its development. We are convinced that with a close cooperation between physiologists, clinicians and bio-engineers, the technology should not be an obstacle. 
Finally, some unresolved questions must be mentioned with relation to TLV. Endotracheal tube-leak is undesirable during TLV. In animal research this problem is circumvented by tying the endotracheal tube into the trachea or by the use of cuffed endotracheal tubes. In newborn babies, the latter solution may increase the risk of tracheal stenosis. It will be necessary to find a reliable but atraumatic cuffed tube for small preterm infants.

The phasic circulatory impact of TLV needs more research.

In our experience fluorothorax is a catastrophic event, evolving in a very short period, and leading to severe hypotension and respiratory deterioration. Although chest drainage will be probably life saving, localizing the side of the fluorothorax is clinically impossible. During TLV there are no audible breathing sounds and the whole chest is radiopaque! Subsequent effective liquid ventilation may become problematic.

Some early TLV experiments used a demand-controlled liquid ventilation system, triggered by the animal's respiratory effort and assisting spontaneous breathing (13-15). All subsequent TLV research has been done in paralysed animals. However, long-term curarization of babies is not desirable. It is not known whether spontaneous, triggered TLV is possible in small, fast breathing subjects.

\section{Partial liquid ventilation}

Initially, comparative studies suggested that PLV was more efficacious and more lung protective than CMV. However, looking in more detail to the methodology (see chapter 5, appendices 4 to 9), one must recognize that the ventilatory management of the control groups was far from ideal. In fact, any clinician would adjust the so-called baseline ventilator settings used in CMV animals. When comparative studies, started to use alternative lung recruitment strategies, the advantage of PLV over gas ventilation largely disappeared (16-18). It took several years before the effect of the gas ventilation strategy during PLV was investigated in depth (19-24). To our knowledge, there is only one study in which the gas ventilation strategy was optimized in both CMV and PLV lung injured animals. Then, PLV achieved significant better ventilation with the same oxygenation as CMV. Only in the dependent lung regions, CMV animals showed more histological lung injury (25). In summary, too few studies compare state of the art PLV with a state of the art gas ventilation strategy. Further preclinical animal work may avoid disappointing human trials.

Since the gaseous lung volume is decreased by liquid instillation, the combination of PLV with intratracheal ventilation seems attractive, and should be further explored.

As with TLV, the growth promoting potential of PLV in immature lungs has not been investigated.

\section{Final comments}

Tidal liquid ventilation celebrates its 35 th birthday. The physiological basis of this technique is strong; the short term results in the animal laboratory are better than with any other strategy. There are still questions regarding technical issues, indications and long-term effects. Clinical trials have been delayed by the need for FDA approval of a liquid ventilator and by tribulations surrounding the PLV trials. 
Partial liquid ventilation research has been overwhelming since its introduction 10 years ago. Despite an impressive volume of data on the subject, few studies support the clear superiority of PLV as a lung recruiting strategy. Long-term benefits are still speculative. The physiological complexity and the technique of application were underrated. The classical closing remark, "more research is needed", is appropriate.

\section{References}

1. Wolfson MR, Jackson JC, Foley DS, Hirschl RB, Gauvin F, Lamm WJ, et al. Multi-Center Comparative Study Of Conventional Mechanical (CMV) To Tidal Liquid Ventilation (TLV) In Oleic Acid (OA) Injured Sheep. Am J Respir Crit Care Med 2000;161(3):A46.

2. Degraeuwe PLJ, Thunnissen FBJM, Jansen NJG, Dormaar JT, Dohmen LRB, Blanco CE. Conventional gas ventilation, liquid-assisted high-frequency oscillatory ventilation, and tidal liquid ventilation in surfactant-treated preterm lambs. International Journal of Artificial Organs 2000;23(11):754-764.

3. Coalson JJ, Winter V, deLemos RA. Decreased alveolarization in baboon survivors with bronchopulmonary dysplasia. Am J Respir Crit Care Med 1995;152(2):640-6.

4. Coalson JJ, Winter VT, Siler Khodr T, Yoder BA. Neonatal chronic lung disease in extremely immature baboons. Am J Respir Crit Care Med 1999;160(4):1333-46.

5. Albertine KH, MacRitchie AN, Young BJ, Cho SC, Kullama LK, Carlton DP, et al. Altered vascular development in preterm lambs with chronic lung injury. Chest 1998;114(1 Suppl):6s-7s.

6. Albertine K, Dahl M, Tabatabaei N, Carlton D, Bland R. Prolonged mechanical ventilation after premature birth inhibits microvascular formation in lungs of preterm lambs. FASEB-J 2000;14(4):A603.

7. Albertine KH, Jones GP, Starcher BC, Bohnsack JF, Davis PL, Cho SC, et al. Chronic lung injury in preterm lambs. Disordered respiratory tract development. Am J Respir Crit Care Med 1999;159(3):945-58.

8. Yoder BA, Siler Khodr T, Winter VT, Coalson JJ. High-frequency oscillatory ventilation - Effects on lung function, mechanics, and airway cytokines in the immature baboon model for neonatal chronic lung disease. Am J Respir Crit Care Med 2000;162(5):1867-1876.

9. Wirtz HR, Dobbs LG. The effects of mechanical forces on lung functions. Respir Physiol 2000;119(1):1-17.

10. Liu M, Skinner SJ, Xu J, Han RN, Tanswell AK, Post M. Stimulation of fetal rat lung cell proliferation in vitro by mechanical stretch. Am J Physiol 1992;263(3 Pt 1):L376-83.

11. Tschumperlin DJ, Oswari J, Margulies AS. Deformation-induced injury of alveolar epithelial cells. Effect of frequency, duration, and amplitude. Am J Respir Crit Care Med 2000;162(2 Pt 1):357-62.

12. Wolfson MR, Greenspan JS, Deoras KS, Rubenstein SD, Shaffer TH. Comparison of gas and liquid ventilation: clinical, physiological, and histological correlates. J Appl Physiol 1992;72(3):1024-31.

13. Moskowitz GD, Shaffer TH, Dubin SE. Liquid breathing trials and animal studies with a demandregulated liquid breathing system. Med Instrum 1975;9(1):28-33.

14. Shaffer TH, Moskowitz GD. Demand-controlled liquid ventilation of the lungs. J Appl Physiol 1974;36(2):208-13.

15. Shaffer TH, Moskowitz GD. An electromechanical demand regulated liquid breathing system. IEEE Trans Biomed Eng 1975;22(5):412-7.

16. Degraeuwe PLJ, Thunnissen FBJM, Vos GD, Blanco CE. High-frequency oscillatory ventilation, partial liquid ventilation, or conventional mechanical ventilation in newborn piglets with saline lavage-induced acute lung injury. A comparison of gas-exchange efficacy and lung histomorphology. Biol Neonate 1999;75(2):118-29.

17. Kinsella JP, Parker TA, Galan H, Sheridan BC, Abman SH. Independent and combined effects of inhaled nitric oxide, liquid perfluorochemical, and high-frequency oscillatory ventilation in premature lambs with respiratory distress syndrome. Am J Respir Crit Care Med 1999;159(4 Pt 1):1220-7.

18. Gothberg S, Parker TA, Abman SH, Kinsella JP. High-frequency oscillatory ventilation and partial liquid ventilation after acute lung injury in premature lambs with respiratory distress syndrome [see comments]. Crit Care Med 2000;28(7):2450-6. 
19. Kaisers U, Kuhlen R, Keske U, Sommerer A, Mohnhaupt A, Falke KJ, et al. Superimposing positive end-expiratory pressure during partial liquid ventilation in experimental lung injury. Eur Respir J 1998;11(5):1035-42.

20. Kirmse M, Fujino Y, Hess D, Kacmarek RM. Positive end-expiratory pressure improves gas exchange and pulmonary mechanics during partial liquid ventilation. Am J Respir Crit Care Med 1998;158(5 Pt 1):1550-6.

21. Zobel G, Rodl S, Urlesberger B, Dacar D, Trafojer U, Trantina A. The effect of positive endexpiratory pressure during partial liquid ventilation in acute lung injury in piglets [see comments]. Crit Care Med 1999;27(9):1934-9.

22. Suh GY, Chung MP, Park SJ, Koh Y, Kang KW, Kim H, et al. Partial liquid ventilation shows dosedependent increase in oxygenation with PEEP and decreases lung injury associated with mechanical ventilation. Journal of Critical Care 2000;15(3):103-112.

23. Manaligod JM, Bendel Stenzel EM, Meyers PA, Bing DR, Connett JE, Mammel MC. Variations in end-expiratory pressure during partial liquid ventilation: impact on gas exchange, lung compliance, and end-expiratory lung volume. Chest 2000;117(1):184-90.

24. Fujino Y, Goddon S, Chiche JD, Hromi J, Kacmarek RM. Partial liquid ventilation ventilates better than gas ventilation. Am J Respir Crit Care Med 2000;162(2 Pt 1):650-7.

25. Fujino Y, Goddon S, Chiche JD, Kacmarek RM. Partial Liquid Ventilation (PLV) Provides Better Ventilation Than Gas Ventilation (GV) With PEEP Set Above Lower Inflection Point (LIP). Am J Respir Crit Care Med 1999;159(4 Pt 2):79A. 
Gastransport en efficiënte gasuitwisseling in de zoogdierlong zijn mogelijk door het ademen van, en zeker door het beademen met een zuurstofbevattende vloeistof. Wegens hun hoog oplossend vermogen voor ademhalingsgassen zijn vloeibare perfluorkoolstofverbindingen (PFKs) zeer geschikt voor deze toepassing. Vloeistofbeademing met PFKs verbetert de longmechanica van een long met toegenomen oppervlaktespanning. Tijdens totale of teug-vloeistof-beademing (TVB) (Engels: tidal liquid ventilation) worden teugvolumes vloeistof mechanisch in en uit de vloeistofgevulde long gepompt. Bij partiële vloeistofbeademing (PVB) (Engels: partial liquid ventilation) wordt de (partieel) met PFKs gevulde long met gas beademd. In hoofdstuk 5 bespreken we, na een inleiding over de ontstaansgeschiedenis van vloeistofbeademing, de fysico-chemische en biologische eigenschappen van PFKs en de fysiologie van de vloeistof-gevulde long. De pathofysiologie van longziekten, waarbij vloeistofbeademing zou kunnen worden toegepast, worden kort geschetst. Ook wordt aandacht besteed aan de huidige lege artis therapie en mogelijke nieuwe behandelstrategieën voor deze respiratoire aandoeningen. De literatuur over TVB en PVB worden apart samengevat met betrekking tot beschrijvende, verklarende en vergelijkende studies. Effecten op hemodynamiek, technische en praktijkgerichte aspecten worden besproken. Bij PVB worden tevens allerlei (combinaties van) respiratoire behandelstrategieèn en technologieën vergeleken.

Door het wijzigen van de intrathoracale en pericardiale druk beïnvloedt kunstmatige beademing het hartminuutvolume en de bloeddruk. Naast een effect op de gemiddelde waarden bestaat er een fasisch effect synchroon met de beademingsteugen. In hoofdstuk 1 hebben we bij respiratoir insufficiënt gemaakte biggen de door gasbeademing (GB), PVB en TVB uitgelokte variabiliteit van hemodynamische parameters gekwantificeerd. TVB induceerde grotere fluctuaties dan PVB in het slagvolume van de linker kamer, de systeem bloeddruk en de perfusiedruk. De oorzaken, maar ook de eventuele gevolgen hiervan zijn niet onderzocht.

In hoofdstuk 2 hebben we PVB vergeleken met GB en hoog frequente oscillatie (HFO) bij biggen die door longlavage respiratoire insufficiënt waren gemaakt. Zowel de GB- als HFOstrategie waren gericht op longontplooing. De drie technieken herstelden een adequate arteriële oxygenatie, echter iets minder goed bij PVB. Ook de longmechanica was minder gunstig na PVB. Histologisch waren er geen verschillen. De stabiliteit van het diermodel werd in vraag gesteld.

Om het eind-expiratoire longvolume constant te houden tijdens TVB werd een regulateur met terugkoppeling ontworpen en getest (hoofdstuk 3). Als invoer signaal voor het regelsysteem werd gebruik gemaakt van de eind-expiratoire occlusiedruk. De werking van het systeem bleek bevredigend, zowel tijdens testsituaties in het laboratorium als bij dierproeven.

Chronische longziekte blijft een belangrijk gezondheidsprobleem bij exprematuren die omwille van neonataal respiratoir distress syndroom werden beademd. Hoog frequente oscillatie en TVB zouden longbeschadiging als gevolg van de beademing kunnen verminderen. In hoofdstuk 4 worden in een vergelijkende studie drie beademingsstrategieën toegepast bij preterm geboren lammeren die onmiddellijk na de geboorte met surfactant werden behandeld. TVB werd gekenmerkt door betere gasuitwisseling dan conventionele beademing met relatief hoge eind-expiratoire druk en hoog-volume HFO. Na TVB was er tevens minder histologische longbeschadiging en een homogenere ontplooiing van de long. 
TVB is een fysiologisch goed onderbouwde techniek. De resultaten bij diermodellen zijn, wat betreft gasuitwisseling en histologische longprotectie, bijna uniform beter dan om het even welke andere beademingsmethode. Verdere research (in hoofdstuk 5 worden enkele suggesties gedaan) en humane trials lijken daarom zinvol. Aanwijzingen dat PVB echt superieur is aan reeds bestaande technieken zijn schaars, ondanks een massa onderzoeksgegevens. PVB is niet geworden wat men ervan voorspeld had: een eenvoudige techniek met dezelfde voordelen als TVB. 


\section{Acknowledgments}

I owe a debt of gratitude to all those who directly or indirectly contributed to the completion of this thesis. I trust they know how much their help has been appreciated. I am grateful to my wife and children for allowing me the time to do my enjoyable, rewarding but time-consuming work. 
Pieter Degraeuwe was born on May 29th 1955, in Duffel, Belgium. He received his M.D., magna cum laude, from the Catholic University Leuven, Belgium, in 1980. Following his residency training in paediatrics at the University Hospital Leuven (1980-1985), he subspecialized in neonatal medicin at the University Hospital Maastricht, The Netherlands (1986-1988). Since then, he has been member of the staff at the department of paediatrics at the same institution. The scientific work presented in this thesis was conducted in the Research Institute Growth and Development (GROW) at Maastricht University. 


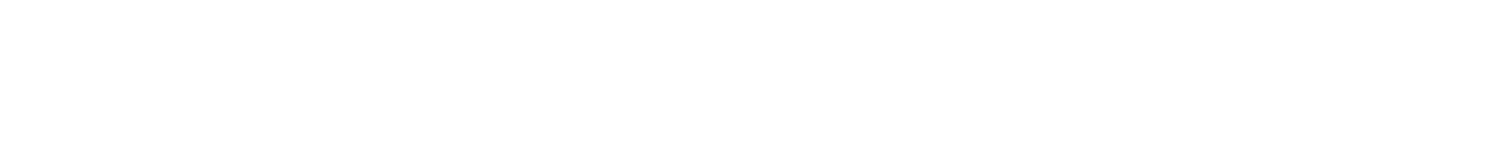


